LUCAS BARAÇAS FIGUEIREDO

\title{
UP-FRONT DESIGN NO DESENVOLVIMENTO ÁGIL DE SOFTWARE CENTRADO NO USUÁRIO
}




\title{
LUCAS BARAÇAS FIGUEIREDO
}

\section{UP-FRONT DESIGN NO DESENVOLVIMENTO ÁGIL DE SOFTWARE CENTRADO NO USUÁRIO}

\author{
Dissertação apresentada à Escola Po- \\ litécnica da Universidade de São Paulo para \\ obtenção do Título de Mestre em Ciências.
}




\title{
LUCAS BARAÇAS FIGUEIREDO
}

\section{UP-FRONT DESIGN NO DESENVOLVIMENTO ÁGIL DE SOFTWARE CENTRADO NO USUÁRIO}

\author{
Dissertação apresentada à Escola Po- \\ litécnica da Universidade de São Paulo para \\ obtenção do Título de Mestre em Ciências.
}

Área de Concentração:

Engenharia de Produção

Orientador:

Prof. Dr. André Leme Fleury 
Autorizo a reprodução e divulgação total ou parcial deste trabalho, por qualquer meio convencional ou eletrônico, para fins de estudo e pesquisa, desde que citada a fonte.

Este exemplar foi revisado e corrigido em relação à versão original, sob responsabilidade única do autor e com a anuência de seu orientador.

São Paulo, de de

Assinatura do autor:

Assinatura do orientador:

\section{Catalogação-na-publicação}

Figueiredo, Lucas Baraças

Up-front design no desenvolvimento ágil de software centrado no usuário / L. B. Figueiredo -- versão corr. -- São Paulo, 2019. $164 \mathrm{p}$.

Dissertação (Mestrado) - Escola Politécnica da Universidade de São Paulo. Departamento de Engenharia de Produção.

1.Desenvolvimento ágil de software 2.Design centrado no usuário 3.Desenvolvimento ágil de software centrado no usuário 4.Up-front design 5.Abordagem Contingencial I.Universidade de São Paulo. Escola Politécnica. Departamento de Engenharia de Produção II.t. 
Dedico ao meu avô José Baraças dos Santos (in memoriam), pessoa que quero ser quando crescer 


\section{AGRADECIMENTOS}

Ao meu orientador, Prof. Dr. André Leme Fleury, por toda a parceria e apoio em todos os momentos do mestrado. Pelo seu jeito brincalhão de encarar os desafios, por nossa grande afinidade nos temas sobre os quais trabalhamos e estudamos e, principalmente, por me encorajar a me manter firme até o fim desta jornada, não poderia pensar em pessoa melhor para ter me orientado nestes últimos três anos.

Aos meus pais e minha irmã, por todo o amor e apoio incondicionais, em todos os momentos. Ao meu pai, por sempre me estimular a aprender mais (e correr mais também!). À minha mãe, por todo o carinho e por me ensinar a ser uma pessoa prática. À minha irmã, pelo companheirismo e por ser um exemplo de determinação. À minha avó, Maria Osira, por ser uma fonte de sabedoria e dedicação.

À Ana Fernández Márquez, maior motivo por eu ter feito o mestrado. Obrigado por todo o carinho, suporte e por me fazer uma pessoa melhor. À família Fernández Márquez, em especial à Maria Pilar (in memoriam), por me fazerem sentir em casa na Espanha.

Aos meus amigos do mestrado: Lorena Gamboa, Filipe Tieppo, Hanna Pamplona, Lucas Magalhães, Lucas Jesus, Flavio Copola, Felipe Canella, Julia Taunay, entre outros, que fizeram este tempo ser muito mais leve e proveitoso. Um agradecimento especial à Diane Reis, que apesar da distância e do pouco contato, me ajudou com diversas dicas e algumas publicações.

Aos meus colegas de trabalho, em especial ao Danilo Toledo, pela disposição em me ajudarem com o mestrado, seja com contribuições diretas ou segurando as pontas no dia-a-dia quando precisei. Obrigado a todos por serem exemplos de aprendizes eternos.

Ao Prof. Dr. Tiago da Silva, por todo o conhecimento e parceria. À Profa. Dra. Janaína Costa pelas críticas pertinentes e construtivas.

Um agradecimento à Lídia Silva pela disposição sempre que precisei de ajuda com o departamento de Engenharia de Produção. 


\section{RESUMO}

O Desenvolvimento Ágil de Software Centrado no Usuário refere-se à integração das abordagens de Desenvolvimento Ágil de Software e Design Centrado no Usuário. Esta integração ganhou interesse recente e se tornou uma tendência, porque as organizações estão progressivamente buscando capturar o melhor dos dois mundos: entregar projetos no prazo, dentro do orçamento, atendendo aos requisitos do negócio e, ao mesmo tempo, criando produtos ou serviços utilizáveis, úteis e desejáveis para o usuário final. A literatura aponta que ao longo do ciclo de vida de criação do produto existem quatro principais momentos nesta integração, sendo o mais utilizado deles o little design up-front, que se refere às atividades realizadas logo antes do início do desenvolvimento, para definição dos requisitos para a equipe ágil e visão do produto. Ainda assim, pesquisas claramente evidenciam que apesar dos benefícios desta integração, o processo do little design up-front ainda é realizado de forma incipiente ou inadequada, pois não há uma definição clara do processo em si, quem são os participantes, como deve ser planejado, executado, quais são seus resultados e sua extensão. Além disso, existem evidências de que a equipe de projeto tende a desviar de práticas prescritas, uma vez que contingências do projeto acabam por influenciar a forma de gerenciar e executar estes processos com maior eficiência. O principal objetivo desta pesquisa, portanto, é propor uma estruturação clara, compreensível e replicável do desenvolvimento ágil de software centrado no usuário com foco em suas atividades antes do início do desenvolvimento, orientando praticantes da área a planejar e executar o Up-Front Design (UFD) em diferentes contextos de projetos de software. Para tanto, foi realizada uma revisão sistemática da literatura no tema para conceituação dos principais tópicos em up-front design do desenvolvimento ágil de software centrado no usuário e criação do modelo de pesquisa. Em seguida, foi realizado um estudo de caso com 27 processos de little design up-front em uma organização com 21 empresas diferentes, de forma a confirmar e/ou contrastar as consolidações e propostas feitas a partir da literatura com estudos de campo, alinhando teoria e prática. Os resultados obtidos permitem que acadêmicos e praticantes tenham uma visão holística do desenvolvimento ágil de software centrado no usuário, com uma separação dos estágios de integração de acordo com diferentes finalidades e um processo cíclico com três alternativas diferentes de iteração, dependendo do objetivo de inovação e melhorias desejadas. Este trabalho também agrega para profissionais da área, propondo limites de tempo para o processo de little design up-front, uma configuração de equipe para processos desta natureza, e uma análise de como os fatores contingenciais influenciam os dois principais responsáveis por este processo: o sponsor e o líder do processo, de forma a auxiliá-los no melhor gerenciamento e execução do up-front design. Este trabalho contribui para o corpo de conhecimento do desenvolvimento ágil de software centro no usuário de forma a estimular a criação de softwares úteis, utilizáveis e atraentes.

Palavras-Chave - Desenvolvimento ágil de software. Design Centrado no usuário. Desenvolvimento ágil de software centrado no usuário. Up-front design. Abordagem contingencial. 


\section{ABSTRACT}

User-Centered Agile Software Development refers to the integration of Agile Software Development and User-Centered Design approaches. This integration has gained interest and became a trend as organizations are progressively pursuing the best of both worlds: delivering projects on time, within budget, and attending to business requirements, and, at the same time, creating products or services that are usable, useful and desirable for the end user. Literature highlights four different moments for this integration, being the most used one the little design up-front, which refers to the activities carried out right before development starts, in order to create a product vision, and define requirements for the agile team from an idea originated internally or externally to the organization. Despite the advantages of such integration, previous researches point out that up-front design is still done in an incipient or inadequate way in organizations, as there is no clear definition of the process itself, who the participants are, how it should be planned, executed, its outcomes, and its extent. In addition, there are evidences that designers and developers tend to act differently than how theory prescribes, because there are internal and external contingencies to the project that end up influencing the way to manage and execute these processes more efficiently, making a simple replication of a process for different contexts proven to be ineffective. The main objective of this research is to propose a clear, comprehensible and replicable structure for the user-centered agile software development life cycle and its stages, with a focus on the activities carried out before development starts, alternatives for team configuration and deadlines for those processes and discuss how contingency factor can influence the process, in order to help companies creating useful, usable, desirable and attractive software. Therefore, a systematic literature review was carried out for conceptualizing the main topics on the theme of up-front design of user centered agile software development and creating a research model. Afterwards a case study was carried out with 27 little up-front design processes of 21 different companies in order to confirm and/or contrast the findings in literature with field studies, to align theory and practice. Results enable academics and practitioners to have a holistic view of the user-centered agile software development with a clear separation of its stages according to different objectives, and a cyclical process with three different iteration alternatives depending on the type of innovation desired. This work also helps practitioners of the area, proposing time limits and a team configuration for the process and an analysis on how contingency factors affect the main players on this process: the sponsor and the process leader, to help them better manage and execute the up-front design. This work contributes to the body of knowledge of user centered agile software development in order to stimulate the creation of useful, usable and attractive software.

Keywords - Agile software development. User centered design. User centered agile software development. Up-front design. Contingency approach. 


\section{LISTA DE FIGURAS}

1 Modelo em cascata. Fonte: Adaptado de Royce (1970) . . . . . . . . . . . 22

2 Processo do SCRUM. Fonte: Adaptado de Schwaber (2004) . . . . . . . . . 26

3 Termos mais comuns de design. Fonte: Adaptado de Gray (2014) e Saffer

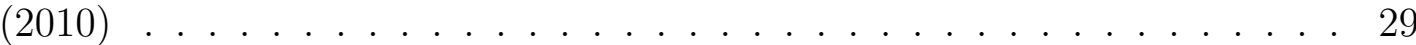

4 Semelhanças e diferenças entre ágil e UCD. Fonte: Adaptado de Salah, Paige e Cairns (2014a) . . . . . . . . . . . . . . . . . 38

5 Planejamento geral da pesquisa. Fonte: O autor. . . . . . . . . . . . . . 49

6 Processo de seleção de estudos. Fonte: O autor. . . . . . . . . . . . . . 52

7 Evolução anual das publicações de UFD em conferências e periódicos com mais estudos no tema. Fonte: O autor. . . . . . . . . . . . . . . . . . 64

8 Rede de citação por país. Fonte: O autor. . . . . . . . . . . . . . . . . 64

9 Rede de co-autoria por país. Fonte: O autor. . . . . . . . . . . . . . 65

10 Rede de co-ocorrência de palavras-chave. Fonte: O autor. . . . . . . . . . . 66

11 Rede de co-autoria por autores Fonte: O autor. . . . . . . . . . . . . 66

12 Rede de co-citação por autores. Fonte: O autor. . . . . . . . . . . . . . . 67

13 Número de publicações por método de pesquisa. Fonte: O autor. . . . . . . 68

14 Número de projetos estudados por publicação. Fonte: O autor. . . . . . . . 69

15 Perspectivas da integração de User Centered Agile Software Development (UCASD). Fonte: O autor. . . . . . . . . . . . . . . . . 70

16 Processo de Integração entre User Centered Design (UCD) e Agile Software Development (ASD). Fonte: Adaptado de Miller (2005) . . . . . . . . . . . 72

17 Primeiro princípio do UCASD: Separação da descoberta e criação do produto. Fonte: Adaptado de Brhel et al. (2015) . . . . . . . . . . . . . . . . 73

18 Representação visual dos diferentes estágios do UCASD. Fonte: Adaptado de Caballero, Moreno e Seffah (2016) . . . . . . . . . . . . . . . . . 73 
19 Modelo de Stage-Gate. Fonte: Adaptado de Cooper (2014) . . . . . . . . . 74

20 Visão geral do UCASD. Fonte: O autor. . . . . . . . . . . . . . . . . 75

21 Número de publicações que mencionaram o uso de uma técnica em UFD.

Fonte: $\mathrm{O}$ autor. . . . . . . . . . . . . . . . . . . . . 78

22 Fases do Little design up-front (LDUF). Fonte: O autor. . . . . . . . . . . 82

23 Técnicas do LDUF. Fonte: O autor. . . . . . . . . . . . . . . . . . 82

24 Tempo investido em atividades de UFD antes do início do desenvolvimento.

Fonte: O autor. . . . . . . . . . . . . . . . . 83

25 Configuração da equipe durante as atividades iniciais de projeto. Fonte: O

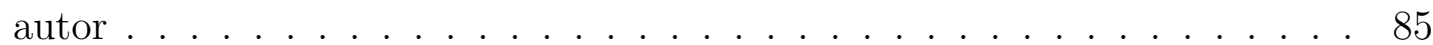

26 Modelo do Design Sprint. Fonte: (GOOGLE, 2016) . . . . . . . . . . . . . 102

27 Atividades do Design Sprint 2.0. Fonte: Adaptado de AJSmart (2018a) . . 103

28 Basecamp - comunicação e recursos do projeto. Fonte: O autor. . . . . . . 107

29 Google Sheets - levantamento dos dados secundários para estudo de caso. Fonte: O autor . . . . . . . . . . . . . . . . . . . 108

30 Influência dos Fatores Contingenciais no LDUF no UCASD. Fonte: O autor.114

31 Framework conceitual de influência dos fatores contingenciais no UFD extraído da literatura. Fonte: O autor . . . . . . . . . . . . . . . . . 115

32 Modelo de Ciclo de Vida do UCASD cíclico e bidirecional no UFD. Fonte:

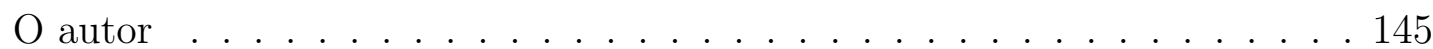

33 Framework conceitual atualizado do mapa de influências dos fatores contingenciais no LDUF. Fonte: O autor . . . . . . . . . . . . . . . 146 


\section{LISTA DE TABELAS}

1 Comparação entre as quatro abordagens de Interaction Design . . . . . . . 32

2 Fatores contingenciais encontrados na literatura . . . . . . . . . . . 46

3 Combinações de termos para pesquisa em bases de dados . . . . . . . . . . 51

$4 \quad$ Expressão buscada . . . . . . . . . . . . . . . . . . . . . . 51

$5 \quad$ Fatores contingenciais apontados na literatura de UCASD . . . . . . . . 88

6 Projetos analisados . . . . . . . . . . . . . . . . . 104

$7 \quad$ Entrevistados . . . . . . . . . . . . . . . . 105

$8 \quad$ Roteiro de Entrevistas . . . . . . . . . . . . . . . . 109

9 Vantagens e desvantagens dos processos de LDUF frente aos processos de Big design up-front (BDUF) . . . . . . . . . . . . . . . . . 122

10 Como os fatores contingenciais influenciam o LDUF segundo a literatura e o estudo de caso . . . . . . . . . . . . . . . . . . . . . . . . . . . . . . . . 140 


\section{LISTA DE SIGLAS}

UCASD User Centered Agile Software Development

ASD Agile Software Development

UFD Up-Front Design

UCD User Centered Design

UX User Experience

XP eXtreme Programming

IxD Interaction Design

UI User Interface

RSL Revisão Sistemática da Literatura

JCR Journal Citation Reports

BDUF Big design up-front

LDUF Little design up-front 


\section{SUMÁRIO}

1 Introdução $\quad 15$

1.1 Questões de pesquisa . . . . . . . . . . . . . . . . . 17

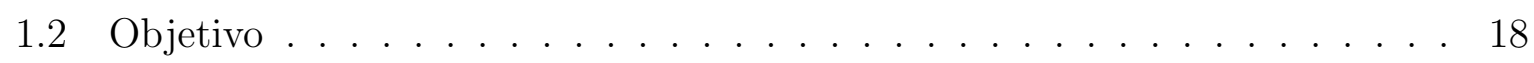

1.3 Justificativa . . . . . . . . . . . . . . . . . . . . . . 19

1.4 Estrutura do documento . . . . . . . . . . . . . . 20

2 Referencial Teórico $\quad 21$

2.1 Desenvolvimento ágil de software . . . . . . . . . . . . . . 21

2.1.1 O surgimento das metodologias ágeis . . . . . . . . . . . . 21

2.1 .2 Manifesto ágil . . . . . . . . . . . . . . . . 23

2.1.3 Metodologias ágeis . . . . . . . . . . . . . . 25

2.2 Design centrado no usuário e literatura relacionada . . . . . . . . . . 26

2.2 .1 Usabilidade . . . . . . . . . . . . . . . . . . 27

2.2.2 User Experience User Experience (UX) . . . . . . . . . . . . . . . . 29

2.2 .3 Interaction Design $(\mathrm{IxD}) \ldots \ldots \ldots \ldots$. . . . . . . . . . . 31

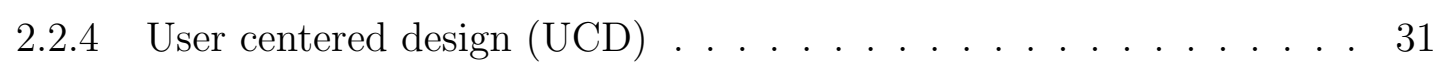

2.3 Desenvolvimento ágil de software centrado no usuário . . . . . . . . . 36

2.3.1 Semelhanças entre métodos ágeis e UCD . . . . . . . . . . . . . 37

2.3.1.1 Foco nas pessoas ................ 37

2.3.1.2 Desenvolvimento iterativo . . . . . . . . . . 38

2.3.1.3 Melhorias baseadas em feedback . . . . . . . . . . 38

2.3.2 Diferenças entre ágil e UCD . . . . . . . . . . . . . . 38

2.3.2.1 Foco no cliente versus foco no usuário . . . . . . . . 38

2.3.2.2 Equipe especialista versus generalista . . . . . . . . . . 39 
2.3.2.3 Software funcionando versus software utilizável . . . . . . 39

2.3.2.4 Visão hoslística versus visão incremental . . . . . . . . . . 39

2.3.2.5 Teste de unidade versus teste de usabilidade . . . . . . . . 40

2.3.2.6 Design necessário vs up-front design . . . . . . . . . . . 40

2.3.3 Benefícios da integração entre ágil e UCD . . . . . . . . . . . . . . 40

2.4 Processo de up-front design $(\mathrm{UFD}) \ldots \ldots \ldots \ldots$. . . . . . . . . . . . 41

2.5 Fatores contingenciais em projetos de software . . . . . . . . . . . . . . 43

$\begin{array}{lll}3 & \text { Método } & 47\end{array}$

3.1 Revisão sistemática da literatura . . . . . . . . . . . . . . . . . . . . 48

3.1.1 Protocolo de revisão sistemática da literatura . . . . . . . . . . . 50

3.1.2 Estratégia de busca . . . . . . . . . . . . . . . . 50

3.1.3 Critérios de seleção e análise qualitativa . . . . . . . . . . . . . . 50

3.2 Estudo de caso . . . . . . . . . . . . . . . . . . . . 53

3.2 .1 Instrumento de pesquisa $\ldots \ldots \ldots \ldots \ldots$

3.2 .2 Estudo piloto . . . . . . . . . . . . . . . . . 54

3.2.3 Definição da unidade de caso . . . . . . . . . . . . . . . . . . 55

3.2.4 Determinação do número de casos . . . . . . . . . . . . . . . 56

3.2 .5 Coleta de dados . . . . . . . . . . . . . . . . . . . . 57

3.2.6 Análise dos dados . . . . . . . . . . . . . . . . . . . . 59

4 Revisão sistemática da literatura $\quad 60$

4.1 Resumo das revisões de literatura existentes . . . . . . . . . . . . . . . 60

4.2 Análise das lacunas nas revisões de literatura existentes . . . . . . . . . . . 62

4.3 Análise bibliométrica e de redes . . . . . . . . . . . . . . . . 63

4.4 Análise de conteúdo . . . . . . . . . . . . . . . . . . . 67

4.4.1 Estado da arte da pesquisa de UFD . . . . . . . . . . . . . . 67

4.4.2 Uma visão holística de UCASD e UFD . . . . . . . . . . . . . . . 71 
4.5 Técnicas de UFD . . . . . . . . . . . . . . . . . . . . . . . . 78

4.5 .1 Técnicas de LDUF . . . . . . . . . . . . . . . . . . 79

4.6 Tempo de execução . . . . . . . . . . . . . . . . . . . . . . . . . . . . 82

4.7 Configuração da equipe . . . . . . . . . . . . . . . . . . . . . . . . . 84

4.8 Fatores contingenciais . . . . . . . . . . . . . . . . 87

4.8.1 Fatores contingenciais associados à organização . . . . . . . . . . . 95

4.8.2 Fatores contingenciais associados ao projeto . . . . . . . . . . 96

4.8.3 Fatores contingenciais associados à equipe . . . . . . . . . . . . 98

5 Estudo de caso $\quad 100$

5.1 Empresa foco do estudo . . . . . . . . . . . . . . . . . . . 100

5.2 Design sprint como framework para LDUF . . . . . . . . . . . . . . 101

5.3 Projetos analisados . . . . . . . . . . . . . . . . . 103

5.4 Entrevistas . . . . . . . . . . . . . . . . . 105

5.5 Proposições e modelo de pesquisa . . . . . . . . . . . . . . . . . 109

6 Resultados e discussão $\quad 116$

6.1 UFD em UCASD . . . . . . . . . . . . . . . . . . . 116

6.1.1 Benefícios para o projeto . . . . . . . . . . . . 117

6.1.2 Benefícios para o produto . . . . . . . . . . . . 118

6.1 .3 Contexto de aplicação . . . . . . . . . . . . . . . . . . . 119

6.1.4 LDUF versus BDUF . . . . . . . . . . . . . . . 120

6.2 Planejamento padrão do LDUF . . . . . . . . . . . . . . . . . 127

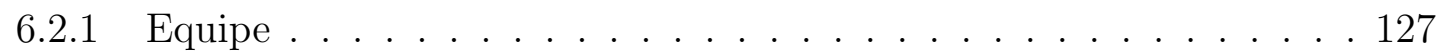

6.2.2 Tempo . . . . . . . . . . . . . . . . . . . 128

6.2.3 Gate de decisão - continuação para desenvolvimento . . . . . . . . . 129

6.3 Influência dos fatores contingenciais . . . . . . . . . . . . . . . 130

6.3.1 Fatores contingenciais associados à organização . . . . . . . . . . 130 
6.3.2 Fatores contingenciais associados ao projeto . . . . . . . . . . 132

6.3.3 Fatores contingenciais associados à equipe . . . . . . . . . . . . 137

6.3.4 Modelo de planejamento e execução do LDUF considerando seus fatores contingenciais . . . . . . . . . . . . . . . . . . 139

7 Conclusão

Referências 


\section{INTRODUÇÃO}

Os metodos ageis por si so, não são mais capazes de garantir a criação de softwares que sejam utilizáveis e que o usuario final queira ou precise (MESZAROS; ASTON, 2006; BLOMKVIST; PERSSON; ÅBERG, 2015; FERREIRA; NOBLE; BIDDLE, 2007a; BRHEL et al., 2015). Isto ocorre, entre outros motivos, porquê os metodos ageis tentam construir um software melhor na visao da pessoa que paga pelo software, tambem chamada de cliente, e nao necessariamente para a pessoa que realmente usa o software, denominada por usuario final. Com isso, muitas equipes de software acabam por receber respostas de aceitacao apos o lancamento do produto na forma de vendas perdidas, contratos cancelados, criticas ruins, resultados abaixo do esperado e baixa reputação (MILLER, 2005). Além disso, apesar do ágil ter ganhado tanta relevância no mercado, por trazer uma visão não tradicional, promovendo iteratividade, adaptação e melhoria constante, note-se que os principais métodos ágeis (eXtreme Programming (XP) e Scrum) permaneceram inertes no tempo, com as mesmas práticas, artefatos e responsabilidades que de décadas atrás quando foram criadas.

Neste contexto, surgiu o Desenvolvimento Ágil de Software Centrado no Usuário (do inglês: User Centered Agile Software Development - UCASD), que refere-se à integração de Desenvolvimento Ágil de Software (do inglês: Agile Software Development - ASD) e o Design Centrado no Usuário (do inglês: User Centered Design - UCD). Como escopo desta pesquisa, o ASD foi considerado como qualquer um dos seus métodos, técnicas, ferramentas, processos e notações existentes, relacionados a práticas de desenvolvimento de software ou atividades de gerenciamento de software, como SCRUM, XP e outros (CABALlERO; MORENO; SEFFAH, 2016); e UCD como todos os métodos, técnicas e procedimentos que colocam o usuário no centro do processo de criação de um produto,

serviço, software ou processo, de maneira significativa, apropriada e rigorosa (DETWEILER; MANAGING, 2007; SALAH; PAIGE; CAIRNS, 2014c).

O UCASD ganhou interesse crescente e se tornou uma tendência, porque as organizações estão progressivamente combinando a abordagem de UCD ao ASD, buscando 
capturar o melhor dos dois mundos: entregar projetos no prazo, dentro do orçamento, atendendo aos requisitos do negócio e, ao mesmo tempo, criando produtos ou serviços utilizáveis, úteis e desejáveis para o usuário final (ARDITO et al., 2017; SILVA et al., 2018). No entanto, pesquisadores como Caballero, Moreno e Seffah (2016), Ardito et al. (2014) evidenciaram que, apesar dos benefícios e soluções propostos na literatura, os métodos e ferramentas de UCD ainda são incorporados de forma muito incipiente ou inadequada aos projetos ágeis.

Embora haja um número razoável de publicações abordando o tópico - algumas revisões de literatura e muitos relatórios empíricos - essa integração de ASD e UCD ainda apresenta lacunas não abordadas. Uma dessas lacunas está relacionada ao UFD. Consideramos UFD como todas as atividades de projeto que estão sendo realizadas antes do início do desenvolvimento efetivo (SILVA et al., 2011). Mais especificamente, de acordo com Mostafa (2013), o UFD é uma fase separada e um período de tempo do projeto, que ocorre antes do início do desenvolvimento, sendo usado para obter requisitos, entender usuários, objetivos do usuário e contexto de uso, usando itens de backlog para criar histórias de usuários e impulsionar o design experimental, antes do início de qualquer desenvolvimento, para obter uma visão abrangente do sistema.

Esta etapa do UFD (foco deste trabalho) é fundamentalmente desafiadora para literatura e prática por integrar duas visoes opostas quanto as atividades previstas, tal que o agil preve minimizar o esforco investido em UFD acreditando que assim tera menos custos em caso de mudancas nos requisitos do projeto, enquanto o UCD preve maximizar o esforco investido nas atividades do UFD acreditando que tera requisitos mais assertivos e menos volateis, diminuindo a necessidade de mudanca dos mesmos ao longo do projeto, tal que por caminhos diferentes ambos visam diminuir retrabalho.

O UFD também é chamado de Sprint 0, Ciclo 0 ou Iteração 0. Embora muito citado em Revisões Sistemáticas de Literatura como uma das formas mais comuns de integração entre ASD e UCD (CABALLERO; MORENO; SEFFAH, 2016; SILVA et al., 2011; BRHEL et al., 2015), o UFD ainda é um tópico com o qual organizações e profissionais têm dificuldade, pois não há uma definição clara do processo em si, quem são os participantes, como deve ser planejado, executado, e quais são seus resultados e sua extensão (SILVA et al., 2011; BRHEL et al., 2015; FOX; SILLITO; MAURER, 2008; WERDER; ZOBEL; MAEDCHE, 2016). Em decorrência disso, é visto na prática que muitas empresas se equivocam ao aplicar um mesmo processo para investigar problemas e oportunidades ainda em estágios exploratórios como para refinar soluções em contexto confirmatório e vice-versa. 
Na literatura, alguns pesquisadores como Adikari, Mcdonald e Campbell (2009), Schön (2017) defenderam que o UFD deveria ser "pequeno", levando-nos ao conceito de Little Design Up-Front (LDUF) em oposição ao Big Design Up-Front (BDUF), que é contra princípios ágeis. No entanto, nenhuma das publicações anteriores definiu claramente o que este "pequeno" significa exatamente. Alguns estudos definem o LDUF como uma abordagem para fornecer apenas detalhes necessários das informações do UCD, conforme necessário, para suportar a análise e o design em iterações ágeis, mas nenhum aborda a extensão necessária e suficiente para o UFD.

Outra lacuna no UCASD que se afasta de um foco em descrever processos e técnicas específicas é investigar como os fatores contingenciais afetam o trabalho na prática. Essa análise é importante, pois a maioria dos estudos são validados apenas em configurações organizacionais específicas, dificultando a replicação de proposições de literatura em diferentes contextos (BRHEL et al., 2015; FERREIRA; SHARP; ROBINSON, 2012; JIA; LARUSDOTTIR; CAJANDER, 2012; WALE-KOLADE; NIELSEN; PAIVARINTA, 2014). Os fatores contingenciais são um conjunto de condições internas ou externas ao projeto que, juntas, ajudam a decidir como gerenciar e operar com maior eficácia (RATBE; KING; KIM, 1999).

A exploração deste tema é complexa por se situar dispersa na intersecção de três grandes áreas distintas: design, computação e gestão. Isso implica em uma diversidade de nomes diferentes para conceitos similares (ex: UX, Interaction Design (IxD), UCD) e nomes semelhantes para conceitos diferentes (ex: desenvolvimento ágil de software centrado no usuário e design centrado no usuário ágil). Além disso, estudos no tema tendem a ser enviesados porque não consideram uma visão completa da integração do UCD ao ASD (perspectivas do desinger, desenvolvedor e gestor) e são em sua grande maioria relatos de experiência da indústria, com pouco rigor metodológico (JURCA; HELLMANN; MAURER, 2014).

\subsection{Questões de pesquisa}

Tendo em vista as lacunas mencionadas, torna-se relevante compreender a diferença entre LDUF e BDUF, suas atividades e extensões - quanto design é considerado "pequeno " ou "grande" - em ambientes ágeis, como estes processos se encaixam no ciclo de vida do UCASD, levantar as características mais determinantes destes processos (técnicas, tempo de execução e configuração de equipe) e entender como os fatores contingenciais do projeto influenciam o processo na prática. 
Para estreitar as lacunas mencionadas acima e desenvolver uma melhor compreensão do tópico para acadêmicos e profissionais, esse trabalho se propõe a responder às seguintes sub-questões de pesquisa:

- QP1: O que exatamente é o processo do UFD e como se encaixa dentro do ciclo de vida do UCASD?

- QP2: Como as atividades de LDUF contrastam com as de BDUF e por que o LDUF é mais apropriado para o UCASD?

- QP3: Quais são as alternativas de tempo e configuração da equipe para planejar e executar o UFD?

- QP4: Quais são os fatores de contingência mais relevantes para o UCASD?

- QP5: Como os fatores contingenciais influenciam o planejamento e a execução do UFD?

Através das questões acima, objetiva-se responder a principal pergunta desta pesquisa:

Como planejar e executar o up-front design no desenvolvimento ágil de software centrado no usuário, considerando seus fatores contingenciais?

\subsection{Objetivo}

O principal objetivo desta pesquisa pode ser definido como:

Propor um processo claro, compreensível e replicável do UCASD com foco em suas atividades iniciais, e um modelo conceitual que oriente praticantes da área a melhor planejar e executar o UFD em diferentes contextos de projetos de software.

Neste sentido, o primeiro objetivo da pesquisa é organizar o atual estado da arte de UCASD trazendo uma maior compreensão dos diferentes momentos de integração entre UCD e ASD e como se encaixam no ciclo de vida do projeto de software.

O segundo objetivo de pesquisa visa a analisar as diferenças entre BDUF e LDUF de maneira sistemática, propondo definições para ambos processos e a forma de transição entre esses diferentes estágios do UCASD. Esta análise compreende de entender as técnicas empregadas e o valor de cada um dos processos para que praticantes possam saber quais deles executar, dependendo de suas necessidades. 
O terceiro objetivo dessa pesquisa almeja incrementar o corpo do conhecimento das principais características ainda mal-definidas no processo de LDUF: tempos de execução do processo e configuração ideal da equipe.

O quarto objetivo da pesquisa compreende de levantar e categorizar os fatores contingenciais de projetos de software em diferentes níveis e etapas do processo de uma maneira lógica para praticantes da área.

Finalmente, o quinto objetivo de pesquisa consiste em entender como as atividades preconizadas na teoria podem ser melhor adaptadas em contextos reais, dependendo das necessidades e circunstâncias dos profissionais da área.

A partir dos objetivos de pesquisa, optou-se inicialmente pela condução de uma Revisão Sistemática da Literatura (RSL), capaz de compilar as principais características supracitadas no tema. A condução de uma revisão sistemática da literatura se faz relevante neste estudo, pois dispõe de técnicas que mapeiam a literatura de maneira não tendenciosa, identificando os principais autores, a evolução do conhecimento sobre o tema e permitem codificar e padronizar o conhecimento acumulado (NEELY, 2005; GUEDES; BORSCHIVER, 2005). A RSL também auxilia na criação do modelo de pesquisa.

Em seguida, para endereçar o problema de como planejar e executar o processo de forma mais eficaz considerando a variabilidade de fatores contingenciais, foi realizado um estudo de caso múltiplo, para validar como as atividades prescritas na teoria podem ser melhor ajustadas à prática dependendo do contexto.

\subsection{Justificativa}

A pesquisa tem por intuito trazer contribuições teóricas ao preencher diversas lacunas da literatura, apontadas anteriormente, com um estudo acadêmico que traz uma visão holística do tema de UCASD, mas também aborda em detalhes o processo de UFD em seus diversos atributos de equipe, atividades e extensão, analisados sob uma ótica contingencial.

Além disso, acadêmicos podem fazer uso de um abrangente sistema de codificação proposto, que categoriza o trabalho existente em UFD. Ao fornecer uma visão ampla da pesquisa atual, este trabalho pode ser usado como ponto de partida para acadêmicos que desejam pesquisar esse campo.

Por uma perspectiva prática, a pesquisa pretende contribuir para praticantes da área, 
como líderes de UX, gerentes de projeto e/ou produto, desenvolvedores e até compradores de software, a refinarem melhor seus processos na construção de novos softwares ou melhoria de existentes, assim como auxiliar organizações com menor maturidade no tema de usabilidade a planejarem e definirem com uma maior eficácia as atividades iniciais da criação do software de forma a satisfazer as necessidades de seu público-alvo.

Finalmente, este trabalho pode contribuir para alcançar o objetivo principal do UCASD, ou seja, estimular a criação de softwares úteis, utilizáveis, desejáveis e atraentes.

\subsection{Estrutura do documento}

A pesquisa foi estruturada em seis capítulos. No Capítulo 2 é apresentada a revisão de literatura sobre os principais conceitos envolvidos no estudo, a partir de referências clássicas e bem aceitas pelas comunidades de pesquisas sobre os temas relacionados, que formam a estrutura elementar deste estudo.

O capítulo 3 apresenta o método de pesquisa, descrevendo os processos adotados em cada etapa do estudo, como os procedimentos utilizados na condução da revisão sistemática da literatura, a elaboração do instrumento de pesquisa e a seleção e condução do estudo de caso em campo.

No capítulo 4, são apresentados os detalhes sobre os procedimentos utilizados na revisão sistemática da literatura. Assim, o capítulo apresenta os resultados obtidos com as análises bibliométrica, de redes e de conteúdo dos artigos mais relevantes para o tema, extraídos das principais conferências e indexadores de estudos científicos da atualidade.

No capítulo 5, são apresentadas as principais informações referentes ao estudo de caso: organização foco do estudo de caso múltiplo, framework utilizado pela empresa como LDUF, projetos avaliados e estrutura das entrevistas.

No capítulo 6 são apresentados e discutidos os resultados obtidos em campo, com uma comparação do encontrado em campo com o levantado na literatura e reesctruturação dos modelos conceituais do UCASD e influência dos fatores contingenciais no LDUF.

Por fim, o capítulo 7 apresenta as conclusões e contribuições deste estudo para o tema de pesquisa, além das limitações presentes e as possíveis pesquisas futuras a partir dos resultados apresentados. 


\section{REFERENCIAL TEÓRICO}

Este capítulo fornece informações essenciais sobre os conceitos mais relevantes para esta pesquisa. O entendimento dos conceitos de ASD, o UCD, a integração destas abordagens e mais especificamente o UFD, é fundamental para compreender a motivação e demais aspectos da pesquisa.

Para apresentar as características mais importantes do desenvolvimento ágil, é discutido o surgimento dele em decorrência da até então mais conhecida metodologia em cascata. Em seguida são apresentados os principais pilares destacados no pensamento ágil, derivados de seu manifesto, e as metodologias ágeis mais comuns.

Na sequência, este capítulo discute o UCD e outros temas da literatura com grande similaridade, como o IxD e UX, e também princípios de usabilidade e atividades relacionadas.

Em seguida são apresentadas as principais áreas de discussão do desenvolvimento ágil de software centrado no usuário presentes na literatura, como características desta integração, principais benefícios, e desafios encontrados na prática. Após conclui-se com um detalhamento da etapa de UFD e uma visão contingencial para análise e gerenciamento de projetos.

\subsection{Desenvolvimento ágil de software}

\subsubsection{O surgimento das metodologias ágeis}

Uma metodologia de desenvolvimento de software pode ser definida por:

- Uma coleção de recomendações de fases, procedimentos, regras, técnicas, ferramentas, documentação, gestão, e treinamento usadas para desenvolver um sistema (AVISON; FITZGERALD, 2003).

Nos primórdios do desenvolvimento de software, quando os projetos eram menos com- 
plexos, e não existia uma percepção clara da distinção entre estes e projetos tradicionais de engenharia civil e mecânica, a primeira metodologia de software disseminada no mercado foi o modelo em cascata (ROYCE, 1970). Esta metodologia apresenta um processo de desenvolvimento linear, claramente separado em 5 etapas sequenciais, como disposto na Figura. 1.

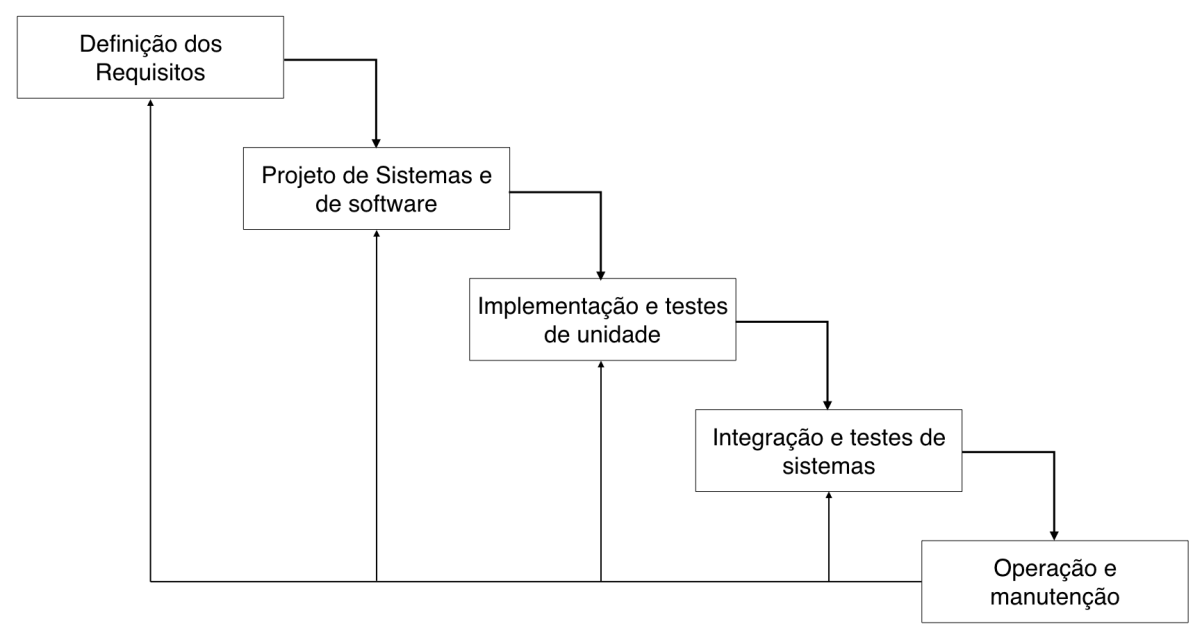

Figura 1: Modelo em cascata. Fonte: Adaptado de Royce (1970)

Embora a linearidade ajudasse na organização do desenvolvimento do software, eliminando assim diversos problemas enfrentados até então, esta estrutura estrita foi se mostrando, com o passar do tempo, ineficaz para lidar com mudanças de escopo, já que para cada nova mudança era necessário voltar à primeira fase do ciclo (definição dos requisitos), gerando uma grande quantidade de retrabalho e impedindo uma resposta rápida e satisfatória em ambientes de constante transformação (BOEHM, 2002).

Como resposta a estes problemas, foram criadas diversas outras alternativas, sendo algumas das mais populares: os modelos evolucionário, em espiral, incremental (SOMMERVILLE, 2010), e os de padronização das boas práticas do desenvolvimento de software através do Software Capability Maturity Model e o Capability Maturity Model Integration (PAULK, 1995; CHRISSIS; KONRAD; SHRUM, 2003). Entretanto, por excederem na formalidade, burocracia e falta de flexibilidade, tampouco eram adequados à contínua transformação exigida pelo negócio (BOEHM, 2002; HIGHSMITH; COCKBURN, 2001).

A partir deste contexto, praticantes e pesquisadores da área começaram a investigar formas iterativas e incrementais de desenvolver o software, de forma a minimizar burocracias e priorizar o desenvolvimento contínuo de pequenas partes do sistema com 
foco em diminuir o retrabalho, mesmo quando haviam mudanças de escopo no projeto tardiamente. Estas iniciativas se iniciaram na década de 1990 e foram posteriormente chamadas de Metodologias Ágeis, do inglês Agile Methodologies (HIGHSMITH; COCKBURN, 2001).

Por essas razões, o desenvolvimento ágil é de certa forma uma resposta aos problemas encarados pelas abordagens tradicionais, ao estimular o aumento de comunicação entre os desenvolvedores com stakeholders, e diminuição de burocracias de baixo valor para o resultado a ser entregue (HODA; NOBLE; MARSHALL, 2013).

Além destas mudanças relacionadas à flexibilidade do projeto, as metodologias ágeis propõem diversos outros valores e princípios relacionados não apenas à esfera de processos, mas também social e estratégica.

\subsubsection{Manifesto ágil}

Apesar do conceito de ágil ter sido mencionado pela primeira vez em 1957 (LARMAN; BASILI, 2003) e as primeiras iniciativas terem ocorrido na década de 1990 (BECK, 1999), o ASD somente foi formalmente estabelecido em 2001 a partir da divulgação do Manifesto Ágil (BECK et al., 2001). Este documento foi concebido em um evento em Utah, nos Estados Unidos, por dezessete líderes da comunidade de software, dentre eles consultores e pesquisadores, com o intuito de estabelecer propostas de princípios e valores para o ASD, para resolver problemas advindos das metodologias existentes até então.

Os valores fundamentais do manifesto ágil são (BECK et al., 2001):

\section{- Indivíduos e interações ao invés de processos e ferramentas.}

As pessoas, em vez de processos e ferramentas, são percebidas como o fator-chave no desenvolvimento ágil de software. Como resultado, os métodos ágeis valorizam as habilidades individuais e dependem de equipes auto-organizáveis, pró-ativas e coesivas, que efetivamente utilizam a comunicação constante. Este foco em indivíduos e interações contrasta com todas as metodologias tradicionais que focam no desenvolvimento de ferramentas e processos institucionalizados.

\section{- Software funcionando ao invés de documentação extensa.}

O foco principal das equipes ágeis é entregar o software funcionando e testado com documentação mínima e suficiente, ao invés de atualizada e completa. 


\section{- Colaboração com o cliente ao invés de negociação de contratos.}

Os métodos ágeis se esforçam para alcançar a satisfação do cliente através de uma interação próxima, em vez de depender apenas dos contratos. Recomenda-se que os clientes sejam colocados junto às equipes de desenvolvimento para conseguir uma interação diária próxima.

\section{- Responder a mudanças ao invés de seguir um plano.}

Os métodos ágeis dão preferência à flexibilidade na aceitação de mudança dos requisitos de um projeto, descartando assim seguir à risca planos definidos previamente. No entanto, os métodos ágeis preveem fornecer à equipe de desenvolvimento competência e autoridade, para ajustar e gerar planos flexíveis que acomodam mudanças, ao invés de evitar o planejamento completo.

A partir destes valores, existem 12 princípios mais concretos que devem ser seguidos por equipes ágeis. A elucidação destes princípios é importante, já que a discussão de integração do ágil com UCD passa por atender ou entrar em conflito com os princípios listados aqui (ABBAS; GRAVELL; WILLS, 2008):

1. Nossa maior prioridade é satisfazer o cliente, através da entrega adiantada e contínua de software de valor.

2. Aceitar mudanças de requisitos, mesmo no fim do desenvolvimento. Processos ágeis se adéquam a mudanças para que o cliente possa tirar vantagens competitivas.

3. Entregar frequentemente software funcionando, de poucas semanas a poucos meses, com preferência a uma menor escala de tempo.

4. Equipe de negócio e desenvolvedores devem trabalhar diariamente em conjunto por todo o projeto.

5. Construa projetos em torno de indivíduos motivados. Dê a eles o ambiente e o suporte necessário e confie neles para fazer o trabalho.

6. O método mais eficiente e eficaz de transmitir informações para e entre uma equipe de desenvolvimento é através de conversa face-a-face.

7. Software funcionando é a medida primária de progresso. 
8. Os processos ágeis promovem desenvolvimento sustentável. Os patrocinadores, desenvolvedores e usuários devem ser capazes de manter um ritmo constante indefinidamente.

9. Contínua atenção à excelência técnica e bom design aumentam a agilidade.

10. Simplicidade - a arte de maximizar a quantidade de trabalho não realizado - é essencial.

11. As melhores arquiteturas, requisitos e designs emergem de equipes auto-organizáveis.

12. Em intervalos regulares, a equipe reflete sobre como se tornar mais eficaz, e para isso refina e ajusta seu comportamento de acordo.

Assim, o desenvolvimento ágil resgata o conceito de iterações proposto por (BOEHM, 1988), contudo incorporando uma abordagem mais flexível, ressaltando a importância estratégica das mudanças para o negócio, a criação de valor para o cliente e a interação entre pessoas.

O manifesto ágil em si, entretanto, não é uma metodologia, senão um agrupamento de orientações em alto nível que serve como base para diversas outras metodologias que serão melhor explicadas adiante.

\subsubsection{Metodologias ágeis}

As metodologias ágeis, por sua vez, ainda que tenham em suas bases os valores e princípios previstos no manifesto ágil (BECK et al., 2001), proveem processos e guias próprios. As principais metodologias ágeis são (HODA; NOBLE; MARSHALL, 2013):

- XP;

- Scrum;

- Feature-Driven Development;

- Dynamic System Development Method;

- Adaptive Software Development;

- Crystal; e

- Lean Software Development. 
Em seguida, é disposta uma breve explicação do Scrum, um dos métodos ágeis mais disseminados no mercado.

Scrum: concentra-se mais nos aspectos inerentes às questões gerenciais do desenvolvimento de software, ou seja, seu foco é mais orientado à gestão de projetos. O Scrum surgiu no início dos anos 1990, a partir do trabalho de Ken Schwaber, Jeff Sutherland e Mike Beedle (SCHWABER, 2004, 2004). Caracteriza-se, principalmente, pelas iterações, conhecidas como Sprints, que possuem duração sugerida de uma a quatro semanas, e pelas reuniões diárias de acompanhamento, conhecidas pelo termo em inglês Stand-up Meetings. Por possuir foco maior na gestão dos projetos, o Scrum geralmente é combinado com as práticas e técnicas apresentadas pela XP no contexto da indústria de software (DYBÅ; DINGSØYR, 2008; ABRAHAMSSON et al., 2003). A Figura 2 apresenta uma síntese do processo do Scrum.

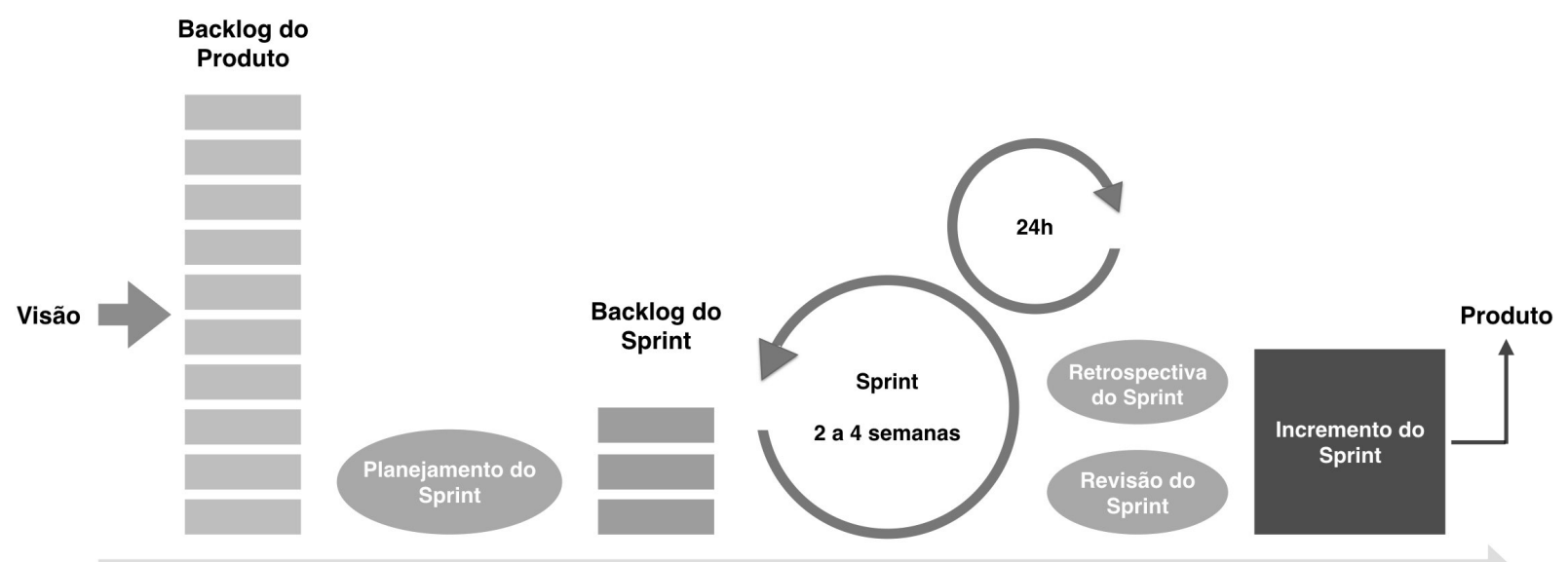

Figura 2: Processo do SCRUM. Fonte: Adaptado de Schwaber (2004)

A simplicidade de implementação e adoção tem feito com que organizações de outros setores adotem a abordagem do Scrum como metodologia para a gestão de projetos de diversas naturezas.

\subsection{Design centrado no usuário e literatura relacio- nada}

Apesar de ser possível criar um software utilizável através de métodos ágeis, ainda que seja uma coincidência, mas nem a XP (JOKELA; ABRAHAMSSON, 2004) nem o Scrum 
(SINGH, 2008) atacam adequadamente as necessidades de usabilidade. Estes métodos carecem de práticas que exerçam essa função de forma sistemática (RANNIKKO, 2011). Isto ocorre porquê a tecnologia é fator dominante no desenvolvimento de software, enquanto objetivos e necessidade dos usuários, contexto de uso, limitações entre outros aspectos ficam em segundo plano (BLOMKVIST, 2005). Com isso, muitas equipes de software evitam o feedback dos clientes durante o desenvolvimento e acabam por receber respostas de aceitação após o lançamento do produto na forma de vendas perdidas, contratos cancelados, críticas ruins, resultados abaixo do esperado e baixa reputação (MILLER, 2005). Em decorrência destes problemas, surge um crescente número de praticantes e pesquisadores que começam a utilizar UCD em projetos de Software.

Além disso, Ritter, Baxter e Churchill (2014) indicam que há muito tempo é preciso considerar as capacidades e características humanas ao projetar tecnologias e sistemas. Como Nickerson (1969) resumiu: "a necessidade do futuro não é tanto as pessoas orientadas para o computador quanto os computadores orientados para as pessoas “. Desde então, vários campos de pesquisa cresceram, preocupados com a forma de conceber tecnologias e sistemas eficazes para uso humano. UX, UCD, IxD são áreas de pesquisa que assumiram esse chamado e garante que os objetivos e as necessidades dos usuários finais do sistema sejam o foco do desenvolvimento do produto (RITTER; BAXTER; CHURCHILL, 2014).

Como os termos UCD, IxD e UX têm um significado muito semelhante (SILVA et al., 2011), o restante deste trabalho centraliza todos estes conceitos do design no termo UCD, por ser o tema mais citado em artigos relacionados a integração com ASD (ZAPATA, 2015).

No entanto, antes de se aprofundar em como UCD é utilizado especificamente no contexto de projetos de software, este trabalho faz uma revisão de outras terminologias complementares do design (SILVA et al., 2013), como IxD e UX, que também visam trabalhar a melhoria da usabilidade do software. Por ser um termo utilizado indiscriminadamente, mesmo na literatura, a seguir é visto as considerações desta pesquisa para este conceito.

\subsubsection{Usabilidade}

O termo usabilidade tem diversas menções na literatura com diferentes definições, de forma que o seu entendimento é complexo, inclusive para a comunidade de software. Apesar de não existir uma definição única aceita na comunidade, alguns pesquisadores já criaram definições como: 
- Um atributo de qualidade de um produto que depende da extensão e desempenho das atividades do UCD em um projeto de desenvolvimento específico (JOKELA; ABRAHAMSSON, 2000).

- A ausência de obstáculos que impedem os usuários de completar suas tarefas com o sistema (NIELSEN; PHILLIPS, 1993).

- A usabilidade assegura otimizações das interações das pessoas com produtos interativos. Os produtos utilizáveis são caracterizados por serem fáceis de aprender, divertidos e eficazes para usar da perspectiva do usuário. A usabilidade é examinada em um conjunto de objetivos que compõem eficiência, eficácia, utilidade, aprendizado, segurança e memorabilidade. Esses objetivos são transformados em critérios de usabilidade que facilitam a avaliação do produto. Exemplos de critérios de usabilidade são o tempo para aprender uma tarefa (capacidade de aprendizado), o tempo para completar uma tarefa (eficiência) e o número de erros feitos ao executar uma determinada tarefa ao longo do tempo (memorabilidade) (ROGERS; SHARP; PREECE, 2011).

Além destes, existem padrões ISO da engenharia de software, relacionados à usabilidade de produtos e processos (SEFFAH; METZKER, 2004), descritas como:

- A capacidade do produto de software de ser entendido, aprendido, usado e atraente para o usuário, quando usado em condições específicas (ISO-9126).

- A medida em que um produto pode ser usado por determinados usuários para atingir metas específicas com efetividade, eficiência e satisfação em um contexto de uso específico (DIS, 2009).

- A facilidade com que um usuário pode aprender a operar, preparar entradas e interpretar saídas de um sistema ou componente (IEEE-Standard-1061).

Isto posto, este trabalho considera que o conceito de usabilidade no contexto de software é uma variável de performance de um sistema relacionado principalmente a seus fatores de:

- Facilidade de uso (completar uma atividade)

- Eficiência (rápido de ser realizado)

- Agradável (é atraente ou satisfaz o usuário de alguma forma) 
Isto posto, a seguir são apresentados os principais termos correlatos a UCD, de forma mais abrangente até mais específica, como definidos na Figura 3.

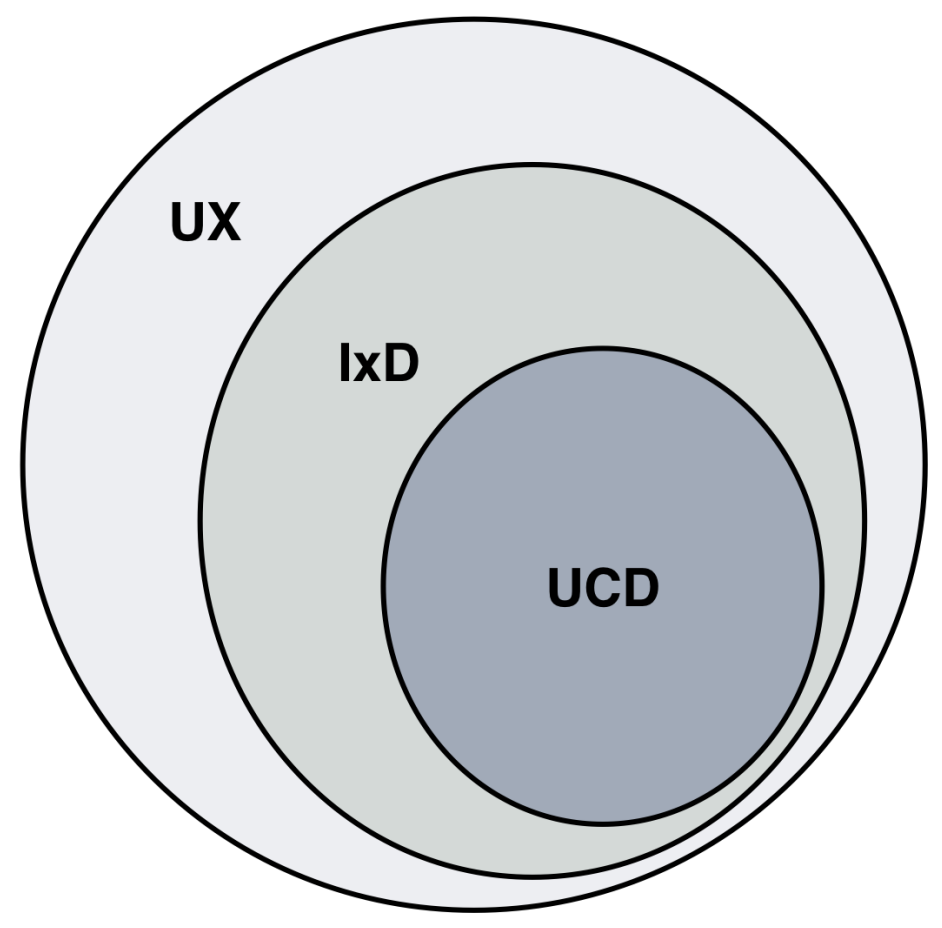

Figura 3: Termos mais comuns de design. Fonte: Adaptado de Gray (2014) e Saffer (2010)

\subsubsection{User Experience UX}

User Experience por sua vez é um conceito mais amplo, pois além dos fatores de usabilidade, considera a utilidade de um produto, ou seja se um produto possui características que um usuário quer ou precisa (LAW et al., 2009).

O conceito de UX também não tem uma definição única aceita por toda a comunidade, mas Law et al. (2009) fizeram um esforço para coletar as principais definições propostas na literatura e na comunidade de praticantes, que descrevem UX como:

- Todos os aspectos da interação do usuário final com a empresa. Os seus serviços e seus produtos. O primeiro requisito para uma experiência de usuário exemplar é atender às necessidades exatas do cliente sem problemas ou incômodo. Em seguida, vem a simplicidade e a elegância que produzem produtos que são uma vontade de ter e vontade de usar. A verdadeira experiência do usuário vai muito além de dar aos clientes o que eles dizem querer, ou fornecer uma lista de funcionalidades (NODDER; NIELSEN, 2010). 
- Uma consequência do estado interno de um usuário (predisposições, expectativas, necessidades, motivação, humor, etc.) as características do sistema projetado (i.e. complexidade, propósito, usabilidade, funcionalidade, etc.) e o contexto (ou o meio ambiente) dentro do qual a interação ocorre (i.e. configuração organizacional / social, significado da atividade, voluntariedade de uso, etc.) (HASSENZAHL; TRACTINSKY, 2006).

- Todo o conjunto de efeitos que é provocado pela interação entre um usuário e um produto, incluindo o grau em que todos os nossos sentidos são gratificados (experiência estética) os significados atribuídos ao produto (experiência de significado) e os sentimentos e emoções que são provocados (experiência emocional) (DESMET; HEKKERT, 2007).

- O valor derivado das interações (ou interações antecipadas) com um produto ou serviço e suporte no contexto de uso (i.e. tempo, localização e disposição do usuário) (SWARD; MACARTHUR, 2007).

- A qualidade da experiência que uma pessoa tem ao interagir com um design específico. Isso pode variar de um artefato específico, como um brinquedo ou site até experiências integradas maiores, como um museu ou um aeroporto (UXNET, 2007). evisão

Segundo Law et al. (2009) não existe um consenso para apenas uma das definições acima, tal que a aceitação dos definições depende da área e experiência do praticante ou pesquisador de UX.

Este trabalho, porém considera como definição de UX o padrão ISO standard (DIS, 2009), que estabelece UX como:

- As percepções e respostas de uma pessoa que resultam do uso ou do uso antecipado de um produto, sistema ou serviço.

As apresentações acima, evidenciam que o conceito de UX vai muito além da usabilidade e está diretamente conectado a relação experimental entre usuário, sistema e contexto de uso. Por se caracterizar de um conceito demasiadamente amplo, esta pesquisa considera publicações e práticas deste campo, mas opta por escolher UCD como a principal interface de integração ao desenvolvimento ágil. 


\subsubsection{Interaction Design ( $\mathrm{IxD})$}

O IxD visa proporcionar uma UX melhorada através de uma combinação de habilidades analíticas e criativas que permitem ao designer de interface do usuário resolver problemas relacionados a uma implementação de User Interface (UI) (BACON, 2005).

Nas palavras de Cooper, Reimann e Cronin (2007) o elemento que caracteriza IxD é o fato de que, diferente de outros conceitos de ciência ou engenharia, não se procura analisar os sistemas como eles são, mas sim como eles poderiam ser.

Rogers, Sharp e Preece (2011) definem que IxD é alcançado através de uma abordagem centrada no usuário, sendo que envolve quatro atividades principais iterativas: identificar necessidades e requisitos do usuário, desenvolver design alternativos, construir versões de design interativo e avaliar a usabilidade do que está sendo construído ao longo do processo. O processo de design de interação tem três características principais: envolver o usuário ao longo do processo de desenvolvimento, identificar e documentar desde o início a experiência do usuário e metas de usabilidade através de atividades de design de interação.

Saffer (2010) classifica o Design de Interação como contextual por natureza e assume que deve resolver problemas específicos em circunstâncias particulares, usando o material disponível. O autor classifica quatro abordagens principais que foram utilizadas no processo de design para o desenvolvimento de produtos interativos de sucesso. As abordagens são: Design centrado na atividade, Design do sistema, Design de gênio e Design centrado no usuário (ver Tabela 1). Os desenvolvedores selecionam qual deles usar de acordo com o projeto. Os melhores designers são aqueles que aplicam mais de uma abordagem no mesmo projeto, mas que a abordagem de design centrada no usuário é a mais popular e explica que a participação do usuário em todas as etapas do processo é crítica (CHAMMAS; QUARESMA; MONTALVAO, 2015).

\subsubsection{User centered design (UCD)}

O termo UCD foi criado por Donald A. Norman na Universidade da Califórnia, em San Diego (RITTER; BAXTER; CHURCHILL, 2014). O conceito tornou-se amplamente popular após a publicação do livro "Design de Sistema Centrado no Usuário: Novas Perspectivas sobre Interação Homem-Computador" em 1986. O conceito ganhou ainda mais atenção e aceitação em seu livro seminal "The Design of Everyday Things" em 1988 (NORMAN, 2013; NORMAN; DRAPER, 1986). No livro, Don Norman descreve a psicologia por trás do que ele considera "bom " e "mau" design através de exemplos. 
Tabela 1: Comparação entre as quatro abordagens de Interaction Design

\begin{tabular}{lllll}
\hline Abordagem & Visão Geral & Usuário & \multicolumn{2}{l}{ Designer } \\
\hline $\begin{array}{l}\text { Design centrado } \\
\text { na atividade }\end{array}$ & $\begin{array}{l}\text { Focado em tarefas e ativida- } \\
\text { des que precisam ser realiza- } \\
\text { das }\end{array}$ & $\begin{array}{l}\text { Praticantes } \\
\text { atividades }\end{array}$ & $\begin{array}{l}\text { Criador de fer- } \\
\text { ramentas para a } \\
\text { ação }\end{array}$ \\
\hline $\begin{array}{l}\text { Design de sis- } \\
\text { tema }\end{array}$ & $\begin{array}{l}\text { Focado nos componentes do } \\
\text { sistema }\end{array}$ & $\begin{array}{l}\text { Conjunto de ob- } \\
\text { jetivos do } \\
\text { tema } \\
\text { sis- }\end{array}$ & $\begin{array}{l}\text { Garatir } \\
\text { todas as partes } \\
\text { do sistema estão } \\
\text { harmônicas }\end{array}$ \\
\hline Design de genio & $\begin{array}{l}\text { Habilidade e talento do de- } \\
\text { signer acostumado a criar } \\
\text { produtos }\end{array}$ & $\begin{array}{l}\text { Fonte de va- } \\
\text { lidação }\end{array}$ & $\begin{array}{l}\text { Fonte de ins- } \\
\text { piração }\end{array}$ \\
\hline $\begin{array}{l}\text { Design centrado } \\
\text { no usuário }\end{array}$ & $\begin{array}{l}\text { Focado nas necessidades e } \\
\text { objetivos do usuário }\end{array}$ & $\begin{array}{l}\text { Lidera o design } \\
\text { de interface }\end{array}$ & $\begin{array}{l}\text { Reflete as neces- } \\
\text { sidades e objeti- } \\
\text { vos do usuário }\end{array}$ \\
\hline
\end{tabular}

Fonte: (SAFFER, 2010)

Ele exalta a importância do design em nossas vidas cotidianas e as consequências de erros causados por maus projetos. Os livros também incluem princípios de construção de produtos bem projetados. Suas recomendações são baseadas nas necessidades do usuário, deixando de lado o que ele considera questões secundárias como a estética. Os principais em destaque são:

- Simplificar a estrutura das tarefas, de modo que as possíveis ações a qualquer momento sejam intuitivas.

- Tornar as coisas visíveis, incluindo o modelo conceitual do sistema, ações, resultados de ações e comentários.

- Obter os mapeamentos diretamente entre os resultados pretendidos e as ações necessárias.

- Explorar as restrições dos sistemas

Em um sentido mais amplo, Salah, Paige e Cairns (2014a) sintetizam o UCD como um conjunto de técnicas, métodos, procedimentos e processos, bem como uma filosofia que coloca o usuário no centro do processo de desenvolvimento de forma significativa, apropriada e rigorosa. O objetivo da aplicação do UCD é tentar satisfazer os usuários através da criação de produtos utilizáveis e compreensíveis que atendam às suas necessidades e interesses, considerando seus objetivos, contextos de uso, habilidades e limitações (MAO et al., 2001; GARRETT, 2010) 
Além disso, os processos UCD são definidos em uma série de padrões ISO (JOKELA; ABRAHAMSSON, 2004). O primeiro padrão relacionado foi ISO 13407 (processos de design centrados em humanos para sistemas interativos), um padrão internacional estabelecido em 1999 que define UCD como:

- Uma abordagem para o desenvolvimento de sistemas interativos que se concentra especificamente na criação de sistemas utilizáveis.

Além disso, a ISO 13407 está focada em explicar um conjunto independente de princípios e atividades de UCD que ajudam na criação de sistemas ou produtos utilizáveis e permite que as organizações compreendam o status do UCD em seu processo de desenvolvimento (JOKELA, 2008). Os princípios de ISO 13407 são: equipe de trabalho multidisciplinar, envolvimento ativo de usuários, design iterativo e alocação de funções apropriadas entre os usuários e o sistema (JOKELA; ABRAHAMSSON, 2004). As principais atividades da UCD de acordo com a norma ISO 13407 são:

1. Especificar o contexto de uso: identificar quais os principais usuários do produto, por que eles usarão o produto, quais são seus requisitos e em que ambiente eles vão usá-lo.

2. Especificar Requisitos: Uma vez que o contexto é especificado, é hora de identificar os requisitos granulares do produto. Este é um processo importante que pode facilitar aos designers criar storyboards e estabelecer metas importantes para que o produto seja bem sucedido.

3. Criar soluções de design e desenvolvimento: com base nas metas e requisitos do produto, começar um processo iterativo de design e desenvolvimento de produtos.

4. Avaliar o produto: os designers de produtos fazem testes de usabilidade para obter o feedback dos usuários sobre o produto. A avaliação do produto é um passo crucial no desenvolvimento de produtos que fornece feedback crítico do produto.

A versão ISO 9241-210 é o padrão mais novo relacionado a UCD, e atualiza versão ISO 13407 em diversos pontos. Segundo a ISO 9241-210 o UCD destina-se a aumentar a aceitação e a produtividade de sistemas interativos, reduzir erros, horas de suporte e treinamento, bem como proporcionar a melhor experiência de usuário possível. O UCD também aborda o desenvolvimento de sistemas interativos focados nas necessidades e interesses dos usuários, com a aplicação de critérios ergonômicos e conhecimento de técnicas 
de usabilidade. Essa abordagem aumenta a eficácia, melhora o bem-estar humano, a acessibilidade e a sustentabilidade e leva em consideração os diferentes efeitos que esses sistemas interativos podem refletir sobre saúde, segurança e desempenho do usuário.

Maguire (2001) afirma que, antes do ISO 9241-210, os métodos de usabilidade foram testados e estabelecidos por desenvolvedores, mas foram aplicados isoladamente e sem um conceito que oriente a integração desses métodos e os alinhe a um único processo. A padronização dessas técnicas alterou a prática dos processos de desenvolvimento de hardware e software para ilustrar como métodos e técnicas diferentes podem ser usados em conjunto e se tornaram ferramenta de guia para os responsáveis pelo projeto de processos e redesenho de hardware e software. Os padrões técnicos estabelecidos pelo ISO compreendem a abordagem de design centrada no usuário e a interação do sistema humano sob uma perspectiva ergonômica. A abordagem do design centrada no usuário permite o uso de procedimentos semelhantes, guias de design padrão e prepara documentação para projetos futuros.

Chammas, Quaresma e Montalvao (2015) relatam que para organizar e realizar a aplicação prática do conhecimento em Ergonomia e Usabilidade, o ISO 9241-210 incorpora requisitos e recomendações ao ISO 13407 (1999) original e também inclui as seguintes mudanças: esclarecer todo o processo iterativo, não apenas a avaliação; enfatizar que os métodos de design centrado no usuário podem ser usados ao longo do ciclo de vida do sistema; explicar as atividades de Design; e também esclarecer princípios de design centrados no usuário. A ISO 9241-210 enaltece a participação dos usuários e explica que estes devem estar envolvidos ao longo do processo de desenvolvimento do projeto enumerando uma série de princípios que devem ser considerados no desenvolvimento do sistema interativo, quando o objetivo é projetar um sistema interativo centrado no usuário e suas necessidades, e que também seja útil e fácil de usar, tal que:

- O projeto deve basear-se na compreensão explícita dos usuários, suas tarefas e ambientes. O projeto deve levar em consideração os aspectos envolvidos no projeto, direta ou indiretamente. O contexto de uso é crucial para o estabelecimento de requisitos do sistema. Uma interface a ser usada no trânsito, por exemplo, deve ser muito diferente de uma para ser usada para agendar uma atividade social, mesmo que o usuário seja a mesma pessoa

- Os usuários devem estar envolvidos em todo o processo de desenvolvimento; O engajamento do usuário é uma valiosa fonte de conhecimento sobre o contexto de uso e deve ser usado para explorar soluções. A natureza e a frequência do engajamento 
dependerão do tipo de projeto em questão

- O projeto deve ser conduzido e refinado através de avaliações com foco no usuário, o que minimiza o risco de o sistema não alcançar requisitos que atendam às necessidades e desejos dos usuários - ou dos outros envolvidos no projeto. Esta avaliação progressiva identifica pontos importantes para a aceitação efetiva do produto;

- O processo de design deve ser iterativo. A iteração é a revisão e aperfeiçoamento das especificações de projeto, a partir da aquisição de novas informações, buscando minimizar os riscos de desenvolver um sistema que não atinja os requisitos e as expectativas dos usuários.

- O design deve abordar toda a experiência do usuário; "A experiência do usuário é resultado da apresentação, funcionalidade, desempenho do sistema, comportamento de interação e capacidades de atendimento de um sistema interativo, tanto em termos de hardware e software. A experiência do usuário também é conseqüente da experiência anterior do usuário, bem como suas atitudes, habilidades, personalidade e personalidade (...), as capacidades, limitações, preferências e expectativas devem ser levadas em consideração na especificação de que os recursos são a competência do usuário e qual o sistema de competência ".

- A equipe do projeto deve incluir habilidades e perspectivas multidisciplinares. Os membros da equipe devem vir de diferentes áreas o suficiente para que as habilidades, experiências e pontos de vista possam ser compartilhados e beneficiar projetos com essa diversidade.

Os principais benefícios da adoção da abordagem do UCD de acordo com a norma ISO 9241-210 são:

- Aumento da produtividade do usuário e eficiência operacional das empresas

- Apoiar redução de custos e formação resultante produtos mais fáceis e compreensíveis;

- O aumento da gama de usuários se beneficia dos produtos, inclusive em termos de acessibilidade, resultando em uma melhor usabilidade e melhor experiência do usuário

- Redução de desconforto e estresse 
- Vantagem competitiva e melhor imagem da marca

- Contribuição para metas sustentáveis

\subsection{Desenvolvimento ágil de software centrado no usuário}

De acordo com Salah, Paige e Cairns (2014a), nos últimos anos existe um crescente interesse por parte da indústria e da academia em como UCD e desenvolvimento ágil de software estão sendo integrados. Isso ocorre devido a três razões:

1. As vantagens relatadas da UCD no software desenvolvido, pois permite aos desenvolvedores entender as necessidades dos potenciais usuários de seus softwares e como seus objetivos e atividades podem ser melhor suportados pelo software, levando a uma melhor usabilidade e satisfação dos usuários.

2. A comunidade ágil dificilmente discute usuários ou interfaces de usuários, o que implica uma negligência da UX ou o foco em projetos UX menos sofisticados. Como nenhum dos principais métodos ágeis fornece explicitamente orientação sobre como desenvolver software utilizável a usabilidade e o design da interface do usuário em uma equipe ágil não são claros e em grande parte subestimados. Ademais, princípios e práticas para a compreensão e obtenção de usabilidade e requisitos de usuários e avaliação de sistemas ágeis em termos de usabilidade e UX geralmente são consideravelmente deficiente. Isto é particularmente desafiador para os sistemas com alta dependência da interface do usuário, pois pode levar a uma usabilidade fraca que resulta em vendas perdidas, produtividade reduzida, baixa satisfação do usuário e pode comprometer a vida de seres humanos se envolve sistemas críticos de segurança.

3. A diferença que existe entre as filosofias de cada abordagem indicam que a integração de ambas é desafiadora. Um exemplo destes desafios (e foco deste trabalho) é como integrar as duas visões opostas quanto às atividades do UFD, tal que o ágil prevê minimizar o esforço investido de UFD acreditando que assim terá menos custos em caso de mudanças nos requisitos do projeto, enquanto o UCD prevê maximizar o esforço investido nas atividades do UFD acreditando que terá requisitos mais assertivos e menos voláteis, diminuindo a necessidade de mudança dos mesmos ao longo do projeto, tal que por caminhos diferentes ambos visam diminuir retrabalho.

Blomkvist (2005) define três formas para se realizar a integração destas abordagens (RANNIKKO, 2011): 
1. As práticas de UCD são adicionadas ao desenvolvimento ágil. Isso permite que organizações, que já estão fazendo desenvolvimento ágil, para entregar sistemas mais utilizáveis sem abandonar seus métodos estabelecidos. A desvantagem é que o papel do UCD pode não ser abrangente o suficiente para oferecer valor ao seu pleno potencial, se apenas algumas práticas separadas forem utilizadas.

2. As práticas ágeis são adicionadas ao framework UCD. Esta abordagem visa tornar o processo UCD mais ágil, não necessariamente para criar um quadro abrangente de desenvolvimento de software.

3. Integração equilibrada entre desenvolvimento ágil e UCD. O desenvolvimento ágil e o UCD são combinados de forma equilibrada. Isso acontece criando uma nova metodologia de desenvolvimento híbrido de software desde o início ou apenas soldando as duas abordagens em conjunto. Os valores, princípios e práticas dos dois estão integrados.

Como o foco desta pesquisa está em projetos que tenham um software como resultado final, este trabalho considera apenas os formatos de integração 1 e 3 como um projeto ágil de software com design centrado no usuário, desconsiderando assim projetos de UCD que apenas busquem aumentar sua agilidade.

\subsubsection{Semelhanças entre métodos ágeis e UCD}

Como apontado anteriormente, um dos motivos de UCD estar sendo utilizado junto do desenvolvimento ágil advém de ambos compartilharem alguns valores e práticas fundamentais, vistos na Figura 4 (LEE; MCCRICKARD, 2007). A mesma figura, também aponta que em contrapartida existem também diferenças entre essas abordagens (RANNIKKO, 2011).

\subsubsection{Foco nas pessoas}

Tanto o ágil como UCD são abordagens com desenvolvimento centrados no ser humano. A filosofia UCD coloca o usuário no centro do processo de desenvolvimento enquanto o XP envolve um representante do cliente no local para criar softwares que atrai usuários (LEE; MCCRICKARD, 2007). 


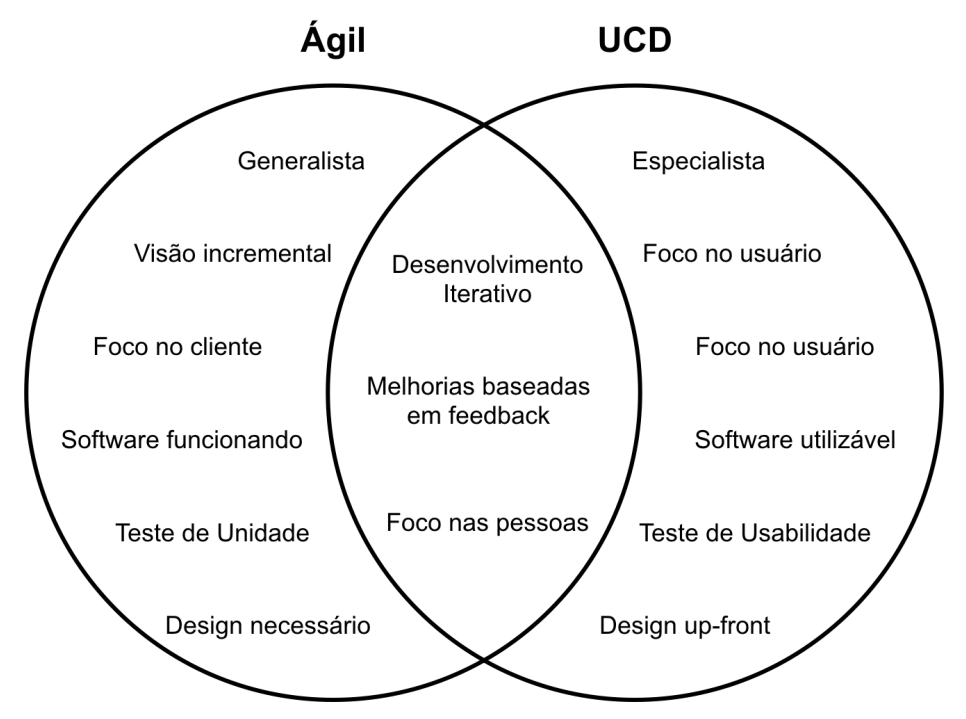

Figura 4: Semelhanças e diferenças entre ágil e UCD. Fonte: Adaptado de Salah, Paige e Cairns (2014a)

\subsubsection{Desenvolvimento iterativo}

Um dos princípios fundadores do UCD é o design iterativo que realiza a melhoria da entrega do sistema através de ciclos de interação ao longo do projeto (LEE; MCCRICKARD, 2007). Métodos ágeis também constroem software iterativamente. Isso reduz o risco do projeto através de feedback constante, contribuindo para a visibilidade do projeto e melhoria contínua do mesmo de acordo com as expectativas do cliente.

\subsubsection{Melhorias baseadas em feedback}

O teste é fundamental para o ágil e o UCD. Tanto métodos ágeis quanto UCD evidenciam a importância de realizar testes constantes do sistema ou da interface visual com usuários e implementar melhorias baseados em seus feedback (SALAH; PAIGE; CAIRNS, 2014a).

\subsubsection{Diferenças entre ágil e UCD}

\subsubsection{Foco no cliente versus foco no usuário}

Uma das maiores diferenças de ágil e UCD é a noção de usuário como stakeholder e como os requisitos de software são desenvolvidos. No UCD usuários são pessoas que realmente utilizam o software, que participam dos requisitos através de entrevistas, estudos de campo (pesquisa de usuários), na avaliação do projeto e implementação através de testes 
de usabilidade. O desenvolvimento ágil também valoriza a colaboração com os usuários e considera a participação dos stakeholders no processo de desenvolvimento como a maneira mais eficaz de se comunicar com os desenvolvedores (RANNIKKO, 2011). Um stakeholder pode ser um usuário final para o software que está sendo desenvolvido, mas muitas vezes ela é um especialista em domínio ou um proprietário do produto que representa a organização do cliente e que não necessariamente usa o software. O desenvolvimento ágil concentra-se em satisfazer as necessidades do cliente e se manter flexível aos requisitos de negócios, mas leva a problemas se não houver ninguém na equipe que realmente possa representar o usuário final (NODDER; NIELSEN, 2010).

\subsubsection{Equipe especialista versus generalista}

Considerando que o ágil presa por equipes multifuncionais que sejam capaz de realizar todo o desenvolvimento sem terceirizar tarefas, esta abordagem dá preferência para perfis generalistas, enquanto isso UCD prevê a alocação de recurso especializado na construção de interfaces visuais (RANNIKKO, 2011).

\subsubsection{Software funcionando versus software utilizável}

De acordo com Sohaib e Khan (2010) as abordagens ágeis centram-se principalmente na produção de software funcionando como uma medida primária de progresso, enquanto as abordagens de usabilidade se concentram na produção de um design utilizável. No entanto, o design utilizável não é necessariamente software funcionando nem software funcionando tem design utilizável.

\subsubsection{Visão hoslística versus visão incremental}

De acordo com Ferreira, Noble e Biddle (2007a) as abordagens ágeis, por um lado, são de natureza incremental e iterativa, uma vez que o software é desenvolvido e lançado em pequenos pedaços. As abordagens ágeis geralmente foco em um desenvolvimento de visão abrangente e explícita da arquitetura do software. Isso é baseado na visão de que os requisitos mudarão à medida que os usuários adquiram a compreensão do que o software pode fazer por eles. Assim, o esforço gasto na engenharia de requisitos formalizados pode ser melhor gasto no desenvolvimento de código que pode ser avaliado pelos clientes. O UCD por sua vez se esforço em considerar o sistema como um todo para garantir coesão e otimizar a experiência do usuário como um todo (ADIKARI; MCDONALD; CAMPBELL, 2009) 


\subsubsection{Teste de unidade versus teste de usabilidade}

O UCD utiliza desenhos de baixa fidelidade para fins de avaliação, que é concluído muito antes das abordagens ágeis que avaliam o código pronto no final de cada iteração (SINGH, 2008).

\subsubsection{Design necessário vs up-front design}

. Os processos de UCD dependem de um UFD para pesquisar sobre o usuário final. Os métodos ágeis, por outro lado, visam iniciar o design sempre que solicitado pelo cliente. Justamente para evitar retrabalho, praticantes evitam uma fase inicial de design muito extensa.

\subsubsection{Benefícios da integração entre ágil e UCD}

O UCD permite que os desenvolvedores compreendam melhor as necessidades dos potenciais usuários do seu software e como seus objetivos e atividades podem ser melhor suportados pelo software. Em decorrência disso, a incorporação do UCD ao desenvolvimento ágil leva a diversos benefícios apontados na literatura, tais como:

- Produtos concebidos apresentam melhor usabilidade e qualidade, resultando em maior satisfação do usuário final e aceitação do produto no mercado (SY, 2007; ARDITO et al., 2014; SCHÖN et al., 2016; LINDSTRÖM; MALMSTEN, 2011; HUSSAIN; SLANY; HOLZINGER, 2012; ADIKARI; MCDONALD; CAMPBELL, 2009; DAYTON; BARNUM, 2009);

- Aumento nas vendas, no sentido de que o próprio produto ajuda a vender (PARSONS et al., 2007; ARDITO et al., 2014);

- Redução de custos de treinamento e/ou suporte ao consumidor (PARSONS et al., 2007; ARDITO et al., 2014);

- Economia de tempo e dinheiro ao ter maior assertividade na definição dos requisitos do projeto e garantir melhores estimativas e priorizações ao longo do mesmo (PATTON, 2002; LINDSTRÖM; MALMSTEN, 2011; FERREIRA; NOBLE; BIDDLE, 2007b);

- Permitir que os stakeholders encontrem uma solução financeiramente viável (FERREIRA; NOBLE; BIDDLE, 2007b) e desenvolvam expectativas realistas e reduzam 
a resistência à mudança ao longo do projeto (KAUTZ, 2011);

- Equipe de desenvolvimento tem maior motivação por ver resultados do software antes do lançamento do produto e ter uma maior visão de para onde o projeto é direcionado (KAUTZ, 2011; SCHÖN et al., 2016; SINGH, 2008).

\subsection{Processo de up-front design (UFD)}

O debate sobre XP vs. Interaction Design entre Kent Beck, pai da programação eXtreme, e Alan Cooper, um dos principais proponentes do design de interação, agregou interesse nesta área (FOX, 2010). Cooper argumenta que o design da interação deve ser concluído antes que qualquer código seja escrito. Beck, por outro lado, argumenta que completar todo o design de interação antecipadamente cria um gargalo para os desenvolvedores e que o desenvolvimento deve começar antes do design estar completo, para permanecer receptivo à mudança de requisitos (VREDENBURG et al., 2002).

Além disso, as abordagens ágeis se concentram em produzir com frequência somente em termos de funcionalidade (SINGH, 2008). Isso resulta na falta de tempo para planejar as atividades de design, realizar pesquisa de usuário e esboçar um design coerente (FEDEROFF; COURAGE, 2009; CHAMBERLAIN; SHARP; MAIDEN, 2006). Aliás, o desenvolvimento ágil incremental é traduzido em partes do todo ou "funcionalidade por funcionalidade“, o que pode resultar em uma interface do usuário fragmentada, sem coerência acarretando em uma má experiência do usuário (ALBISETTI, 2010).

Davis e Venkatesh (2004) apontam que em uma amostra de 6700 projetos em mais de 500 empresas, $24 \%$ dos projetos de software foram cancelados e $17 \%$ tiveram problemas de custo. Segundo os autores, fatores que são preponderantes para isso ocorrer é a falta de estabilidade nos requisitos do projeto e falta de utilidade do produto construído (por não atenderem as necessidades e objetivos do usuário).

Para estabelecer um design coerente requer entender os usuários, o contexto e seus objetivos (KOLLMANN, 2008). O UFD é um período de pré-desenvolvimento separado que é usado em projetos de desenvolvimento ágil para obter requisitos, entender usuários, objetivos de usuários e contexto de uso, usar itens de backlog para criar histórias de usuários e conduzir o design de UX antes de iniciar qualquer desenvolvimento para obter uma visão abrangente do sistema (CHAMBERLAIN; SHARP; MAIDEN, 2006; FOX; SILLITO; MAURER, 2008; KOLLMANN, 2008; BUDWIG; JEONG; KELKAR, 2009;

HUSSAIN; SLANY; HOLZINGER, 2012). O UFD também é referido como: "Fase de 
exploração" ou "Fase Zero" ou "Ciclo Zero" ou "Sprint Zero" ou "Iteração 0" ou "Release 0" ou "Descoberta do Produto".

De acordo com Obendorf, Schmolitzky e Finck (2006), definir uma visão global do projeto com métodos de usabilidade no início é uma solução para o desenvolvimento de um projeto bem sucedido com uma metodologia ágil. Na mesma linha, Felker, Slamova e Davis (2012) indicam a aplicação de entrevista contextual no início de sua abordagem para obter uma visão holística antes do desenvolvimento. Eles afirmam que essa prática ajudou a definir prioridades iniciais. Concluíram que a realização de uma entrevista contextual completa de antemão revelou-se incrivelmente útil e os ciclos ágeis poderiam se concentrar apenas no design e na implementação (CABALLERO; MORENO; SEFFAH, 2016).

Budwig, Jeong e Kelkar (2009), entretanto, relataram que a falta de tempo para o UFD leva a uma maior pressão no trabalho e a um esforço desperdiçado para a equipe da UX, a fim de acompanhar o ritmo da equipe de desenvolvimento, enquanto que a utilização do sprint 0 resultou em diminuição do desgaste e aprimorou o equilíbrio de trabalho para os membros da equipe da UX. Ferreira, Noble e Biddle (2007a) relataram o efeito positivo do UFD na mitigação de erros no julgamentos de design, má priorização de tarefas, problemas de redesign, problemas de usabilidade e estimativas de trabalho imprecisas. Outros autores como Meszaros e Aston (2006), Lievesley e Yee (2006) também relatam que o UFD traz uma visão holística do sistema, prevenindo retrabalhos no desenvolvimento ágil.

Em relação à duração do UFD, existem relatos na literatura que variam de poucos dias a alguns meses (FOX; SILLITO; MAURER, 2008; ALBISETTI, 2010; WILLIAMS; FERGUSON, 2007).

Ainda assim, o UFD para projetos ágeis se diferenciam de projetos tradicionais com estrutura definida, já que esta etapa também precisa priorizar a criação de software de forma flexível, autônoma, e dinamicamente adaptável para seu contexto (PAAY et al., 2009). Paay et al. (2009) alegam que existe uma tendência de designers de interação mudarem de métodos estruturados para uma abordagem de design mais inspiracional neste formato de projeto, promovendo uma forma flexível de assimilar a informação dos usuários no processo de design.

De acordo com Brhel et al. (2015), no entanto, embora a literatura constata claramente a importância do UFD em geral, existe atualmente uma lacuna de conhecimento em relação à extensão das atividades de UFD e à aplicação real de práticas de usabilidade (KUUSINEN, 2014; LIZANO; SANDOVAL; STAGE, 2014). Assim, segundo Brhel 
et al. (2015) é necessária uma pesquisa empírica adicional para investigar a extensão das atividades de UFD em relação aos diferentes fatores contingenciais de um projeto, como equipe, produto e organização, sugerindo inclusive o entendimento de como diferentes características do produto de software, como a maturidade, complexidade e grau de interação com stakeholders, influenciam a extensão e o resultado das atividades de UFD.

\subsection{Fatores contingenciais em projetos de software}

A teoria contingencial de projetos apresenta um corpo de literatura que argumenta que como os projetos não são iguais, não devem ser estruturados e gerenciados da mesma forma (HOWELL; WINDAHL; SEIDEL, 2010). O estudo de gerenciamento baseado em contingência de projetos surgiu gradualmente nas últimas duas décadas com enquadramentos específicos para o gerenciamento de projetos que foram influenciados por pesquisas de disciplinas e áreas de estudo como inovação, teoria organizacional, gerenciamento, informática, gerenciamento de produtos e engenharia (SAUSER; REILLY; SHENHAR, 2009). Howell, Windahl e Seidel (2010) discutem de forma eloquente o modo como a teoria contingencial de projetos se desenvolveu a partir da teoria clássica de contingência organizacional baseando-se em pesquisas de inovação e as perspectivas organizacionais do projeto (SHENHAR; DVIR, 2007; DONK; MOLLOY, 2008).

A teoria clássica da contingência organizacional propõe que a eficácia de uma organização esteja relacionada ao seu "ajuste" com o seu meio ambiente (BURNS; STALKER, 1961; LAWRENCE; LORSCH, 1967). A teoria contingencial de projetos também argumenta que a melhor abordagem para gerenciar um projeto depende de seu contexto e que a eficácia do mesmo está relacionada à forma como as abordagens e as condições da organização e do projeto se encaixam mutuamente (HOWELL; WINDAHL; SEIDEL, 2010). De acordo com Sauser, Reilly e Shenhar (2009), uma abordagem de contingência para a gestão de projetos necessariamente investiga a extensão do ajuste ou desajuste entre as características do projeto e a abordagem de gerenciamento de projetos. Isso é consistente com a pesquisa que examina os tipos de organização duradoura baseando-se na teoria contingencial de projetos que sugere que a eficácia organizacional depende da capacidade da organização de se adaptar ao meio ambiente e que há necessidade de congruência entre o meio ambiente e a estrutura (JUNIOR; CARVALHO, 2009).

No âmbito do Design, Ferreira, Sharp e Robinson (2011) argumentam que a dificuldade de se concentrar em processos ou métodos é que os processos raramente são seguidos mecanicamente na prática. Fitzgerald (1997) entrevistou participantes de oito organizações 
diferentes e descobriu que nenhum deles seguiu métodos rigorosamente. Ainda nisso, Ferreira, Sharp e Robinson (2011) apontam que este fenômeno semelhante está presente entre os designers. Gasson (1999) mostra como um processo de projeto centrado no usuário foi desviado na prática, devido às contingências que surgiram. Fitzgerald (1997) descreve a abordagem pragmática dos praticantes para seguir os métodos prescritos - eles estavam baseando suas ações no que era apropriado e suficiente para suas necessidades particulares, condizentes com a relação entre os indivíduos e seu ambiente. Ferreira, Sharp e Robinson (2011) acrescentam que para se obter um melhor entendimento de desenvolvimento ágil e UCD é importante considerar o trabalho realizado por ambos na prática, como ações contingenciadas, tal que a descrições de processos por si só não são adequadas para a compreensão da prática, sendo necessário levar em consideração o cenário mais amplo em que os praticantes estão incorporados. Em vez de considerar as equipes de desenvolvimento ágil e UCD como unidades autônomas separadas de sua configuração organizacional mais ampla, é preciso levar em consideração as configurações realistas em que realizam seu trabalho, como por exemplo levar em conta que podem depender de outras partes para terem feito o seu trabalho e que o seu conjunto organizacional mais amplo tem consequências para a forma como realizam o seu trabalho.

Considerando esta abordagem contingencial, Lemétayer (2010) levantou (ver Tabela 2) os principais fatores contingenciais em projetos de desenvolvimento de software, separados em contingências do projeto e da organização.

A teoria contingencial de projetos em projetos de software, entretanto, ainda está voltada em sua maior parte para a escolha da melhor metodologia de gestão de software (LEMÉTAYER, 2010; AHIMBISIBWE; CAVANA; DAELLENBACH, 2015), sobretudo na questão entre gestão ágil e tradicional. Isto posto, este trabalho visa explorar em maiores detalhes, revisar e complementar os fatores contingenciais anteriormente listados que sejam mais relevantes para o UFD no desenvolvimento ágil de software centrado no usuário, considerando a literatura no tema.

Tendo em vista o objetivo da pesquisa foram apresentados nesse capítulo conceitos fundamentais e elementares para a compreensão das metodologias ágeis, seus princípios e valores. Similarmente foram apresentados a abordagem de UCD para o contexto de desenvolvimento de software e os conceitos mais importantes relacionados a este, como usabilidade, IxD e UX. Em seguida foram apresentadas as iniciativas de integração destas abordagens para criação de projetos que também criem produtos que usuários querem e precisam e portanto aumentando substancialmente a aceitação do mesmo. Após isso foram detalhados os principais desafios deste tipo de projetos sobretudo a questão do UFD e 
como este é influenciado pelos fatores contingenciais do projetos. Essa apresentação dos principais conceitos da pesquisa tem como propósito servir de alicerce para a RSL, que irá discutir e analisar em maiores detalhes os fatores contingenciais de projetos de software que utilizem ambas as abordagens ágil e UCD e os principais componentes a serem planejados para o UFD. Assim, os conceitos e termos apresentados nesta seção são essenciais para a compreensão e contextualização do restante deste trabalho. 
Tabela 2: Fatores contingenciais encontrados na literatura

\begin{tabular}{|c|c|}
\hline Fator Contingencial & Literatura \\
\hline \multicolumn{2}{|l|}{ Fatores da Organização } \\
\hline \multicolumn{2}{|l|}{$\begin{array}{l}\text { Fatores de compliance e go- } \\
\text { vernança }\end{array}$} \\
\hline Incerteza do mercado & $\begin{array}{l}\text { Highsmith (2010); Pixton et al. (2009); Wysocki } \\
\text { (2009) }\end{array}$ \\
\hline Cultura Corporativa & Misra et al. (2009) \\
\hline Natureza do Contrato & Koch $(2005)$ \\
\hline Tamanho da organização & $\begin{array}{l}\text { Charvat (2003); Cockburn (2007); Highsmith } \\
\text { (2010) }\end{array}$ \\
\hline $\begin{array}{l}\text { Apoio da gestão para uma } \\
\text { abordagem }\end{array}$ & Ratbe et al. (2000) \\
\hline Aprendizagem colaborativa & $\begin{array}{l}\text { Charvat (2003) Livermore (2008); Misra et al. } \\
\text { (2009) }\end{array}$ \\
\hline \multicolumn{2}{|l|}{ Fatores do projeto } \\
\hline $\begin{array}{l}\text { Presença local dos membros } \\
\text { da equipe/cliente }\end{array}$ & $\begin{array}{l}\text { Cockburn (2000); Highsmith (2010); Koch (2005); } \\
\text { Pixton et al. (2009); Wysocki (2009) }\end{array}$ \\
\hline $\begin{array}{ll}\text { Cultura } & \text { do } \\
\text { Time/Empoderamento } & \\
\text { da Equipe } & \\
\end{array}$ & $\begin{array}{l}\text { Boehm and Turner (2003); Highsmith (2010); } \\
\text { Koch (2005); Misra et al. (2009); Strode, Huff, } \\
\text { and Tretiakov (2009) }\end{array}$ \\
\hline $\begin{array}{l}\text { Envolvimento e Compro- } \\
\text { mentimento do Cliente }\end{array}$ & $\begin{array}{l}\text { Ceschi, Sillitti, Succi, and De Panfilis (2005); } \\
\text { Chow and Cao (2008); Koch (2005); Misra et al. } \\
\text { (2009); Wysocki (2009) }\end{array}$ \\
\hline $\begin{array}{l}\text { Competência e Maturidade } \\
\text { da equipe }\end{array}$ & $\begin{array}{l}\text { Boehm and Turner (2003); Chow and Cao (2008); } \\
\text { Koch (2005); Misra et al. (2009); Pixton et al. } \\
\text { (2009); Ratbe et al. (2000); Wysocki (2009) }\end{array}$ \\
\hline Custo do Projeto & $\begin{array}{l}\text { Charvat (2003); Ratbe et al. (2000); Wysocki } \\
\text { (2009) }\end{array}$ \\
\hline Criticidade do Projeto & $\begin{array}{l}\text { Boehm and Turner (2003); Charvat (2003); Cock- } \\
\text { burn (2000, 2007); Highsmith (2010); Koch (2005); } \\
\text { Pixton et al. (2009) }\end{array}$ \\
\hline Duração do projeto & $\begin{array}{l}\text { Highsmith (2010); Pixton et al. (2009); Ratbe et } \\
\text { al. (2000); Wysocki (2009) }\end{array}$ \\
\hline $\begin{array}{l}\text { Tamanho do projeto (horas } \\
\text { de homem) }\end{array}$ & Burns and Dennis (1985) \\
\hline $\begin{array}{lr}\text { Incerteza do } & \text { pro- } \\
\text { jeto/estabilidade } & \text { dos } \\
\text { requisitos } & \end{array}$ & $\begin{array}{l}\text { Boehm and Turner (2003); Burns and Dennis } \\
\text { (1985); Highsmith (2010); Koch (2005); Pixton et } \\
\text { al. (2009); Ratbe et al. (2000); Shenhar (2001); } \\
\text { Wysocki (2009) }\end{array}$ \\
\hline $\begin{array}{l}\text { Proporção da Organização } \\
\text { afetada }\end{array}$ & Ratbe et al. (2000); Wysocki (2009) \\
\hline Tamanho da equipe & $\begin{array}{l}\text { Boehm and Turner (2003); Charvat (2003); Cock- } \\
\text { burn (2000, 2007); Highsmith (2010); Koch (2005); } \\
\text { Pixton et al. (2009) }\end{array}$ \\
\hline Incerteza tecnológica & $\begin{array}{l}\text { Charvat (2003); Ratbe et al. (2000); Tortam } \\
\text { (2004); Wysocki (2009) }\end{array}$ \\
\hline Urgência & Highsmith (2000) ; Ratbe et al. (2000) \\
\hline
\end{tabular}

Fonte: (LEMÉTAYER, 2010) 


\section{MÉTODO}

Este trabalho tem como principal objetivo responder a questão macro de pesquisa:

Como planejar e executar o up-front design no desenvolvimento ágil de software centrado no usuário, considerando seus fatores contingenciais?

De acordo com Morabito et al. (2018) é fundamental escolher métodos e técnicas aderentes que permitam responder organizada e satisfatoriamente às sub-questões de pesquisa para alcançar resultados academicamente relevantes.

- QP1: O que exatamente é o processo do UFD e como se encaixa dentro do ciclo de vida do UCASD?

- QP2: Como as atividades de LDUF contrastam com as de BDUF e por que o LDUF é mais apropriado para o UCASD?

- QP3: Quais são as alternativas de tempo e configuração da equipe para planejar e executar o UFD?

- QP4: Quais são os fatores contingenciais mais relevantes para o UCASD?

- QP5: Como os fatores contingenciais influenciam o planejamento e a execução do UFD?

Considerando que as quatro primeiras questões de pesquisa decorrem da falta de alinhamento entre autores e formalizações consolidadas nesta linha de pesquisa de UCASD, optou-se inicialmente pela condução de uma revisão sistemática de literatura (RSL), capaz de compilar as principais características supracitadas no tema. A condução de uma RSL se faz relevante neste estudo, pois dispõe de técnicas que mapeiam a literatura de maneira não tendenciosa, identificando os principais autores, a evolução do conhecimento sobre o tema e permitem codificar e padronizar o conhecimento acumulado (NEELY, 2005; GUEDES; BORSCHIVER, 2005). A RSL também auxilia na criação do modelo de pesquisa. 
Num segundo momento, é realizado um estudo de caso para validar/complementar os achados na literatura e responder a quinta questão de pesquisa e consequentemente a questão principal, relacionadas aos fatores contingenciais. Esta abordagem se mostra relavante não apenas por se tratar de um tema emergente (CROOM, 2010) e pouco explorado na literatura de UCASD (BRHEL et al., 2015; FERREIRA; SHARP; ROBINSON, 2012), mas também por ser uma estratégia de pesquisa que foca no entendimento de dinâmicas presentes em configurações únicas, e pode ser usado para o desenvolvimento de teoria ao combinar observações da RSL, senso comum e novas experiências (EISENHARDT, 1989), tão adequado para a análise contingencial. O objetivo principal do estudo de caso, portanto, consiste em confirmar e/ou contrastar as consolidações e propostas feitas na revisão sistemática da literatura com estudos de campo, de forma a alinhar teoria e prática.

A seguir, é descrito a construção do protocolo de pesquisa de cada uma das abordagens. Na Figura 5, é ilustrado o planejamento geral da pesquisa:

\subsection{Revisão sistemática da literatura}

A RSL permite identificar e sintetizar os resultados de diferentes pesquisas (IRSHAD; PETERSEN; POULDING, 2018) e estruturar o estado da arte de um tema particular, evidenciando autores e correntes de opinião nos temas em desenvolvimento (PALMARINI et al., 2018). Além disso a RSL oferece técnicas que possibilitam desenvolver processos, estruturas, estabelecer causa-efeito e auxiliar na descoberta de lacunas de literatura e evidenciar oportunidades de estudos futuros (MAIER; MEYER; STEINBEREITHNER, 2016; DIKICI; TURETKEN; DEMIRORS, 2017). O objetivo desta RSL foi de identificar o estado-da-arte do UFD em UCASD.

Para garantir rigor e transparência no processo de seleção dos estudos mais adequados, foi utilizado como referência o protocolo de pesquisa de Brhel et al. (2015) (RSL com maior fator de impacto no tema) e Carvalho, Fleury e Lopes (2013). Assim, para esse processo, foram realizadas as análises bibliométrica, de redes e de conteúdo sobre a amostra dos estudos selecionados.

A análise bibliométrica teve como objetivo identificar as áreas de concentração e evolução das publicações do tema ao longo do tempo (GUEDES; BORSCHIVER, 2005; NEELY, 2005). A análise de redes permitiu compreender melhor as relações entre as publicações selecionadas (TAKEY; CARVALHO, 2016). Finalmente a análise de conteúdo auxilia na coleta e inspeção de informações para responder as questões de pesquisa (WA- 


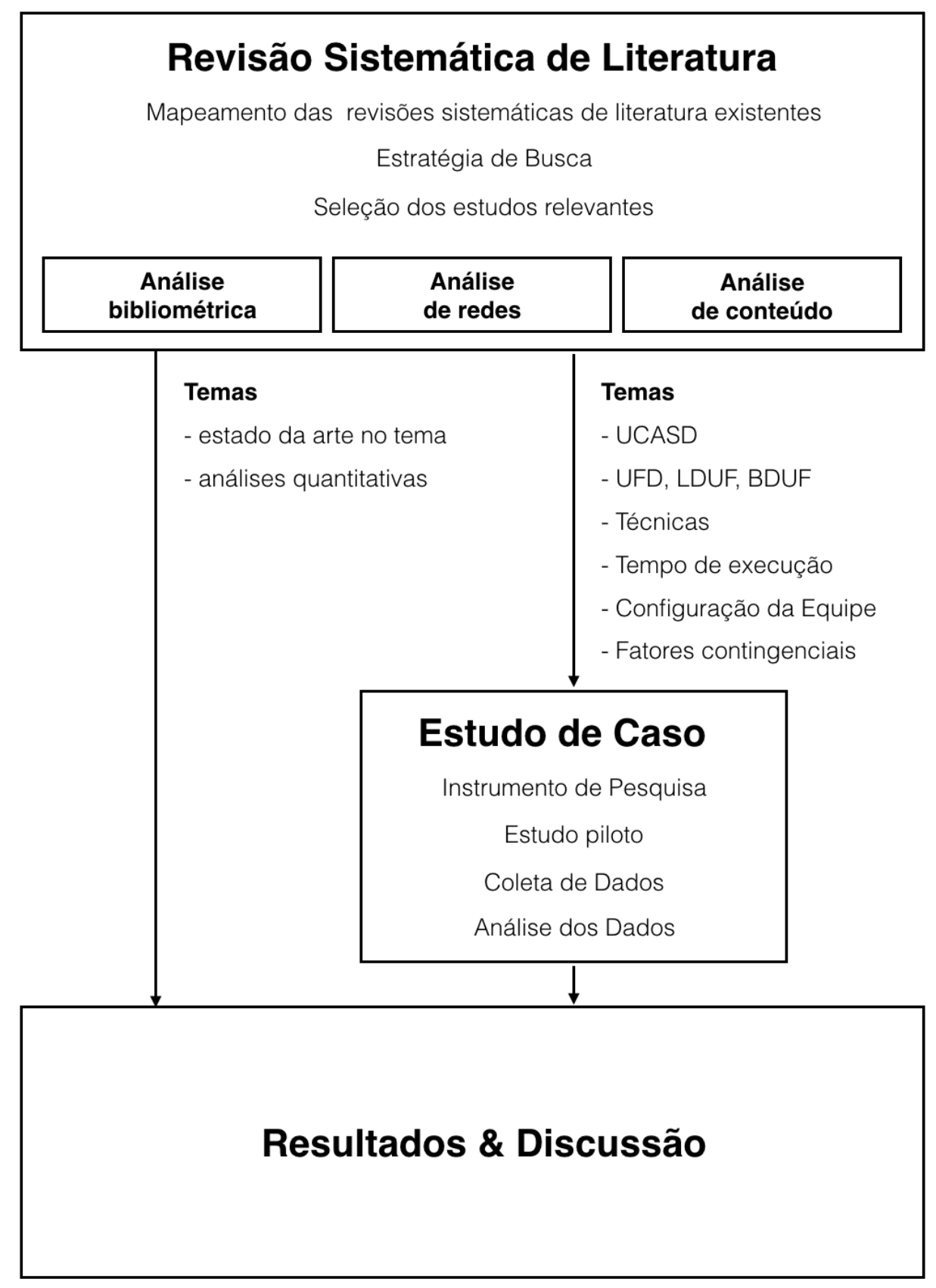

Figura 5: Planejamento geral da pesquisa. Fonte: O autor.

SIKE, 2017) comparando e contrastando os achados na literatura (HAZEN; OVERSTREET; BOONE, 2015).

O detalhamento do método utilizado para realização da RSL é descrito a seguir e os resultados obtidos com sua realização serão apresentados no Capítulo 4. 


\subsubsection{Protocolo de revisão sistemática da literatura}

Para garantir rigor e transparência no processo de investigação dos estudos adequados e responder as questões de pesquisa introduzidas anteriormente, seguimos o protocolo baseado em Brhel et al. (2015): (1) estratégia de busca com termos e fontes de artigos apropriadas; (2) critérios de seleção dos estudos relevantes; (3) análise qualitativa para responder às questões de pesquisa; e (4) métodos de extração e síntese de dados para consolidar o conhecimento existente (análises bibliométrica, de redes e de conteúdo).

O protocolo de revisão foi conduzido por dois autores e validado por um especialista em RSL.

\subsubsection{Estratégia de busca}

Para mapear a maior quantidade de artigos relevantes para o tema, a pesquisa abrangeu diferentes fontes de estudos, sendo três dos principais indexadores de estudos científicos da atualidade: ISI - Web of Science (WoS), o Elsevier Scopus e ScienceDirect, e as duas principais conferências sobre métodos ágeis - XP (desde 2002) e Agile (desde 2003) (SILVA et al., 2015). O indexador da Web of Science foi selecionado porque agrega resultados de outros indexadores, como ProQuest, Wiley e Scopus, e indexa periódicos com fator de impacto relevante (JCR - Journal Citation Report). As bases de dados Scopus e ScienceDirect foram selecionadas, pois permitem o acesso ao maior banco de artigos acadêmicos revisados por pares. As conferências nos permitem acessar artigos que são relevantes para o assunto, mas não fazem parte de periódicos indexados.

Como existem muitas definições diferentes para o UFD e UCASD na literatura, com o objetivo de incluir a amostra mais completa de estudos, a expressão buscada nos três indexadores é uma análise combinatória de todos os termos de interesse em UFD, UCD e ASD (vide Tabela 3), unindo as estratégias de busca vistas em Brhel et al. (2015) e Werder, Zobel e Maedche (2016), conforme descrito na Tabela 4.

\subsubsection{Critérios de seleção e análise qualitativa}

O processo de filtragem para atingir o conjunto final de artigos foi composto por quatro etapas, como visto na Fig. 6. Na etapa inicial, todas as consultas aos indexadores foram executadas em julho de 2018, considerando apenas artigos de periódicos e conferências publicados após a data de 2001 (publicação do manifesto ágil). Além disso, apenas artigos em inglês, português, espanhol e francês foram considerados. O indexador Web of Science 
Tabela 3: Combinações de termos para pesquisa em bases de dados

\begin{tabular}{|l|l|l|}
\hline Termos ASD - (t.ASD) & Termos UCD - (t.UCD) & Termos UFD - (t.UFD) \\
\hline Agile Method* & Usability & Cycle Zero \\
Agile Develop* & User Experience & Phase Zero \\
Agile Project Management & UX & Sprint Zero \\
Scrum & Interaction Design & Iteration 0 \\
Extreme Programming & User Centered Design & Release 0 \\
XP & Human Centered Design & Explore Phase \\
& & Product Discovery \\
& & Up front design \\
& & Little design up front \\
& Big design up front \\
& & Product Explore \\
& & Product Scope \\
& & Product Ideation \\
\hline
\end{tabular}

Fonte: O autor

Tabela 4: Expressão buscada

\begin{tabular}{|l|}
\hline Expressão Buscada \\
\hline (t.ASD OR t.UCD) AND (t.UFD) ->(WERDER; ZOBEL; MAEDCHE, 2016) \\
OR \\
(t.ASD AND t.UCD) ->(BRHEL et al., 2015) \\
\hline
\end{tabular}

Fonte: O autor

resultou em 207 artigos, o Scopus resultou em 455 artigos e o ScienceDirect forneceu 24 publicações. Todas as publicações da conferência XP após 2002 e as publicações da conferência Agile após 2003 (disponíveis on-line) foram revisadas, levando à inclusão em uma amostra de 30 artigos do XP e 32 artigos da Agile.

Uma segunda etapa foi realizada para remover todas as duplicatas da amostra inicial de 795 publicações, resultando em 507 estudos.

Na terceira etapa, as publicações foram excluídas com base em seus títulos, palavraschave e resumos. O critério de inclusão foi:

- O artigo focava na integração de UCD e ASD, pois a maioria não especifica declaradamente o processo de UFD.

Os critérios de exclusão foram:

- Não disponível online;

- A publicação foi um workshop, painel ou tese e superou o filtro dos indexadores como um artigo de periódico ou conferência. 
Após esta etapa, a amostra restante consistiu de 206 publicações.

Como não era possível descobrir de antemão quais artigos explicitamente abordaram o processo de UFD no UCASD, a última etapa envolveu uma análise mais detalhada do conteúdo dos artigos para entender quais deles abordavam as atividades de UFD ou fatores contingenciais. Assim, da mesma forma que em Brhel et al. (2015), realizamos uma análise de texto completo de cada publicação. Primeiro, lendo a introdução da amostra e conclusão, e em caso de dúvida, todo o conteúdo foi escaneado para avaliar a sua relevância para responder às nossas perguntas de pesquisa, levando a uma amostra final de 95 artigos. Esta se torna, portanto, a RSL com maior amostragem de artigos avaliados no tema de UCASD até o presente momento.

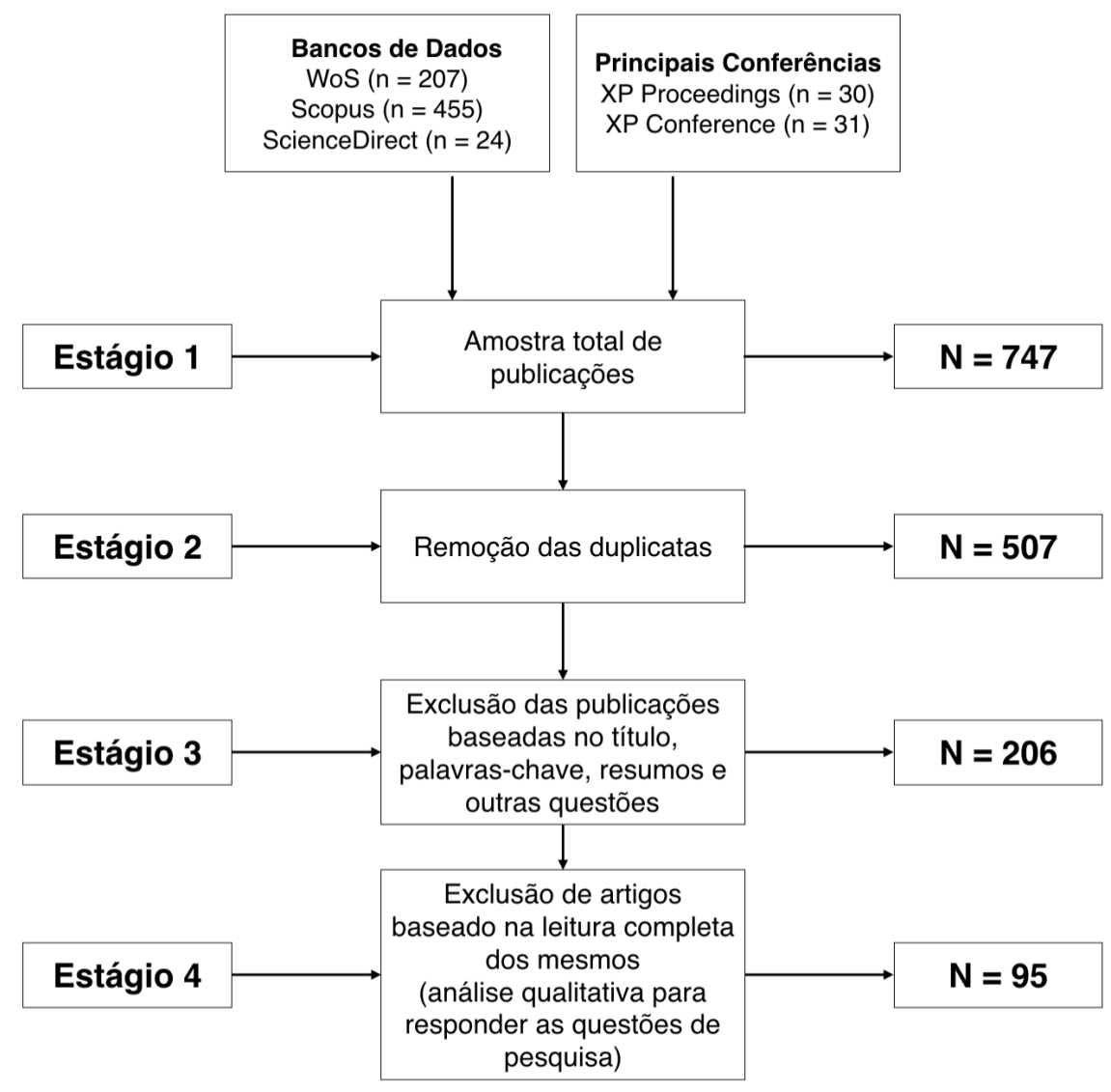

Figura 6: Processo de seleção de estudos. Fonte: O autor.

A análise dos 95 artigos escolhidos é apresentada no Capítulo 4.

Como mencionado na introdução o restante desta pesquisa visa confirmar e/ou contrastar as consolidações e propostas feitas na RSL com estudos de campo, de forma a alinhar teoria e prática. 


\subsection{Estudo de caso}

Como mencionado, o estudo de caso é uma abordagem metodológica relevante sobretudo no que tange a avaliação da influência dos fatores conteingenciais sobre o UFD.

O desenvolvimento da teoria através dos resultados do estudo de caso se dará tanto na validação, rejeição ou modificação de conceitos explorados na RSL, quanto na identificação de novos conceitos que possam expandir a base teórica (GARBULHO, 2017).

\subsubsection{Instrumento de pesquisa}

Optou-se, portanto, pelo estudo de caso exploratório, seguindo as recomendações de Eisenhardt (1989), Yin (2015), como método para a realização deste estudo. De acordo com Eisenhardt (1989), Yin (2015), o método de estudo de caso deve ser aplicado de maneira disciplinada e estruturada, pois são essas características que distinguem a pesquisa acadêmica de estudos com outras finalidades. Do mesmo modo Miguel (2010) alerta sobre a importância de um planejamento cuidadoso para que não haja comprometimento do estudo de caso como trabalho de pesquisa científica.

O desenvolvimento meticuloso de um protocolo aumenta a qualidade e confiabilidade dos resultados obtidos através do estudo de caso. Logo, o protocolo de pesquisa deve descrever os procedimentos de campo, o roteiro de entrevistas, as condições para o uso desse instrumento e o processo de coleta de dados, prescrevendo diretrizes sobre como esses dados deverão ser coletados (EISENHARDT, 1989; YIN, 2015; MIGUEL, 2010). O protocolo, além auxiliar na descrição geral do estudo, possibilita a antecipação de problemas e auxilia no controle geral sobre o processo de pesquisa (MIGUEL, 2010).

Levando em consideração esse procedimento, estabeleceu-se para este estudo um protocolo para a coleta de dados, por meio da análise documental, de entrevistas, e observações in-loco.

Dessa maneira, com base nas premissas apresentadas por Eisenhardt (1989), Yin (2015), Miguel (2010), foram estabelecidos os seguintes procedimentos para a estruturação do trabalho realizado em campo:

1. Desenvolvimento das questões de apoio que compõem o roteiro semi-estruturado de entrevistas (ver Capítulo 5);

2. Elaboração dos procedimentos de contato com os entrevistados, contendo a apre- 
sentação dos objetivos da pesquisa, convite para entrevistas e requisição de dados secundários relevantes;

3. Realização de estudo piloto para melhoria dos procedimentos (detalhado na próxima seção);

4. Coleta prévia dos dados secundários dos projetos;

5. Realização das entrevistas com os representantes dos casos selecionados para o estudo;

6. Observações realizadas in-loco de projetos estudados;

7. Verificação da necessidade de informações adicionais e complementares, daquelas obtidas por meio das entrevistas, e notificação dos entrevistados, quando necessário;

8. Registro dos dados através da transcrição das anotações dos dados secundários e gravações das entrevistas;

9. Desenvolvimento individual e descritivo das narrativas dos casos;

10. Análise cruzada dos casos por meio da triangulação dos dados coletados em campo com o referencial teórico levantado na RSL.

O protocolo apresentado dirigiu a realização geral da pesquisa, porém foram feitos alguns ajustes e melhorias nas suas diretrizes ao longo da condução do estudo. Vale salientar que, apesar da descrição aparentemente linear, as etapas apresentadas pelo protocolo foram realizadas de modo dinâmico, em iterações cíclicas e contínuas (AZENHA, 2018).

Por fim, o instrumento de pesquisa foi avaliado através da condução de um estudo piloto, cujo objetivo foi verificar sua a capacidade de coletar informações relevantes, que permitissem responder à questão de pesquisa apresentada por este estudo. A seguir, serão detalhados os procedimentos adotados para a realização do estudo piloto.

\subsubsection{Estudo piloto}

Para verificar a confiabilidade do instrumento em relação aos objetivos da pesquisa é necessária a realização de um teste piloto que permita avaliar a capacidade desse instrumento para coletar dados de qualidade (FORZA, 2002). Além disso, Eisenhardt (1989), Miguel (2010) ressaltam a importância da execução do teste piloto antes da coleta efetiva 
dos dados, pois sua execução auxilia a identificar possíveis ajustes e correções necessárias ao instrumento de pesquisa antes do pesquisador ir definitivamente à campo.

O objetivo da realização de piloto para este estudo foi verificar a qualidade do instrumento desenvolvido, bem como analisar a sua capacidade de coletar dados que permitissem responder as questões de pesquisa, além de garantir que os resultados obtidos futuramente em campo estejam alinhados com os objetivos propostos pelo estudo. Assim, o teste piloto foi iniciado assim que o desenvolvimento do instrumento de pesquisa foi concluído. De acordo com Forza (2002), o teste piloto pode ser realizado com pessoas que trabalham no mercado, consultores, especialistas, colegas e até mesmo com pessoas que são parte do público alvo para entrevistas. Seguindo a recomendação de Forza (2002), o teste piloto deste estudo contou com a participação de um respondente que atua como pesquisador de UX e atua conduzindo processos de design sprints como UFD de UCASD.

Para a realização da entrevista do estudo piloto, foi realizada uma entrevista presencial com cerca de duas horas de duração. Antes do início da entrevista o entrevistado foi informado sobre o tema da pesquisa e os detalhes sobre a realização do piloto. No final, foi solicitado ao entrevistado que criticasse e fizesse considerações sobre o roteiro de entrevistas, a dinâmica das conversas, o método de arguição e a abordagem das entrevistas.

Com base nos resultados obtidos, foi possível elencar as seguintes contribuições da realização do estudo piloto para esta pesquisa:

- Permitiu avaliar a qualidade e a capacidade do instrumento de pesquisa em coletar resultados alinhados com a questão central e os objetivos de pesquisa;

- Possibilitou identificar melhorias na ordenação e na redação das questões do roteiro de entrevistas, além de revelar lacunas nas explicações durante arguição;

- Possibilitou estimar o tempo médio das entrevistas, revelando possíveis otimizações para tornar as conversas mais dinâmicas;

- Auxiliou a identificar diversos insights e confirmar a viabilidade do framework estabelecido pela revisão sistemática da literatura em um contexto prático.

\subsubsection{Definição da unidade de caso}

A unidade refere-se à um indivíduo num contexto definido, e pode ser entendido atualmente como um grupo social, uma organização, um conjunto de relações, um papel ou processo social (LIMA et al., 2012). A seleção de uma população ajuda a definir os limites 
para generalizar as descobertas, e na situação em que se pretende desenvolver teoria a partir do estudo de caso, eles podem ser escolhidos para replicar casos anteriores ou estender a teoria emergente (EISENHARDT, 1989). A unidade de análise investigada neste estudo são os processos de LDUF (Design Sprint), com foco nas contingências da organização, do projeto e da equipe de cada processo e também as principais características do LDUF na visão de profissionais e gestores.

Para solucionar os problema apontado pela literatura e prática, e responder à questão principal de pesquisa, este estudo busca ir além de encontrar as correlações entre fatores contingenciais e componentes do UFD, tendo o objetivo de confrontar a literatura com casos empíricos e realizar uma análise holística em cima da relação proposta, no contexto de empresas que realizam UCASD (CROOM, 2010).

\subsubsection{Determinação do número de casos}

Visando aumentar a variabilidade de contingências em projetos de software, optou-se por um estudo com múltiplos casos, cuja triangulação dos dados fortalece o potencial dos resultados obtidos (LIMA et al., 2012; YIN, 2015).

Neste sentido, empresas prestadoras de serviço de desenvolvimento ágil de software centrado no usuário para outras empresas se mostram como ideais, porquê dispõe de uma maior quantidade de projetos a serem analisados, diferente de empresas de produto próprio que acabam tendo contingências e equipes similares envolvidas.

Por outro lado, é difícil encontrar empresas no mercado brasileiro que trabalhem com o modelo de desenvolvimento de software ágil centrado no usuário de forma integrada, ou seja, o ciclo de vida da criação do software é realizada sem a necessidade de trabalhar etapas do projeto em separado (em decorrência dos stage-gates), que acaba sendo o padrão de mercado, ao realizar as etapas iniciais com agências de design e o desenvolvimento com fábricas de software.

Neste cenário, foi selecionada como base para o restante do estudo uma única empresa pela grande quantidade de projetos que se enquadra no ciclo de vida de desenvolvimento de software ágil centrado no usuário capaz de executar projetos ao longo de todas as etapas do ciclo de vida do UCASD, e por ser uma empresa na qual o autor deste estudo teve maior abertura e conveniência para realizar o estudo de caso.

Por um lado existe uma desvantagem no que tange a análise dos fatores contingenciais associados à organização, ao existir uma menor variância com uma empresa central, ainda 
que exista uma certa variância pois o processo de UFD é realizado em parceria com seus clientes para os quais são construídos os softwares.

Por outro lado existe uma vantagem de facilitação na interpretação dos achados, já que o encadeamento de influências organizacionais sobre o projeto e a equipe, implica numa variabilidade muito complexa, e estudar múltiplas organizações exigiria a construção de um arcabouço complexo de difícil generalização.

Apesar da organização foco deste estudo já ter realizado 93 processos de Design Sprint, foram avaliados apenas 27 projetos de 21 empresas diferentes que se enquadraram nos critérios mínimos de inclusão (vide Capítulo 5). Ainda assim, esta pesquisa utiliza como critérios mínimos de aceitação do estudo de caso os quatro testes de qualidade proposto em Yin (2015):

- Validade do construto: a coleta de dados utilizou múltiplas fontes de evidências e o relatório foi revisado pelo entrevistado;

- Validade interna: a análise de dados adequou-se ao padrão na literatura e construiuse a explanação dos conceitos a partir da RSL;

- Validade externa: o projeto de pesquisa definiu uma lógica de replicação dos casos a partir do estudo piloto e iteratividade das entrevistas;

- Confiabilidade: a coleta de dados utilizou protocolo de estudo de caso e foi desenvolvido um banco de dados com os aprendizados.

Além disso, como visto na Figura 14, esta pesquisa se torna o estudo de caso com maior número de casos analisados (27), uma vez que os três artigos com maior número de projetos avaliados eram duas revisões de literatura e uma survey. Além disso os casos selecionados cobrem uma diversidade grande de segmentos de mercado e tamanhos de empresas, atendendo aos pedidos de Jurca, Hellmann e Maurer (2014). Desta forma, esta quantidade de casos analisados se baseia no princípio de suficiência de dados ao mesmo tempo que promove uma generalização teórica com a variedade de contextos necessária para dar credibilidade à teoria derivada do caso (LIMA et al., 2012; YIN, 2015).

\subsubsection{Coleta de dados}

Por lidar com fenômenos da vida real que não estão confinados em uma situação de experimento, é necessário que na coleta de dados o investigador se atenha à condição de 
observador, submetendo-se às condições do cenário do caso proposto, e criando procedimentos para se precaver em caso de possíveis imprevistos (YIN, 2015).

Para esta pesquisa, primeiramente realizou-se levantamento de dados secundários, através das documentações produzida nos projetos analisados. As fontes de documentação analisadas foram: basecamp (ferramenta de centralização da comunicação com decisões tomadas e recursos produzidos nos projetos), redmine (documentação de profissionais e horas empregadas em cada projeto para análise do esforço e tempo de execução), google docs (documentações dos achados em campo e definições de requisitos dos projetos) e apresentações de resultados em PDFs ou Keynotes (consolidação do UFD e requisitos do projeto). Uma descrição mais detalhada da coleta e documentação dos dados secundários de cada projeto pode ser vista no Capítulo 5.

Os dados secundários que fugiram do comportamento padrão (sendo considerando padrão o planejamento e execução das atividades segundo Knapp, Zeratsky e Kowitz (2016)) foram anotados e serviram como base de perguntas para os entrevistados. Para não enviesar a resposta de cada entrevistado, estas perguntas eram feitas ao final, específica apenas para os projetos que ele liderou, e de maneira aberta (ex: se um processo havia utilizado mais horas que previsto na etapa comercial, era perguntado ao entrevistado: "Porquê este processo utilizou mais horas? O que aconteceu para isso ocorrer?").

Logo, em um segundo momento buscou-se explorar e confirmar os dados levantados em entrevistas com os líderes dos projetos. Foram conduzidas cinco entrevistas semiestruturadas, para permitir abertura a novas informações não advindos da RSL, com roteiro construído a partir das proposições teóricas levantadas no tópico de revisão bibliográfica. As entrevistas foram presenciais e duraram entre 90 e 150 minutos, dependendo do entrevistado, sendo que um dos entrevistados já não trabalha mais na empresa, e sim na área de UX de uma multinacional.

Os áudios das entrevistas foram gravados para posterior análise e tabulação segundo os pontos centrais do roteiro prévio de entrevista, para facilitar a generalização analítica.

A descrição detalhada da empresa foco deste estudo, os projetos selecionados para a realização dos estudos de caso, o perfil dos entrevistados e roteiro de entrevistas utilizado para condução das conversas são apresentados no capítulo 5 . 


\subsubsection{Análise dos dados}

Os dados coletados em campo foram transcritos, compilados e organizados para serem utilizados na construção da narrativa dos casos. Durante o processo de transcrição, caso surgissem lacunas ou dúvidas sobre a interpretação do material compilado, os entrevistados eram novamente contatados para maiores explicações sobre os pontos identificados na análise. Após esse processo, as informações foram estruturadas e enviadas para que os entrevistados complementassem, corrigissem e confirmassem as informações transcritas.

A partir das transcrições, foram construídas narrativas descritivas dos casos. Os resultados obtidos com esse processo foram analisados por meio da triangulação entre as fontes primárias/secundárias e o referencial teórico construído pela RSL, conforme recomendado por Eisenhardt (1989), Yin (2015).

De acordo com Eisenhardt (1989), a análise cruzada dos casos possibilita identificar padrões e correlações internas entre os casos, tornando assim os resultados qualitativos da pesquisa mais robustos e confiáveis.

Com base no processo de triangulação dos resultados recomendado por Eisenhardt (1989), os casos foram analisados individualmente e de forma cruzada, buscando identificar padrões nos resultados que permitissem obter respostas para a questão central e os objetivos propostos pela pesquisa.

Os resultados obtidos com a realização dos estudos de caso são apresentados e discutidos no capítulo 6. 


\section{REVISÃO SISTEMÁTICA DA LITERATURA}

Os principais objetivos desta RSL são traçar um panorama do atual estado da arte de UFD em UCASD, identificar as alternativas para gerenciar e executar atividades, escolha do time e tempo de execução e levantar quais os fatores contingenciais podem influenciar o processo. Assim, em um primeiro momento, é feito uma revisão das principais RSLs no tema e lacunas identificadas, seguidos da apresentação e discussão dos resultados obtidos. Os achados nesta RSL buscam sistematizar e classificar as características do UFD encontradas na literatura, os quais se configuram como o alicerce teórico para as iniciativas de pesquisa de campo empreendidas por este estudo.

\subsection{Resumo das revisões de literatura existentes}

Alguns autores fizeram um esforço para trazer uma melhor compreensão de como as abordagens de ASD e UCD estão sendo integradas.

Silva et al. (2011) é a primeira RSL no tema. Os autores identificaram aspectos-chave do UCASD, com foco nas práticas mais relevantes, argumentando que as mais significativas na literatura são conduzir o LDUF antes do início do desenvolvimento, criar uma colaboração próxima entre especialistas em usabilidade e desenvolvimento, e deslocar os designers para que trabalhem um sprint antes da equipe de desenvolvimento. O estudo se concentra na integração geral, mas não explica detalhadamente as práticas mais comuns, como a extensão do processo LDUF.

Com uma perspectiva diferente, Barksdale e McCrickard (2012) concentraram-se nos aspectos sociais do UCASD. Embora os autores tenham desenvolvido uma análise mais teórica, eles também propuseram uma mudança interessante na estrutura da equipe, criando a função de Product Owner de Usabilidade, mudando a forma como as equipes de design e desenvolvimento interagem. No entanto, estas e outras sugestões sociais são meramente teóricas e não foram validadas pelos autores no campo. 
Salah, Paige e Cairns (2014c) conduziram um RSL como base para uma tese de doutorado sobre modelos de maturidade. O foco foi definir os desafios, potenciais fatores de sucesso e práticas no UCASD. Segundo esses autores, o primeiro, e mais relevante, desafio mencionado é a falta de tempo para as atividades do UFD. Embora paradoxais, os autores apenas sugerem a realização de UFD, o que significa alocação de tempo quando supostamente não existe - como uma prática bem sucedida para este desafio. Outros desafios listados pelos autores que são relevantes para este estudo, por serem pouco explorados na literatura, são: otimizar o trabalho entre designers e desenvolvedores; gerenciar a carga de trabalho dos profissionais de UCD, porque eles geralmente têm que trabalhar simultaneamente em vários projetos, e a falta de documentação necessária para o bom trabalho da equipe.

Jurca, Hellmann e Maurer (2014) realizaram uma revisão quantitativa com o objetivo de descobrir tendências sobre o UCASD quanto às abordagens metodológicas e tipos de investigação mais citados como publicações no campo. Os autores apontaram que a maioria dos artigos são relatórios empíricos, artigos de opinião ou filosóficos e propostas de solução. Desta forma, é difícil tirar conclusões claras deles e difíceis de replicar as investigações. Os autores recomendaram que maiores avaliações, validações e estudos rigorosamente conduzidos sejam realizados no campo.

Brhel et al. (2015) realizaram uma RSL e formalizaram um conjunto de princípios para UCASD, num modelo similar ao Manifesto Ágil. Este trabalho forneceu uma visão melhor sobre a literatura no campo, uma vez que fundiu diferentes dimensões, tais como técnicas, processos, tecnologias, pessoas e aspectos sociais, que são geralmente abordados separadamente em estudos anteriores. Seu primeiro princípio - o mais relevante para este estudo - é que o UCASD deve se basear em fases separadas de descoberta de produto (também conhecida como UFD) e criação de produto (design e desenvolvimento do mesmo). Os autores também apontam para uma necessidade na compreensão dos fatores contingenciais e temporizações de um projeto de desenvolvimento de software ágil centrado no usuário.

Caballero, Moreno e Seffah (2016) contribui sugerindo que existem quatro possíveis momentos nesta integração, que são:

- BDUF: A equipe da UCD aplica técnicas de design antes de iterações ágeis para reunir uma visão holística do sistema a ser construído;

- LDUF: uma interação de design mínima é feita antes que a equipe de desenvolvimento comece com as iterações ágeis. Isso permite que a equipe passe algum 
tempo discutindo as diretrizes globais básicas que darão consistência e coerência ao desenvolvimento subsequente;

- Interação de Design Implícita: as técnicas de UCD são aplicadas para projetar a interação das histórias do usuário a serem desenvolvidas em cada iteração;

- Trabalho Paralelo: a equipe de UCD trabalha em paralelo com uma iteração à frente da equipe de desenvolvimento. Assim, os desenvolvedores abordam o desenvolvimento de histórias de usuários cuja interação já foi projetada.

Os autores, no entanto, não detalham a extensão de cada tipo de integração, onde começa e termina, seus resultados ou como cada um deve ser realizado.

\subsection{Análise das lacunas nas revisões de literatura exis- tentes}

Após a análise dos trabalhos apresentados, três grandes deficiências foram evidenciadas.

Primeiramente, o UFD, apesar de ser o processo mais citado na literatura de UCASD, ainda carece de formalização. Não há uma definição clara do processo, quem são os participantes, como este deve ser planejado, executado e seus resultados (CABALLERO; MORENO; SEFFAH, 2016; BRHEL et al., 2015; SILVA et al., 2011). Por exemplo, quanto a extensão das atividades do UFD, enquanto alguns estudos defendem que deve existir um grande processo para entender os usuários e explorar potenciais mercados (BDUF), a maioria favorece um processo mais curto (LDUF) para ajudar a equipe na definição dos requisitos do projeto, sugerindo que o BDUF não é uma opção, pois é contra os princípios ágeis.

Em segundo lugar, a compreensão dos fatores contingenciais que influenciam as descrições de processos é uma contribuição altamente valiosa para Ferreira, Sharp e Robinson (2012) e Brhel et al. (2015), como há evidências de que desenvolvedores e designers (FITZGERALD, 1997; GASSON, 1999; BELCHEV; BAKER, 2009) desviam dos processos prescritos na prática. Portanto, uma análise mais aprofundada deste tópico deve ser realizada, uma vez que nenhuma das revisões anteriores investiga como o ambiente afeta a maneira como os desenvolvedores, designers e gerentes trabalham.

Terceiro, como a grande maioria das publicações no campo é baseada em relatos de experiência e proposições de solução, com poucas contribuições reais para a prática, este 
artigo relembra Jurca, Hellmann e Maurer (2014) exigindo pesquisas com abordagens metodológicas rigorosas, resultados claros e contribuições para teoria e prática.

Além disso, Ferreira, Sharp e Robinson (2012) e Wale-Kolade, Nielsen e Paivarinta (2014) argumentam que existe uma lacuna de conhecimento na literatura da UFD porque a maioria das sugestões propostas são reflexões teóricas ou relatos de casos, originados de projetos específicos e validados apenas dentro do contexto da organização analisada (JIA; LARUSDOTTIR; CAJANDER, 2012). Além disso, poucos são os estudos que aplicam abordagens metodológicas rigorosas para descobrir como os fatores contingenciais de equipe, projeto e organização afetam o processo de UFD, o que, por sua vez, explica por que os profissionais têm dificuldade em replicar o processo de UFD eficientemente. Essa lacuna foi destacada em Jurca, Hellmann e Maurer (2014) e Silva et al. (2015), que concluíram que a grande maioria das publicações no campo são proposições de soluções baseadas apenas em relatos de experiência, sem histórico de pesquisas objetivando avaliar e validar as fases do processo.

Esta RSL, portanto, tem como foco estreitar as lacunas mencionadas na literatura e prática com uma abordagem metodológica rigorosa para formalizar o processo UFD - duração, equipe envolvida, técnicas - e explorar os fatores contingenciais que podem influenciar o plano e execução do UFD.

Ainda assim, antes de atacar estas lacunas, são feitas análises bibliométricas e de redes para mapear o atual estudo da arte em UFD do UCASD.

\subsection{Análise bibliométrica e de redes}

Uma visão inicial baseada na estatística descritiva apresenta o número de publicações por ano, ver Figura 7. É relevante observar que $42 \%$ da amostra foi publicada nos últimos cinco anos (2014-2018) evidenciando o interesse crescente no tema. Apenas 7 conferências, séries de publicações e periódicos incluíram 58\% dos 95 artigos analisados, e os mais importantes são Notas de Aula em Ciência da Computação (incluindo notas de conferência em Inteligência Artificial e Notas de Palestra em Bioinformática) e Agile Conference (20\%).

A rede de citação por país (ver Figura 8) evidenciou autores de diferentes países que se referenciaram uns aos outros. Dos 32 países, apenas 7 possuem pelo menos 5 artigos publicados. Para melhor visualização foi aplicado o filtro recomendado pelo software VOSviewer 1.6.6, evidenciando os dados mais representativos, este filtro foi aplicado em 


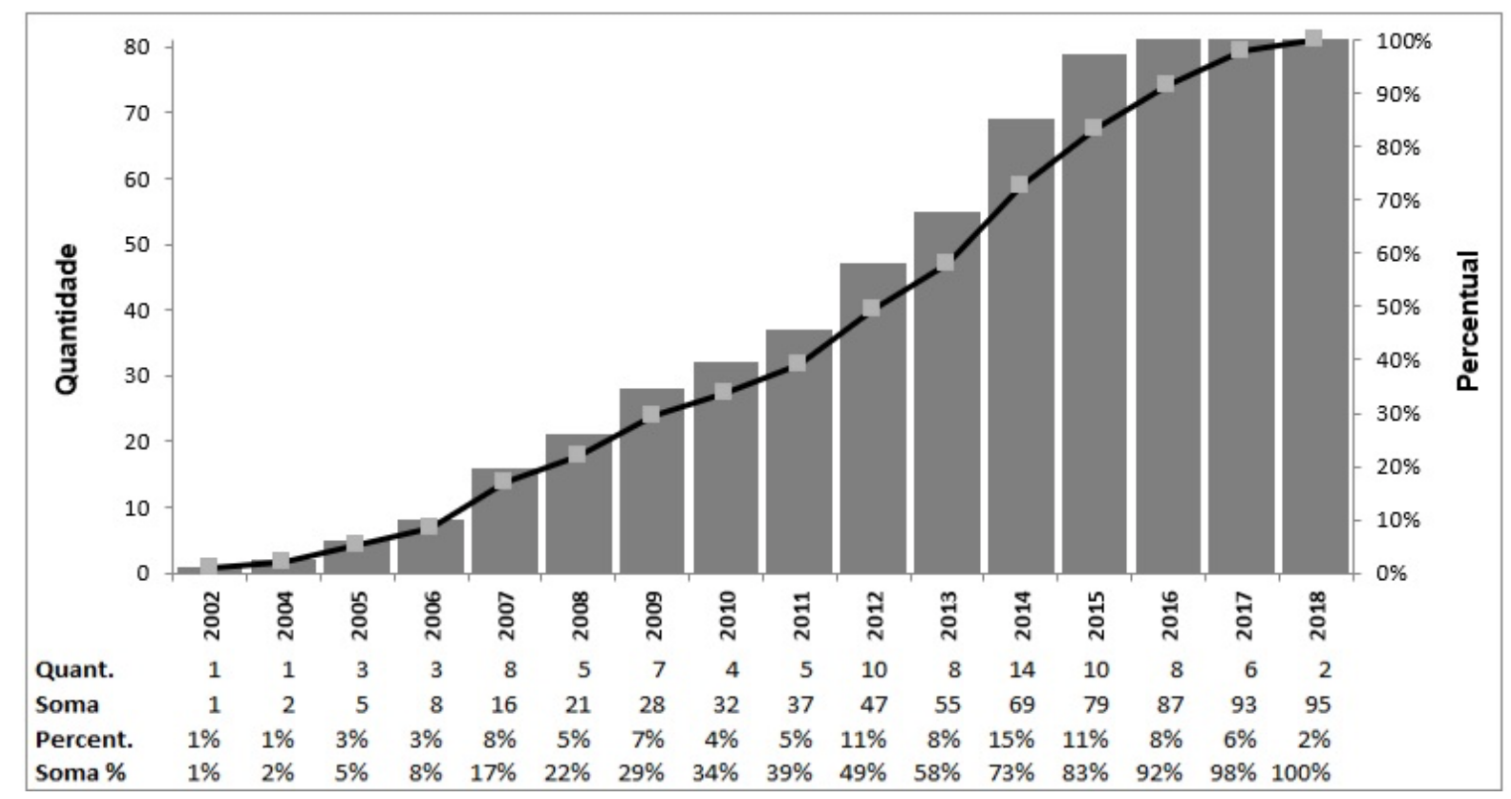

\begin{tabular}{|c|c|c|c|c|c|c|c|c|c|c|c|c|c|c|c|c|c|c|}
\hline \multirow[b]{2}{*}{ Conferências e Revistas } & \multicolumn{18}{|c|}{ Ano } \\
\hline & ণิ & & & & & & & & & & & & & & $=$ & & $\begin{array}{l}\bar{\Xi} \\
\text { 。ِ }\end{array}$ & $\%$ \\
\hline \multicolumn{19}{|l|}{ Lecture Notes em Computer Science (incluindo subseries Lecture } \\
\hline Notes em Inteligência Artificial e Lecture Notes em Bioinformáticas) & 0 & & & 2 & 4 & 0 & 1 & 0 & 1 & 2 & 1 & 5 & 1 & 3 & 0 & 0 & & $23 \%$ \\
\hline Proceedings - Agile Conference & 0 & 0 & 2 & 1 & 1 & 4 & 3 & 1 & 2 & 3 & 1 & 1 & 0 & 0 & 0 & 0 & & $20 \%$ \\
\hline ACM International Conference Proceeding Series & 0 & 0 & 0 & 0 & 0 & 0 & 0 & 0 & 0 & 1 & 1 & 1 & 1 & 0 & 0 & 0 & 4 & $4 \%$ \\
\hline Conferência em Human Factors em Computing Systems - Proceedings & 0 & 0 & 0 & 0 & 0 & 1 & 1 & 0 & 0 & (2) & 1 & 0 & 1 & 0 & 0 & 0 & 4 & $4 \%$ \\
\hline Lecture Notes em Business Information Processing & 0 & 0 & 0 & 0 & 0 & 0 & 1 & 0 & 0 & & & 1 & 0 & 0 & 0 & 0 & 4 & $4 \%$ \\
\hline IEEE Latin America Transactions & 0 & 0 & 0 & 0 & 0 & 0 & 0 & 0 & 0 & & & 0 & 1 & 1 & 0 & 0 & 2 & $2 \%$ \\
\hline Total & 0 & 1 & 3 & 3 & 5 & 5 & 6 & 1 & 3 & 7 & 5 & 8 & 4 & 4 & 0 & 0 & & $58 \%$ \\
\hline
\end{tabular}

Figura 7: Evolução anual das publicações de UFD em conferências e periódicos com mais estudos no tema. Fonte: O autor.

todas as redes desta seção. É possível notar apenas dois agrupamentos principais, descritos respectivamente pelo número de citações e de artigos publicados: o agrupamento preto, representando $62 \%$ das citações, composto pelo Canadá (290; 12), Reino Unido $(256 ; 11)$ e Estados Unidos da América (223; 17); e o agrupamento cinza claro, composto pela Alemanha (176; 6), Brasil (145; 9), Finlândia (113; 10) e Espanha (15; 7). As principais conexões são entre o Reino Unido e Canadá; Reino Unido e Estados Unidos; Estados Unidos e Canadá; Brasil e Canadá e Brasil e Estados Unidos.

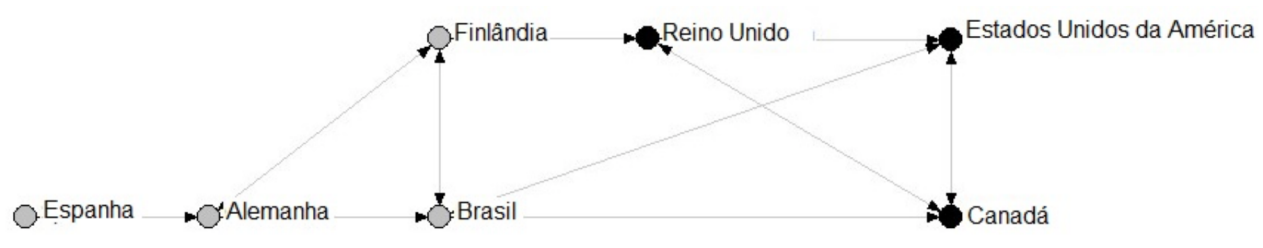

Figura 8: Rede de citação por país. Fonte: O autor.

A rede de coautoria por país (ver Figura 9) identificou autores de diferentes países que 
publicaram juntos, considerando o mesmo filtro mencionado anteriormente. Os resultados incluíram sete principais países, dispostos em cinco agrupamentos: o agrupamento preto, composto por Canadá, Brasil e Estados Unidos; o aglomerado cinza escuro, composto apenas pelo Reino Unido; o aglomerado cinza claro, composto apenas pela Finlândia; o agrupamento cinza mais claro, composto pela Alemanha, e o agrupamento branco, composto pela Espanha. As principais conexões são entre Canadá com Brasil, com Reino Unido e com Estados Unidos.

A rede de citação por país evidenciou citações entre países desenvolvidos e em desenvolvimento, onde o Brasil é o único país emergente na rede.

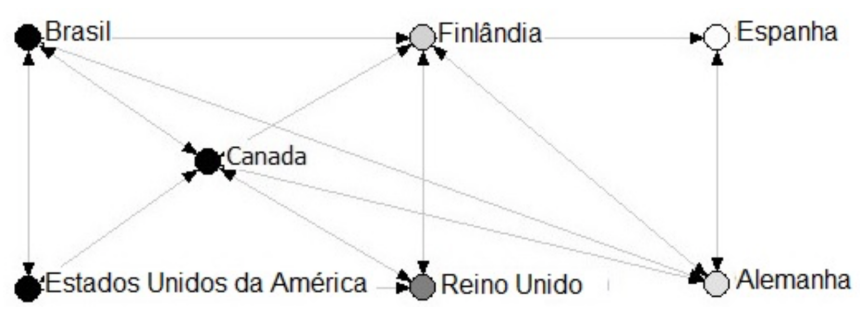

Figura 9: Rede de co-autoria por país. Fonte: O autor.

A rede de co-ocorrência de palavras-chave (vide Figura 10) evidenciou as conexões entre as palavras-chave mais relevantes. Da amostra inicial de 546 palavras-chave, 26 apresentaram pelo menos 7 ocorrências. É possível observar três agrupamentos principais e suas ocorrências mais representativas. O agrupamento preto é composto de interação humano-computador (6\%), desenvolvimento de software ágil (5\%), design centrado no usuário (3\%) e integração (3\%). O agrupamento cinza escuro é composto por engenharia de software (9\%), design centrado no usuário (5\%), engenharia de usabilidade (5\%), usabilidade (3\%), métodos ágeis (3\%), interfaces de usuário (3\%) métodos iterativos (3\%), design centrado no usuário (3\%), sistemas de manufatura ágil (3\%), software de computador $(2 \%)$, programação extrema $(2 \%)$, gerenciamento de projetos $(2 \%)$ e projetos humanos (2\%). E o agrupamento cinza claro inclui design de software (9\%), design (7\%), desenvolvimento ágil (7\%), scrum (4\%), experiência do usuário (4\%), ágil (3\%), pesquisa $(2 \%)$, design de experiência do usuário $(2 \%)$ e experiência do usuário (UX) (2\%).

As principais conexões são entre design de software e engenharia de software; design de software e desenvolvimento de software ágil; design de software e interação humanocomputador; e engenharia de software e desenvolvimento ágil. A rede de co-ocorrência de palavras-chave evidenciou três vezes o design centrado no usuário, destacando a importância desta palavra-chave e sua relevância em diferentes situações.

A rede de co-autoria por autores (ver Figura 11) evidencia autores que pesquisaram 


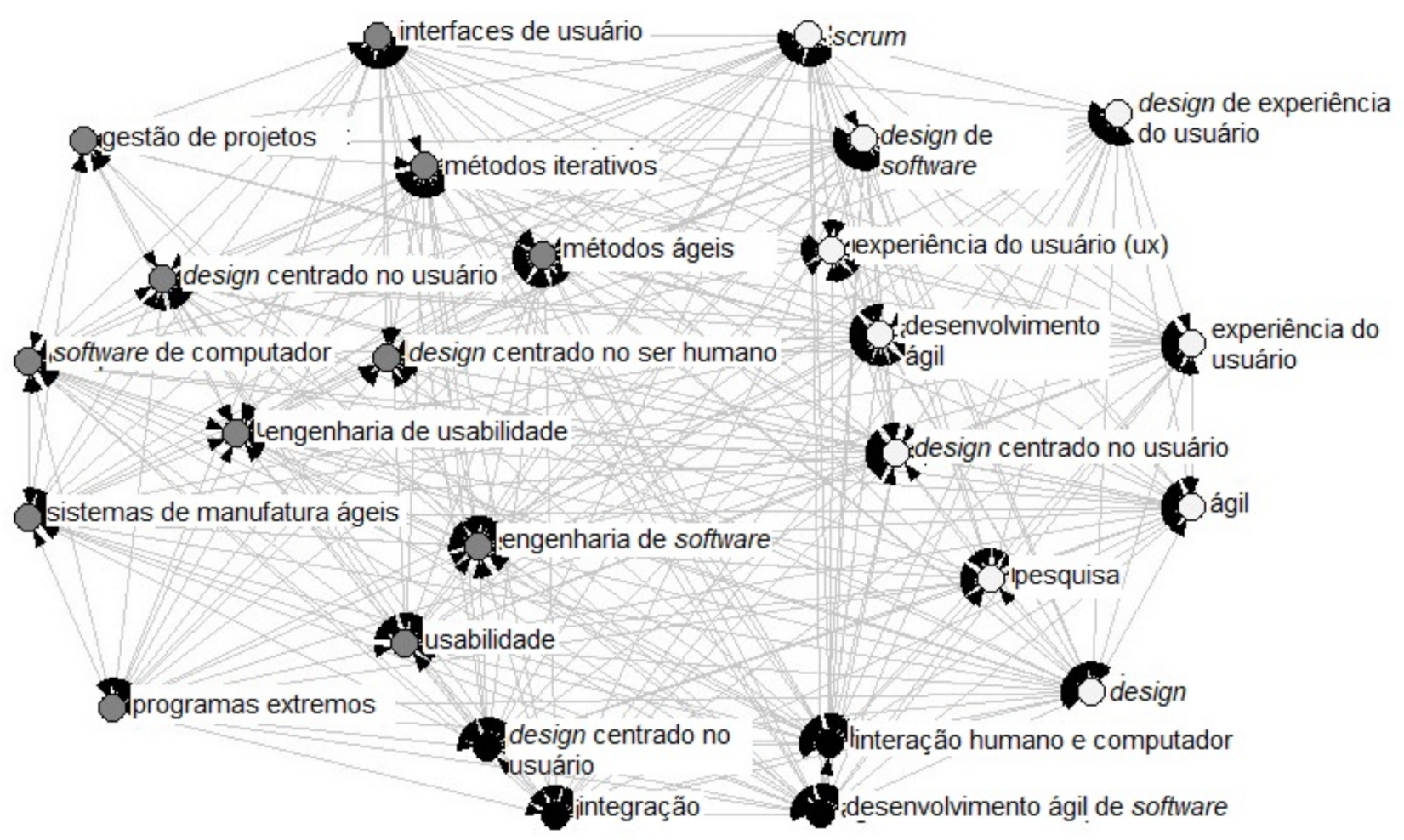

Figura 10: Rede de co-ocorrência de palavras-chave. Fonte: O autor.

juntos e inicialmente incluía 232 autores diferentes. Apenas 6 autores, no entanto, tiveram pelo menos 5 publicações e foram incluídos na figura. É possível notar dois agrupamentos principais. O agrupamento preto, inclui Da Silva (141 citações), Maurer (223 citações) e Silveira (37 citações). O agrupamento cinza escuro inclui Ferreira (92 citações) e Sharp (186 citações). Esses resultados estão de acordo com a tese de Ph.D. de Schön (2017) sobre os principais grupos de pesquisa no domínio.
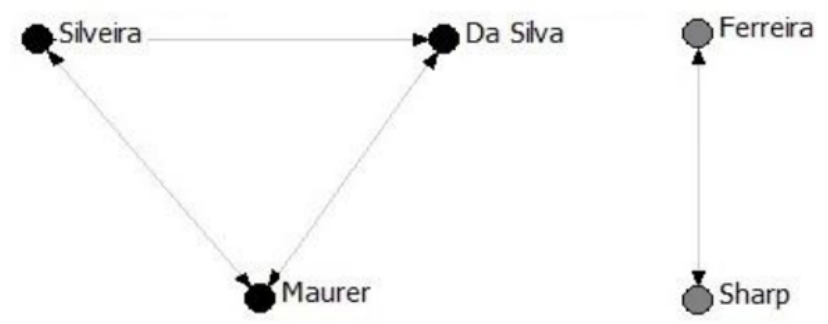

Figura 11: Rede de co-autoria por autores Fonte: O autor.

A co-citação por autores (ver Figura 12) evidencia 2.140 autores diferentes, com apenas 35 autores com pelo menos 20 citações. Pode-se notar três agrupamentos principais. O aglomerado negro é composto por Milchrahm, Patton, Hussain, Tscheligi, Shahzad, Wolkerstorfer, Slany e Lechner. O aglomerado cinza escuro é composto por Nielsen, Martin, Chamberlain, Beedle, Holtzblatt, Maiden, Maurer, Fox, Beyer, Cockburn, Beck, 
Gulliksen, Schwaber e Sillito. E o aglomerado cinza claro é composto por Memmel, Miler, Baker, Sharp, Reiterer, Lee, Abrahamsson, Noble, Biddle, Holzinger, Robinson e Ferreira. As principais conexões são entre Sharp e Ferreira, Sharp e Maurer, Ferreira e Maurer, e Sharp e Hussain.

Por fim, a rede de co-autoria de autores apresentou apenas cinco autores que publicaram juntos, evidenciando a falta de cooperação na pesquisa da UFD, no entanto, considerando a rede de co-citação, é possível observar uma rede robusta, revelando que os fundamentos teóricos estão sendo combinados e podem impulsionar futuras iniciativas de pesquisa acadêmica.

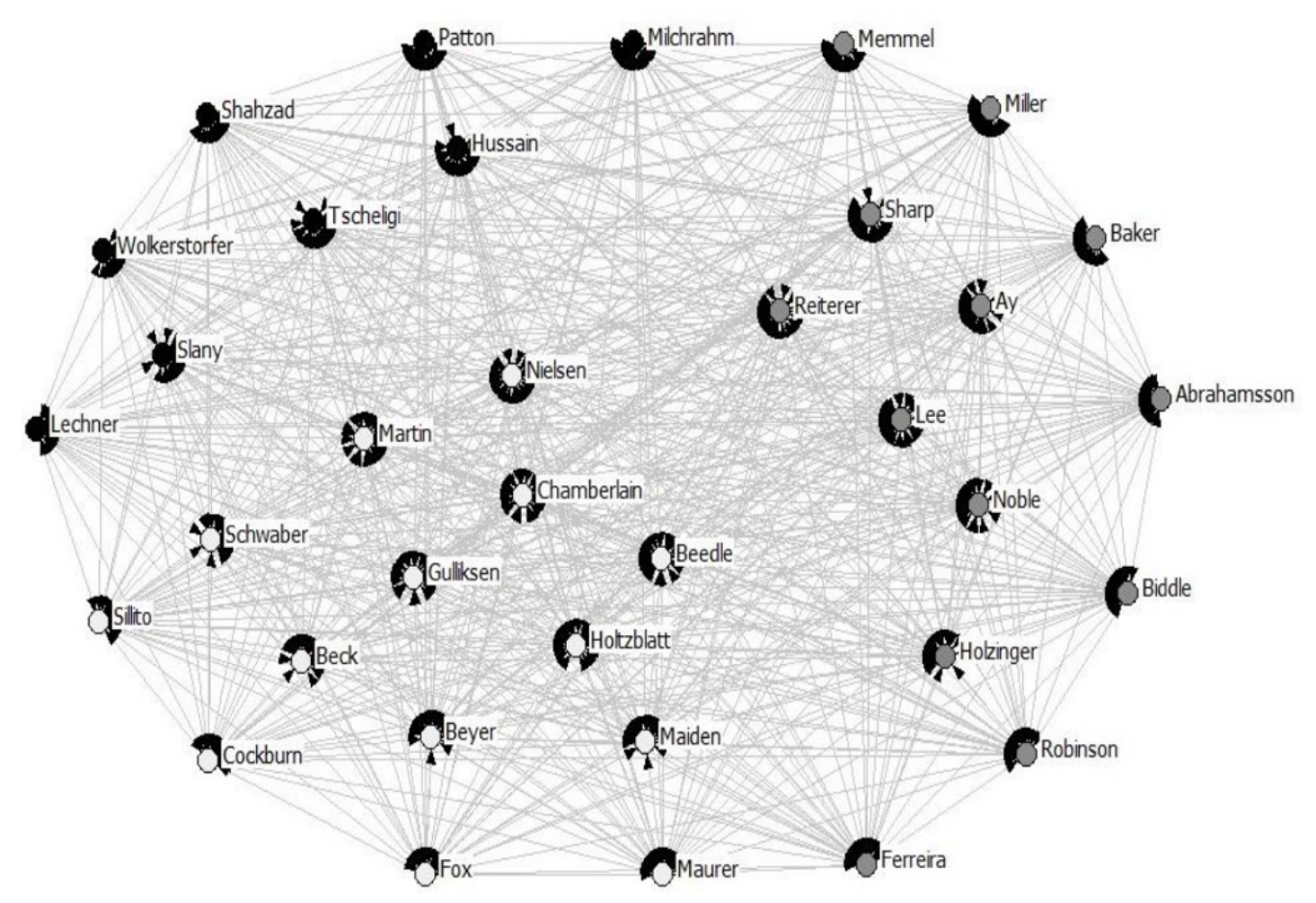

Figura 12: Rede de co-citação por autores. Fonte: O autor.

\subsection{Análise de conteúdo}

\subsubsection{Estado da arte da pesquisa de UFD}

A análise de conteúdo teve como foco recuperar as informações gerais dos artigos para mapear o estado da arte em UFD do UCASD, e dados relevantes para responder as questões de pesquisa, apontadas na primeira seção, quanto às técnicas, tempo e configuração da equipe do UFD do UCASD e os fatores contingenciais que afetam como as 
atividades do UFD são planejadas e executadas.

O método de pesquisa de cada artigo foi identificado (ver Figura 13). A amostra evidenciou uma mistura equilibrada entre pesquisas que seguem uma abordagem conceitual ( $\mathrm{n}=29$ - revisão de literatura, experimental e teórica) e uma abordagem empírica ( $\mathrm{n}=$ 52 - estudo de caso, survey e pesquisa-ação).

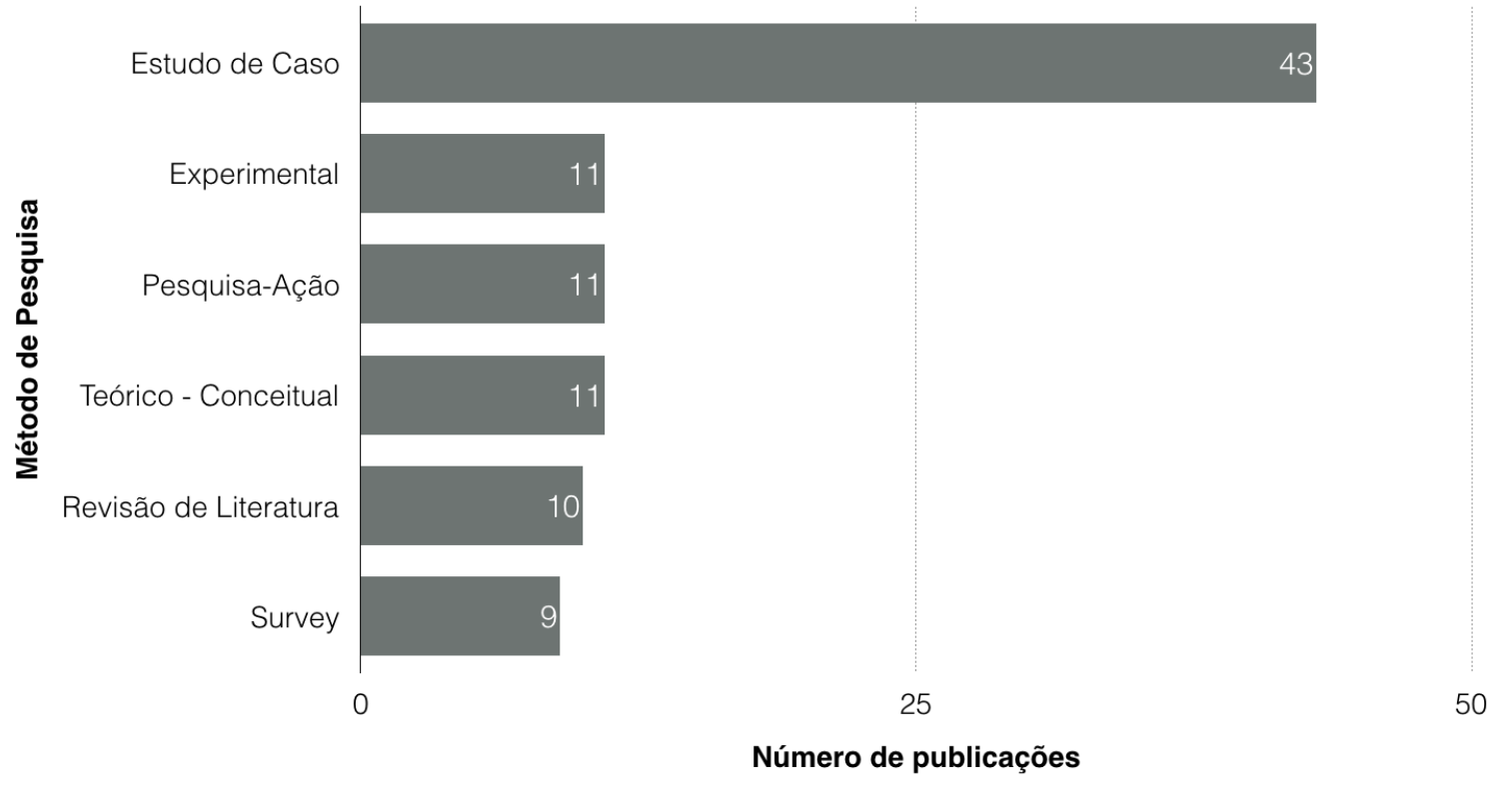

Figura 13: Número de publicações por método de pesquisa. Fonte: O autor.

Os gráficos das Figura 13 e Figura 14 evidenciaram que a maioria das pesquisas em campo é altamente influenciada por relatos de experiências na indústria de estudos de caso único, com propostas altamente enviesadas em seus próprios ambientes (SILVA et al., 2011; BRHEL et al., 2015; JURCA; HELLMANN; MAURER, 2014; KUUSINEN; MIKKONEN; PAKARINEN, 2012). Essa também pode ser uma das razões para a falta de consistência e uniformidade nos construtos aplicados, o que por sua vez implica em uma maior dificuldade em compreender e utilizar as principais terminologias, dificultando a pesquisa e a prática no assunto. Isso está especialmente presente nos campos interdisciplinares, por ser utilizado em múltiplos contextos, como é o caso do gerenciamento de projetos (ARITUA; SMITH; BOWER, 2009).

Considerando a interdisciplinaridade do UCASD, os estudos tendem a ser enviesados, porque consideram apenas uma visão limitada sobre a integração de UCD e ASD (ver Figura 15). Isso pode ser visto em estudos que consideram apenas a perspectiva do Product Owner ou Product Manager (MILLER, 2005; FARINANGO; BENAVIDES; LOPEZ, 2015; DOBRIGKEIT; PAULA et al., 2017), do designer ou profissional de UCD (WALEKOLADE; NIELSEN; PAIVARINTA, 2014; BEYER; HOLTZBLATT; BAKER, 2004; 


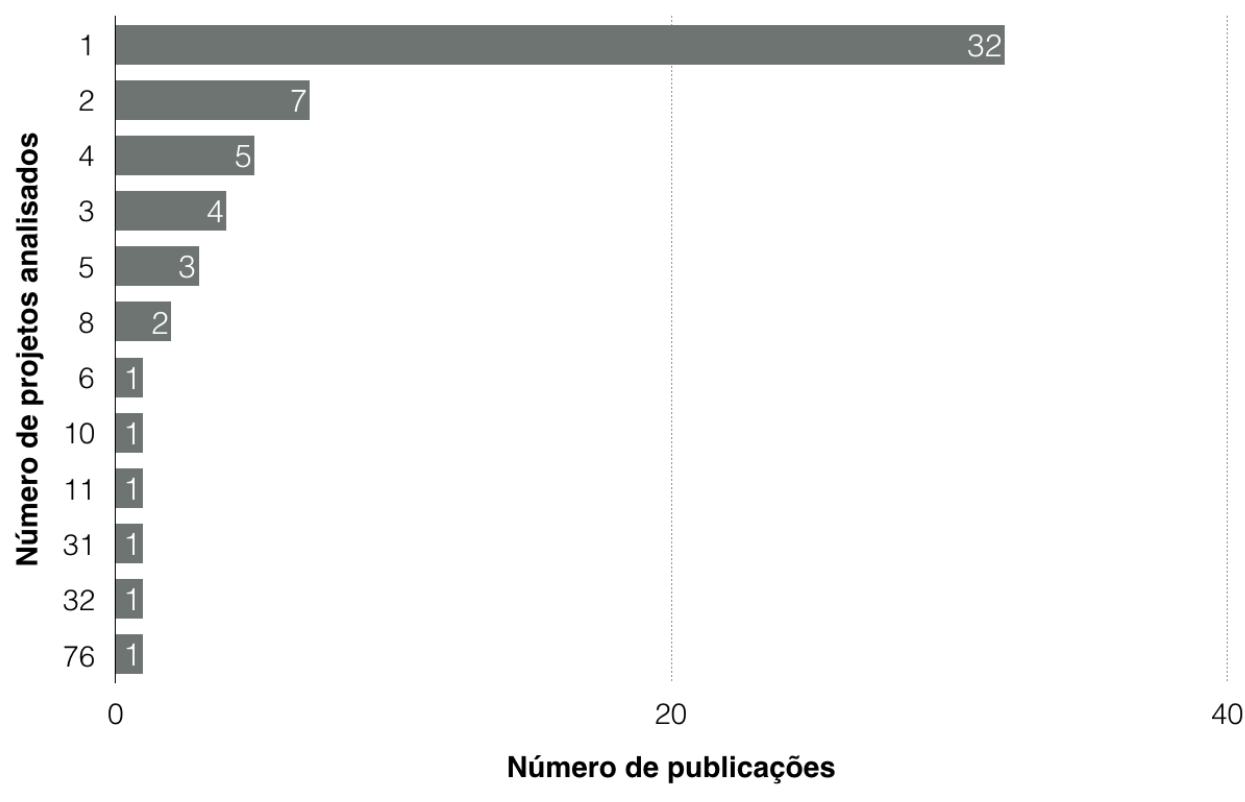

Figura 14: Número de projetos estudados por publicação. Fonte: O autor.

FISHER; BANKSTON, 2009; LÁRUSDÓTTIR; CAJANDER; GULLIKSEN, 2012; ISA et al., 2014) e do desenvolvedor (ARDITO et al., 2014; BEGNUM; FURUHEIM, 2016; CARVALHO; SILVA; SILVEIRA, 2016; HIGHSMITH; COCKBURN, 2001; RAGNARSDOTTIR, 2010; NOSSEIR et al., 2012; HUMAYOUN; DUBINSKY; CATARCI, 2011; CHOMA; ZAINA; SILVA, 2015; TEKA; DITTRICH; KIFLE, 2017), e poucos são os estudos que explicam uma visão mais voltada para os negócios (marketing, sócios, finanças, etc.) (WALE-KOLADE; NIELSEN; PAIVARINTA, 2014; FERREIRA, 2008; FOX; SILLITO; MAURER, 2008; NAJAFI; TOYOSHIBA, 2008; SINGH, 2008; SILVA et al., 2013; SALAH; PAIGE; CAIRNS, 2014a; CABALLERO; MORENO; SEFFAH, 2014), ou até mesmo ter uma visão completa de todos eles (FERREIRA, 2008; NAJAFI; TOYOSHIBA, 2008; SINGH, 2008; SILVA et al., 2013; SALAH; PAIGE; CAIRNS, 2014a).

O termo UFD foi mencionado pela primeira vez em 2002. Ruthford (2002) apresenta brevemente o UFD como uma nova oportunidade para os profissionais de UCD começarem a trabalhar mais cedo no processo de desenvolvimento de software, podendo trabalhar em um estágio mais exploratório e não se limitando a avaliações de usabilidade do que já estava sendo desenvolvido. Depois, o UFD é tratado como uma parte da integração do UCASD, até 2007, quando Ferreira, Noble e Biddle (2007b) publica um artigo específico sobre UFD como um tópico de destaque no UCASD, na época referido como Design de Interação Up-Front, com os autores identificando os principais conceitos e práticas que ainda são válidos para o UFD, tais como:

- Existem Vantagens no Design de Interação Up-Front: fazer essas atividades 


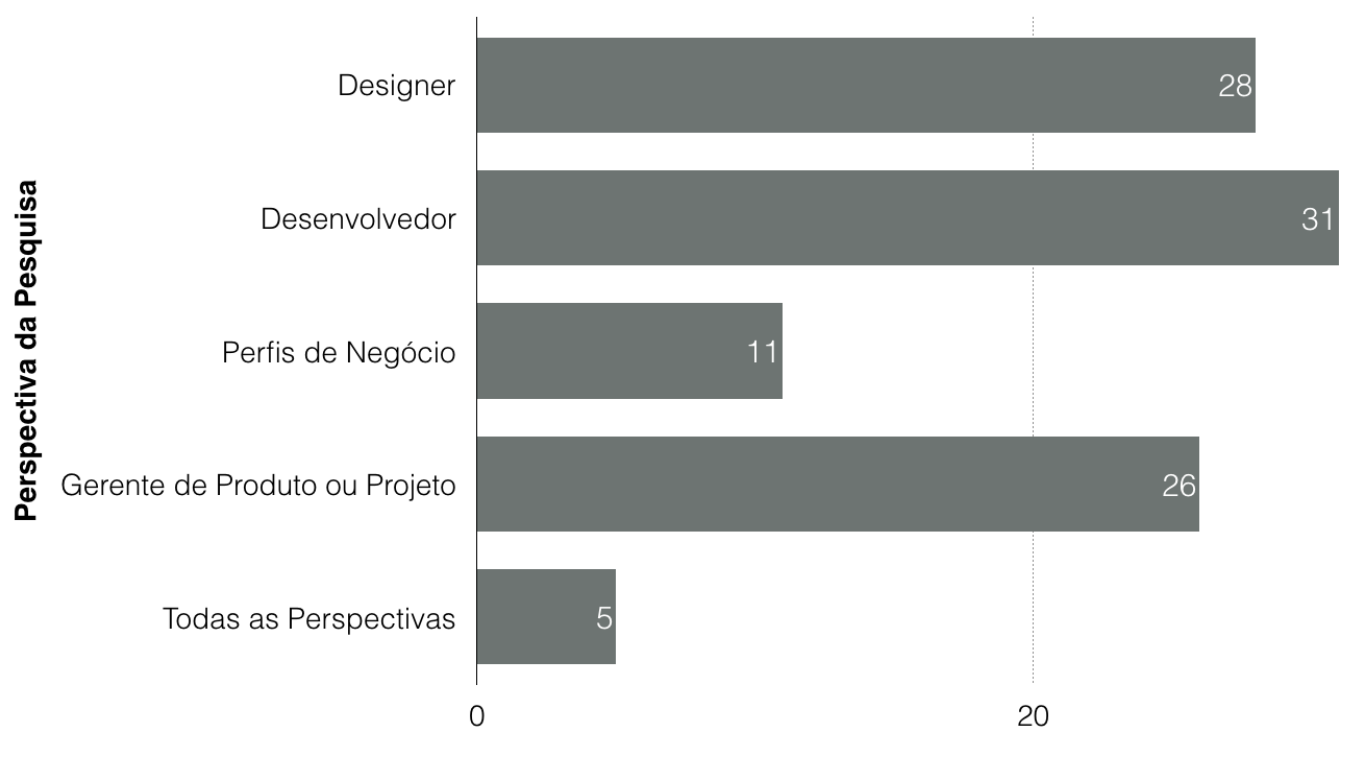

Número de Publicações

Figura 15: Perspectivas da integração de UCASD. Fonte: O autor.

é benéfico para o projeto a partir das perspectivas de todos os envolvidos no projeto;

- Faça a maior parte, embora não todo, Design de Interação Up-Front: isso significa focar nas coisas centrais que precisam ser decididas, mas não em pontos secundários para evitar o desperdício, sabendo que os requisitos mudarão;

- Grande parte do projeto inicial envolve o estudo de clientes e usuários: essa é uma consideração essencial, pois não apenas o usuário, mas outras partes interessadas (como o cliente) devem estar envolvidas. Esse envolvimento dos stakeholders raramente é citado na literatura;

- Design de interação também é informado pela implementação do software: significa que o trabalho de UCD não deve ser confinado ao UFD, pois novos insights aparecerão quando o software começar a ser desenvolvido;

- Custo e Tempo são os problemas: os autores alertam contra o design de código inicial, tal que quaisquer atividades que envolvam codificação, como a programação do protótipo, geram um desperdício dispendioso. Assim, o UFD deve se ater a atividades mais rápidas e baratas.

Após Ferreira, Noble e Biddle (2007b), existe uma dificuldade na codificação de publicações em UFD do UCASD devido a uma baixa uniformidade e consistência nos termos utilizados. Esta baixa uniformidade é vista no uso do construto, como alguns se referem ao UFD como sprints do processo de desenvolvimento (i.e. Ciclo 0, Iteração 0, Sprint 0, 
etc.) ou um estágio no projeto (Design de interação inicial (FERREIRA, 2008; HUSSAIN; SLANY; HOLZINGER, 2009b), Atividades de pré-descoberta (FISHER; BANKSTON, 2009), fase de exploração, etc.).

Outro problema na codificação do UFD do UCASD começa por definições pouco claras e sem ampla concordância na literatura sobre o escopo e o resultado de suas atividades (BRHEL et al., 2015). Algumas sugestões para descrevê-lo são vistas em Silva et al. (2011), Mostafa (2013) sugerindo o UFD como uma coleção de atividades dispersas, que envolvem criar uma visão de produto (SALAH; PAIGE; CAIRNS, 2014a), entrevistar usuários (ARDITO et al., 2014; DOBRIGKEIT; PAULA et al., 2017; MANWARING; CARTER; MAYNARD, 2017), gerar novas ideias (ASUNCION et al., 2011; DEUFF; COSQUER; FOUCAULT, 2010), etc., mas com poucos esclarecimentos sobre quais atividades devem ser realizadas e nenhuma define claramente onde e como começa ou como se conecta ao início do desenvolvimento.

Além disso, há uma discussão em andamento quanto à extensão do UFD, pois alguns defendem um BDUF, longo processo de atividades de UCD (KEENAN; BUSTARD, 2005), enquanto a maioria defende o LDUF (SILVA et al., 2011; BRHEL et al., 2015; ADIKARI; MCDONALD; CAMPBELL, 2009; BEYER; HOLTZBLATT; BAKER, 2004), um processo curto antes do início do desenvolvimento. De acordo com Silva et al. (2011), apesar de vários trabalhos recomendarem LDUF sobre BDUF por ter mais sinergia com a mentalidade ágil de não desperdiçar muito esforço em UFD, eles não comentam quais técnicas ou artefatos deveriam ser usados em um comparado ao outro, nem mesmo o que poderia ser chamado de pequeno ou grande foi definido.

Portanto, como não há uma definição clara proposta na literatura para LDUF e BDUF, e poucos são os artigos que se posicionam em um ou outro, os seguintes tópicos (técnicas, duração, configuração da equipe) extraídos da literatura são codificados sob UFD em geral, com uma análise em cada um dos assuntos sobre a dualidade LDUF vs. BDUF.

\subsubsection{Uma visão holística de UCASD e UFD}

Para facilitar uma melhor compreensão das questões de pesquisa, sobre o que é o UFD do UCASD, como ele se encaixa dentro do ciclo de vida do produto e a diferenciação do LDUF e do BDUF, foram revisados os modelos e definições mais relevantes no tema, juntamente com temas de pesquisa adjacentes para posicionar onde o UFD se encaixa dentro do ciclo de vida do software. 
Um dos modelos de processo de integração mais citados (ver Figura 16), elaborado por Miller (2005) e melhorado por Sy (2007), sugeriu que a integração de UCD em ASD poderia ser feita em dois momentos, um "Ciclo 0" precedendo o desenvolvimento e trabalhar o design em paralelo com o desenvolvimento de software.

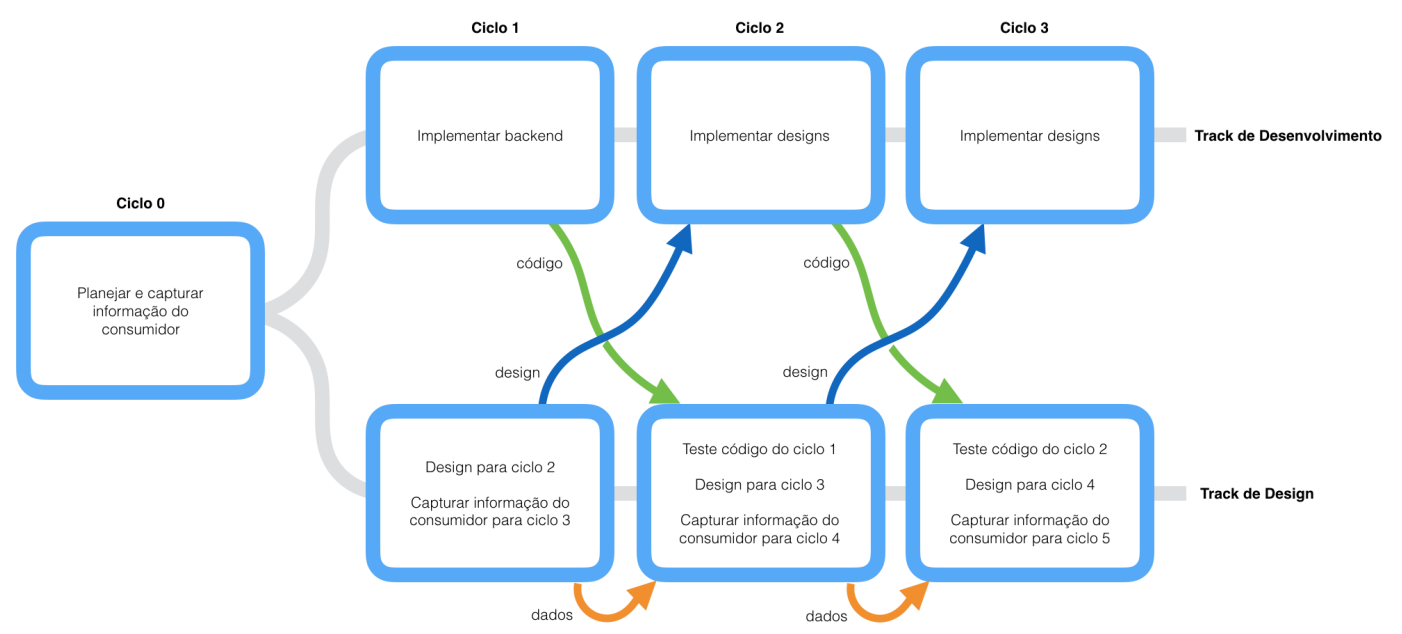

Figura 16: Processo de Integração entre UCD e ASD. Fonte: Adaptado de Miller (2005)

O problema com esse modelo é que o Ciclo 0 é visto como parte do processo de desenvolvimento. Essa mentalidade levou a um grande problema no UCASD, no qual as equipes acabaram não tendo tempo suficiente para executar as atividades do UFD (SALAH; PAIGE; CAIRNS, 2014b; ISOMURSU et al., 2012). À luz desse desafio, alguns anos depois, Brhel et al. (2015) proposto como o primeiro princípio de integração de UCD e ASD: (1) UCASD deve basear-se em descobertas separadas de produtos (alta referência em UFD) e fases de criação de produtos (ver Figura 17).

Embora Brhel et al. (2015) sugerem a separação do UFD da fase de descoberta e criação do produto, ele ainda reconhece que ainda há um grande mal-entendido nos conceitos de LDUF e BDUF e seus contrastes. Com isso em mente, Caballero, Moreno e Seffah (2016) propôs diferenciar os diferentes estágios em que UCD e ASD estão integrados, propondo que existe uma diferença entre LDUF e BDUF em diferentes estágios no UCASD, posicionando o segundo fora do projeto de software ágil - ainda não especificando a diferença entre os dois conceitos. Eles também dividem o trabalho de projeto em andamento com desenvolvimento em dois, um como design de interação implícita como técnicas de UCD usadas dentro de um sprint de desenvolvimento e uma trabalho paralelo, um sprint separado onde os designers trabalham antecipadamente para fornecer insumos para os desenvolvedores em sprints futuros (ver Figura 18).

No entanto, o que ainda falta nas proposições acima é uma visão holística da criação 

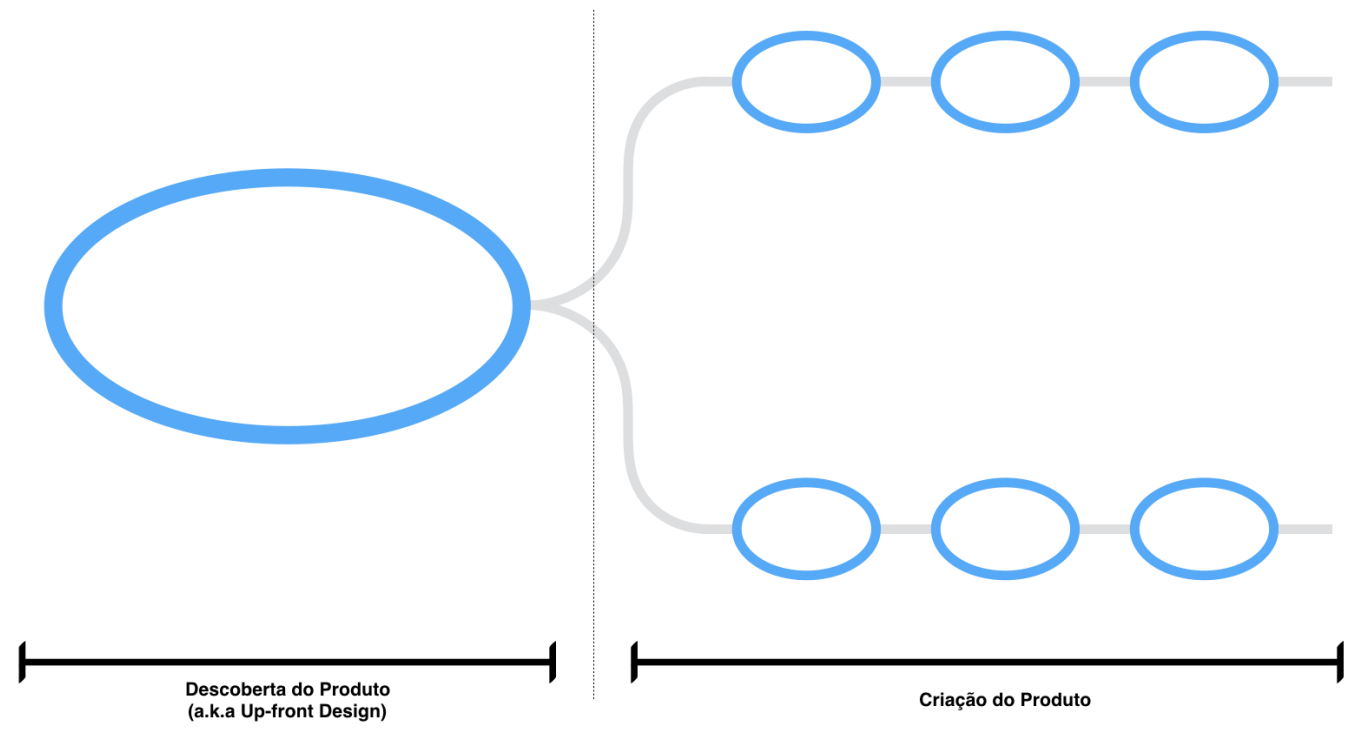

Figura 17: Primeiro princípio do UCASD: Separação da descoberta e criação do produto. Fonte: Adaptado de Brhel et al. (2015)
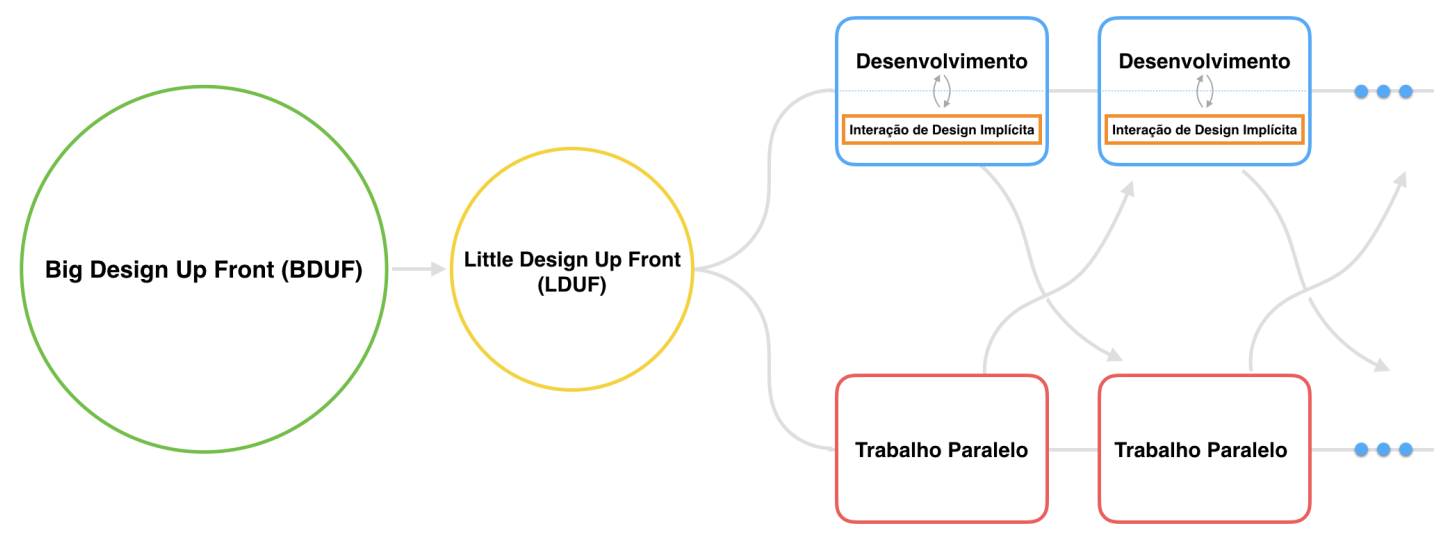

Figura 18: Representação visual dos diferentes estágios do UCASD. Fonte: Adaptado de Caballero, Moreno e Seffah (2016)

do produto, como a área de UCASD ainda é altamente influenciada pela mentalidade orientada para a projetos, como apresentado na Figura 14. Até então, nenhum dos modelos apresentados mostram como é que tantos projetos são descontinuados, o que ocorre depois que o projeto conclui, onde cada etapa do processo termina, etc.

Para ganhar essa perspectiva, o estudo traz a atenção ao modelo Stage-Gate de Cooper (2014), que também é uma estrutura para projetar e desenvolver produtos com uma abordagem orientada ao usuário (ver Figura 19).

Com o modelo de Cooper (2014), torna-se visível que esta separação proposta por Brhel et al. (2015) é, na verdade, um gate de decisão para avaliar se o produto deve 


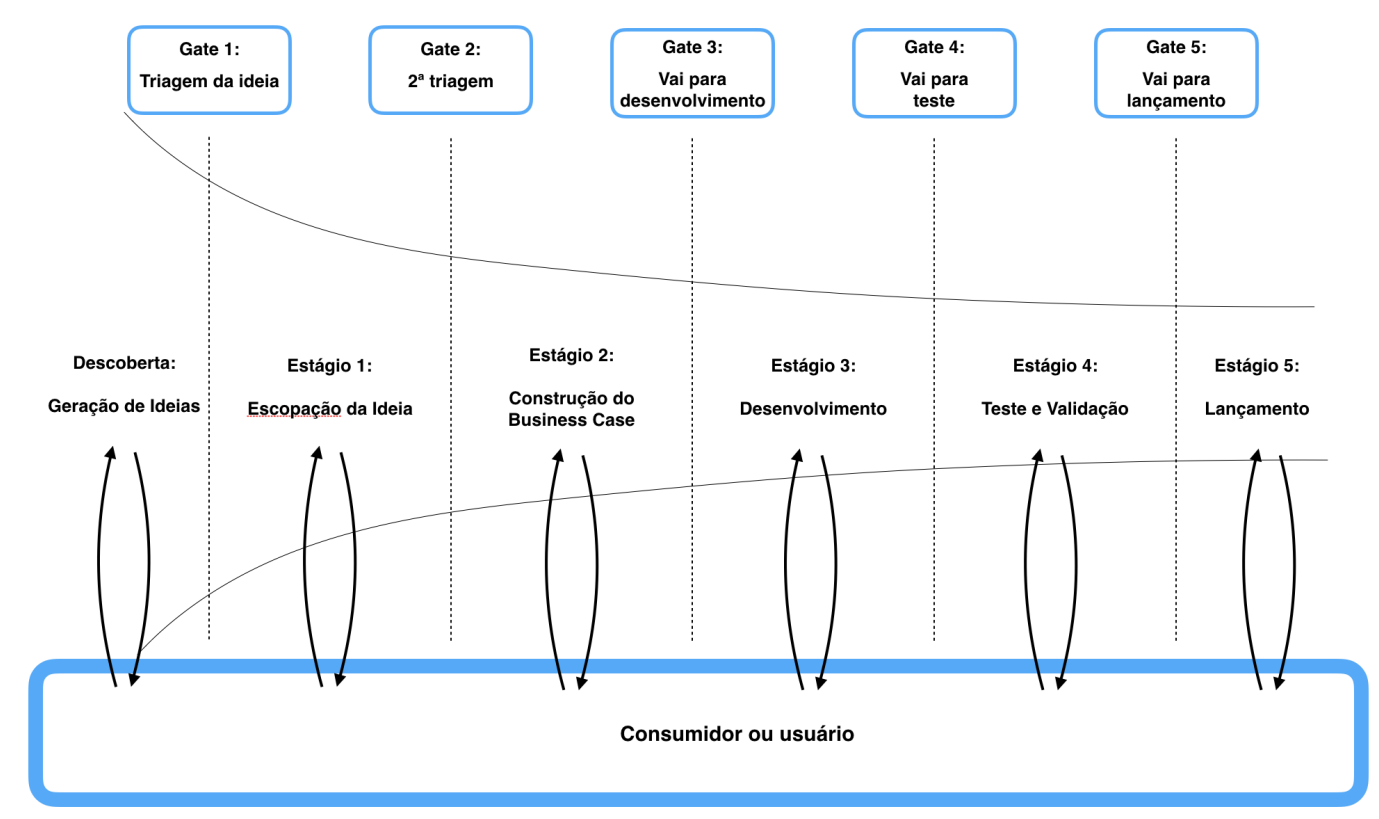

Figura 19: Modelo de Stage-Gate. Fonte: Adaptado de Cooper (2014)

continuar ou não para a fase de desenvolvimento (exigindo maiores esforços e investimento).Honious e Clark (2006) é o único artigo que aborda claramente o uso de stagegates em UCASD, com rodadas de venda de projetos e financiamento de CEOs. Traçando paralelos com os modelos de stage-gate Cooper (2014) e de Caballero, Moreno e Seffah (2016), torna-se claro que:

- O BDUF está intimamente relacionado com as fases de geração de ideias e escopo;

- O LDUF está intimamente relacionado ao estágio Construção do Business-Case;

- Embora existam semelhanças em suas atividades, BDUF e LDUF devem ser vistos como processos diferentes em diferentes estágios do ciclo de vida do UCASD, já que existe um gate de triagem entre eles;

Tendo em vista os modelos e premissas mencionados anteriormente, foi proposto na Figura 20 um fluxo de trabalho sobre como o UFD se ajusta dentro do ciclo de vida do produto.

Considerando o ciclo de vida do UCASD, foi apresentado uma proposição mais detalhada sobre os três principais conceitos deste estudo (BDUF, LDUF e UFD) e os gates que permeiam o processo:

- BDUF: Processo de duração extensiva focado na busca de oportunidades de negócios fora da organização e intimamente relacionado a métodos empáticos para entender 


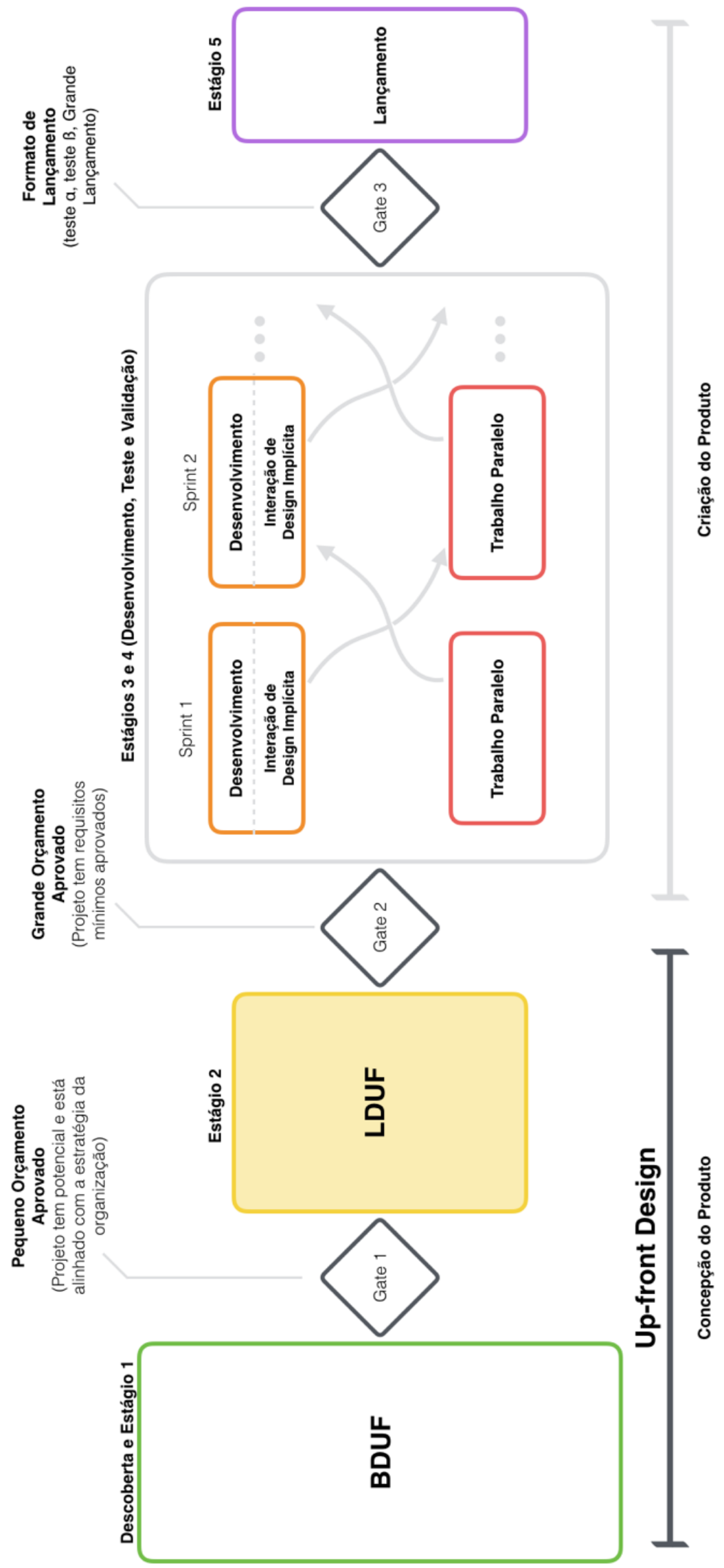

Figura 20: Visão geral do UCASD. Fonte: O autor. 
usuários (COOPER, 2001), gerar ideias e validar soluções de alto nível para um mercado. Esses estágios tendem a ser isolados do projeto de software, pois os resultados estão mais sujeitos a serem descontinuados. As principais metodologias utilizadas nesta fase são o Design de Interação e o Design Thinking e podem gerar múltiplas oportunidades para a empresa. Esses processos tendem a ter um escopo mais amplo, para investigar vários problemas e soluções, de modo que a maior fonte de dados provenha de problemas ainda a serem descobertos com usuários finais. É comum terceirizar as tarefas na $B D U F$ para as agências de design ou pesquisa, de modo que a equipe que entende os usuários e o mercado não seja necessariamente a mesma que participa do desenvolvimento de software (LIIKKANEN et al., 2014). Essa fase geralmente termina com uma validação das partes interessadas para decidir se vale a pena perseguir o projeto, o que significa que mais recursos devem ser alocados a ele;

- LDUF: Um processo de ritmo acelerado e alta demanda de recursos focado em melhorar a idéia para uma solução mais concreta, trazendo maior consistência e coerência ao produto a ser desenvolvido (CABALLERO; MORENO; SEFFAH, 2016; SILVA et al., 2011). Esses processos tendem a ser mais associados ao projeto de software, com menor possibilidade de serem descontinuados no pré-projeto e, portanto, há uma preocupação maior com a geração de requisitos de sistema consistentes. Esse estágio pode ser iniciado pela continuação de uma proposta do BDUF ou por uma demanda mais específica identificada internamente na organização. O LDUF é frequentemente executado pelo menos em parte pela equipe que acabará por trabalhar no projeto e termina com uma aprovação do diretório para iniciar o desenvolvimento e uma integração nos requisitos de projeto dos membros da equipe ágil que não participaram desse estágio inicial;

- UFD: Compreende todas as atividades relacionadas ao UCD realizadas antes do início do desenvolvimento ágil (MOSTAFA, 2013). Um escopo completo implicaria em fazer processos os de BDUF e LDUF, mas pode variar dependendo do projeto, pois algumas empresas podem decidir executar apenas um ou outro. Contempla atividades exploratórias para entender os usuários, a competição no mercado e gerar ideias para criar produtos que os usuários precisam e finalizam com atividades confirmatórias com design de solução, validação de protótipo e requisitos do projeto, para fornecer uma visão coerente e holística do projeto para a equipe ágil (CABALLERO; MORENO; SEFFAH, 2016; BRHEL et al., 2015; CARVALHO; SILVA; SILVEIRA, 2016; SILVA; SILVEIRA; MAURER, 2013; BEYER; HOLTZBLATT; 
BAKER, 2004; ISA et al., 2014; RAGNARSDOTTIR, 2010; TEKA; DITTRICH; KIFLE, 2017; SILVA et al., 2013; SALAH; PAIGE; CAIRNS, 2014a; MANWARING; CARTER; MAYNARD, 2017; CIVJAN J., 2010; ROJAS; MACÍAS, 2015; GLOMANN, 2018).

- O gate 1 entre BDUF e LDUF valida se a ideia gerada no processo longo vale a pena ser levada adiante, pois está alinhada com a estratégia da empresa e tem um mercado que pode ser potencialmente desenvolvido.

- O gate 2 é o último ponto no qual um projeto pode ser matado antes de entrar em uma etapa de investimento mais alto. Uma vez passado este gate, compromissos financeiros são substanciais. Geralmente precisa ter requisitos mínimos (técnicos e de negócio) aprovados por um comitê com equipes de desenvolvimento, marketing e operações (COOPER; CORDOVA, 2014).

- O gate 3 é o último ponto antes da comercialização total ao mercado. Este gate se concentra na qualidade das atividades de testes pilotos e validação de seus resultados. Critérios para passar o portão se concentram grande parte no retorno financeiro esperado e adequação do lançamento aos planos de operações e marketing (COOPER; CORDOVA, 2014).

Embora o restante deste trabalho proponha separações entre o escopo das atividades do BDUF e do LDUF, o estudo enfoca o segundo porque:

- Embora as atividades do BDUF precedam o processo de desenvolvimento de software, muitos autores o consideram fora do escopo do UCASD, pois é contra princípios ágeis (BROWN; LINDGAARD; BIDDLE, 2011; BEYER; HOLTZBLATT; BAKER, 2004);

- O LDUF tem um escopo mais restrito e definido, pois muitas vezes começa com um escopo definido na oportunidade para a qual ele pretende produzir uma solução, enquanto o BDUF tem um escopo aberto e pode variar consideravelmente, sendo mais difícil de sistematizar;

- Poucos artigos defendem e apresentam o BDUF no contexto do desenvolvimento ágil e, portanto, seria difícil tirar conclusões definitivas com base em um pequeno número de publicações. 
Nas próximas seções, este artigo sistematiza as informações de UFD com foco no LDUF, definindo uma configuração de time e limite de tempo ideal para este processo e analisa como os fatores contingenciais o afetam.

\subsection{Técnicas de UFD}

Existem muitas possíveis técnicas de design e engenharia para usar durante o UFD. Como existem variações de técnicas similares, como a Consulta Contextual e Entrevista com Usuário ou Revisões e Teste do Usuário e Teste de Usabilidade, etc. E geralmente os autores não descrevem profundamente as técnicas que usaram ou analisaram em seu processo UFD, decidiu-se fazer uma categorização mais precisa das técnicas de campo. Para tanto, primeiro todas as possíveis técnicas foram extraídas da literatura, e definiu-se uma breve descrição a cada uma, em seguida agrupou-se aquelas que tinham definições muito semelhantes.

Para entender quais técnicas são mais utilizadas no UFD, a Figura 21 consolida todas as técnicas citadas pela quantidade de vezes em que aparece em diferentes publicações.

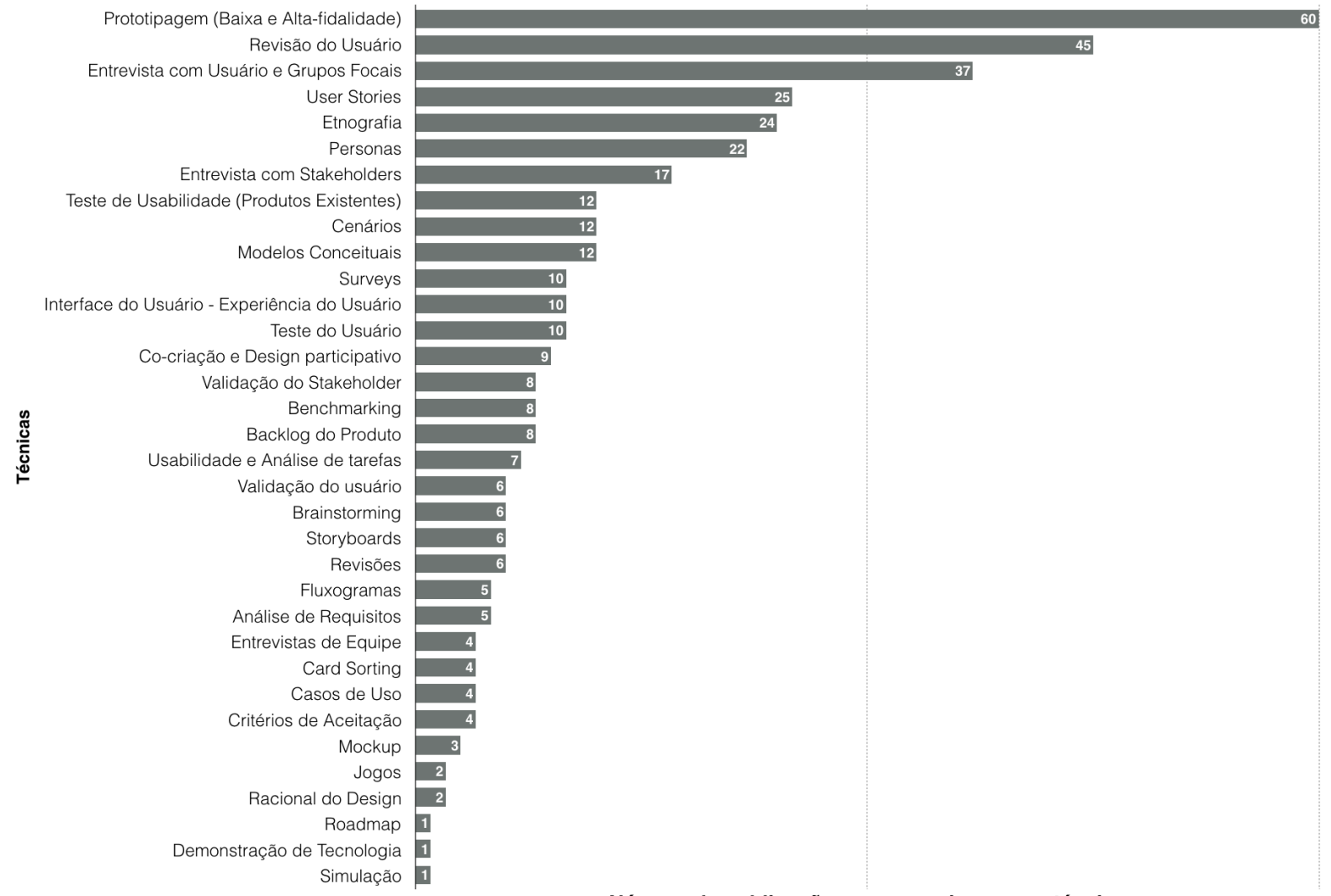

Número de publicações que mencionaram a técnica

Figura 21: Número de publicações que mencionaram o uso de uma técnica em UFD. Fonte: $\mathrm{O}$ autor. 
É importante notar que essa consolidação é diferente da proposta em Brhel et al. (2015), já que este artigo contempla técnicas utilizadas em todo o ciclo de vida do UCASD, enquanto este artigo considera apenas técnicas usadas no UFD. Por essa razão, técnicas como o teste de protótipos desenvolvidos não estão presentes, e algumas técnicas mencionadas em Brhel et al. (2015) classificados como Pesquisa do Usuário foram divididos em várias técnicas menores.

A seguir, analisou-se ainda como o uso dessas técnicas difere ao executar um BDUF ou um LDUF e organizá-los em diferentes fases sequenciais.

\subsubsection{Técnicas de LDUF}

Os melhores esforços na literatura para sintetizar as técnicas usadas na integração de UCD e ASD são vistos nas RSLs de Silva et al. (2011), Caballero, Moreno e Seffah (2016), Brhel et al. (2015). O primeiro fez uma primeira tentativa de codificar os principais termos da área, mas acabou misturando técnicas (ex: Protótipos de Low-fi, Peronas) com processos e práticas (ex: LDUF, One sprint ahead). O segundo traz uma visão interessante sobre quais técnicas são mais usadas, com cada metodologia ágil, como protótipos sendo mais ou menos iguais em Scrum e XP, enquanto histórias de usuários, personas, cenários e testes de usabilidade, por exemplo, são usados em combinação com o XP. No entanto, tem uma visão simplista das atividades da UCD, já que codifica apenas 11 técnicas diferentes, em oposição a 36 técnicas agrupadas neste artigo (CABALLERO; MORENO; SEFFAH, 2016). Embora Brhel et al. (2015) façam o melhor esforço para categorizar técnicas dentro das quatro fases da norma ISO: pesquisa, especificação, projeto e avaliação (DIS, 2009), ainda é intangível para profissionais da área como as técnicas são colocadas em prática, sem orientação clara sobre como as atividades podem ser solicitadas, planejadas, executadas e como elas são separadas entre os estágios do UCASD.

Assim, explorou-se mais profundamente o processo de LDUF e definiu-se uma estrutura que:

- Estende as fases vistas na (DIS, 2009) a passos mais concretos / acionáveis: incluindo o esclarecimento de onde o processo começa e como ele se conecta ao início da fase de desenvolvimento;

- Inclui atividades somente do LDUF: atividades de UCD relacionadas a outros estágios do UCASD, como BDUF - estudos de etnografia ou protótipo codificado do "Trabalho paralelo", são excluídos; 
- Apresenta um fluxo de trabalho: as fases de significado e, consequentemente, as atividades são sequencialmente organizadas no tempo.

Como um todo, a estrutura do LDUF gera requisitos de solução a partir de necessidades identificadas, obtidas externamente da fase de BDUF ou internamente a partir das percepções de stakeholders (BERTHOLDO et al., 2014; LUCENA et al., 2016). Para garantir que o projeto seja implementado como esperado, ele começa com uma fase de planejamento para entender as necessidades do projeto, orçamento, prazos, equipe envolvida, etc.

O processo em si inicia com a integração da equipe que participará do processo e um alinhamento inicial com os principais stakeholders do projeto, como o cliente e os gerentes de alto nível (BROWN; LINDGAARD; BIDDLE, 2011). Nesse alinhamento, a equipe do projeto pode explorar as motivações do projeto, descobrir quaisquer descobertas anteriores nos processos da $B D U F$, entender as expectativas do projeto e até obter uma visão de alto nível do mercado para a qual a solução é destinada e possíveis concorrentes (ASUNCION et al., 2011; ISA et al., 2014; BUDWIG; JEONG; KELKAR, 2009; TAWFIK; BELDEN; MOORE, 2013; GONZALEZ; TOLEDO; MUOZ, 2015; MAY, 2012; LUCENA et al., 2016; DÜCHTING; ZIMMERMANN; NEBE, 2007; TEIXEIRA et al., 2016). Nesta fase, também é importante definir claramente os papéis dos membros da equipe e as atividades gerais do processo LDUF (BRHEL et al., 2015; CHAMBERLAIN; SHARP; MAIDEN, 2006; MILLER, 2005; NAJAFI; TOYOSHIBA, 2008; SINGH, 2008; SALAH; PAIGE; CAIRNS, 2014a).

Para garantir que o produto a ser criado / aprimorado esteja alinhado com as necessidades do mercado, a equipe conduz as atividades de pesquisa do usuário. Diferentemente de $B D U F$ que usa pesquisa exploratória para encontrar problemas desconhecidos e desvendar novas oportunidades possivelmente com longas interações de usuários (estudos de etnografia), as atividades de $L D U F$ devem ser aceleradas, portanto a pesquisa do usuário nesta fase se concentra em validar suposições de equipe com interações de usuário mais rápidas (entrevistas, surveys) (BRHEL et al., 2015; MILLER, 2005; DOBRIGKEIT; PAULA et al., 2017; ISA et al., 2014; UNGAR; WHITE, 2008; CIVJAN J., 2010; HODGETTS, 2005; ROJAS; MACÍAS, 2015; BERTHOLDO et al., 2014; TEIXEIRA et al., 2016).

Depois de entender as necessidades dos usuários e antes de criar soluções, é proposto uma etapa intermediária: consolidação do conhecimento, onde a equipe consolida descobertas de campo, em insights acionáveis, como definição de processo de definição do 
usuário (Personas) (CABALLERO; MORENO; SEFFAH, 2016; PLONKA et al., 2014; ROJAS; MACÍAS, 2015) (cenários, casos de uso e storyboard) (FERREIRA; NOBLE; BIDDLE, 2007a; BEYER; HOLTZBLATT; BAKER, 2004; BERTHOLDO et al., 2014) e geração de idéias (brainstorms, priorização por cards) (TEKA; DITTRICH; KIFLE, 2017; DEUFF; COSQUER; FOUCAULT, 2010). Em seguida, a equipe projeta uma solução que atenda às necessidades do usuário, primeiro abordando seus requisitos (ex: histórias de usuário, fluxo de trabalho) (HIGHSMITH; COCKBURN, 2001; ANWAR et al., 2014; MAGüES; CASTRO; ACUñA, 2016) e, em seguida, criando um protótipo, para que possa ser validado pelos usuários finais (SALAH; PAIGE; CAIRNS, 2014c; JIA; LARUSDOTTIR; CAJANDER, 2012; SILVA; SILVEIRA; MAURER, 2013; DOBRIGKEIT; PAULA et al., 2017; LÁRUSDÓTTIR; CAJANDER; GULLIKSEN, 2012; NOSSEIR et al., 2012; SILVA et al., 2013; SALAH; PAIGE; CAIRNS, 2014a; MANWARING; CARTER; MAYNARD, 2017; TAWFIK; BELDEN; MOORE, 2013; BERTHOLDO et al., 2014; NAVARRO; PEREZ; SEVILLA, 2016). Há evidências de que o LDUF tende a criar protótipos de maior fidelidade do que o BDUF, já que também precisa avaliar a usabilidade do produto e fornecer requisitos claros para a equipe de desenvolvimento, enquanto o BDUF está mais preocupada na validação de conceitos (WALE-KOLADE, 2015; CARVALHO; SILVA; SILVEIRA, 2016; SILVA; SILVEIRA; MAURER, 2013; ROJAS; MACÍAS, 2015; BERTHOLDO et al., 2014).

As atividades finais, definidas aqui como definição de requisitos, incorporam atividades tradicionais de desenvolvimento de software, de modo que, depois que a equipe aprende insights validando suas suposições de protótipo, os recursos produzidos durante LDUF (personas, cenários, protótipos, etc.) são revisados para incorporar a perspectiva do usuário, definindo especificações técnicas e visão do produto em documentos que são compreensíveis para os stakeholders decidirem entrar em estágio de desenvolvimento e requisitos claros que a equipe ágil pode usar para iniciar o desenvolvimento (SILVA et al., 2011; FERREIRA; NOBLE; BIDDLE, 2007b; CHAMBERLAIN; SHARP; MAIDEN, 2006; ASUNCION et al., 2011; SALAH; PAIGE; CAIRNS, 2014b; BELCHEV; BAKER, 2009; SILVA; SILVEIRA; MAURER, 2013; DOBRIGKEIT; PAULA et al., 2017; HUMAYOUN; DUBINSKY; CATARCI, 2011; FOX; SILLITO; MAURER, 2008; NAJAFI; TOYOSHIBA, 2008; SINGH, 2008; RUTHFORD, 2002; PRIOR et al., 2013; MEMMEL; GUNDELSWEILER; REITERER, 2007; ANWAR et al., 2014; TAWFIK; BELDEN; MOORE, 2013; PLONKA et al., 2014; UNGAR; WHITE, 2008). A Figura 22 resume as fases e técnicas do LDUF. 


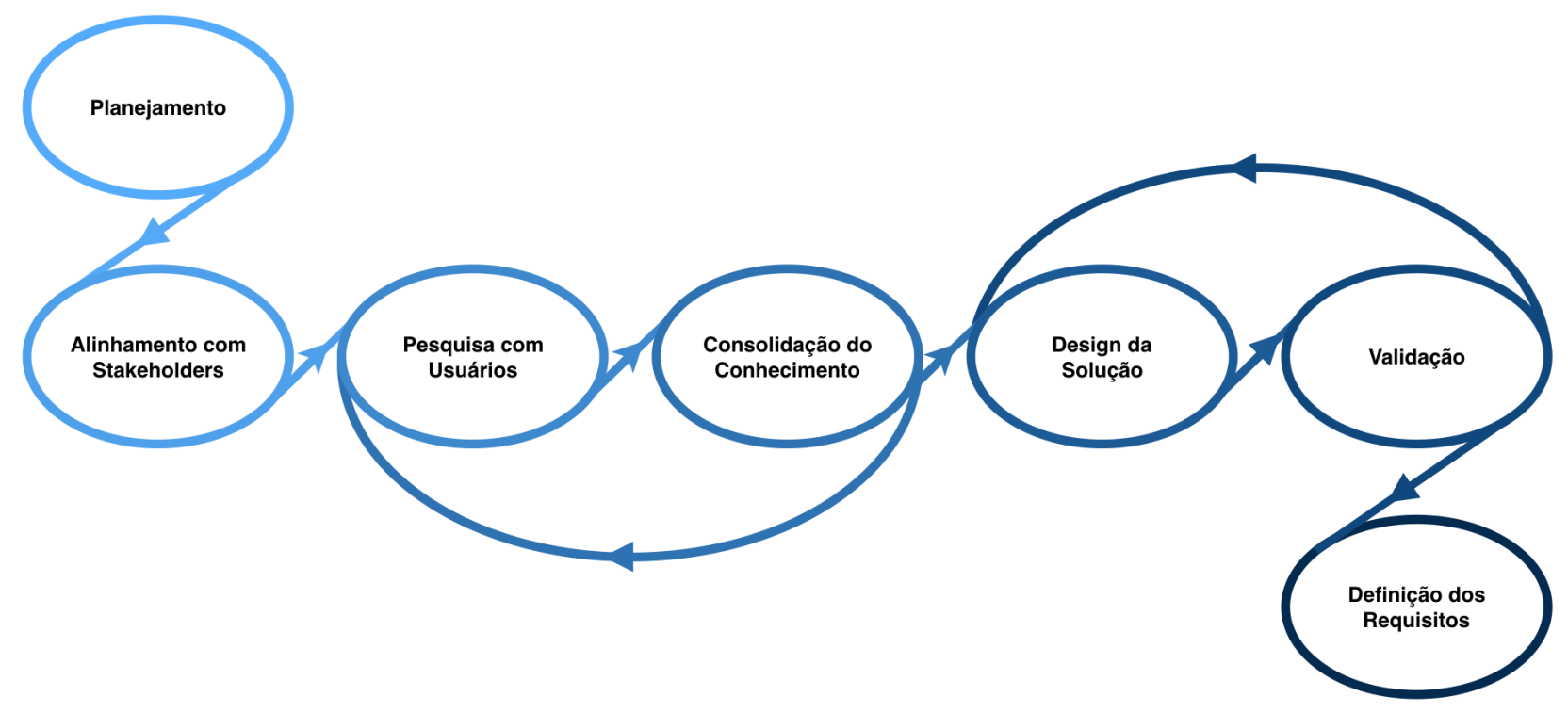

Figura 22: Fases do LDUF. Fonte: O autor.

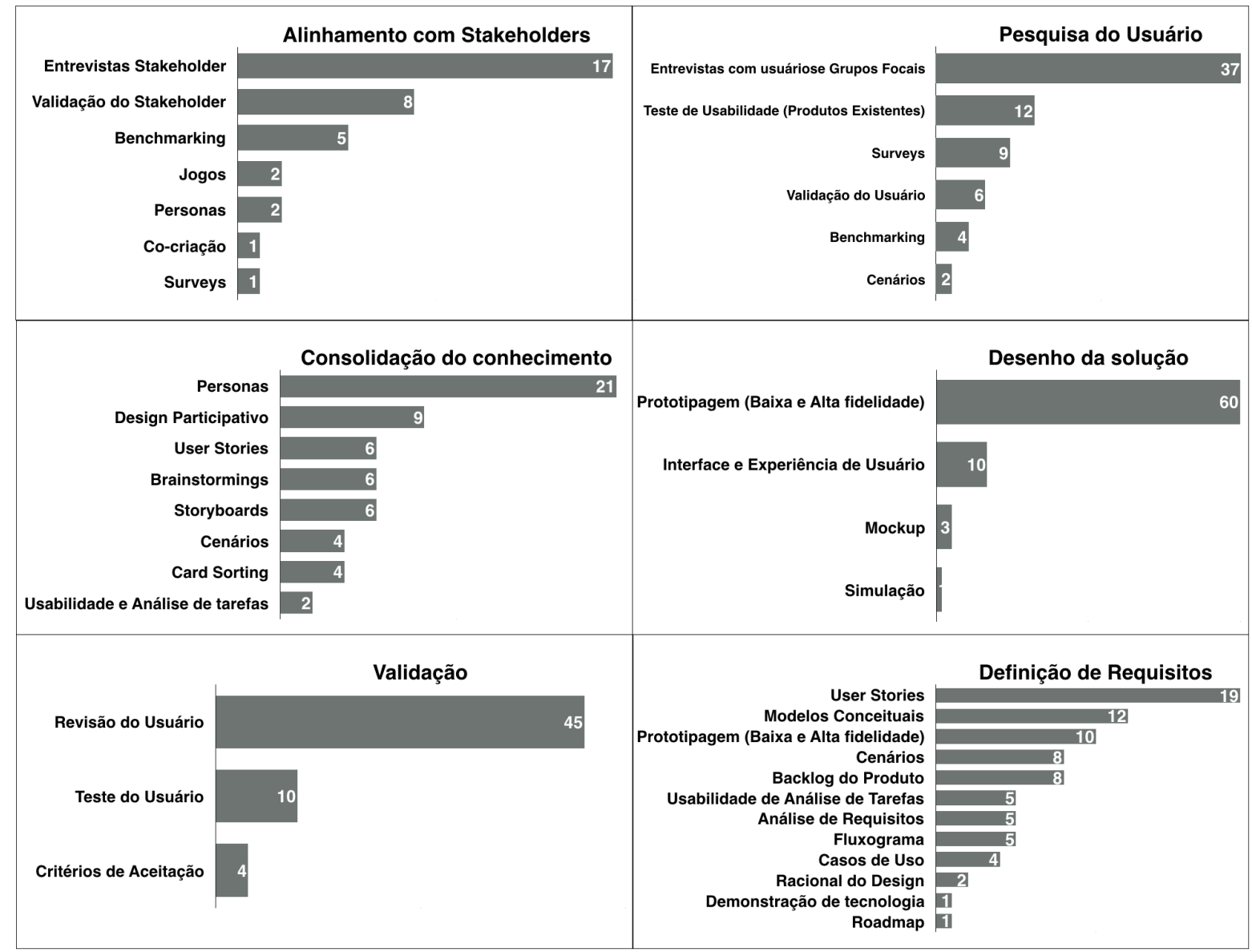

Figura 23: Técnicas do LDUF. Fonte: O autor.

\subsection{Tempo de execução}

Apesar da importância de entender o agendamento das atividades de UFD em projetos ágeis (SALAH; PAIGE; CAIRNS, 2014b; FOX; SILLITO; MAURER, 2008; SALAH; 
PAIGE; CAIRNS, 2014a), apenas 19 de 95 publicações analisadas relataram o tempo que levou para conduzir essas atividades. Além disso, esse período de tempo varia entre alguns dias (menos de uma semana) a mais de um mês, evidenciando que não existe um consenso entre profissionais e pesquisadores.

Além disso, muitas obras definem o tempo de UFD com base em sprints, sem definir o comprimento de cada sprint (que no limite pode levar de uma a quatro semanas) (CARVALHO; GRILLO; TESSARI, 2015; BUDWIG; JEONG; KELKAR, 2009; PRIOR et al., 2013). Para compilar os achados na literatura, o presente trabalho considera um sprint médio de 2 semanas e, portanto, resume o tempo para executar as atividades da UFD na Figura 24.

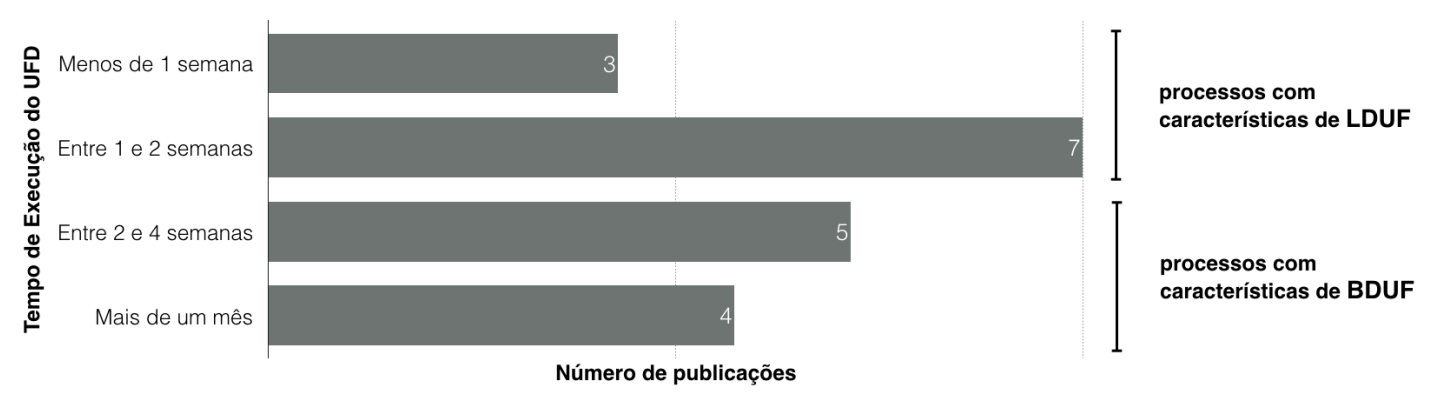

Figura 24: Tempo investido em atividades de UFD antes do início do desenvolvimento. Fonte: O autor.

Este trabalho usa como base processos mais usados na prática, que se encaixam nos critérios de LDUF estabelecidos neste documento, como o Design Studio (MANWARING; CARTER; MAYNARD, 2017; UNGAR; WHITE, 2008; BERTHOLDO et al., 2014) e o Design Sprint (LUCENA et al., 2016; KNAPP; ZERATSKY; KOWITZ, 2016; TEIXEIRA, 2017) para definir um tempo limite para a execução das atividades de LDUF. O IBM Design Thinking Process (LUCENA et al., 2016) e o Lean UX, por exemplo, não são considerados, pois ultrapassam o escopo do LDUF (CARVALHO; GRILLO; TESSARI, 2015; MAY, 2012), pois também trabalham em paralelo com o desenvolvimento.

O processo do Design Studio, desde o planejamento até a execução, pode ser feito em exatamente 13 dias úteis (UNGAR; WHITE, 2008). O Design Sprint (LUCENA et al., 2016) é um processo do Google que pode ser executado em 5 dias, e mais alguns dias devem ser usados com antecedência para seu planejamento. Considerando os resultados da Figura 24 , é possível visualizar que processos feitos em menos de 2 semanas estão geralmente dentro do escopo das atividades de LDUF (FERREIRA; SHARP; ROBINSON, 2012; BEYER; HOLTZBLATT; BAKER, 2004; FOX; SILLITO; MAURER, 2008). Estudos com mais de duas semanas, no entanto, tendem a realizar atividades que vão além do 
escopo do LDUF, como em Ferreira, Sharp e Robinson (2012) no qual o estudo apresenta estudos etnográficos (mais orientados para o BDUF) nos quais apenas a fase de pesquisa do usuário pode levar várias semanas e, segundo Humayoun, Dubinsky e Catarci (2011) o UFD pode ser executado entre 2 a 4 semanas, porém com um protótipo desenvolvido, o que por sua vez é contra os princípios ágeis vistos em Ferreira (2008). Desta forma, é recomendado que as atividades do LDUF, tanto planejamento quanto execução, se enquadrem dentro de um período de tempo de até 2 semanas.

\subsection{Configuração da equipe}

A configuração de uma equipe ideal para conduzir o projeto inicial antes do início do desenvolvimento é um tópico de discussão constante. Para trazer um melhor entendimento sobre a configuração da equipe proposta por Fox, Sillito e Maurer (2008), Caballero, Moreno e Seffah (2016), este estudo utilizou as definições apresentadas em Fox, Sillito e Maurer (2008), Sohaib e Khan (2010), Jurca, Hellmann e Maurer (2014) que classificam o trabalho como:

- Abordagem especializada: significa que a equipe usou um profissional de UCD para conduzir o trabalho;

- Abordagem generalista: significa que a equipe usou alguém que não é formalmente treinado em UCD, geralmente da própria equipe ágil (PO, desenvolvedor, Scrum master) para executar atividades de UCD;

- Abordagem generalista / especialista (híbrida): significa que um dos membros do grupo foi formalmente treinado em UCD e tem uma vasta experiência em desenvolvimento de software.

Com essa classificação em mente, este estudo resume as descobertas da equipe na Figura 25. É importante notar que nem todos os trabalhos analisados nessa RSL descreveram formalmente a equipe envolvida, e alguns estudaram vários projetos com diferentes abordagens, de tal maneira que um único artigo pode ser classificado em mais de uma abordagem. Um exemplo é o estudo de Salah, Paige e Cairns (2014a) onde 12 projetos foram avaliados, e em 4 deles a abordagem de condução de atividades com um especialista em UX é usada e outros 8 projetos foram feitos com uma equipe generalista.

De acordo com Beyer, Holtzblatt e Baker (2004) é recomendado ter a participação de um especialista para realizar as atividades do LDUF com maior qualidade, pois o uso 


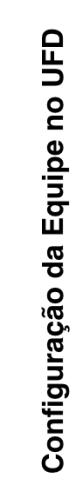

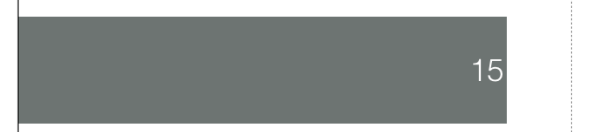

Número de publicações

Figura 25: Configuração da equipe durante as atividades iniciais de projeto. Fonte: O autor

de desenvolvedores nesta fase implica inevitavelmente uma diminuição na eficiência da equipe.

Projetos que podem seguir uma abordagem híbrida são ideais porque podem unir o melhor dos dois mundos. De um lado, eles fornecem alta qualidade na condução de atividades do LDUF, mas também considerando a viabilidade técnica, e tendem a ter uma equipe de desenvolvimento bem informada, aumentando a motivação da equipe do projeto, bem como promovendo conhecimento tácito com a equipe, evitando a necessidade de extensa documentação (BROWN; LINDGAARD; BIDDLE, 2011; HONIOUS; CLARK, 2006). A desvantagem dessa abordagem é a rara disponibilidade de recursos com tais características ou, eventualmente, o custo extra de ter todos os funcionários participando de todas as etapas, de modo que a opção de acompanhar as atividades iniciais com um especialista é mais usada financeiramente.

A alternativa de conduzir o LDUF com pessoas da equipe ágil (PO ou Dev) sem treinamento formal na condução dessas atividades acaba sendo uma alternativa para empresas que não possuem um profissional dedicado para realizar essas atividades. No entanto, ele ainda é válido, pois vários estudos apontam para bons resultados, mesmo seguindo essa configuração de equipe (TEKA; DITTRICH; KIFLE, 2017; FERREIRA, 2008; KUUSINEN; MIKKONEN, 2013), mostrando que mesmo as empresas que não dispõe de recursos de UX ainda devem conduzir o LDUF. No entanto, uma alternativa é realizar as atividades com a equipe ágil, mas com a disponibilidade esporádica de um profissional de UX para solucionar dúvidas da equipe ou auxiliá-la em atividades específicas, melhorando o resultado final do processo (HUMAYOUN; DUBINSKY; CATARCI, 2011).

Além disso, há evidências de que algumas empresas que não possuem recursos de UX terceirizam esse estágio do projeto com empresas terceirizadas, como agências de design. 
Existe uma preocupação em seguir este caminho, pois existe um maior risco deste órgão externo produzir soluções sem considerar a viabilidade técnica dos projetos. Uma solução proposta para estes casos é o de alocar um desenvolvedor de projeto com os projetistas da agência, na função de analista de negócios, durante todo o processo para garantir que a viabilidade técnica seja respeitada na criação da nova solução (SILVA; SILVEIRA; MAURER, 2013; KUUSINEN; MIKKONEN; PAKARINEN, 2012; BUDWIG; JEONG; KELKAR, 2009).

Outra discussão presente nos artigos é a dedicação profissional da UCD para o projeto como membro em período integral ou meio-período. Problemas com o uso de recursos de meio período para o projeto foram encontrados em várias publicações (SALAH; PAIGE; CAIRNS, 2014b, 2014a; BERTHOLDO et al., 2014). Bertholdo et al. (2014) fez uma análise interessante neste ponto, argumentando que, idealmente, o especialista em UX deveria trabalhar em tempo integral no projeto. Caso contrário, ele começa a perder informações importantes durante as interações com os desenvolvedores e a falta de tempo para realizar as atividades de design do LDUF conforme planejado. A solução proposta pelo autor aponta para a participação do designer em tempo integral na equipe de desenvolvimento, inclusive usando o conceito de design de pares (semelhante à programação em pares), no entanto, entre um designer e um desenvolvedor. Em relação a essa questão, Nielsen (2009) descreve a prática chamada "Declínio do departamento centralizado de UX" como resultado de suas experiências. Ele diz que todos os seus estudos de caso indicam que o pessoal de UX deve estar localizado junto aos desenvolvedores e outros membros do projeto e não dentro de um departamento de UX centralizado compartilhado por projetos. Assim, a equipe de UX seria considerada parte da equipe do projeto.

Quando necessário discutir um tópico diferente sobre o trabalho em domínios específicos (por exemplo, medicina, educação) é recomendado o uso de um recurso especializado na área em todo o processo do LDUF (TAWFIK; BELDEN; MOORE, 2013; GONZÁLEZ et al., 2013). O ideal é que esse recurso participe em tempo integral de todo o processo LDUF, pois dessa forma ele pode contribuir para a criação de soluções "fora da caixa", mas quando isso não for possível, a participação em momentos específicos do processo, com suporte específico aos designers, influencia positivamente a criação de soluções com maior viabilidade técnica e satisfação do usuário.

Embora, em teoria, seria mais interessante também usar desenvolvedores em LDUF, para diminuir a necessidade de documentação de recursos LDUF e aumentar os problemas de viabilidade técnica (tanto mais críticos neste estágio que em BDUF) (BLOMKVIST, 2005), não há correlação na amostra que indique que o processo LDUF deve seguir uma 
abordagem em vez das outras, sugerir que a questão da disponibilidade de UCD de especialistas híbridos é um fator mais importante para definir a configuração da equipe para atividades de LDUF.

Resumindo, quando comparado com o estudo realizado por Silva et al. (2011), os achados apontam que, apesar de ter um especialista na equipe continua a ser a abordagem mais utilizada, há uma tendência crescente de usar as abordagens generalista ou generalista/especialista. Isso pode ser explicado pela disseminação de técnicas de design no mundo organizacional por agências de design como IDEO e Google (LUCENA et al., 2016) e um interesse em empresas de desenvolvimento tradicionais para integrar o LDUF em seus processos, mesmo sem ter praticantes de UCD disponíveis.

\subsection{Fatores contingenciais}

Todos os processos e técnicas mencionados acima são apenas recomendações para cenários idealmente criados, ou seja, onde o cliente entende o valor das atividades de UCD, há orçamento, tempo e recursos ilimitados suficientes para executar como prescrito na teoria.

Segundo Ferreira, Noble e Biddle (2007a), existem evidências que na realidade dificilmente isso acontece, pois desenvolvedores, designers, stakeholders tendem a desviar das práticas prescritas (CHAMBERLAIN; SHARP; MAIDEN, 2006; ISA et al., 2014). Esta seção, portanto, tem como objetivo descobrir quais são os fatores contingenciais mais relevantes que influenciam o processo e as pessoas envolvidas. Posteriormente é discutida a melhor forma de a equipe adaptar o processo de acordo com os fatores apresentados abaixo.

Por esta abordagem contingencial ser um campo inexplorado no tema de UCASD (FERREIRA; NOBLE; BIDDLE, 2007a), este trabalho usa referências de pesquisadores de ASD (LEMÉTAYER, 2010; VIJAYASARATHY; BUTLER, 2016).

Analogamente a Lemétayer (2010) este estudo propõe a categorização de fatores contingenciais em diferentes níveis para facilitar sua compreensão e aplicabilidade. Fatores contingenciais associados à organização são geralmente tratados por gerentes de alto nível em cargos de diretoria, fatores contingenciais associados ao projetos devem ser tratados pelo escritório de projetos ou gerentes de produto seniors e fatores contingenciais associados à equipe pelos Product Owners e às vezes os próprios membros da equipe. A estruturação, portanto, de qual nível cada fator contingencial se enquadra, está explicado 
na seguinte definição:

- Organização: fatores que estão intimamente relacionados ao ambiente da organização e aos padrões vinculados à esfera organizacional;

- Projeto: fatores específicos de um único projeto que não necessariamente são afetados por como a organização geralmente opera e tendem a variar entre projetos de uma mesma empresa;

- Equipe: fatores intimamente relacionados ao comportamento humano, interação, e capacidade da equipe.

Considerando a definição acima, este estudo resume os fatores contingenciais encontrados na literatura na Tabela 5 .

Tabela 5: Fatores contingenciais apontados na literatura

de UCASD

\begin{tabular}{|c|c|c|}
\hline Fatores Contingenciais & Definição & Referências \\
\hline \multicolumn{3}{|c|}{ Fatores contingenciais associados à organização } \\
\hline $\begin{array}{l}\text { Tamanho da companhia } \\
(\mathrm{n}=9)\end{array}$ & $\begin{array}{l}\text { Número de fun- } \\
\text { cionários que tra- } \\
\text { balham dentro da } \\
\text { organização }\end{array}$ & $\begin{array}{l}\text { (FERREIRA; NOBLE; BIDDLE, } \\
\text { 2007a; CHAMBERLAIN; SHARP; } \\
\text { MAIDEN, 2006; BROWN; LIND- } \\
\text { GAARD; BIDDLE, 2011; ISO- } \\
\text { MURSU et al., 2012; CARVALHO; } \\
\text { SILVA; SILVEIRA, 2016; SA- } \\
\text { LAH; PAIGE; CAIRNS, 2014a; } \\
\text { KUUSINEN, 2015; MEMMEL; } \\
\text { GUNDELSWEILER; } \\
\text { RER, 2007; TAWFIK; BELDEN; } \\
\text { MOORE, 2013; ANWAR et al., } \\
\text { 2014; HOKKANEN; VÄÄNÄNEN- } \\
\text { VAINIO-MATTILA, 2015; HONI- } \\
\text { OUS; CLARK, 2006) }\end{array}$ \\
\hline $\begin{array}{l}\text { Suporte da gestão às ativi- } \\
\text { dades de UCD }(\mathrm{n}=5)\end{array}$ & $\begin{array}{l}\text { Os gerentes de alto } \\
\text { escalão da empresa } \\
\text { entendem o valor e } \\
\text { promovem o uso de } \\
\text { atividades de UCD }\end{array}$ & $\begin{array}{l}\text { (SALAH; PAIGE; CAIRNS, 2014a; } \\
\text { TEKA; DITTRICH; KIFLE, 2017; } \\
\text { FERREIRA; NOBLE; BIDDLE; } \\
\text { 2007a; ARDITO et al., 2014; } \\
\text { DETWEILER; MANAGING, 2007) }\end{array}$ \\
\hline
\end{tabular}




\begin{tabular}{|c|c|c|}
\hline Fatores Contingenciais & Definição & Referências \\
\hline $\begin{array}{l}\text { Organizações orientadas a } \\
\text { projetos ou produtos }(\mathrm{n}= \\
\text { 3) }\end{array}$ & $\begin{array}{l}\text { Empresas } \\
\text { tadas a projetos } \\
\text { têm sucesso medido } \\
\text { entregando projetos } \\
\text { dentro do prazo } \\
\text { e do orçamento, } \\
\text { enquanto empresas } \\
\text { orientadas a pro- } \\
\text { dutos são menos } \\
\text { limitadas à fatores } \\
\text { clássicos e favore- } \\
\text { cem a qualidade do } \\
\text { produto e valor para } \\
\text { o cliente }\end{array}$ & $\begin{array}{l}\text { (BROWN; LINDGAARD; BID- } \\
\text { DLE, 2011; ISOMURSU et al., } \\
\text { 2012; CHOMA; ZAINA; SILVA, } \\
\text { 2015; FERREIRA, 2008; PLONKA } \\
\text { et al., 2014) }\end{array}$ \\
\hline $\begin{array}{l}\text { Maturidade do UCD ( } \mathrm{n}= \\
\text { 2) }\end{array}$ & $\begin{array}{lr}\text { Uma escala } & \text { de } \\
\text { desempenho } & \text { em } \\
\text { quão bem } & \text { uma } \\
\text { organização } & \text { pode } \\
\text { gerenciar e operar } \\
\text { atividades de UCD }\end{array}$ & $\begin{array}{lr}\text { (KUUSINEN; } & \text { MIKKONEN; } \\
\text { PAKARINEN, 2012; } & \text { CHAM- } \\
\text { BERLAIN; SHARP; } & \text { MAIDEN, } \\
2006) & \end{array}$ \\
\hline
\end{tabular}

\begin{tabular}{|c|c|c|}
\hline \multicolumn{3}{|c|}{ Fatores contingenciais associados ao projeto } \\
\hline $\begin{array}{l}\text { Acessibilidade aos usuários } \\
\text { finais }(\mathrm{n}=10)\end{array}$ & $\begin{array}{l}\text { Grau em que a } \\
\text { equipe de projeto } \\
\text { tem acesso aos } \\
\text { utilizadores reais } \\
\text { do software, seja } \\
\text { para realizarem } \\
\text { entrevistas, testes } \\
\text { com protótipos, etc. }\end{array}$ & $\begin{array}{l}\text { (ARDITO et al., 2014; WALE- } \\
\text { KOLADE; NIELSEN; PAIVA- } \\
\text { RINTA, 2014; SALAH; PAIGE; } \\
\text { CAIRNS, 2014b; TEKA; DIT- } \\
\text { TRICH; KIFLE, 2017; SALAH; } \\
\text { PAIGE; CAIRNS, 2014a; MEM- } \\
\text { MEL; GUNDELSWEILER; REI- } \\
\text { TERER, 2007; TAWFIK; BEL- } \\
\text { DEN; MOORE, 2013; UNGAR; } \\
\text { WHITE, 2008; CIVJAN J., 2010; } \\
\text { GONZALEZ; TOLEDO; MUOZ, } \\
\text { 2015) }\end{array}$ \\
\hline
\end{tabular}




\begin{tabular}{|c|c|c|}
\hline Fatores Contingenciais & Definição & Referências \\
\hline $\begin{array}{l}\text { Tipo de software a ser de- } \\
\text { senvolvido }(\mathrm{n}=8)\end{array}$ & $\begin{array}{l}\text { Relacionado aos di- } \\
\text { ferentes tipos de in- } \\
\text { terface a serem pro- } \\
\text { totipados (web, mo- } \\
\text { bile, wearable, etc.) }\end{array}$ & $\begin{array}{l}\text { (FERREIRA; NOBLE; BIDDLE, } \\
\text { 2007a; CHAMBERLAIN; SHARP; } \\
\text { MAIDEN, 2006; BROWN; LIND- } \\
\text { GAARD; BIDDLE, 2011; CAR- } \\
\text { VALHO; SILVA; SILVEIRA, 2016; } \\
\text { HIGHSMITH; COCKBURN, 2001; } \\
\text { CHOMA; ZAINA; SILVA, 2015; } \\
\text { FERREIRA, 2008; TAWFIK; BEL- } \\
\text { DEN; MOORE, 2013; GONZALEZ; } \\
\text { TOLEDO; MUOZ, 2015; HOD- } \\
\text { GETTS, 2005) }\end{array}$ \\
\hline $\begin{array}{l}\text { Métodos ágeis utilizados } \\
\text { durante o desenvolvimento } \\
(\mathrm{n}=8)\end{array}$ & $\begin{array}{l}\text { Metodologias para } \\
\text { desenvolvimento de } \\
\text { software que englo- } \\
\text { bam os princípios } \\
\text { ágeis (SCRUM, XP, } \\
\text { Lean, etc.) }\end{array}$ & $\begin{array}{l}\text { (ROJAS; MACÍAS, 2015; HOD- } \\
\text { GETTS, 2005; GONZALEZ; } \\
\text { TOLEDO; MUOZ, 2015; MEM- } \\
\text { MEL; GUNDELSWEILER; REI- } \\
\text { TERER, 2007; MANWARING; } \\
\text { CARTER; MAYNARD, 2017; } \\
\text { SALAH; PAIGE; CAIRNS, 2014a; } \\
\text { TEKA; DITTRICH; KIFLE, 2017; } \\
\text { BROWN; LINDGAARD; BID- } \\
\text { DLE, 2011; FERREIRA; NOBLE; } \\
\text { BIDDLE, 2007a; CABALLERO; } \\
\text { MORENO; SEFFAH, 2016) }\end{array}$ \\
\hline $\begin{array}{l}\text { Tempo suficiente e pro- } \\
\text { tegido para atividades de } \\
\text { UCD }(\mathrm{n}=5)\end{array}$ & $\begin{array}{l}\text { A equipe do pro- } \\
\text { jeto tem tempo sufi- } \\
\text { ciente para executar } \\
\text { as atividades plane- } \\
\text { jadas da UCD }\end{array}$ & $\begin{array}{l}\text { (DETWEILER; } \\
\text { 2007; JURCA; HELLMANAN; } \\
\text { MAURER, 2014; BELCHEV; } \\
\text { BAKER, 2009; SALAH; PAIGE; } \\
\text { CAIRNS, 2014a; MEMMEL; GUN- } \\
\text { DELSWEILER; REITERER, 2007; } \\
\text { FERREIRA; NOBLE; BIDDLE, } \\
\text { 2007a) }\end{array}$ \\
\hline
\end{tabular}




\begin{tabular}{|c|c|c|}
\hline Fatores Contingenciais & Definição & Referências \\
\hline $\begin{array}{l}\text { Compromisso do cliente (n } \\
=5)\end{array}$ & $\begin{array}{l}\text { Grau em que o cli- } \\
\text { ente (a pessoa que } \\
\text { paga pelo projeto) } \\
\text { está comprometida } \\
\text { em ser acessível à } \\
\text { equipe do projeto, } \\
\text { ganhando sua con- } \\
\text { fiança e ajudando-os } \\
\text { a tomar decisões }\end{array}$ & $\begin{array}{l}\text { (MAY, 2012; FERREIRA; NOBLE; } \\
\text { BIDDLE, 2007a; MEMMEL; GUN- } \\
\text { DELSWEILER; REITERER, 2007; } \\
\text { FERREIRA; SHARP; ROBINSON, } \\
\text { 2012; ARDITO et al., 2017) }\end{array}$ \\
\hline $\begin{array}{l}\text { Domínio onde o software é } \\
\text { desenvolvido }(\mathrm{n}=4)\end{array}$ & $\begin{array}{l}\text { Área de especia- } \\
\text { lização em que o } \\
\text { produto é concebido } \\
\text { (Médico, Finan- } \\
\text { ceiro, Educacional, } \\
\text { etc.) }\end{array}$ & $\begin{array}{l}\text { (BROWN; LINDGAARD; BID- } \\
\text { DLE, 2011; ISOMURSU et al., } \\
2012 \text {; ISA et al., 2014; SA- } \\
\text { LAH; PAIGE; CAIRNS, 2014a; } \\
\text { MANWARING; CARTER; } \\
\text { MAYNARD, 2017; SAVAGE- } \\
\text { KNEPSHIELD et al., 2014) }\end{array}$ \\
\hline $\begin{array}{l}\text { Projeto existente ou novo } \\
\text { produto }(\mathrm{n}=3)\end{array}$ & $\begin{array}{l}\text { Se o produto / } \\
\text { serviço já existe ou } \\
\text { não }\end{array}$ & $\begin{array}{l}\text { (SALAH; PAIGE; CAIRNS, 2014a; } \\
\text { NAJAFI; TOYOSHIBA, 2008; } \\
\text { FERREIRA, 2008; BROWN; } \\
\text { LINDGAARD; BIDDLE, 2011) }\end{array}$ \\
\hline $\begin{array}{l}\text { Destinatário do projeto (n } \\
=3 \text { ) }\end{array}$ & $\begin{array}{l}\text { Se o cliente final } \\
\text { do produto é a } \\
\text { própria empresa que } \\
\text { o constrói, outro } \\
\text { negócio ou cliente } \\
\text { final }\end{array}$ & $\begin{array}{l}\text { (ISOMURSU et al., 2012; BEYER; } \\
\text { HOLTZBLATT; BAKER, 2004; } \\
\text { MANWARING; CARTER; MAY- } \\
\text { NARD, 2017; TAWFIK; BELDEN; } \\
\text { MOORE, 2013) }\end{array}$ \\
\hline $\begin{array}{l}\text { Nível de inovação do pro- } \\
\text { jeto }(\mathrm{n}=3)\end{array}$ & $\begin{array}{l}\text { Grau de inovação } \\
\text { que um produto } \\
\text { apresenta, conside- } \\
\text { rando soluções de } \\
\text { mercado disponíveis }\end{array}$ & $\begin{array}{lr}\text { KUUSINEN; } & \text { VÄÄNÄNEN- } \\
\text { VAINIO-MATTILA, } & 2012 ; \\
\text { DEUFF; COSQUER; FOUCAULT, } \\
\text { 2010; BEYER; HOLTZBLATT; } \\
\text { BAKER, 2004) }\end{array}$ \\
\hline
\end{tabular}




\begin{tabular}{|c|c|c|}
\hline Fatores Contingenciais & Definição & Referências \\
\hline $\begin{array}{l}\text { Falta de definição formal } \\
\text { do papel de membros da } \\
\text { equipe }(\mathrm{n}=2)\end{array}$ & $\begin{array}{l}\text { Grau em que o as } \\
\text { atividades a serem } \\
\text { realizadas no pro- } \\
\text { cesso foram clara- } \\
\text { mente separadas en- } \\
\text { tre participantes }\end{array}$ & $\begin{array}{l}\text { (ISOMURSU et al., 2012; KUUSI- } \\
\text { NEN; MIKKONEN; PAKARINEN, } \\
\text { 2012; SALAH; PAIGE; CAIRNS, } \\
\text { 2014a) }\end{array}$ \\
\hline $\begin{array}{l}\text { Quantidade de stakehol- } \\
\text { ders envolvidos }(\mathrm{n}=2)\end{array}$ & $\begin{array}{l}\text { Número de stakehol- } \\
\text { ders (que não fa- } \\
\text { zem parte da equipe } \\
\text { do projeto) que par- } \\
\text { ticipam do processo } \\
\text { UFD }\end{array}$ & $\begin{array}{l}\text { (TAWFIK; BELDEN; MOORE, } \\
\text { 2013; KUUSINEN; VÄÄNÄNEN- } \\
\text { VAINIO-MATTILA, 2012) }\end{array}$ \\
\hline $\begin{array}{l}\text { Orçamento suficiente e } \\
\text { protegido para atividades } \\
\text { de UCD }(\mathrm{n}=2)\end{array}$ & $\begin{array}{l}\text { Equipe do projeto } \\
\text { tem orçamento su- } \\
\text { ficiente para execu- } \\
\text { tar atividades plane- } \\
\text { jadas de UCD? }\end{array}$ & $\begin{array}{l}\text { (MEMMEL; GUNDELSWEI- } \\
\text { LER; REITERER, 2007; SALAH; } \\
\text { PAIGE; CAIRNS, 2014a) }\end{array}$ \\
\hline
\end{tabular}




\begin{tabular}{|c|c|c|}
\hline Fatores Contingenciais & Definição & Referências \\
\hline $\begin{array}{l}\text { Disponibilidade do profis- } \\
\text { sional de UCD para o pro- } \\
\text { jeto }(\mathrm{n}=19)\end{array}$ & $\begin{array}{l}\text { Se o profissional de } \\
\text { UCD é parcial ou } \\
\text { totalmente alocado } \\
\text { para os projetos que } \\
\text { ele é atribuído }\end{array}$ & $\begin{array}{l}\text { (UNGAR; WHITE, 2008; ANWAR } \\
\text { et al., 2014; KUUSINEN, 2015; } \\
\text { PRIOR et al., 2013; DEUFF; } \\
\text { COSQUER; FOUCAULT, 2010; } \\
\text { MANWARING; CARTER; MAY- } \\
\text { NARD, 2017; SILVA et al., 2013; } \\
\text { NAJAFI; TOYOSHIBA, } 2008 ; \\
\text { TEKA; DITTRICH; KIFLE; } \\
\text { 2017; KUUSINEN; MIKKONEN; } \\
\text { PAKARINEN, 2012; SILVA; } \\
\text { SILVEIRA; MAURER, 2013; CAR- } \\
\text { VALHO; SILVA; SILVEIRA, 2016; } \\
\text { ISOMURSU et al., 2012; SALAH; } \\
\text { PAIGE; CAIRNS, 2014b; MILLER, } \\
\text { 2005; BROWN; LINDGAARD; } \\
\text { BIDDLE, 2011; WALE-KOLADE; } \\
\text { NIELSEN; PAIVARINTA, 2014; } \\
\text { FERREIRA; SHARP; ROBIN- } \\
\text { SON, 2012; SALAH; PAIGE; } \\
\text { CAIRNS, 2014c; DETWEILER; } \\
\text { MANAGING, 2007) }\end{array}$ \\
\hline $\begin{array}{l}\text { Estrutura da equipe }(\mathrm{n}= \\
10)\end{array}$ & $\begin{array}{l}\text { Composição de } \\
\text { equipe com especia- } \\
\text { lista, generalistas ou } \\
\text { perfil híbrido }\end{array}$ & $\begin{array}{l}\text { (FERREIRA; SHARP; ROBIN- } \\
\text { SON, 2012; FERREIRA; NOBLE; } \\
\text { BIDDLE, 2007b; ISOMURSU } \\
\text { et al., 2012; SILVA; SILVEIRA; } \\
\text { MAURER, 2013; CHOMA; ZAINA; } \\
\text { SILVA, 2015; FERREIRA, 2008; } \\
\text { NAJAFI; TOYOSHIBA, 2008; } \\
\text { SILVA et al., 2013; KUUSINEN, } \\
\text { 2015; ANWAR et al., 2014) }\end{array}$ \\
\hline
\end{tabular}




\begin{tabular}{|c|c|c|}
\hline Fatores Contingenciais & Definição & Referências \\
\hline $\begin{array}{l}\text { Distribuição física da } \\
\text { equipe e do cliente }(\mathrm{n}=8)\end{array}$ & $\begin{array}{l}\text { Distância em que os } \\
\text { usuários são aloca- } \\
\text { dos física / geografi- } \\
\text { camente (a alocação } \\
\text { pode variar em ter- } \\
\text { mos de piso, prédio, } \\
\text { país, fuso horário) }\end{array}$ & $\begin{array}{l}\text { (FERREIRA; SHARP; ROBIN- } \\
\text { SON, 2012; BROWN; LIND- } \\
\text { GAARD; BIDDLE, 2011; ISO- } \\
\text { MURSU et al., 2012; JURCA; } \\
\text { HELLMANN; MAURER, 2014; } \\
\text { SALAH; PAIGE; CAIRNS, 2014a; } \\
\text { BUDWIG; JEONG; KELKAR, } \\
\text { 2009; KUUSINEN, 2015; TAWFIK; } \\
\text { BELDEN; MOORE, 2013; HONI- } \\
\text { OUS; CLARK, 2006; HODGETTS, } \\
\text { 2005; BLOMKVIST; PERSSON; } \\
\text { ABERG, 2015) }\end{array}$ \\
\hline $\begin{array}{l}\text { Maturidade da equipe }(\mathrm{n}= \\
6)\end{array}$ & $\begin{array}{l}\text { Experiência em anos } \\
\text { dos membros sobre } \\
\text { as atividades que de- } \\
\text { vem realizar }\end{array}$ & $\begin{array}{l}\text { (KUUSINEN, 2014; BLOMKVIST; } \\
\text { PERSSON; ABERG, 2015; HONI- } \\
\text { OUS; CLARK, 2006; KUUSINEN; } \\
\text { VÄÄNÄNEN-VAINIO-MATTILA, } \\
\text { 2012; SALAH; PAIGE; CAIRNS, } \\
\text { 2014a; KUUSINEN; MIKKO- } \\
\text { NEN; PAKARINEN, 2012; ISO- } \\
\text { MURSU et al., 2012; BROWN; } \\
\text { LINDGAARD; BIDDLE, 2011; } \\
\text { WALE-KOLADE; } \\
\text { PAIVARINTA, 2014) }\end{array}$ \\
\hline $\begin{array}{l}\text { Interação entre os mem- } \\
\text { bros da equipe }(\mathrm{n}=5)\end{array}$ & $\begin{array}{l}\text { Nível de interação } \\
\text { entre profissionais } \\
\text { de diferentes funções } \\
\text { (designers vs Devs x } \\
\text { Gerentes) em quão } \\
\text { aberta a equipe é } \\
\text { para fazer perguntas } \\
\text { uns aos outros e se- } \\
\text { gurança psicológica } \\
\text { para criticar o } \\
\text { próprio trabalho }\end{array}$ & $\begin{array}{l}\text { (BROWN; LINDGAARD; BID- } \\
\text { DLE, 2011; SALAH; PAIGE; } \\
\text { CAIRNS, 2014b; ISOMURSU } \\
\text { et al., 2012; SALAH; PAIGE; } \\
\text { CAIRNS, 2014a; KUUSINEN; } \\
\text { VÄÄNÄNEN-VAINIO-MATTILA, } \\
\text { 2012; HODGETTS, 2005; FER- } \\
\text { REIRA; NOBLE; BIDDLE, 2007a; } \\
\text { KUUSINEN, 2014) }\end{array}$ \\
\hline
\end{tabular}




\begin{tabular}{|c|c|c|}
\hline Fatores Contingenciais & Definição & Referências \\
\hline $\begin{array}{l}\text { Tamanho da equipe do } \\
\text { projeto }(\mathrm{n}=3)\end{array}$ & $\begin{array}{l}\text { Número de pessoas } \\
\text { que participam de } \\
\text { todas as ativida- } \\
\text { des do processo } \\
\text { (não contam parti- } \\
\text { cipações específicas) }\end{array}$ & $\begin{array}{l}\text { (HONIOUS; } \text { CLARK, 2006; } \\
\text { MEMMEL; GUNDELSWEILER; } \\
\text { REITERER, 2007; BEYER; } \\
\text { HOLTZBLATT; BAKER, 2004; } \\
\text { FERREIRA; SHARP; ROBINSON, } \\
\text { 2012) }\end{array}$ \\
\hline $\begin{array}{l}\text { Multidisciplinaridade da } \\
\text { equipe }(\mathrm{n}=3)\end{array}$ & $\begin{array}{l}\text { Diversidade de ori- } \\
\text { gens nas quais os } \\
\text { membros da equipe } \\
\text { são especializados }\end{array}$ & $\begin{array}{l}\text { (KUUSINEN; MIKKONEN; PA- } \\
\text { KARINEN, 2012; MANWARING; } \\
\text { CARTER; MAYNARD, 2017; } \\
\text { SOHAIB; KHAN, 2010) }\end{array}$ \\
\hline
\end{tabular}

Fonte: O autor

Na próxima seção, é analisado como cada um desses fatores contingenciais influencia o planejamento e execução das técnicas prescritas.

\subsubsection{Fatores contingenciais associados à organização}

Para os fatores contingenciais de nível superior (aqueles relacionados ao contexto organizacional), o tamanho da organização foi o fator mais citado. Estudos incluem de grandes multinacionais (FERREIRA; SHARP; ROBINSON, 2012; CHAMBERLAIN; SHARP; MAIDEN, 2006; BROWN; LINDGAARD; BIDDLE, 2011; CARVALHO; SILVA; SILVEIRA, 2016; KUUSINEN, 2015; TAWFIK; BELDEN; MOORE, 2013) a pequenas empresas (FERREIRA; SHARP; ROBINSON, 2012; BROWN; LINDGAARD; BIDDLE, 2011; ANWAR et al., 2014; HOKKANEN; VÄ̈̈NÄNEN-VAINIO-MATTILA, 2015) com resultados positivos em ambos os casos, sugerindo que o tamanho da empresa não é uma restrição para a execução desse processo. As equipes de grandes empresas tendem a trabalhar de forma independente, levando a uma constante necessidade de atualização de stakeholders sobre as decisões do projeto, demorando mais tempo (FERREIRA; SHARP; ROBINSON, 2012). Os membros de pequenas empresas tendem a realizar atividades que vão além da descrição do seu trabalho, sendo multifuncionais e trabalhando em estreita colaboração com outros membros, o que leva a discussões e tomada de decisões mais rápidas e menos documentação (BROWN; LINDGAARD; BIDDLE, 2011).

Outro fator importante no nível organizacional é a diferenciação entre empresas que são orientadas a produtos e aquelas orientadas a projetos. As empresas orientadas a 
produtos têm uma preocupação mais significativa com o produto final criado e seus resultados, mesmo que isso signifique extrapolar estimativas de tempo e orçamento, enquanto empresas orientadas a projetos são mais limitadas a fatores clássicos que determinam o sucesso do projeto, como terminar o projeto no prazo e orçamento previstos (BROWN; LINDGAARD; BIDDLE, 2011). Ficou evidenciado que as empresas orientadas a projetos acabam sendo pressionadas por contratos, falta de visão do cliente sobre os benefícios do UFD e tendem a ter menos tempo para executar estes processos, fazendo deste um trabalho desafiador (ARDITO et al., 2017).

Outros fatores organizacionais relevantes citados na literatura são a maturidade da organização na UCD, que afeta sua capacidade de conduzir e adaptar o UFD de acordo com as necessidades de cada projeto, estando intimamente relacionado com o último fator de Suporte à Gestão nas atividades da UCD.

\subsubsection{Fatores contingenciais associados ao projeto}

A dimensão do projeto é a que apresenta mais fatores contingenciais extraídos da literatura. Embora seja um dos mais citados: "tipo de software a ser desenvolvido" (web, móvel, wearable, etc.), não existe grandes variações sobre como o projeto foi executado.

A acessibilidade aos usuários finais foi apontada como uma grande dificuldade dentro do LDUF, por restrições de tempo. No caso de estudos que não tiveram acesso a usuários reais, uma alternativa encontrada para validar a solução foi validá-la com especialistas na área ou, em último caso, com membros da empresa que não estavam envolvidos no projeto.Um desafio significativo sobre esse fator contingencial é discutido em alguns artigos, pois às vezes há características intrínsecas ao projeto que diferem o usuário final do projeto para uma pessoa comum. Alguns exemplos são vistos em Tawfik, Belden e Moore (2013) quando a disponibilidade de médicos para as etapas de entendimento e validação foi extremamente difícil, complicando a prototipagem e o teste e Teka, Dittrich e Kifle (2017) onde os usuários finais só falavam dialetos africanos e os designers não podiam ter contato direto com os usuários finais, tal que todas as atividades tinham que ser intermediadas por profissionais locais de TI.

A metodologia ágil utilizada no projeto também foi considerada um fator importante por uma variedade de estudos (CABALLERO; MORENO; SEFFAH, 2016; FERREIRA; SHARP; ROBINSON, 2012; BROWN; LINDGAARD; BIDDLE, 2011; TEKA; DITTRICH; KIFLE, 2017; SALAH; PAIGE; CAIRNS, 2014a; MANWARING; CARTER; MAYNARD, 2017; MEMMEL; GUNDELSWEILER; REITERER, 2007; GONZALEZ; 
TOLEDO; MUOZ, 2015; HODGETTS, 2005; ROJAS; MACÍAS, 2015). Neste tópico, Rojas e Macías (2015) fazem uma análise interessante sobre a aderência de cada método ágil às atividades de UCD, nas quais o Scrum e o XP se mostram as mais adequadas quanto as questões de serem iterativos e valorizarem o conhecimento multidisciplinar, mas não combinaram bem com os tópicos de envolvimento ativo do usuário e avaliações com usuários finais.

O compromisso do cliente também foi considerado um fator importante. A falta de compromisso leva a atrasos no feedback do cliente, dificultando a produtividade das equipes e, consequentemente, a satisfação do usuário final (SALAH; PAIGE; CAIRNS, 2014a). As soluções propostas estavam relacionadas a provocar comunicação contínua e constante com o cliente e incluí-lo durante decisões importantes do projeto.

Outro fator que altera a alocação da equipe é o domínio onde o software é desenvolvido. Acontece que, em projetos fora do campo do senso comum, muitas vezes é necessário planejar a participação de "especialistas" no campo para validar e contribuir com conhecimento para a equipe de UFD (TEKA; DITTRICH; KIFLE, 2017; TAWFIK; BELDEN; MOORE, 2013).

O nível de inovação no projeto é diretamente proporcional a necessidade de mais tempo para que novos participantes entendam os usuários e definam os requisitos com os stakeholers (KUUSINEN; VÄ̈̈NÄNEN-VAINIO-MATTILA, 2012; DEUFF; COSQUER; FOUCAULT, 2010).

O número de stakeholders envolvidos no processo de UFD foi considerado como um fator contingencial, afetando principalmente o estágio de entendimento dos stakeholders, onde há uma necessidade de entender os requisitos de mais partes (TAWFIK; BELDEN; MOORE, 2013; KUUSINEN; VÄÄNÄNEN-VAINIO-MATTILA, 2012). Isso também afeta o tempo de transição entre as fases, pois é necessário um maior alinhamento com as diferentes partes para garantir que todos estejam alinhados com as decisões tomadas ao longo do projeto. Afetando o agendamento de atividades para envolver todos os envolvidos em reuniões críticas.

Fazer o UFD para novos projetos e os existentes tendem a diferir no entendimento do usuário. Como novos projetos não tem usuários reais, essa etapa consiste principalmente em entrevistas com potenciais usuários e suas motivações e necessidades, enquanto os produtos existentes podem testar com usuários reais na plataforma, validando problemas e testes de usabilidade no produto disponível para o mercado, estando mais alinhado em encontrar problemas e oportunidades na solução existente. 
Tempo e orçamento suficientes e protegidos para conduzir as atividades de UFD também foram apontados como fatores contingenciais (FERREIRA, 2012; MEMMEL; GUNDELSWEILER; REITERER, 2007; SALAH; PAIGE; CAIRNS, 2014a; BELCHEV; BAKER, 2009; JURCA; HELLMANN; MAURER, 2014; DETWEILER; MANAGING, 2007). Depois de alguns projetos mal sucedidos que tiveram seu UFD interrompido (fornecendo baixo valor para o projeto), uma solução testada e validada foi criar o conceito de resultados mínimos fornecidos pela equipe do UFD (independentemente do tempo e do orçamento), antes que qualquer codificação fosse iniciada.

A falta de uma definição formal do papel dos membros da equipe foi encontrado como uma causa para algumas atividades serem mal executadas. Os facilitadores do projeto devem reservar um tempo para delinear claramente os marcos, os resultados e as responsabilidades (TAWFIK; BELDEN; MOORE, 2013) de cada um dos participantes.

Embora não seja citado por muitos autores, um fator crítico contingencial é o destinatário do projeto (empresa própria, desenvolvimento para terceiros, B2B, B2C). Isso se dá pois afeta as etapas de entendimento e validação do usuário da solução de design, pois nas soluções B2B existem vários clientes, já que a pessoa que compra é muitas vezes diferente da pessoa que usa a solução que é diferente da pessoa que aprova o orçamento da solução. Enquanto para as soluções B2C todos esses papéis tendem a cair nas mãos de apenas uma pessoa. As soluções B2B tendem a exigir mais tempo e recursos de UFD.

\subsubsection{Fatores contingenciais associados à equipe}

Por fim, os fatores contingenciais da equipe também são muito relevantes para os praticantes da UFD, já que tendem a afetar profundamente as atividades do dia-a-dia.

A disponibilidade do profissional de UCD ao longo do processo foi o tema mais citado, por ser um problema recorrente de empresas que o profissional de UCD precisa atender a diversos projetos, e acaba por não ter foco em nenhum deles.

A maturidade da equipe (experiência em anos) e a competência foram citadas por vários autores por impactar na alocação da equipe e na flexibilidade desta para adaptarse as atividades de UCD inicialmente planejadas.

O nível de interação entre os membros da equipe (principalmente designers e desenvolvedores) tem sido um tema de constantes conflitos na literatura e prática. Falta de comunicação tende a levar a lutas de poder entre designers e desenvolvedores, sendo mais eficaz criar uma subcultura (dentro do contexto do projeto) acordada pelos membros 
da equipe para apoiar a cooperação e colaboração entre partes (FERREIRA; SHARP; ROBINSON, 2011).

Outro fator contingencial citado na literatura foi a distribuição física da equipe e do cliente. Vários artigos relatam uma diminuição na qualidade da comunicação quando os membros da equipe não são alocados no mesmo ambiente.

Existem indicadores de que a integração UCD com ASD não é totalmente suportada ou limitada, o que significa que a última etapa de refinar entregáveis para a equipe de desenvolvimento é severamente afetada (ALMUGHRAM; ALYAHYA, 2017) e para que os desenvolvedores entendam realmente o usuário, eles teriam que participar até certo ponto no processo de UFD (BLOMKVIST; PERSSON; ÅBERG, 2015). A alternativa, como os participantes relataram, era comunicar verbalmente seu entendimento do usuário aos desenvolvedores sob demanda ao longo do projeto.

Os achados na literatura supracitados, porém, apresentam algumas limitações:

- As publicações analisadas avaliam poucos projetos, como visto na Figura 14.

- Existe uma interpretação do pesquisador no levantamento de fatores contingenciais, já que não há uma clara exposição dos mesmos nos estudos.

Tendo em vista estas limitações, o trabalho continua com um estudo de caso múltiplo que irá confirmar e/ou contrastar cada um dos principais tópicos desta pesquisa: ciclo de vida do UCASD, BDUF versus LDUF, técnicas envolvidas, tempo de execução, configuração de equipe e fatores contingenciais. A partir dos achados em campo é feita uma discussão sobre cada um dos temas e por fim uma remodelação do modelo de pesquisa preenchendo as lacunas de literatura e que servem como um guia para praticantes da área. 


\section{ESTUDO DE CASO}

O objetivo principal deste estudo de caso consiste em confirmar e/ou contrastar as consolidações e propostas feitas na RSL com estudos de campo, de forma a examinar como a teoria é verificada efetivamente na prática.

Como mencionado na seção de método, seguindo as recomendações de Eisenhardt (1989), Jurca, Hellmann e Maurer (2014) este estudo buscou analisar uma diversidade de casos de UFD em uma organização que consegue trabalhar o UCASD de uma maneira unificada, ou seja, capaz de executar todas as etapas do ciclo de vida da criação do software, com foco nas etapas de LDUF e posterior design e desenvolvimento ágil do software.

\subsection{Empresa foco do estudo}

A empresa selecionada conta com cerca de 40 funcionários e atua como prestadora de serviços para criação de software, principalmente mobile, para empresas terceiras, ao longo de todo o ciclo de vida do UCASD, sendo as principais atividades realizadas:

- Design Sprints - para concepção de novas aplicações digitais ou melhoria de existentes (este é o framework utilizado para realizar o UFD)

- Design de interfaces

- Desenvolvimento do Software

- Gestão do Produto (análise de métricas, organização do backlog do produto, etc.)

A empresa começou a integrar técnicas de UCD ao desenvolvimento de software em 2012, a partir da necessidade de melhorar a qualidade dos requisitos de projetos de software solicitados por clientes, com a intenção de criar softwares que consumidores finais precisassem ou quisessem. 
Inicialmente eram realizados processos de Design Thinking (BDUF) junto a equipe do cliente, com duração de dois a três meses, e eram utilizados toolkits de mercado como o Human centered design toolkit (2009) e o The field guide to human centered design (2015) da IDEO.

A partir de 2016 a Google apresenta um novo modelo alternativo para realização do UFD com um processo mais curto e objetivo para a definição de requisitos do projeto de software - o Design Sprint (KNAPP; ZERATSKY; KOWITZ, 2016).

Realizado o processo de Design Sprint, a equipe de desenvolvimento inicia um processo de definição técnica dos requisitos do projeto que por sua vez é desenvolvido por uma equipe de produto (geralmente composta por designers, desenvolvedores e um Product Owner).

O grau de agilidade da etapa de design e desenvolvimento do software varia de acordo com cada cliente. Atualmente no portfólio da empresa, a maior parte dos projetos se enquadra dentro de um desenvolvimento ágil, pois não existe um escopo pré-definido (também chamado de escopo aberto), onde os clientes apenas contratam a alocação de uma equipe, permitindo que os valores e princípios ágeis, assim como os rituais do SCRUM sejam seguidos de forma mais aderente. Existem, entretanto, projetos realizados sob escopo fechado, no qual equipe utiliza alguns rituais do SCRUM para tornar o desenvolvimento iterativo e envolver o cliente na criação do software, porém como o escopo já é pré-definido, algumas características de desenvolvimento mais tradicional são necessárias, e nestes casos o UFD costuma ser realizado à parte da criação do software, seguindo assim características de desenvolvimento híbrido (AZENHA, 2018).

\subsection{Design sprint como framework para LDUF}

A empresa de consultoria IDEO foi uma das principais responsáveis pela rápida expansão do termo Design Thinking, e aplicação de técnicas de design no mundo corporativo, não apenas pelos bons resultados apresentados como o primeiro mouse da Apple, entre outros trabalhos com Coca-Cola, IKEA, Ford, mas sobretudo pela tática de guerrilha de compartilhamento de guias com técnicas do design, também conhecidos como toolkits, que auxiliam qualquer pessoa ou organização a executar o processo de Design Thinking de forma autônoma, como o Human centered design toolkit (2009), Design thinking for educators (2011) e o The field guide to human centered design (2015).

Além da IDEO, existem outras referências que também criaram seus próprios guias 
com técnicas de design como o instituto de design de Stanford com o Bootcamp Bootleg (PLATTNER, 2010), a Lahti escola de inovação da Finlândia com o Playbook for Strategic Foresight and Innovation (CARLETON; COCKAYNE; TAHVANAINEN, 2013) entre outros.

Dentre as diversas opções que surgiram no mercado, uma das metodologias que está em maior evidência, concebida pela Google Ventures, é o processo do Design Sprint (KNAPP; ZERATSKY; KOWITZ, 2016). O Design Sprint se diferencia dos demais guias por incorporar os conceitos de Lean Startup ao Design Thinking, pela facilidade de sua aplicação e a capacidade de conseguir bons resultados em um espaço de tempo muito curto. Diferente dos materiais anteriores, que eram uma compilação de técnicas de design desconexas entre si, o Design Sprint propõe um modelo fechado com métodos específicos e sequenciais, e uma discussão sobre os princípios relacionados permitindo adaptações do modelo para diferentes contextos. Uma rica discussão desta integração pode ser vista numa conversa descontraída conduzida pelo Google entre os maiores expoentes de cada tema, Tim Brown, Eric Ries e Jake Knapp em Hangouts for entrepreneurs (STARTUPS, 2014).

O modelo do Design Sprint, na Figura 26, apresenta algumas diferenças sobre o modelo de Design Thinking visto em Geissdoerfer, Bocken e Hultink (2016), com uma etapa de tomada de decisão sobre a melhor ideia gerada na etapa de divergência (ideação) para se ater apenas as ideias principais da solução a serem validadas, um tempo estimado para realização do processo e um fluxo unidirecional, de forma a manter o processo sempre objetivo e sem divergir do foco do sprint (influência dos princípios lean).

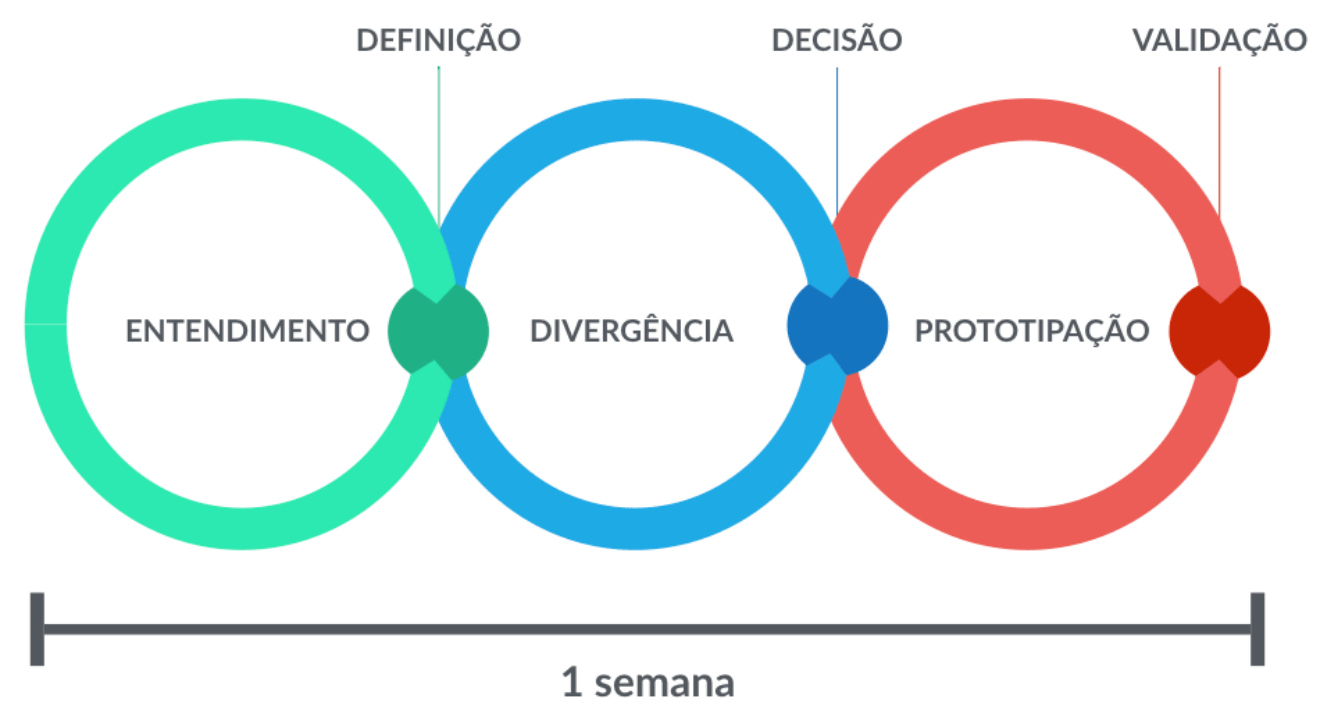

Figura 26: Modelo do Design Sprint. Fonte: (GOOGLE, 2016)

Em busca de melhorias em processos, no entanto, a organização tem executado uma 
versão atualizada do processo, chamado de Design Sprint 2.0 proposto pela agência de design AJ\&Smart (AJSMART, 2018b), no qual a etapa de Entendimento é reduzida, de forma que o processo é realizado em 4 dias (e não 5 dias como proposto em Knapp, Zeratsky e Kowitz (2016)).
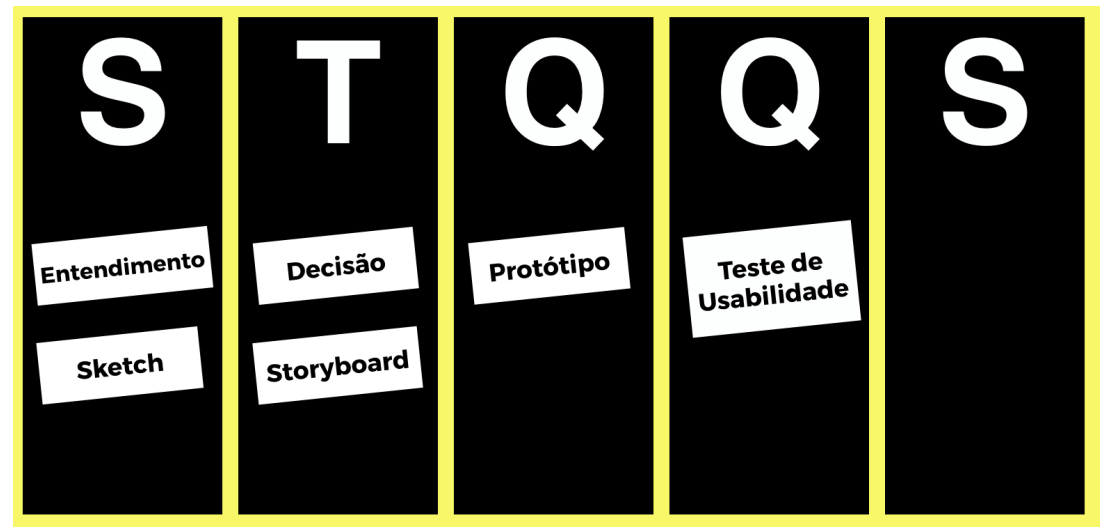

Figura 27: Atividades do Design Sprint 2.0. Fonte: Adaptado de AJSmart (2018a)

\subsection{Projetos analisados}

Cada um dos projetos analisados constituiu de um processo de design sprint realizado pela organização foco deste estudo em conjunto com uma empresa cliente. Nestes projetos a organização principal aportou de dois a quatro consultores, que conduziram uma equipe multidisciplinar do cliente com cerca de sete pessoas de diferentes áreas e níveis de senioridade da empresa cliente. Alguns destes processos foram vendidos como projetos em separado e outros haviam sido vendidos junto da etapa de desenvolvimento. Os design sprints serviram para a concepção de novos produtos ou melhoria de produtos existentes.

Apesar de serem encontrados no histórico da empresa 93 processos de design sprint, esta pesquisa restringiu-se a avaliar apenas 27 deles, abrangendo 21 empresas diferentes como cliente. Essa limitação decorreu dos seguintes critérios mínimos de inclusão:

- Foi possível encontrar documentação suficiente sobre os principais tópicos avaliados - composição da equipe, tempo e esforço de execução, contingencias do processo

- O líder do processo se enquadrava nos requisitos mínimos para ser entrevistado (condução de três design sprints e participação em processos longos de Design Thinking)

- O líder do processo ainda trabalhava na empresa ou estava disponível de alguma forma para realizar a entrevista. 
A seguir é possível visualizar a gama de casos analisados neste estudo de campo, em projetos que foram conduzidas o processo de UFD.

Tabela 6: Projetos analisados

\begin{tabular}{|c|c|c|c|c|}
\hline $\begin{array}{l}\text { Empresa } \\
\text { cliente do } \\
\text { projeto }\end{array}$ & Segmento & $\begin{array}{l}\text { Tamanho } \\
\text { da empresa } \\
\text { (pessoas) }\end{array}$ & $\begin{array}{l}\text { Participantes } \\
\text { no processo }\end{array}$ & $\begin{array}{l}\text { Líder do } \\
\text { projeto }\end{array}$ \\
\hline A & Varejo & +100.000 & 15 & Diretor \\
\hline B & Farmacêutica & +50.000 & 16 & $\begin{array}{l}\text { Gerente de } \\
\text { Produto }\end{array}$ \\
\hline $\mathrm{C}$ & Hospital & +1.000 & $\begin{array}{l}10 \\
9\end{array}$ & $\begin{array}{l}\text { Gerente de } \\
\text { Produto } \\
\text { Gerente de } \\
\text { Produto }\end{array}$ \\
\hline $\mathrm{D}$ & Farmacêutica & +5.000 & $\begin{array}{l}10 \\
6 \\
7\end{array}$ & $\begin{array}{l}\text { Líder UX } 2 \\
\text { Diretor } \\
\text { Gerente de } \\
\text { Produto }\end{array}$ \\
\hline $\mathrm{E}$ & Plano de Saúde & +1.000 & 12 & Líder UX 1 \\
\hline $\mathrm{F}$ & Bens de Consumo & +100.000 & 12 & $\begin{array}{l}\text { Gerente de } \\
\text { Produto }\end{array}$ \\
\hline G & $\begin{array}{l}\text { Laboratório Exa- } \\
\text { mes }\end{array}$ & +5.000 & $\begin{array}{l}15 \\
18\end{array}$ & $\begin{array}{l}\text { Diretor } \\
\text { Diretor }\end{array}$ \\
\hline $\mathrm{H}$ & $\begin{array}{l}\text { Materiais de Lim- } \\
\text { peza }\end{array}$ & +50 & 8 & $\begin{array}{l}\text { Gerente de } \\
\text { Produto }\end{array}$ \\
\hline $\mathrm{I}$ & Finanças & +1 & 5 & Líder UX 1 \\
\hline $\mathrm{J}$ & Análise de Dados & +100 & 10 & Líder UX 1 \\
\hline K & Finanças & +10 & 9 & Líder UX 1 \\
\hline $\mathrm{L}$ & Drogaria & +10.000 & 12 & Líder UX 2 \\
\hline M & Hospital & +5.000 & $\begin{array}{l}7 \\
8 \\
6\end{array}$ & $\begin{array}{l}\text { Líder UX } 1 \\
\text { Líder UX } 1 \\
\text { Líder UX } 1\end{array}$ \\
\hline
\end{tabular}




\begin{tabular}{|l|l|l|l|l|}
\hline $\begin{array}{l}\text { Empresa } \\
\text { cliente do } \\
\text { projeto }\end{array}$ & Segmento & $\begin{array}{l}\text { Tamanho } \\
\text { da empresa } \\
\text { (pessoas) }\end{array}$ & $\begin{array}{l}\text { Participantes } \\
\text { no processo }\end{array}$ & $\begin{array}{l}\text { Líder do } \\
\text { projeto }\end{array}$ \\
\hline $\mathrm{N}$ & $\begin{array}{l}\text { Administradora } \\
\text { de condomínios }\end{array}$ & +500 & 10 & Líder UX 1 \\
\hline $\mathrm{O}$ & Alimentícia & +100.000 & 8 & Líder UX 1 \\
\hline $\mathrm{P}$ & E-commerce & +5.000 & 7 & Líder UX 2 \\
\hline $\mathrm{Q}$ & E-commerce & +50 & 7 & Líder UX 2 \\
\hline $\mathrm{R}$ & Saúde & +10 & 10 & Líder UX 3 \\
\hline $\mathrm{S}$ & Drogaria & +10.000 & 8 & Líder UX 3 \\
\hline $\mathrm{T}$ & Bem-Estar & +1 & 8 & Líder UX 3 \\
\hline $\mathrm{U}$ & E-commerce & +50.000 & 10 & Líder UX 2 \\
\hline
\end{tabular}

Fonte: O autor

\subsection{Entrevistas}

A empresa estudada estimula que diversos funcionários da empresa liderem processos de design sprint, para se capacitarem na utilização de técnicas de UCD em quaisquer etapas do processo de desenvolvimento do software. Dada uma necessidade de conhecimento do processo mais a fundo e a comparação destes processos com os processos que a empresa executava de Design Thinking, foram selecionadas apenas pessoas que tivessem conduzido um mínimo de três design sprints e participado em um processo mais longo de Design Thinking. Foram entrevistados, portanto, cinco profissionais de diferentes cargos que se enquadravam no perfil escolhido, relacionados às áreas de design e experiência do usuário, produto e diretoria e as informações foram consolidadas, como mostra a Tabela 7:

Tabela 7: Entrevistados

\begin{tabular}{|l|l|l|}
\hline Empresas analisadas & Cargo do Entrevistado & Departamento \\
\hline A, D, G (x2) & Diretor de UX e Novos Negócios & Diretoria Geral \\
\hline B, C (x2), D, F, H & Gerente de Produto & Produtos \\
\hline E, I, J, K, M (x3), N, O & Líder de UX 1 & Produtos \\
\hline D, L, P, Q, U & Líder de UX 2 & Design \\
\hline
\end{tabular}




\begin{tabular}{|l|l|l|}
\hline Empresas analisadas & Cargo do Entrevistado & Departamento \\
\hline R, S, T & Líder de UX 3 & Design \\
\hline
\end{tabular}

Fonte: O autor

O processo de entrevista iniciava-se com um convite, o levantamento dos processos que o entrevistado havia liderado e um pedido de acesso aos documentos específicos do projeto.

Antes do início das entrevistas foi realizado o levantamento de dados secundários. Inicialmente era analisado o Redmine do projeto, para avaliação dos esforços empregados e os prazos de execução. Esta análise permitiu avaliar a redução das horas ao longo do tempo de processos mais longos para mais curtos, e identificar eventuais pontos de atenção (processos que haviam utilizado muito menos ou mais horas que previsto).

Em seguida foram avaliados o Basecamp dos projetos. Esta ferramenta serve como um centralizador da comunicação com decisões tomadas e recursos produzidos nos projetos (vide Figura 28). Através desta ferramenta foi possível identificar o número de participantes do processo, as técnicas realizadas, o processo de recrutamento e acessibilidade aos usuários da solução, outros stakeholders envolvidos, etc. Além disso, o basecamp agrega outras documentações sobre o projeto como Google Docs, Apresentações de Keynote, PDFs com anotações variadas sobre o projeto, motivação, desafio a ser trabalhado, telas do protótipo, requisitos de desenvolvimento, etc.

Não existe uma formalização exata do processo de documentação na empresa, por isso foram escolhidos apenas aqueles projetos que detinham documentação mínima para levantar informações o suficiente para discutir os projetos junto a seus líderes na etapa de entrevista.

A coleta e documentação dos dados secundários dos projetos, portanto, foi realizada através de uma leitura extensa dos recursos mencionados acima e posterior codificação dos achados nos seguintes tópicos:

\section{- Segmento da empresa cliente}

\section{- Tamanho da empresa cliente}

- Número de participantes no processo (apenas equipe do cliente)

- Líder do processo (consultor que facilitou o processo) 


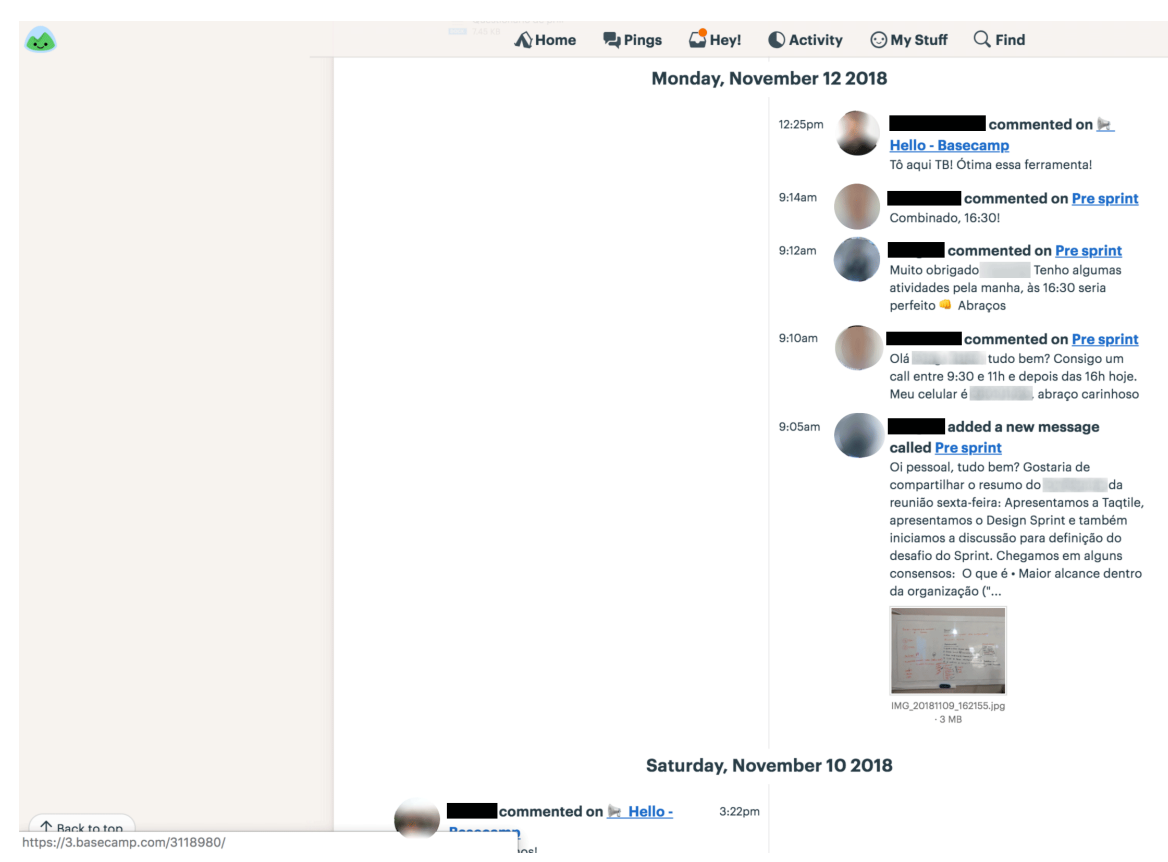

Figura 28: Basecamp - comunicação e recursos do projeto. Fonte: O autor.

- Data do processo (mês em que processo foi realizado)

- Esforços empregados pela organização foco deste estudo (quantas horas os consultores da organização focal utilizaram para realizar todo o processo)

- Valor de venda do projeto

- Esforço executado acima do esperado? (projeto utilizou mais horas que o previsto pela área comercial)

- Consultores no processo (número de consultores da organização foco deste estudo que participaram deste estudo)

- Sponsor participou do processo?

- Projeto tinha recurso de design? (alguns dos consultores era da área de design da empresa)

- Seguiu para etapa de desenvolvimento (Design Sprint seguir para etapa de desenvolvimento?)

- Notas sobre etapa pré-sprint - planejamento (pontos de interesse a questionar líder do processo)

- Notas sobre etapas - entendimento e definição (pontos de interesse a questionar líder do processo) 
- Notas sobre etapas - divergência e decisão (pontos de interesse a questionar líder do processo)

- Notas sobre etapas - prototipagem e validação (pontos de interesse a questionar líder do processo)

- Recrutamento de usuários (pontos de interesse a questionar líder do processo)

Para consolidação dos achados foi utilizada uma planilha de Google Sheets (ver Figura 29), que serviu como base para posterior indagação aos entrevistados sobre as características dos processos em geral, e contingências de cada projeto (ex: para os projetos que não tiveram a participação do sponsor, foi perguntado ao entrevistado: "qual foi o impacto da ausência do sponsor em determinado processo?").

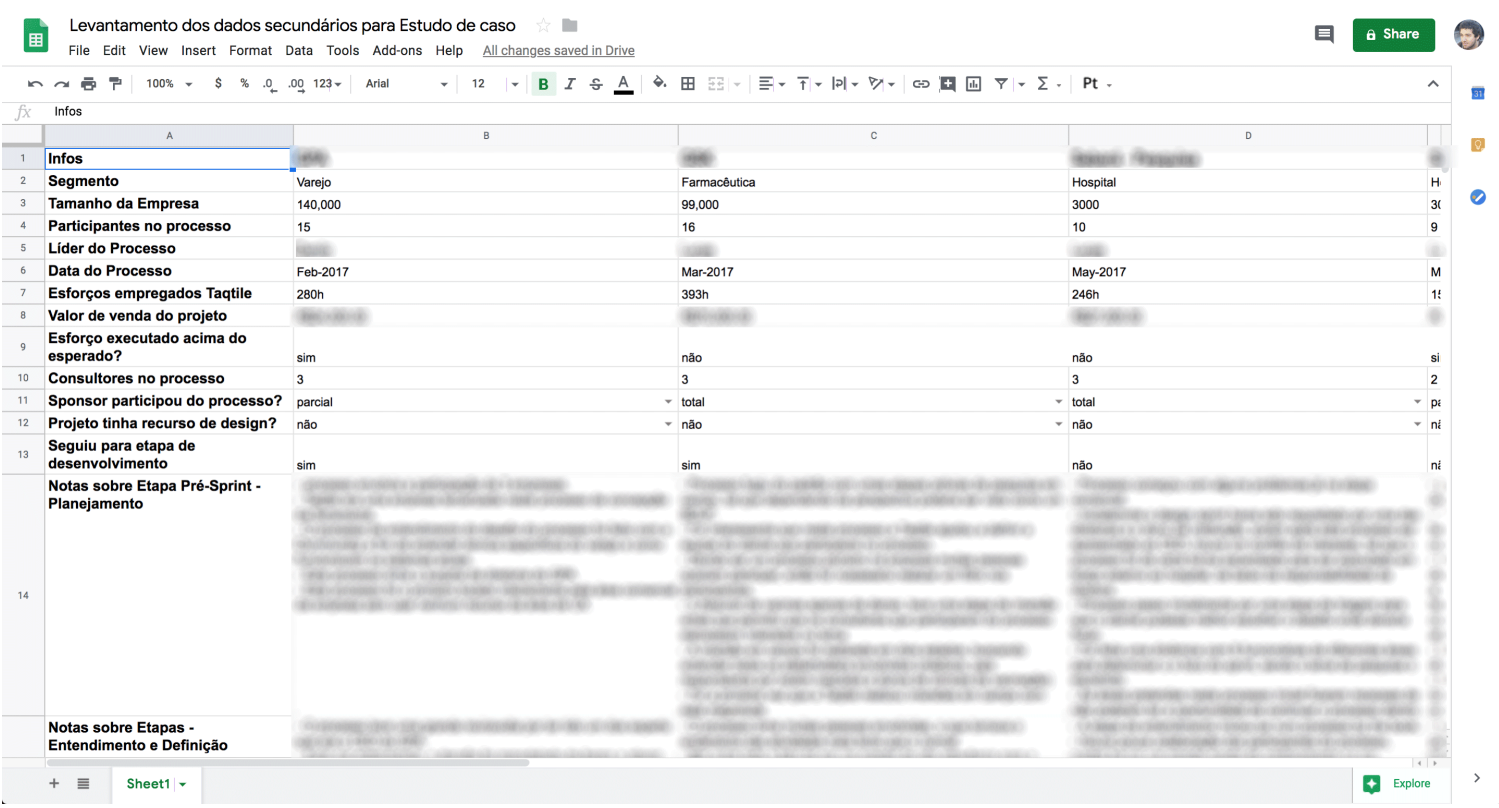

Figura 29: Google Sheets - levantamento dos dados secundários para estudo de caso. Fonte: O autor

Após levantamento dos dados secundários dos projetos de cada entrevistado, foram feitas entrevistas presenciais que duraram entre 90 e 150 minutos, dependendo do entrevistado e tinham por objetivo analisar os principais tópicos das perguntas de pesquisa: raison d'être do UFD (benefícios para o UCASD), quais contextos ele se mostra mais relevante, uma comparação dos processos de BDUF e LDUF e análise da equipe, tempo de execução e dos fatores contingenciais.

A condução das entrevistas seguiu o questionário visto na Tabela 8, onde inicialmente os entrevistados foram apresentados ao tema de pesquisa, em seguida eram questionados 
sobre o porquê da realização dos Design Sprints, quais suas contribuições para a criação do software, e em seguida os casos eram revisados sucintamente a partir dos principais achados na análise documental dos projetos e a última parte da entrevista era conduzida de forma semi-estruturada, com perguntas abertas, de forma a estimular novos insights para melhor composição do modelo criado.

Os áudios das entrevistas foram gravados para posterior análise e tabulação segundo os pontos centrais do roteiro prévio de entrevista, para facilitar a generalização analítica.

\subsection{Proposições e modelo de pesquisa}

As proposições de pesquisa foram extraídas da literatura (ver Tabela 8), e culminam com a análise das questões de pesquisa sobre a realização do LDUF no contexto do UCASD.

Tabela 8: Roteiro de Entrevistas

\begin{tabular}{|c|c|c|c|}
\hline ID & Proposições & ID & Pergunta \\
\hline $\mathrm{P} 1$ & $\begin{array}{l}\text { As organizações buscam integrar } \\
\text { UCD ao desenvolvimento ágil para al- } \\
\text { cançar vantagens no projeto e pro- } \\
\text { duto de software (SY, 2007; AR- } \\
\text { DITO et al., 2014; LINDSTRÖM; } \\
\text { MALMSTEN, 2011; SCHÖN et al., } \\
\text { 2016; HUSSAIN; SLANY; HOLZIN- } \\
\text { GER, 2009a; ADIKARI; MCDO- } \\
\text { NALD; CAMPBELL, 2009; DAY- } \\
\text { TON; BARNUM, 2009; PARSONS et } \\
\text { al., 2007; PATTON, 2002; KAUTZ, } \\
\text { 2011; SINGH, 2008). }\end{array}$ & Q1 & $\begin{array}{l}\text { Quais são os benefícios para o pro- } \\
\text { jeto em adotar uma abordagem de } \\
\text { UCD para projetos ágeis de soft- } \\
\text { ware? }\end{array}$ \\
\hline & & Q2 & $\begin{array}{l}\text { Quais são os benefícios para o pro- } \\
\text { duto em adotar uma abordagem de } \\
\text { UCD para projetos ágeis de soft- } \\
\text { ware? }\end{array}$ \\
\hline
\end{tabular}




\begin{tabular}{|c|c|c|c|}
\hline ID & Proposições & ID & Pergunta \\
\hline $\mathrm{P} 2$ & $\begin{array}{l}\text { As organizações buscam realizar } \\
\text { up-front design em projetos ágeis } \\
\text { para alcançar uma visão compre- } \\
\text { ensiva do produto antes de iniciar } \\
\text { qualquer esforço de desenvolvi- } \\
\text { mento (CHAMBERLAIN; SHARP; } \\
\text { MAIDEN, 2006; FOX; SILLITO; } \\
\text { MAURER, 2008; KOLLMANN, } \\
\text { 2008; BUDWIG; JEONG; KEL- } \\
\text { KAR, 2009; HUSSAIN; SLANY; } \\
\text { HOLZINGER, 2012; OBENDORF; } \\
\text { SCHMOLITZKY; FINCK, 2006; } \\
\text { FELKER; SLAMOVA; DAVIS, 2012; } \\
\text { CABALLERO; MORENO; SEFFAH, } \\
\text { 2016; FERREIRA; NOBLE; BID- } \\
\text { DLE, 2007a; MESZAROS; ASTON, } \\
\text { 2006; LIEVESLEY; YEE, 2006). }\end{array}$ & Q3 & $\begin{array}{l}\text { Qual é a diferença entre iniciar pro- } \\
\text { jetos que tenham passado por uma } \\
\text { etapa de up-front design e projetos } \\
\text { que não o fazem? }\end{array}$ \\
\hline P3 & $\begin{array}{l}\text { Existem diferenças significativas en- } \\
\text { tre o planejamento e execução de pro- } \\
\text { cessos mais extensos como de Design } \\
\text { Thinking para processos mais cur- } \\
\text { tos e com técnicas fechadas como o } \\
\text { Design Sprint (WERDER; ZOBEL; } \\
\text { MAEDCHE, 2016; ALMUGHRAM; } \\
\text { ALYAHYA, 2017; SY, 2007; AR- } \\
\text { DITO et al., 2014; CABALLERO; } \\
\text { MORENO; SEFFAH, 2016; SILVA et } \\
\text { al., 2011) }\end{array}$ & Q6 & $\begin{array}{l}\text { Comparando o que era feito em pro- } \\
\text { cessos de Design Thinking de longa } \\
\text { duração com o que tem sido feito } \\
\text { hoje em processos de Design Sprint: }\end{array}$ \\
\hline
\end{tabular}




\begin{tabular}{|c|c|c|c|}
\hline ID & Proposições & ID & Pergunta \\
\hline & & $\begin{array}{l}\text { Q7 } \\
\text { Q8 } \\
\text { Q9 }\end{array}$ & $\begin{array}{l}\text { O que é melhor ou pior na etapa de } \\
\text { desenho da solução e escolha do que } \\
\text { será prototipado? } \\
\text { O que muda nas etapas de prototi- } \\
\text { pagem e validação? } \\
\text { Quais são as principais diferenças } \\
\text { nos processos como um todo? }\end{array}$ \\
\hline $\mathrm{P} 4$ & $\begin{array}{l}\text { Existem diversas características que } \\
\text { precisam ser levados em consideração } \\
\text { para estruturação do up-front de- } \\
\text { sign, como técnicas, equipe envol- } \\
\text { vida e tempo de execução (BRHEL } \\
\text { et al., 2015; FERREIRA; NO- } \\
\text { BLE; BIDDLE, 2007b; FERREIRA; } \\
\text { SHARP; ROBINSON, 2011; FER- } \\
\text { REIRA, 2012; MAGUIRE, 2001) }\end{array}$ & $\begin{array}{l}\text { Q11 } \\
\text { Q12 }\end{array}$ & $\begin{array}{l}\text { Com que perfil de profissionais } \\
\text { vocês costumam executar o UFD? } \\
\text { Quanto tempo é necessário para re- } \\
\text { alizar o Design Sprint? Porquê? }\end{array}$ \\
\hline
\end{tabular}




\begin{tabular}{|c|c|c|c|}
\hline ID & Proposições & ID & Pergunta \\
\hline P5 & $\begin{array}{l}\text { Não existe uma forma ideal de se } \\
\text { realizar o up-front design de um } \\
\text { projeto de software, mas o que deve } \\
\text { ser considerado é a combinação de } \\
\text { fatores contingenciais do ambiente do } \\
\text { projeto e do projeto, que ajustados } \\
\text { auxiliam na decisão a ser tomado } \\
\text { no planejamento dos esforços iniciais } \\
\text { do projeto (WERDER; ZOBEL; } \\
\text { MAEDCHE, 2016; FOX, 2010; } \\
\text { BARKSDALE; MCCRICKARD, } \\
\text { 2012; CABALLERO; MORENO; } \\
\text { SEFFAH, 2016; BRHEL et al., 2015; } \\
\text { FERREIRA; NOBLE; BIDDLE, } \\
\text { 2007b; FERREIRA; SHARP; RO- } \\
\text { BINSON, 2011; WALE-KOLADE; } \\
\text { NIELSEN; PAIVARINTA, 2014; } \\
\text { WALE-KOLADE, 2015; JIA; LA- } \\
\text { RUSDOTTIR; CAJANDER, 2012) }\end{array}$ & Q14 & $\begin{array}{l}\text { Existem características referentes a } \\
\text { um tipo de projeto ou a um cliente } \\
\text { que podem alterar o planejamento } \\
\text { de como o Design Sprint deve ser } \\
\text { realizado? }\end{array}$ \\
\hline P6 & $\begin{array}{l}\text { A estruturação do up-front design de } \\
\text { um projeto de software ágil deve le- } \\
\text { var em consideração os fatores contin- } \\
\text { genciais da organização, do projeto e } \\
\text { da equipe (WALE-KOLADE; NIEL- } \\
\text { SEN; PAIVARINTA, 2014; ARDITO } \\
\text { et al., 2014; KAUTZ, 2011; BRHEL } \\
\text { et al., 2015; LÁRUSDÓTTIR; CA- } \\
\text { JANDER; GULLIKSEN, 2012) }\end{array}$ & Q15 & $\begin{array}{l}\text { Quais são os fatores que você ana- } \\
\text { lisa antes de começar um Design } \\
\text { Sprint que te ajudam a pensar em } \\
\text { como planejar o processo? }\end{array}$ \\
\hline
\end{tabular}




\begin{tabular}{|l|l|l|l|}
\hline ID & Proposições & ID & Pergunta \\
\hline \multirow{1}{*}{} & Q16 & $\begin{array}{l}\text { Em que ocasiões você teve que sair } \\
\text { do script? Porquê? } \\
\text { Quais fatores você gostaria saber de } \\
\text { cada processo de antemão para me- } \\
\text { lhor organizar cada Design Sprint? } \\
\text { Quais variáveis você gostaria de ter } \\
\text { controle para melhorar o processo e } \\
\text { resultado do Design Sprint? } \\
\text { Perguntas específicas de cada } \\
\text { projeto, baseado no levanta- } \\
\text { mento de dados secundários (es- } \\
\text { sas perguntas foram exploratórias e } \\
\text { variadas dependendo dos processos } \\
\text { executados por cada um dos entre- } \\
\text { vistados) }\end{array}$ \\
\hline
\end{tabular}

Fonte: $\mathrm{O}$ autor

Para facilitar a leitura da compilação do caso, optou-se por iniciar a análise a partir das questões de pesquisa iniciais sobre os benefícios da integração de UCD e ASD não encontrados na literatura, o ciclo de vida do UCASD e as diferenças entre os processos pré-desenvolvimento: LDUF e BDUF (vide Figura 30).

Na sequência são analisadas as principais características dos processos de LDUF com foco nos fatores contingenciais levantados na RSL visualizados na Figura 31.

Conforme apresentado no framework conceitual de pesquisa, extraído da literatura, foram estabelecidos 22 fatores contingenciais dentro de 3 categorias, sendo que os fatores organizacionais serão analisados parcialmente sobre o escopo da empresa focal do estudo e da empresa cliente, e os fatores de projeto e equipe, avaliados por projeto através de dados secundários e entrevista com seus líderes, a serem exploradas no estudo de caso, visando facilitar a análise e apresentação da generalização analítica do estudo de caso.

O formato de análise escolhido tem interesse em combinar padrões entre os casos (processos) que possam contribuir com estes fatores contingenciais de origem teórica.

Para a apresentação das lições aprendidas com os casos, optou-se pela descrição direta das informações relevantes separadas de acordo com o interesse de cada contingência, 


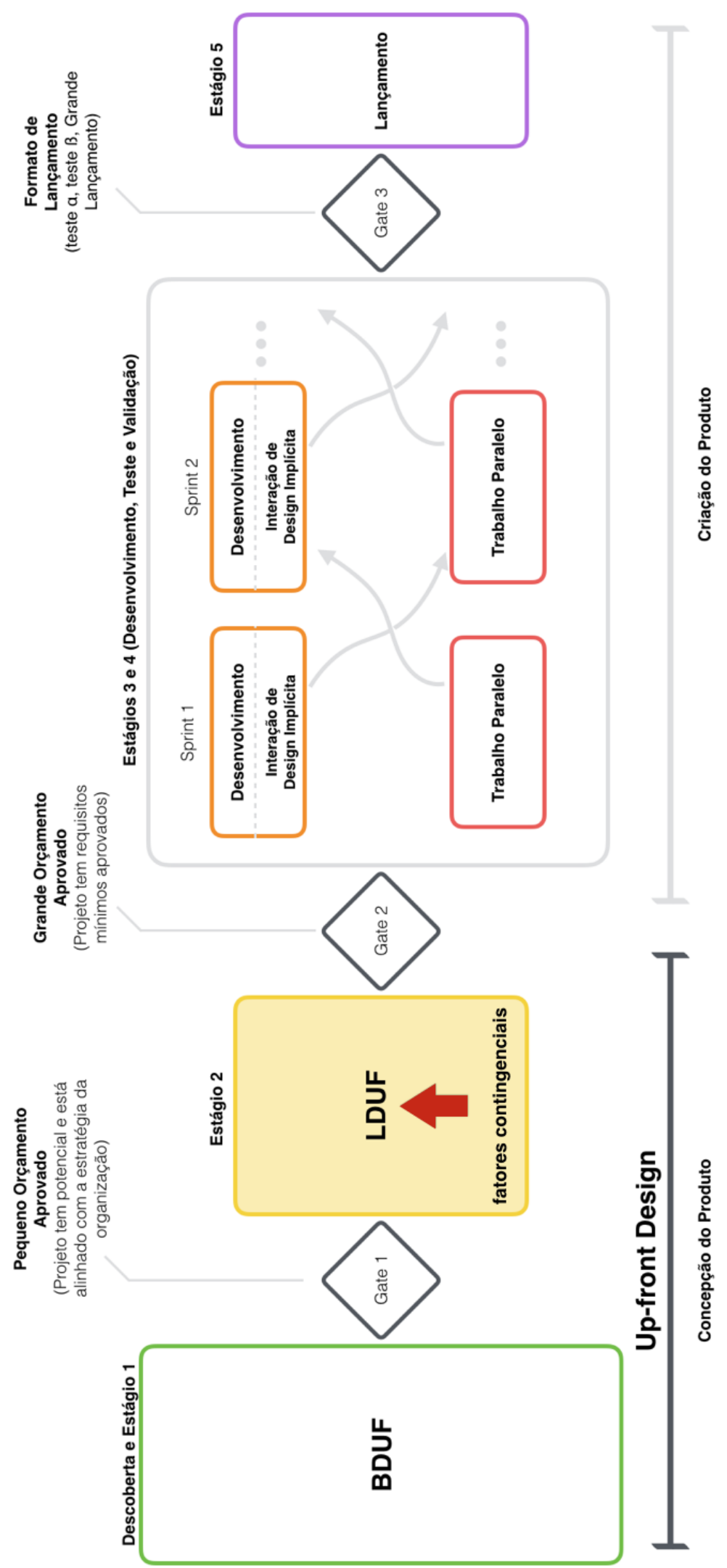

Figura 30: Influência dos Fatores Contingenciais no LDUF no UCASD. Fonte: O autor. 


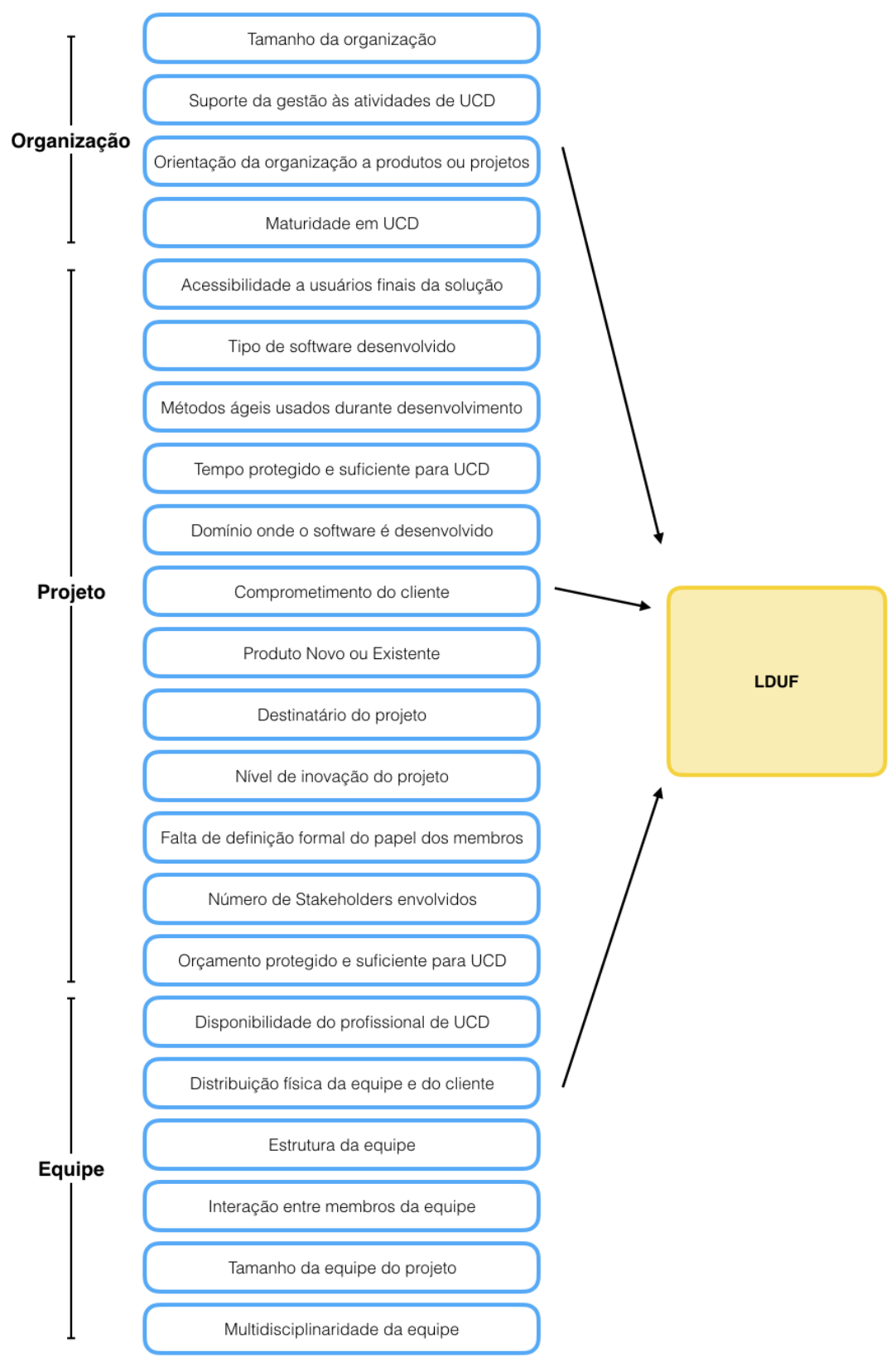

Figura 31: Framework conceitual de influência dos fatores contingenciais no UFD extraído da literatura. Fonte: O autor

de modo a facilitar as conclusões, sem uma narrativa separada para cada caso. Nessa situação, o capítulo de resultados abrigará os conjunto de padrões analisados, separados de acordo com sua relação com cada um dos fatores contingenciais, de forma a confirmar, refutar e complementar os achados na literatura.

Por último, para análise qualitativa dos fatores contingenciais obtidos em campo, esta pesquisa utiliza como referência as recomendações de Miles et al. (1994) através do aprimoramento de um framework conceitual capaz de sintetizar de forma gráfica e compreensível os principais aprendizados desta pesquisa. 


\section{RESULTADOS E DISCUSSÃO}

Neste capítulo são apresentados e discutidos os resultados obtidos com a realização dos estudos de caso. As análises feitas buscaram evidenciar características em comum ou díspares levantadas na RSL com os principais aspectos do UFD e fatores contingenciais mais relevantes nos processos avaliados no ponto de vista dos entrevistados.

Na primeira parte deste capítulo foram avaliadas as percepções dos entrevistados sobre o processo de UFD: quais são os benefícios aportados e como se encaixa no UCASD (vide questão de pesquisa 1).

Na sequência, foi feita uma comparação dos processos de BDUF e LDUF, e foram adicionadas informações relevantes (não obtidas na literatura) sobre os principais pontos do LDUF: Equipe, Tempo de execução e gate de decisão - Vai para Desenvolvimento (vide questões de pesquisa 2 e 3 ).

Por último foram analisados individualmente como cada um dos fatores contingenciais influenciaram processos de LDUF com base no levantamento de dados secundários e visão dos entrevistados. Os achados em campo foram contrastados com a literatura e, a partir disso, foram feitas melhorias no modelo de ciclo de vida do UCASD (vide Figura 30) e o framework conceitual de influências dos fatores contingenciais sobre o LDUF (vide Figura $31)$.

\subsection{UFD em UCASD}

Como a primeira questão de pesquisa tem um ponto inicial teórico (o que é o UFD), incialmente foram explanados os construtos mais relevantes para a pesquisa, e em seguida iniciou-se o questionário de forma a entender a percepção dos entrevistados sobre a incorporação do UFD em projetos ágeis de software. Para os entrevistados, foi um consenso que esta etapa de concepção da solução antes do desenvolvimento tende a ser opcional, já que apenas o desenvolvimento em si é o necessário para se se obter um soft- 
ware, porém o UFD se mostra relevante por ser uma maneira alternativa para definir requisitos de software e dispor de antemão de uma visão do produto, e neste sentido traz diversos benefícios tanto para o projeto de software (fatores críticos para o sucesso do projeto, atrelados a tríade - custo, prazo e escopo) como para o produto criado (fatores críticos de sucesso para o produto, atrelados a resultados financeiros deste, visibilidade, reconhecimento, etc.), sendo alguns deles já mencionados pela literatura, e outros ainda não mapeados, descritos a seguir.

\subsubsection{Benefícios para o projeto}

Dentre os benefícios destacados pelos entrevistados, existem aqueles que reforçam pontos já mencionados na literatura, como:

- Promover maiores discussões entre designers e desenvolvedores, em busca de melhor qualidade de software (FERREIRA; SHARP; ROBINSON, 2012).

- Aumento da motivação da equipe, que tem maior consciência das motivações do projeto e se sente mais dona do produto, ao invés de apenas encarar o projeto como realizar tarefas sem um propósito maior (KAUTZ, 2011; SINGH, 2008; SCHÖN et al., 2016).

- Testes de usabilidade permitem reconhecer possíveis falhas no sistema, reduzindo retrabalho de desenvolvimento (DAVIS; VENKATESH, 2004).

- Com a entrega do protótipo, existe uma redução da expectativa do cliente (tal que com o protótipo ele pode ter uma visão grande do sistema já em seu início) que em outros casos demora muito mais quando parte direto para o desenvolvimento, dando maior tranquilidade para o time de projeto (KAUTZ, 2011).

- Economia de tempo e dinheiro ao ter maior assertividade na definição dos requisitos do projeto e garantir melhores estimativas e priorizações ao longo do mesmo (PATTON, 2002; LINDSTRÖM; MALMSTEN, 2011).

Além dos pontos acima, também foram identificados os seguintes benefícios para o projeto de software quando executado o UFD:

- Auxilia na reconstrução e aprimoramento de briefing, resultando em projetos com requisitos menos voláteis. 
- O trabalho de co-criacão, permite entender melhor os stakeholders envolvidos, trazendo diversos benefícios ao projeto, tanto no âmbito comercial com o cliente ou consumidor final, como para melhorar uma comunicação com estes, evitando retrabalhos durante o projeto.

- Como consequência do ponto acima, também foi citada uma maior facilidade em vender melhorias no projeto para o próprio cliente (permitindo maior flexibilidade em caso de necessidade de aumento de escopo).

- Equipe de desenvolvimento tende a realizar entregas mais aderentes ao que o cliente deseja.

- Aumenta o engajamento do cliente ao longo do projeto.

Um dos respondentes cujo background é majoritariamente técnico, disse que existe um importante contraponto a ser levado em consideração nesta etapa, já que a ausência de restrições técnicas no UFD pode favorecer a inovação, no entanto existe um risco de que a equipe do UFD conceba uma solução inviável de ser implementada tecnologicamente, frustrando o cliente no médio prazo.

\subsubsection{Benefícios para o produto}

Foi possível confirmar o principal benefício para o produto, apresentado na literatura:

- Conhecer reais necessidades dos usuários e construir produtos que tenham maior relevância para o usuário final, tendem a trazer melhores resultados para o produto criado (SY, 2007; ARDITO et al., 2014; ADIKARI; MCDONALD; CAMPBELL, 2009; HUSSAIN; SLANY; HOLZINGER, 2012; DAYTON; BARNUM, 2009; LINDSTRÖM; MALMSTEN, 2011; SCHÖN et al., 2016).

Além disso, emergiram das conversas com os entrevistados, outros benefícios secundários para o produto, são eles:

- Reduzir custos do projeto e diminuir time-to-market, ao conseguir priorizar melhor os recursos mais importantes do projeto e lançar o produto no mercado com mais velocidade.

- A percepção de valor do usuário facilita na definição inicial do backlog e roadpmap do produto (MOSTAFA, 2013). 


\subsubsection{Contexto de aplicação}

Não houve consenso dos participantes quanto aos contextos de aplicação mais relevantes para se integrar UCD ao ágil. Dois participantes indicaram essa integração deve ser feita para todos os tipos de projetos, visto que, no pior dos casos, existem os benefícios relacionados a melhoria de interação entre membros da equipe (motivação, comunicação, etc.), e da equipe do projeto com outros stakeholders (maior empatia pelo usuário, maior comprometimento do cliente ao longo da criação do software, etc.). Por outro lado, três outros entrevistados levantaram três características que justificam em maior ou menor grau o valor da realização do UFD antes do início do desenvolvimento. A seguir um detalhamento sobre cada uma delas.

\section{Projetos com grandes problemas de negócio ou UX (não técnicos) a serem resolvidos}

Quando são analisadas os principais tópicos de gestão de produtos - alcançar objetivos de negócio, atender necessidades de mercado, utilizar tecnologia disponível, existe um valor enorme em realizar o processo de UFD quando há uma incerteza sobre como encontrar uma solução que atenda as necessidades de consumidores de um mercado em potencial, e ainda seja capaz de produzir resultados financeiros significativos. Pelas etapas de alinhamento com stakeholders, e validação de protótipos com potenciais consumidores, o UFD permite aumentar a assertividade de um produto que atenda a estas duas necessidades.

Um contraponto levantado por um dos entrevistados, é que existem casos onde se realiza UFD para reestruturar a interface visual de softwares existentes (este foi o caso de dois projetos da empresa $\mathrm{M}$ e de projetos das empresas, P, Q, R e U). Porém, nestes casos, o modelo de Trabalho Paralelo pode se mostrar mais condizente, pois consegue atacar diretamente os testes de usabilidade com clientes e fornecer requisitos imediados a equipe de desenvolvimento, sem que seja necessário retardar o início do desenvolvimento das melhorias levantadas.

\section{Projetos que os requisitos ainda estão instáveis}

Iniciar o desenvolvimento de projetos cujos requisitos ainda são incertos, seja porquê o cliente não soube definir os micro-requisitos do projeto, ou porquê existe um entendimento diferente dos mesmos para cada um dos stakeholders do projeto, tendem a exigir maior retrabalho após cada entrega parcial do software.

Neste sentido, o UFD apresenta algumas características fundamentais para garantir maior alinhamento com stakeholders e menor retrabalho futuro. 
As etapas de alinhamentos com stakeholders contribuem para garantir que o software de alguma forma incorpore as necessidades dos diferentes envolvidos no projeto (ex: área de marketing tem diferentes necessidades da área comercial e de TI).

O protótipo por apresentar uma interface visual permite que todos tenham uma visão mais palpável do que será o produto final criado.

A etapa de validação traz consigo a voz do consumidor preponderante para a organização, de forma que os achados em campo tendem a dar maior confiabilidade aos requisitos definidos.

\section{Projetos cujas regras de negócio não sejam regidas pela integração com sistemas legados}

Em projetos em que há uma grande necessidade de integração com sistemas legados, tendem a ter uma maior limitação técnica de que dados estão disponíveis, como podem ser acessados, o que podem restringir o valor gerado nestes processos de UFD.

A integração com sistemas legados não inviabiliza a execução do UFD, inclusive pode facilitar a criação do software, porém implica em uma maior restrição do mesmo e exige a presença de pessoas técnicas com conhecimento destes sistemas legados, para garantir que a solução é tecnicamente viável de ser implementada posteriormente.

É importante lembrar que a discussão acima somente se enquadra em projetos em que existe um usuário final. São desconsiderados, portanto, projetos de software que não tem interfaces com nenhum ser humano, como integração entre sistemas, armazenamento de dados, etc.

\subsubsection{LDUF versus BDUF}

Como dito no capítulo 5, a organização foco deste estudo teve uma transição há alguns anos atrás de realizar o BDUF onde eram realizados processos de Design Thinking por cerca de 2 a 4 meses para o LDUF através da realização de Design Sprints de 1 semana. Deste movimento participaram quatro dos cinco entrevistados o que naturalmente já representa uma preferência pelo segundo modelo em detrimento do primeiro. Ainda assim, após a análise da etapa de UFD, os entrevistados foram questionados a comparar os processos de BDUF e LDUF de forma a trazer vantagens de desvantagens de um frente ao outro.

Neste sentido, é importante salientar de que a análise feita pelos entrevistados está 
intimamente conectada à comparação do framework do Design Sprint com os processos de Design Thinking (orientados pelos guias da IDEO).

Para simplificar o processo comparativo, foi solicitado aos autores que comparassem os processos em cada uma das diferentes etapas dos mesmos.

A seguir são descritos os principais pontos que emergiram das respostas dos entrevistados, sendo que para aderência ao restante da pesquisa, Design Sprint é o LDUF enquanto processos mais longos de Design Thinking são descritos como BDUF. 
Tabela 9: Vantagens e desvantagens dos processos de LDUF frente aos processos de BDUF

\begin{tabular}{|c|c|c|}
\hline Etapas & $\begin{array}{l}\text { Vantagens do LDUF frente ao } \\
\text { BDUF }\end{array}$ & $\begin{array}{l}\text { Desvantagens do LDUF frente } \\
\text { ao BDUF }\end{array}$ \\
\hline $\begin{array}{l}\text { Entender e } \\
\text { Definir }\end{array}$ & $\begin{array}{l}\text { A etapa de definição (escolha de } \\
\text { um foco mais específico do problema } \\
\text { maior) ajuda a equipe a se man- } \\
\text { ter focada apenas no que é mais } \\
\text { importante. O conceito de parking } \\
\text { lot (estacionar as ideias menos pri- } \\
\text { oritárias para serem atacadas pos- } \\
\text { teriormente em outros projetos) e } \\
\text { definir um foco principal, fomenta } \\
\text { que as demais atividades do sprint } \\
\text { sejam realizadas todas dentro do } \\
\text { tempo previsto. Em processos de } \\
\text { Design Thinking, nesta etapa de en- } \\
\text { tendimento, durante o momento de } \\
\text { divergência muitas vezes a equipe de } \\
\text { projeto se estendia demasiadamente } \\
\text { sem trazer muitos benefícios para } \\
\text { o processo. Um caso exemplo do } \\
\text { mencionado anteriormente foi um } \\
\text { projeto com uma farmacêutica, que } \\
\text { em decorrência da intenção do cli- } \\
\text { ente de abarcar as ideias de todas } \\
\text { as áreas da empresa, acabou por } \\
\text { tornar o processo longo, com sua } \\
\text { execução em } 6 \text { meses. }\end{array}$ & $\begin{array}{l}\text { No Design Sprint existe um maior } \\
\text { enviesamento do processo pois toda } \\
\text { a etapa de entendimento se faz in- } \\
\text { ternamente com orientação de - te- } \\
\text { chnology push, através dos partici- } \\
\text { pantes e experts, e portanto justa- } \\
\text { mente para evitar desperdícios, não } \\
\text { prevê avaliação de fatores externos } \\
\text { como testes de usabilidade do pro- } \\
\text { duto final, pesquisas extensas em } \\
\text { campo com usuários de fora da em- } \\
\text { presa, análise de dados ou outras } \\
\text { técnicas de observação mais comuns } \\
\text { no Design Thinking, mais orientado } \\
\text { a inovação no modelo market-pull } \\
\text { (FIGUEIREDO et al., 2019). }\end{array}$ \\
\hline
\end{tabular}




\begin{tabular}{|c|c|c|}
\hline Etapas & $\begin{array}{l}\text { Vantagens do LDUF frente ao } \\
\text { BDUF }\end{array}$ & $\begin{array}{l}\text { Desvantagens do LDUF frente } \\
\text { ao BDUF }\end{array}$ \\
\hline $\begin{array}{l}\text { Divergência } \\
\text { e Decisão }\end{array}$ & $\begin{array}{l}\text { A etapa de decisão (escolha de ape- } \\
\text { nas uma solução principal e "aban- } \\
\text { dono" das demais) facilita o trabalho } \\
\text { da equipe na etapa de prototipagem } \\
\text { por focar apenas nos conceitos mais } \\
\text { importantes para compor a solução } \\
\text { final. } \\
\text { Soluções desenhadas na etapa de di- } \\
\text { vergência não escolhidas como pri- } \\
\text { oritárias para prototipagem podem } \\
\text { ser utilizadas como insumos para re- } \\
\text { alização de novos Design Sprints ou } \\
\text { até projetos individuais. A mentali- } \\
\text { dade que uma nova iteração do De- } \\
\text { sign Sprint é curta ajuda na orga- } \\
\text { nização desses potenciais "próximos } \\
\text { passos" que por sua vez acaba sendo } \\
\text { mais organizada que em processos } \\
\text { de Design Thinking. } \\
\text { O processo de criação de conceitos } \\
\text { e soluções, realizado de forma indi- } \\
\text { vidual e anônima previsto no De- } \\
\text { sign Sprint, difere dos brainstorms } \\
\text { mais adotados em processos de De- } \\
\text { espaço para ideias que não sejam } \\
\text { apenas dos participantes de maior } \\
\text { influência na empresa. }\end{array}$ & $\begin{array}{l}\text { A procura de benchmarks é um } \\
\text { passo muito pouco explorado no } \\
\text { Design Sprint. Nas referências de } \\
\text { Design Thinking existem diversas } \\
\text { metodologias específicas para faci- } \\
\text { litar essa etapa do trabalho. Esse } \\
\text { pode ser um potencial limitador de } \\
\text { criação de ideias, justificando o De- } \\
\text { sign Thinking como uma processo } \\
\text { ideal para conceber ideias "fora da } \\
\text { caixa". }\end{array}$ \\
\hline
\end{tabular}




\begin{tabular}{|c|c|c|}
\hline Etapas & $\begin{array}{l}\text { Vantagens do LDUF frente ao } \\
\text { BDUF }\end{array}$ & $\begin{array}{l}\text { Desvantagens do LDUF frente } \\
\text { ao BDUF }\end{array}$ \\
\hline $\begin{array}{l}\text { Protótipo e } \\
\text { validação }\end{array}$ & $\begin{array}{l}\text { No Design Sprint, as tarefas de pro- } \\
\text { totipagem são bem específicas e aju- } \\
\text { dam a equipe a realizar o protótipo } \\
\text { em menos tempo. O tempo de um } \\
\text { dia acaba obrigando a equipe a re- } \\
\text { duzir escopos e focar apenas no es- } \\
\text { sencial }\end{array}$ & $\begin{array}{l}\text { Na etapa de prototipagem do De- } \\
\text { sign Sprint, em decorrência do } \\
\text { tempo restrito para prototipar, ge- } \\
\text { ralmente são criados componentes } \\
\text { da interface visual que não são } \\
\text { alinhados com o produto final e } \\
\text { portanto são descartados posterior- } \\
\text { mente. Em processos anteriores de } \\
\text { Design Thinking sem essa restrição, } \\
\text { era investido um tempo maior nesta } \\
\text { etapa, que no caso de ser validado } \\
\text { pelo cliente, parte do protótipo já } \\
\text { era reaproveitado durante a etapa } \\
\text { de design da interface visual do pro- } \\
\text { duto. } \\
\text { A prototipagem em um dia prevista } \\
\text { no Design Sprint tende a ser ori- } \\
\text { entada a produtos digitais e existe } \\
\text { pouca orientação de como pode ser } \\
\text { feita para produtos de outra natu- } \\
\text { reza. Validar protótipos não digi- } \\
\text { tais realizados em menos de um dia } \\
\text { pode ser uma tarefa complexa. }\end{array}$ \\
\hline
\end{tabular}




\begin{tabular}{|c|c|c|}
\hline Etapas & $\begin{array}{l}\text { Vantagens do LDUF frente ao } \\
\text { BDUF }\end{array}$ & $\begin{array}{l}\text { Desvantagens do LDUF frente } \\
\text { ao BDUF }\end{array}$ \\
\hline $\begin{array}{l}\text { Processo } \\
\text { como um } \\
\text { todo }\end{array}$ & $\begin{array}{l}\text { A atuação da equipe costuma ser fa- } \\
\text { cilitada pelo processo já apresentar } \\
\text { uma sequência de métodos defini- } \\
\text { dos. Além disso, por ser um fra- } \\
\text { mework mais fechado, é possível re- } \\
\text { plicá-lo com recursos de menor ma- } \\
\text { turidade. } \\
\text { A realização do processo em curto } \\
\text { espaço de tempo, mantém a equipe } \\
\text { mais focada e motivada para al- } \\
\text { cançar os objetivos finais, enquanto } \\
\text { em processos de Design Thinking } \\
\text { mais longos era perceptível uma dis- } \\
\text { persão dos participantes ao longo do } \\
\text { trabalho. } \\
\text { Um ponto em evidência no Design } \\
\text { Sprint é a participação do spon- } \\
\text { sor como decisor do processo. Isso } \\
\text { tende a garantir a continuação do } \\
\text { mesmo por a solução concebida es- } \\
\text { tar alinhada com os objetivos da } \\
\text { empresa. } \\
\text { O processo de Design Sprint de- } \\
\text { obter aprendizados de forma muito } \\
\text { rápida }\end{array}$ & $\begin{array}{l}\text { Justamente por apresentar um pro- } \\
\text { cesso definido, o Design Sprint, } \\
\text { mesmo quando adaptado, acaba } \\
\text { sendo limitado pelas técnicas envol- } \\
\text { vidas. No Design Thinking, proces- } \\
\text { sos podem ser melhor balanceados } \\
\text { dependendo do contexto. } \\
\text { Por mais enxuto que seja o pro- } \\
\text { cesso de Design Sprint, ele ainda } \\
\text { assim exige a participação de uma } \\
\text { equipe multidisciplinar durante um } \\
\text { mínimo período de tempo. Esta } \\
\text { alocação pode ser complexa e cara, } \\
\text { de forma que pequenos desafios po- } \\
\text { dem não justificar a realização de } \\
\text { um Design Sprint. Assim, depen- } \\
\text { dendo do caso, adotar metodologias } \\
\text { isoladas vistas nas referências de } \\
\text { Design Thinking, pode apresentar } \\
\text { uma melhor relação custo-benefício. }\end{array}$ \\
\hline
\end{tabular}

Fonte: O autor

Como visto no Quadro 9, existem diversas novidades no Design Sprint que justificam a sua utilização em outro momento do ciclo de vida do UCASD, como alternativa a definição de requisitos clássicas de engenharia de software (TEIXEIRA, 2017).

Baixa barreira de experimentação: Por ser um processo curto e com técnicas pré-determinadas, existe vantagens de baixo investimento necessário e num formato de 
fácil replicação, onde qualquer funcionário/empresa pode começar a realizar internamente processos desta natureza.

Alinhamento com alta gerência "garante" continuação do trabalho: A participação de um stakeholder da alta gerência como decisor no Design Sprint, e a forma como ele pode conduzir o Sprint de forma a alinhá-lo com os objetivos da empresa e a equipe que porventura irá trabalhar no projeto, permite que o projeto concebido entre diretamente na etapa de desenvolvimento, sem passar pela etapa de seleção de projetos (JUNIOR; CARVALHO, 2009), sendo assim não é apenas um grande motivador para os participantes do sprint (de que estão produzindo algo que provavelmente sairá do papel), mas também elimina gastos desnecessários, de colocar esforço na geração de ideias que serão descartadas.

Orientado a inovações incrementais: Por seu caráter enxuto, de sempre manter discussões focadas apenas no que é prioritário e criação de soluções que sejam possíveis de serem testadas com algum consumidor, o Design Sprint limita o potencial de criação de soluções que produzam uma inovação radical. Por suas influências da Lean Startup, de caráter incremental e contínuo, o Design Sprint tende a conceber soluções que tragam inovações incrementais, de menor risco, mais fáceis de se obter e de serem gerenciadas por startups.

Estes três argumentos de baixo custo, garantia de alinhamento aos objetivos da empresa e orientação à inovações contínuas e incrementais, sugerem que, diferente de processos de Design Thinking, utilizados para geração de ideias (DOROW et al., 2016), o Design Sprint se enquadra como uma metodologia a ser realizada como parte inicial de projetos, antes de seu desenvolvimento, para sanar dúvidas do mesmo e reduzir incertezas do projeto, definir uma visão do produto, como visto no modelo de pesquisa (vide Figura 20).

Além disso, ficou evidenciado que o Design Sprint se mostra mais eficiente quando existe um escopo de trabalho bem definido. Pelo entendimento ser realizado inteiramente a partir de conhecimento internos a empresa e experts, sem tempo para análises e observações externas, os participantes ficam limitados a trabalhar com insumos do que já é conhecido pelos participantes do processo. Neste sentido, para trabalhar em problemas capciosos (RITTER; BAXTER; CHURCHILL, 2014), fica evidenciado a necessidade da participação de experts que aportem grande conhecimento aos participantes do sprint, ou que seja incluída uma etapa prévia de entendimento de variáveis desconhecidas pelos participantes ou até mesmo de geração de ideias como em processos de Design Thinking. 


\subsection{Planejamento padrão do LDUF}

\subsubsection{Equipe}

Após a análise de diferenças entre processos com características de LDUF e BDUF, os entrevistados foram questionados quanto aos principais tópicos de preocupação no planejamento do LDUF.

Com relação à estruturação da equipe, o primeiro ponto e mais importante a ser estabelecido é a definição do facilitador do processo.

Para três entrevistados, o facilitador pode ser uma pessoa de qualquer background como TI, design, gestão, etc. Enquanto que dois outros entrevistados acreditam que seria mais interessante se esta pessoa ter conhecimentos prévios de UX. Essa não convergência de ideias, de certa forma, é um reflexo da abertura de alternativas de equipe vistas na RSL, de equipes especialistas e generalistas, onde cada uma das opções tem seus prós e contras.

Ainda assim, os entrevistados todos convergiram na questão de responsabilidades e importância deste personagem e do seu papel dentro do processo de UFD. O facilitador é o maior responsável pelo andamento e consequente sucesso do Design Sprint. Entre suas responsabilidades, existem partes de planejamento, como garantir a agenda dos participantes do sprint (difícil de conciliar por ser um processo que exige participação em tempo integral de diversas pessoas), encontrar um local ideal para condução das atividades, e pré-alinhamento do desafio e expectativas de resultados com os sponsors do projeto. Além disso como parte mais operacional, é exigido dele que sejam disponibilizados à equipe insumos e conhecimentos para os participantes realizarem o sprint, seja por organização de informações disponíveis, realização de estudos prévios em campo e garantir a participação de experts adequados para o processo, além de realizar a condução dos participantes em cada uma das etapas. Em decorrência de algumas falhas de comunicação nos projetos das empresas C, D e M, onde participantes declararam não poder participar no processo por conflito de agenda ou processo ter sido iniciado sem claros alinhamentos com os stakeholders mais importantes para o processo, três dos entrevistados ressaltaram ser importante que todas as tarefas tenham um único responsável (ainda que esta pessoa seja auxiliada por outras) pois o grande número de participantes, e condição de tempo restrito, exige que não exista perda de informações ou atividades não realizadas por falta de um responsável claro.

Em referência ao restante da equipe, a organização tenta seguir as recomendações do 
Design Sprint, buscando formar equipes multidisciplinares de seis a sete pessoas. Além disso, a expertise normalmente está espalhada em várias cabeças diferentes, e ter certeza que todo mundo está começando alinhado é fundamental para o sucesso do programa. Designers sabem de coisas que os desenvolvedores desconhecem, os sponsors do projeto sabem de coisas que os gestores de produtos não sabem e assim por diante (KNAPP; ZERATSKY; KOWITZ, 2016). Neste sentido, os processos em geral são conduzidos com dois a três consultores da organização foco deste estudo e uma equipe do cliente de cerca de seis a sete pessoas. Este tamanho de equipe permite trabalhar com um grupo que não seja tão pequeno, a ponto de ter suficientes pontos de vista sobre o negócio, nem tão grande, pois tendem a aumentar as discussões dificultando que as atividades se encaixem no limite de tempo disponível. Ainda foi levantado pelos entrevistados um ponto ainda não mencionado na literatura do tema de que idealmente a equipe deve ser composta de perfis diferentes, com pelo menos uma pessoa da alta gerência com visão mais estratégica e capaz de garantir que o resultado gerado no processo esteja alinhado com as expectativas da empresa, bem como uma pessoa mais operacional que tenha maior contato com o cliente final e possa aportar ao grupo esta visão do cliente (já que, como visto na seção anterior, neste processo o usuário final costuma não participar do processo).

Um outro ponto que surgiu em duas entrevistas relacionado à esfera de equipe destes processos, foi a disponibilidade dos participantes do processo, quanto à estes serem esporádicos ou integrais no processo. Ambos entrevistados comentaram que é preferível um time mais enxuto a uma equipe maior que não está $100 \%$ envolvida no processo. Na seção seguinte de fatores contingenciais serão descritos porquê das preferências da equipe por estas orientações de formação da equipe e o que ocorreu em alguns casos onde ela não foi seguida.

\subsubsection{Tempo}

O livro de Knapp, Zeratsky e Kowitz (2016) apresenta o framework como a fórmula para solução de grandes problemas em 5 dias. Ainda assim, desde os princípios de aplicabilidade deste processo junto a seus clientes, houve uma variação grande do tempo exigido para condução das atividades previstas.

De volta à 2016, quando a organização começou a executar processos de Design Sprint, normalmente os processos eram realizados em duas semanas. O motivo exposto pelo líder de UX 1 e o diretor de porquê não era possível executar os processos em cinco dias como previsto no livro, decorria do fato de ser muito complexo demandar a alocação de um de- 
terminado grupo de pessoas (muitas vezes algumas delas não serem diretamente ligadas ao projeto) integralmente durante toda uma semana. Além disso, a organização executava atividades além do escopo previsto no sprint para aportar maior valor ao processo (realizando busca de benchmarks e construindo protótipos de altíssima fidelidade). Com o passar do tempo, a metodologia de Design Sprint ficou mais conhecida no mercado, aumentando a consciência de clientes do valor de alocar uma equipe $100 \%$ no processo, e os líderes de processo se conscientizaram que as atividades extras incluídas no processo não aportavam tanto valor ao resultado final, de forma que pouco a pouco a organização conseguiu enxugar o processo de 2 semanas para processos de cinco dias úteis.

Em 2018 através de discussão da comunidade global de designers, popularizou-se uma versão ainda mais ágil do processo, em quatro dias, o Design Sprint 2.0 (COURTNEY, 2018). Nos últimos meses a organização conseguiu acompanhar essas evoluções e tem feito processos de sprint neste tempo delimitado. Os maiores aprendizados são de que a equipe apenas deve manter-se focada naquilo que é mais crítico para o desafio proposto e seguir as atividades como propostas dentro do limite de tempo que os processos costumam chegar em seu final com resultados de alto valor, considerando os aprendizados, o tempo e esforços envolvidos. A organização agora busca outras formas de aprimoramento de eficácia do processo, seja por redução do tempo das atividades, ou melhorias no processo de pré-sprint, para garantir que as pessoas estão trabalhando no desafio "certo" e com insumos suficiente (HALL, 2013).

\subsubsection{Gate de decisão - continuação para desenvolvimento}

Apesar de não ser apresentado nem na literatura nem nos referenciais da área (KNAPP; ZERATSKY; KOWITZ, 2016), existe invariavelmente uma etapa onde o cliente precisa decidir pela continuação ou não do conceito criado, seja um novo produto ou melhoria de um existente, para uma etapa de desenvolvimento mais custosa.

Neste sentido, a organização estudada sempre teve um mesmo modelo de apresentação dos resultados do processo para a equipe do cliente envolvida (que muitas vezes não acompanhava os testes do protótipo) junto a alta gerência que deveria avaliar a continuação ou não para as etapas posteriores.

Essa apresentação era composta por:

- Principais tomadas de decisão pela equipe ao longo do processo (qual o desafio, quais os objetivos de longo prazo, etc.) 
- A solução (interfaces visuais, requisitos técnicos e de negócio do produto concebido)

- Aprendizados do processo (o que foi descoberto com o teste da solução)

- Priorização do roadmap do produto a partir dos aprendizados no processo

- Estimativa de custos das próximas etapas

O mapeamento das atividades acima propõe um novo formato de definição de requisitos de software clássico proposta no ASD pois incorpora pontos críticos de visão do produto, e uma expectativa prévia de resultados que o produto pode alcançar quando implementadas para um determinado mercado. Este formato está em linha com as propostas da literatura para esta etapa, conforme visto em Silva et al. (2011), Ferreira, Noble e Biddle (2007b), Chamberlain, Sharp e Maiden (2006), Asuncion et al. (2011), Salah, Paige e Cairns (2014b), Belchev e Baker (2009), Silva, Silveira e Maurer (2013), Dobrigkeit, Paula et al. (2017), Humayoun, Dubinsky e Catarci (2011), Fox, Sillito e Maurer (2008), Najafi e Toyoshiba (2008), Singh (2008), Ruthford (2002), Prior et al. (2013), Memmel, Gundelsweiler e Reiterer (2007), Tawfik, Belden e Moore (2013), Anwar et al. (2014), Plonka et al. (2014), Ungar e White (2008).

\subsection{Influência dos fatores contingenciais}

Na última etapa da entrevista, os participantes foram questionados sobre quais eram os fatores contingenciais mais relevantes em seus processos de Design Sprint e como estas afetaram o planejamento e execução considerados ideais, exposto nas seções anteriores.

O questionário foi feito em cima dos dados levantados a partir da análise de dados secundários da empresa (sendo analisado projeto a projeto os principais fatores contingenciais), e em seguida era aberto a cada um dos entrevistados um espaço para agregar maiores informações não coletadas anteriormente, ou que simplesmente fosse além dos projetos mapeados.

Os resultados e discussão expostos a seguir já são uma consolidação dos achados por entrevistado e seus projetos.

\subsubsection{Fatores contingenciais associados à organização}

O tamanho da organização se mostrou um fator contingencial mais relevante quando a empresa cliente era muito pequena (até 50 funcionários), como eram os casos 
das empresas H, I, K, Q e R. Nestes projetos, exceto pela organização Q, todos tiveram a participação dedicada do proprietário da empresa, o que garante um maior alinhamento do resultado no LDUF com as expectativas da empresa, aumentando a possibilidade que o projeto avance para a etapa de desenvolvimento e reduzindo a necessidade de documentação extensa do processo para a etapa de Gate de decisão de continuação do projeto. Por outro lado, em casos de empresas maiores, seja uma empresa de 1.000 funcionários ou 100.000 não houve diferenças substanciais notadas que impactassem o sprint. Além disso, diferente do que encontrado na literatura em (FERREIRA; SHARP; ROBINSON, 2012) não foi possível afirmar que projetos em empresas maiores demoram mais tempo, já que sprints com organizações muito grandes como F, O e U conseguiram ser executadas dentro do tempo previsto enquanto $\mathrm{A}, \mathrm{B}, \mathrm{C}$ e $\mathrm{M}$ que eram organizações de menor porte tiveram problemas para se enquadram dentro do limite previsto.

O suporte da gestão às atividades de UCD se mostrou como um dos pontos mais críticos para o sucesso do processo no ponto de vista dos entrevistados. Nas empresas C, D, L e U foram citados como os projetos onde haviam um maior descaso da organização cliente para com a realização e valor do processo. Segundo os entrevistados os pontos mais afetados no processo foram a etapa de composição da equipe e entrevista com experts, pois a empresa cliente não disponibilizava recursos com conhecimentos de valor para o processo e/ou não ofereceram ajuda para recrutar pessoas que aportar ainda que em um único momento conhecimentos necessários para o bom andamento do processo. Ausências de experts resultaram em processos com discussões mais pobres sobre os desafios, os problemas existentes ou até mesmo criação de soluções pouco atraentes para o cliente final. Outro problema citados nas organizações $\mathrm{M}$ e $\mathrm{N}$ foi o caso de os próprios participantes do processo ficarem desmotivados quando percebiam que a alta gerência encontrava pouco valor no trabalho executado, exigindo um maior trabalho para o facilitador de manter o grupo engajado. Por último foi citado um caso isolado da organização T, onde um dos sponsors do projeto já tinha uma ideia pré-definida da solução, o que na opinião do líder do processo inutilizaram as atividades de entendimento do problema, porquê a solução já estava pré-determinada. Os achados em campo confirmam o encontrado na literatura, e incrementam a ideia de que a alta gerência é parte crítica para composição da equipe ideal e motivação da mesma.

A orientação da empresa a projetos ou produtos não foi considerado um fator relevante pelos entrevistados. Na opinião de quatro entrevistados, este fator acaba sendo muito mais impactante para a etapa de desenvolvimento. Apenas um dos entrevistados comentou que organizações orientadas a produtos tendem a aceitar uma interação de 
sprint (em caso de necessidade de maiores validações após o primeiro sprint - ocorrido na empresa M), porém de uma forma geral não foi possível afirmar o quão determinante foi este fator. Estes achados contrapõe o encontrado na RSL em (BROWN; LINDGAARD; BIDDLE, 2011).

Diferente dos fatores acima esta pesquisa analisou a maturidade de gerenciamento e operação das atividades de UCD da organização foco desta pesquisa, em vez de analisar cada uma das empresas dos projetos, já que o líder do processo pertencia a empresa estudada. Segundo três entrevistados, a maturidade da organização tem um peso muito menor que a capacidade do indivíduo que lidera o processo de LDUF, tal que apenas a maturidade da equipe se mostra relevante. Por outro lado, dois outros entrevistados acreditam que com o passar dos anos a organização foi aprendendo o valor de cada atividade em cada situação, e os aprendizados individuais nos diversos projetos executados permitiram um aprendizado geral dos líderes de UX, tal que estes continuamente conseguiam adaptar melhor o Design Sprint ao contexto de cada projeto. Desta forma, diferente do aferido na RSL, o estudo de caso aponta que este fator contingencial menor impacto no processo, principalmente em casos de aplicação de frameworks fechados como é caso do Design Sprint, Design Studio, etc. que o tamanho da organização e o suporte da alta gestão para as atividades de UCD. Por outro lado para processos de BDUF por serem mais abrangentes e pouco definidos, aí neste caso a maturidade de UCD se mostra mais relevante.

\subsubsection{Fatores contingenciais associados ao projeto}

Acessibilidade aos usuários finais da solução é um fator que tende a ser mais simples de gerenciar em processos de Design Sprint que nos de BDUF onde há uma fase de imersão ou co-criação com usuários finais da solução, já que no primeiro existe apenas um ponto de contato com estes, durante a validação da solução. Contudo, como previsto na RSL este é um dos fatores de maior preocupação dos líderes do processo, pois devido ao fato do Design Sprint ser muito curto, quaisquer problemas no recrutamento de pessoas podem implicar em atrasos consideráveis ao processo e foi um dos pontos que mais suscitou aprendizados. Para ilustrar a criticidade deste fator, ainda que os líderes entrevistados disseram que este tópico é validado frequentemente antes do início do processo, houveram dificuldades na atividade de recrutamento de projetos com as empresas: B, C, D, G, L, M e S, ou seja 1/3 dos processos tiveram algum tipo de problema nesta etapa. A partir de relatos dos entrevistados, foram levantadas duas variáveis a serem consideradas nesta etapa, se o usuário é real (solução existente) ou hipotético 
(durante o processo é traçado um perfil de público-alvo da solução), e se o usuário é um consumidor final de um serviço ou a solução tem público muito amplo, existe relativa facilidade em encontrar buscar e recrutar pessoas para fazerem testes de usabilidade, em caso contrário, se o usuário pertence a um nicho muito específico, que requer uma atenção especial (ex: médicos de uma determinada área, funcionários internos de uma organização, etc.) existe maior probabilidade de existirem problemas no recrutamento dos mesmos. Das quatro possibilidades, as maiores dificuldades advieram de usuários com características muito específicas e/ou hipotéticos, caso dos projetos B, C, D, G pois nem o cliente tem um canal de comunicação com este potencial usuário e dificilmente bonificações por recrutamento são atraentes o suficiente para justificar que usuários compareçam aos testes. As alternativas encontradas pelas equipes nestes processos foram ou usar rede de contatos através de funcionários da própria empresa ou realizar testes de guerrilha, onde um entrevistador dirige-se a algum local onde encontrará potenciais usuários da aplicação e um teste mais informal é conduzido em um curto espaço de tempo. Em visão oposta ao proposto na literatura (MEMMEL; GUNDELSWEILER; REITERER, 2007; SINGH, 2008; FISHER; BANKSTON, 2009), dois entrevistados foram contundentes quanto a não realizar validação da solução com experts ou funcionários da empresa que não satisfaziam o critério de potencial usuário da solução, pois segundo estes o grande objetivo de se realizar o processo de LDUF é conseguir antecipar aprendizados de um eventual lançamento de uma funcionalidade ou ferramenta, e testar isso com um público errado, pode levar o grupo a obter aprendizados irreais sobre o produto, potencialmente atrapalhando o desenrolar do projeto que por sua vez estaria baseado em achismos.

De forma análoga ao encontrado na literatura, o tipo de software a ser desenvolvido se mostrou como um fator de baixo impacto no desenrolar do processo. Apenas um dos entrevistados comentou que em projetos onde havia a necessidade de testar soluções no desktop poderiam exigir maior trabalho durante a etapa de prototipagem, porém o único aprendizado é de que o escopo deste deve ser reduzido com se comparado com interfaces visuais menores, como tablet e mobile.

A metodologia ágil utilizada durante a etapa de desenvolvimento também foi um ponto que os entrevistados não enxergaram como um fator relevante a ser considerado no planejamento ou execução do sprint contrariando os achados na literatura. Segundo alguns entrevistados o LDUF deveria ser agnóstico a qualquer metodologia ágil pois ao ser uma etapa desvinculada ao desenvolvimento e que pode ser descontinuada dependendo dos resultados do sprint, não deveria ter relação com o mesmo. Esta proposição vai de encontro com o defendido por Brhel et al. (2015), porém contratia o previsto em Rojas e 
Macías (2015).

Tempo e orçamento suficientes e protegido para as atividades de UCD foram outros pontos que os entrevistados comentaram que deixaram de ser uma grande preocupação quando eram feitos processos de BDUF para o modelo atual de Design Sprints. De acordo com dois entrevistados isso se deve ao fato de o Design Sprint ser uma metodologia tão curta que dificilmente o cliente decidiria interromper o processo no meio, tal que apenas houve relatos de problemas deste tipo na empresa $G$, por problemas que aumentaram a duração do processo. Dois entrevistados também comentaram que o fato de existir uma menor preocupação com esta questão do tempo se deve ao fato de o Design Sprint ser uma metodologia que se popularizou no mercado, tal que muitos dos clientes se conscientizaram do tempo mínimo de participação dos envolvidos para alcançar resultados mínimos (teste do protótipo ao final do quarto dia) ser um benchmark de mercado e independente da opinião de uma pessoa ou outra. Esta pesquisa, entretanto, não tem como validar se este fator seria mais relevante em outros cenários, já que geralmente estes tópicos são acertados em etapas comerciais, o que seria diferente de empresas onde um funcionário precisaria pedir a direção por recursos da empresa para participarem de um processo como estes. Estes resultados são contrários ao encontrado em (FERREIRA, 2012; MEMMEL; GUNDELSWEILER; REITERER, 2007; SALAH; PAIGE; CAIRNS, 2014a; JURCA; HELLMANN; MAURER, 2014) possivelmente por eles avaliarem processos abertos, de natureza diferente ao Design Sprint.

O grau de compromisso com o cliente foi um dos pontos mais comentados pelos entrevistados como um fator muito relevante para o processo, e de difícil previsibilidade, no qual em diversos casos foram surpreendidos negativamente, como foram os casos com as empresas C, D, I, L, M, N, P e R. Os impactos mencionados pelos entrevistados foram distintos, tais como:

- Problemas no recrutamento de participantes para o sprint

- Recrutamento de experts relevantes para o processo

- Falta de participação ativa dos participantes no processo, com poucas contribuições destes para o mesmo

- Não comparecimento em dias obrigatórios do processo

- Participantes deixavam atividades do sprint para realizar outras atividades

- Recrutamento de usuários finais da solução 
- Dificuldade de conciliação de agendas, exigindo que processo fosse quebrados em mais dias do que necessário

Ainda que seja um fator intangível, pois afeta o sprint como um todo, percebe-se que a falta de comprometimento do cliente afeta principalmente o andamento das atividades do sprint. Uma solução sugerida por um dos participantes é utilizar o stakeholder de maior poder dentro da organização para blindar os participantes do sprint de pendências externas e participar ainda que em momentos pontuais para explicar o valor do processo e o potencial impacto a ser alcançado. Estes achados estão alinhados com os vistos em Kautz (2011)

Domínio onde o software é desenvolvido apenas é um ponto de preocupação em processos onde são necessários conhecimentos de experts que fogem do senso comum, ou como comentado anteriormente, em casos onde o usuário final da solução se distingue de uma pessoa qualquer. Para estes cenários, os pontos de atenção assemelham-se aos citados no fator: "Acessibilidade aos usuários finais da solução".

Apesar da organização trabalhar principalmente na conceituação de novos produtos, existem muitos projetos que se enquadram dentro de um projeto existente (casos nas empresas F, L, M, P, Q, R, S e U). Neste sentido, realizar processos de Design Sprints para produtos existentes frente a novos, foi um tópico onde não houve consenso entre os respondentes. De acordo com três entrevistados existe um valor muito grande em realização de testes de usabilidade prévios sobre o produto existente e que justificam a adaptação de atividades do processo para ser mais orientado a melhorar o que existe. Por outro lado outros dois entrevistados comentaram que este processo anterior assemelha-se ao processo de imersão em campo, onde o resultado principal é de orientar as discussões do grupo sobre o campo do problema, mas que ainda assim não necessitam de adaptação no processo, pois o mesmo também poderia ser orientado a mudanças estruturais no produto. A partir dos insumos coletados, percebe-se que não existe uma necessidade em de diferenciação do processo para trabalhar na criação de um novo produto ou melhoria de um existente, mas sim em função das melhorias almejadas, sejam elas incrementais no produto, inovações incrementais ou radicais, tal que para as melhorias, faz mais sentido iniciar o processo com testes de usabilidade, enquanto que para produzir inovações, faz-se necessário repensar o produto além da sua utilização atual, senão que todo seu conceito.

Destinatário do projeto significa aquela pessoa para quem o projeto é construído. Nos projetos estudados temos uma separação em quatro principais públicos: Business-toConsumer, onde o usuário final é aquele que compra e usa o produto (casos: B, G, L, M, 
O, P, Q, S, T, U), Business-to-Business, onde o usuário final é um, o processo de decisão de compra é mais complexo (casos: A, F, H, J, R), e os Marketplaces, onde existem mais soluções, pelo menos uma para cada uma das partes envolvidas (casos: D, E, G, K, N) ou quando a ferramenta é interna para os próprios funcionários (casos: C, I, M). Cada um dos modelos, tem um maior impacto na decisão de qual pessoa será estudada em possíveis etapas de imersão e quem irá validar o produto. Dois respondentes concordaram que o Design Sprint, independente do modelo acima, tem que escolher um único stakeholder como foco do processo, seja ele comprador, usuário, ou outro stakeholder, para evitar perda de foco ou conflitos de interesse, objetivando sempre escolher como foco aquele perfil que seja mais crítico para o sucesso do projeto na visão do cliente. Ainda assim, os processos D e $\mathrm{N}$ fizeram uma nova etapa de prototipagem e teste para validar a solução com um segundo stakeholder envolvido. Na grande maioria dos processos, no entanto, dois líderes de projeto comentaram que é possível simplificar esta validação da outra parte, colocando um representante da mesma no sprint (ex: E e G contaram com a presença de médicos que supostamente seriam os usuários da solução de uma das pontas, enquanto K contava com dois consultores de finanças que utilizariam a ferramenta, validando apenas o resultado entregue para o cliente e certificando que seria possível construir a ferramenta que ele precisaria em uma segundo momento). Estes resultados estão de acordo com o encontrado na literatura (ISA et al., 2014; ARDITO et al., 2017), ainda que na mesma não haviam sido mapeados dois modelos de projeto de Marketplace ou utilização da ferramenta para público interno e seus impactos para o processo.

O nível de inovação envolvido no projeto foi um tema de discordância entre os entrevistados. Dois deles concordam que o principal objetivo do sprint é validar rapidamente algumas hipóteses com o protótipo e testes e evoluir a partir dos aprendizados, independente do grau de inovação ou complexidade do projeto, alegando que os aprendizados sobre um conceito palpável são muito mais valiosos que realizar técnicas de entendimento de potenciais consumidores da solução antes de iniciar o processo do sprint. Por outro lado três outros respondentes acreditam que quando existem mais variáveis desconhecidas, existe uma maior necessidade de realização de estudos em campo antes e inclusão de mais pessoas com backgrounds diferentes como parte do processo para garantir um maior entendimento do usuário, processo, tema estudado. Exemplos deste segundo passo foram vistos nos processos B, onde foram feitos estudos de campo em três estados com diferentes stakeholders para mapear o tema estudado, em $\mathrm{G}$ foram feitas diversas validações como usuários finais de um processo complexo dentro de uma organização para levantar pontos de falha no processo atual, e em $\mathrm{S}$ foram feitos diversos estudos qualitativos e quantitati- 
vos prévios ao Design Sprint para entender melhor o perfil e preferências do consumidor final. Ainda assim, no processo de F, foi concebida uma solução de altíssimo grau inovador, que apresentou diversas falhas na etapa de validação, mas que segundo o líder deste processo, foram aprendizados que não seriam possíveis de se obter apenas com estudos e mapeamento da situação atual, pois o usuário jamais pensaria em como o processo atual poderia ser melhorado pela ferramenta idealizada. Neste processo inclusive foi feita uam segunda interação de sprint a partir dos insumos aprendidos e uma nova solução foi muito bem avaliada pelos consumidores da mesma. Esta pesquisa, portanto, entende que não existe necessariamente uma resposta ideal para adaptar ou não o processo (com etapas anteriores de imersão como previsto na literatura), porém expõe a possibilidade de que o processo de LDUF pode inclusive anteceder o processo de BDUF, tal que este processo mais longo pode ser iniciado e orientado a partir de novas oportunidades identificadas no processo mais curto (CABALLERO; MORENO; SEFFAH, 2016). Faz-se necessário a partir destes achados realizar adaptações no modelo proposto na literatura.

A falta de definição formal dos papeis de cada membro da equipe apareceu em alguns processos, como em $\mathrm{B}, \mathrm{D}$ e $\mathrm{N}$ onde os clientes eram responsáveis pelo recrutamento dos usuários do teste, e não o fizeram, ocasionando em atrasos no sprint, bem como em S e U onde os próprios membros da organização foco deste estudo não tinham definido bem quem se encarregaria de cada tarefa, o que levou a algumas atividades malfeitas no último instante, porém este tópico aparenta se enquadrar muito mais como uma boa prática, do que um fator a ser avaliado no processo do sprint e em como ele pode impactar suas dimensões. Estes achados vão de encontro com (KUUSINEN; MIKKONEN; PAKARINEN, 2012; SALAH; PAIGE; CAIRNS, 2014b).

A quantidade de stakeholders envolvidos não foi um ponto levantado pelos entrevistados como um fator determinante para o planejamento e execução do processo. O número de participantes ativos no mesmo por sua vez teve maiores influências, como pode ser visto na seção a seguir.

\subsubsection{Fatores contingenciais associados à equipe}

Os fatores: disponibilidade do profissional de UX e a estrutura da equipe foram fatores que aparecerem em conjunto na visão dos entrevistados e também foi outro ponto que não houve consenso entre os respondentes. Para o diretor da empresa e um dos líderes de UX, o facilitador da equipe pode ter qualquer background, já que as habilidades demandadas como saber controlar uma equipe, fazer perguntas relevantes, ter uma visão 
estratégica e operacional de viabilidade do produto, não necessariamente são parte do design. Para este entrevistado a maturidade do facilitador se mostra mais relevante, e é por isso que a empresa tem buscado formar facilitadores a partir destas competências de líderes e não apenas pela experiência desta pessoa na execução de sprints. Por outro lado, para um dos líderes de UX é preponderante você ter a presença de um designer na equipe integralmente alocado, pois para se obter aprendizados relevantes, é importante que o protótipo seja de alta-fidelidade e o feedback recebido nos testes é melhor quando o designer participa de todas o processo de sprint. A visão exposta pelo diretor se enquadra naquilo defendido em Lucena et al. (2016), porém ao mesmo tempo a visão do líder de UX também vai de encontro com o defendido em Bertholdo et al. (2014). Ainda que não opostas estas visões sugerem que uma equipe é melhor disposta quando dotada de um líder mais experiente acompanhado de um profissional de UX.

A distribuição física da equipe não pode ser avaliada na organização estudada, já que todos os processos de design sprint foram realizados quase que em sua totalidade presencialmente junto ao cliente. Apenas etapas de imersão ou testes em campo eram feitos à distância ou sem a participação do cliente, porém todas as etapas de entendimento sempre foram feitas em conjunto com o cliente. Neste sentido, foi impossível avaliar as influências deste fator contingencial dentro da amostras de processos estudados.

Apesar de já ter sido comentado, a maturidade da equipe foi um tema de discussão interessante. Segundo o diretor e um dos líderes de UX da empresa, quanto maior a maturidade e competência da equipe, maior a capacidade de aproveitar os recursos (tempo esforços dos participantes) em todo o UFD concentrando-se em atividades mais críticas, e tendo maior facilidade de adaptação do processo dependendo dos fatores contingenciais existentes, enquanto que em equipes menos experientes, há uma tendência maior em seguir frameworks fechados como é o caso próprio Design Sprint ou de Lean UX e Design studio. Neste sentido, além das vantagens comerciais de se tratar de uma metodologia conhecida no mercado, a organização utiliza Design Sprints também por uma questão estratégica, por ser possível de ser realizada com recursos de menor senioridade da empresa e uma "garantia" de resultados rápidos e relevantes. Isso vai de encontro com os achados na literatura em Ungar e White (2008), May (2012), Liikkanen et al. (2014), Lucena et al. (2016).

A interação entre os membros da equipe foi um ponto que apareceu apenas em uma das entrevistas, relacionado com a falta de abertura e menor capacidade de contribuição de alguns membros do processo quando estão trabalhando sob a supervisão de seus chefes. Neste sentido um dos líderes de UX comenta que em alguns projetos, como: E, M, 
$\mathrm{N}$ e $\mathrm{O}$, por se tratarem de empresas predominantemente estruturadas hierarquicamente, estas pessoas subordinadas contribuíram menos, acatando a ideias de seus supervisores ao invés de proporem alternativas próprias que agregariam mais ao processo. Ainda assim, o entrevistado não soube sugerir possíveis soluções para contornar esta situação. Não foi identificado, entretanto, problemas de poder entre membros da equipe como visto em Ferreira, Sharp e Robinson (2011).

A quantidade de participantes envolvidos no projeto apenas impactou no tamanho da equipe ativa ou experts que participaram pontualmente no processo. Assim como discutido anteriormente, houveram processos que detinham um número de participantes ativos muito grande (ex: número de participantes A: 13, B: 15, E: 10, G: 12, L: 9, S: 14) contribuindo negativamente para as etapas do processo fluirem mais lentamente e desgaste maior dos participantes, tal que a recomendação é manter uma máximo de 7 participantes ativos, com demais stakeholders aportando conhecimento apenas em momentos pontuais.

A multidisciplinaridade da equipe foi um ponto mencionado por três dos entrevistados, como algo crucial para a estruturação do sprint. Esta multidisciplinaridade distingue este processo do modelo clássico de definição de requisitos de um projeto de engenharia. Segundo o diretor da empresa e dois líderes de UX, a experiência e conhecimento geralmente não são compartilhados igualmente por todos os membros do time. Áreas de negócios sabem coisas que engenheiros não sabem, times de operação têm experiência que designers nem sabiam que eram possíveis, e assim por diante. Neste sentido, um dos grandes valores do Design Sprint é justamente de trazer todas estas pessoas para trabalharem juntas. Para ilustrar este valor, foram resgatadas as soluções melhor avaliadas em cada sprint, e existe uma diversificação de atores, tal que nos processos em alguns processos as soluções votadas partiram de pessoas da diretoria: A, B, D, F, J, M, O, P, S, U em outros processos de perfis gerenciais ou coordenação: C, D, E, G, I, K, N, T e também outros processos que partiram do time operacional C, D, G, H, L, M, Q, R. Sem contar que existe uma discussão mais rica no levantamento de problemas e hipóteses, a divisão quase igualitária de "melhores" soluções evidencia o valor de trabalhar o projeto com pessoas de diversos backgrounds e funções distintas na organização.

\subsubsection{Modelo de planejamento e execução do LDUF conside- rando seus fatores contingenciais}

Embora os modelos anteriores de UCASD sejam unidirecionais (MILLER, 2005; SY, 2007; BRHEL et al., 2015; CABALLERO; MORENO; SEFFAH, 2016; COOPER, 2014), 
com base nas discussões de BDUF versus LDUF e os fatores contingenciais de "produtos existentes frente a novos" " "nível de inovação envolvido no projeto" foi possível identificar duas possíveis melhorias ao modelo de ciclo de vida de UCASD, mapeadas na Figura 32.

1. Processo cíclico: Ficou evidenciado no estudo de caso e em alguns autores na literatura que, além do desenvolvimento de novos produtos, o UFD vai além do lançamento, podendo ser utilizado para melhorias de produtos existentes (BROWN; LINDGAARD; BIDDLE, 2011; NAVARRO; PEREZ; SEVILLA, 2016; MANWARING; CARTER; MAYNARD, 2017; KUUSINEN, 2014; MEMMEL; GUNDELSWEILER; REITERER, 2007; ARROQUI et al., 2016). Portanto, com base nos modelos e premissas mencionados, faz-se relevante também adicionar uma visão cíclica ao ciclo de vida do UCASD baseada no objetivo de melhoria almejado para o produto: inovação radical, inovação incremental e melhoria incremental.

2. Processo bidirecional no UFD: Da mesma forma que não é necessário iniciar o ciclo de vida do UCASD com um processo de BDUF (ADIKARI; MCDONALD; CAMPBELL, 2009; BROWN; LINDGAARD; BIDDLE, 2011), foi identificada a possibilidade de realizar este processo mais longo a partir de novas oportunidades levantadas no LDUF que não foram consideradas como prioritárias, porém que podem ser atacadas em outros projetos paralelos.

Além disso, os resultados e discussões feitos nas seções anteriores de fatores contingenciais permitiram contrastar a influência que os fatores contingenciais exercem sobre fases do processo, stakeholders, membros da equipe e inclusive outros fatores contingenciais do processo, expostos na literatura com os encontrados em campo, vistos na Tabela 10.

É importante comentar que os fatores de disponibilidade do profissional de UCD para o projeto e Estrutura da Equipe foram integradas em um mesmo fator.

Tabela 10: Como os fatores contingenciais influenciam o

LDUF segundo a literatura e o estudo de caso

\begin{tabular}{|l|l|l|}
\hline $\begin{array}{l}\text { Fatores Contingenci- } \\
\text { ais }\end{array}$ & $\begin{array}{l}\text { O que é influenciado no } \\
\text { processo - Segundo litera- } \\
\text { tura }\end{array}$ & $\begin{array}{l}\text { O que é influenciado no } \\
\text { processo - Segundo es- } \\
\text { tudo de caso }\end{array}$ \\
\hline \multicolumn{2}{|c|}{ Fatores contingenciais associados à organização } \\
nização & $\begin{array}{l}\text { Alta gerência e Gate de De- } \\
\text { cisão para projeto }\end{array}$ \\
\hline
\end{tabular}




\begin{tabular}{|c|c|c|}
\hline $\begin{array}{l}\text { Fatores Contingenci- } \\
\text { ais }\end{array}$ & $\begin{array}{l}\text { O que é influenciado no } \\
\text { processo - Segundo litera- } \\
\text { tura }\end{array}$ & $\begin{array}{l}\text { O que é influenciado no } \\
\text { processo - Segundo es- } \\
\text { tudo de caso }\end{array}$ \\
\hline $\begin{array}{l}\text { Suporte da Gestão às ati- } \\
\text { vidades de UCD }\end{array}$ & Equipe & Alta gerência e Equipe \\
\hline $\begin{array}{l}\text { Orientação da empresa a } \\
\text { produtos ou projetos }\end{array}$ & $\begin{array}{l}\text { Fatores contingenciais de prazo } \\
\text { e orçamento dedicado às ativi- } \\
\text { dades de UCD }\end{array}$ & - \\
\hline Maturidade em UCD & Equipe & $\begin{array}{l}\text { Líder do Processo e Gestão de } \\
\text { atividades }\end{array}$ \\
\hline \multicolumn{3}{|c|}{ Fatores contingenciais associados ao projeto } \\
\hline $\begin{array}{l}\text { Acessibilidade aos } \\
\text { usuários finais }\end{array}$ & $\begin{array}{l}\text { Etapa de Validação e Tempo de } \\
\text { Execução }\end{array}$ & $\begin{array}{l}\text { Etapa de Validação e Tempo } \\
\text { de Execução }\end{array}$ \\
\hline $\begin{array}{l}\text { Tipo de software a ser de- } \\
\text { senvolvido }\end{array}$ & - & $\begin{array}{l}\text { Etapa de Prototipagem } \\
\text { (pouca relevância) }\end{array}$ \\
\hline $\begin{array}{l}\text { Métodos ágeis utiliza- } \\
\text { dos durante o desenvolvi- } \\
\text { mento }\end{array}$ & Definição dos Requisitos & - \\
\hline $\begin{array}{l}\text { Tempo suficiente e pro- } \\
\text { tegido para atividades de } \\
\text { UCD }\end{array}$ & $\begin{array}{l}\text { Todas as Atividades e Tempo } \\
\text { de execução }\end{array}$ & $\begin{array}{l}\text { Pouca influência em proces- } \\
\text { sos de LDUF }\end{array}$ \\
\hline Compromisso do cliente & Tempo de execução e Equipe & $\begin{array}{l}\text { Equipe, Atividades de Enten- } \\
\text { dimento, Recrutamento e Va- } \\
\text { lidação e Alta Gerência }\end{array}$ \\
\hline $\begin{array}{l}\text { Domínio onde o software } \\
\text { é desenvolvido }\end{array}$ & Equipe & $\begin{array}{l}\text { Etapa de Validação e Tempo } \\
\text { de Execução }\end{array}$ \\
\hline $\begin{array}{l}\text { Projeto existente ou } \\
\text { novo produto }\end{array}$ & $\begin{array}{l}\text { Entendimento do Usuário e Va- } \\
\text { lidação }\end{array}$ & - \\
\hline Destinatário do projeto & $\begin{array}{l}\text { Entendimento do Usuário e Va- } \\
\text { lidação e Tempo de Execução }\end{array}$ & $\begin{array}{l}\text { Entendimento do Usuário, } \\
\text { Validação e Equipe }\end{array}$ \\
\hline $\begin{array}{l}\text { Nível de inovação do pro- } \\
\text { jeto }\end{array}$ & $\begin{array}{l}\text { Alinhamento com Stakeholder, } \\
\text { Entendimento do Usuário e } \\
\text { Tempo de Execução }\end{array}$ & Equipe \\
\hline
\end{tabular}




\begin{tabular}{|c|c|c|}
\hline $\begin{array}{l}\text { Fatores Contingenci- } \\
\text { ais }\end{array}$ & $\begin{array}{l}\text { O que é influenciado no } \\
\text { processo - Segundo litera- } \\
\text { tura }\end{array}$ & $\begin{array}{l}\text { O que é influenciado no } \\
\text { processo - Segundo es- } \\
\text { tudo de caso }\end{array}$ \\
\hline $\begin{array}{l}\text { Falta de definição formal } \\
\text { do papel de membros da } \\
\text { equipe }\end{array}$ & Equipe & $\begin{array}{l}\text { pouca relevância na Va- } \\
\text { lidação }\end{array}$ \\
\hline $\begin{array}{l}\text { Quantidade de stakehol- } \\
\text { ders envolvidos }\end{array}$ & $\begin{array}{l}\text { Alinhamento com Stakeholders } \\
\text { e Tempo de Execução }\end{array}$ & - \\
\hline $\begin{array}{l}\text { Orçamento suficiente e } \\
\text { protegido para ativida- } \\
\text { des de UCD }\end{array}$ & $\begin{array}{l}\text { Todas as Atividades e Tempo } \\
\text { de execução }\end{array}$ & $\begin{array}{l}\text { Pouca influência em proces- } \\
\text { sos de LDUF }\end{array}$ \\
\hline \multicolumn{3}{|c|}{ Fatores contingenciais associados à equipe } \\
\hline $\begin{array}{l}\text { Disponibilidade do pro- } \\
\text { fissional de UCD para o } \\
\text { projeto e Estrutura da } \\
\text { Equipe }\end{array}$ & Equipe & $\begin{array}{l}\text { Fator contingencial de Matu- } \\
\text { ridade da Equipe, Líder do } \\
\text { Processo e Equipe }\end{array}$ \\
\hline $\begin{array}{l}\text { Distribuição física da } \\
\text { equipe e do cliente }\end{array}$ & Equipe & Não foi possível validar \\
\hline Maturidade da equipe & $\begin{array}{l}\text { Fator contingencial de estru- } \\
\text { tura da equipe }\end{array}$ & $\begin{array}{l}\text { Equipe e Orçamento vincu- } \\
\text { lado ao projeto }\end{array}$ \\
\hline $\begin{array}{l}\text { Interação entre os mem- } \\
\text { bros da equipe }\end{array}$ & $\begin{array}{l}\text { Entendimento do Usuário, Va- } \\
\text { lidação, Definição de Requisitos } \\
\text { e Equipe }\end{array}$ & $\begin{array}{l}\text { Equipe, Alta Gerência e } \\
\text { Atividades de Desenho da } \\
\text { Solução }\end{array}$ \\
\hline $\begin{array}{l}\text { Tamanho da equipe do } \\
\text { projeto }\end{array}$ & Equipe e Tempo de execução & Equipe e Tempo de execução \\
\hline $\begin{array}{l}\text { Multidisciplinaridade da } \\
\text { equipe }\end{array}$ & $\begin{array}{l}\text { Consolidação dos resultados e } \\
\text { Equipe }\end{array}$ & $\begin{array}{l}\text { Entendimento do Usuário e } \\
\text { Desenho da solução }\end{array}$ \\
\hline
\end{tabular}

Fonte: O autor

Esta pesquisa tem por objetivo mapear de forma simples e objetiva o mapa de influencia que cada fator contingencial de um projeto afetam o LDUF, e em como a organização e os líderes destes processos podem melhor planejar e executar este tipo de atividades. Desta forma, seguindo as recomendações em Miles et al. (1994), o mapa de influências dos fatores contingenciais sobre a etapa de LDUF visto em Figura 31 evolui a partir dos 
achados em campo e consolidados na Tabela 10, para o framework conceitual visto na Figura 33, de forma a responder a principal pergunta de pesquisa.

A Figura 33 foi montada considerando uma maior relevância para os achados em campo que os levantados na literatura, visto que, como o tema de fatores contingenciais ainda não é extenso na literatura, são raros os estudos que de fato expõe estes aspectos com relevância em seus textos, de forma que muitos dos pontos levantados na literatura são interpretações deste pesquisador e devem ter portanto menor peso. Além disso, como visto na RSL a maioria dos artigos na área se baseiam em estudo de caso único, tal que a pesquisa feita em campo neste estudo vislumbra uma variabilidade muito maior de projetos e entrevistados, justificando o maior peso para estes últimos achados.

O framework conceitual aponta que existem duas grandes peças chaves na organização e execução do sprint, que são o sponsor do projeto (alta gerência) e o líder do processo. Como antevisto na RSL, os fatores organizacionais tendem a ficar sob a esfera de responsabilidade da alta gerência do cliente que patrocina o projeto, que por sua vez, acaba tendo grandes influências nos momentos iniciais e finais do processo, de disponibilizar equipe e recursos coerentes ao processo e avaliação dos resultados do mesmo no gate de decisão para escolha de continuar com o projeto para as etapas de desenvolvimento. A partir disso o líder do processo se encarrega da da manutenção de um processo adequado, gerenciando os fatores de equipe relacionados a estruturação da equipe, condução da mesma e os fatores contingenciais do projeto que em sua maioria afetam o decorrer das atividades do processo, o tempo de execução e a qualidade dos resultados alcançados consequentemente.

Como discutido nas seções acima, os fatores mais relevantes para a alta gerência são o suporte da gestão às atividades de UCD, o grau de compromisso do cliente e a estruturação da equipe, enquanto para o líder do processo são a acessibilidade aos usuários finais da solução e interação entre membros da equipe. Fica evidenciado que os maiores pontos de atenção destes principais fatores contingenciais do processo podem ser acompanhados e eventuais problemas mitigados já na etapa de planejamento do projeto.

A pesquisa em campo também permitiu mapear que alguns fatores contingenciais vistos na literatura tem baixo impacto no processo, como: orientação da empresa a produtos ou processos, quais métodos ágeis são utilizados durante a etapa de desenvolvimento e a quantidade de stakeholders envolvidos.

Os achados nesta pesquisa também evidenciam que a utilização do Design Sprint, por ser um framework fechado, reduz o impacto de alguns fatores contingenciais, como é a 
maturidade da equipe do processo, já que há menor necessidade de utilização de recursos de maior maturidade, e ainda reduz os problemas de prazo e orçamento protegidos para o processo, já que são processos pré-determinados. A redução do impacto destes fatores no projeto podem justificar a popularização do LDUF no mercado nacional, como visto em Teixeira (2017), o que por sua vez não invalida a realização de processos mais longos de BDUF pois devem ser utilizados para contextos e finalidades diferentes.

Além disso os achados desta pesquisa bem como o framework conceitual detalhado acima servem como um guia a praticantes da área no entendimento dos pontos de atenção nos diferentes estágios do processo, simplificando assim o gerenciamento deste. 


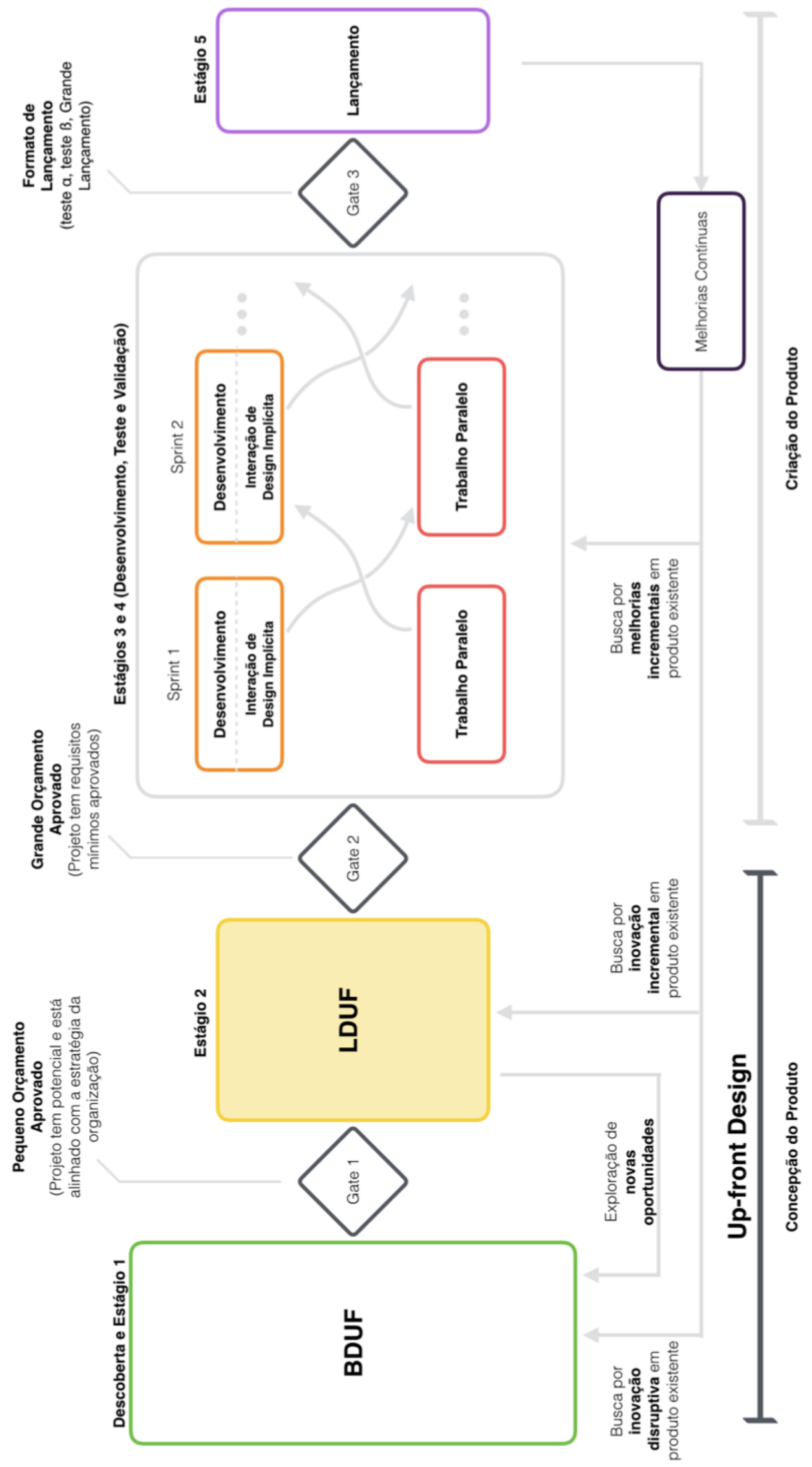

Figura 32: Modelo de Ciclo de Vida do UCASD cíclico e bidirecional no UFD. Fonte: O autor 


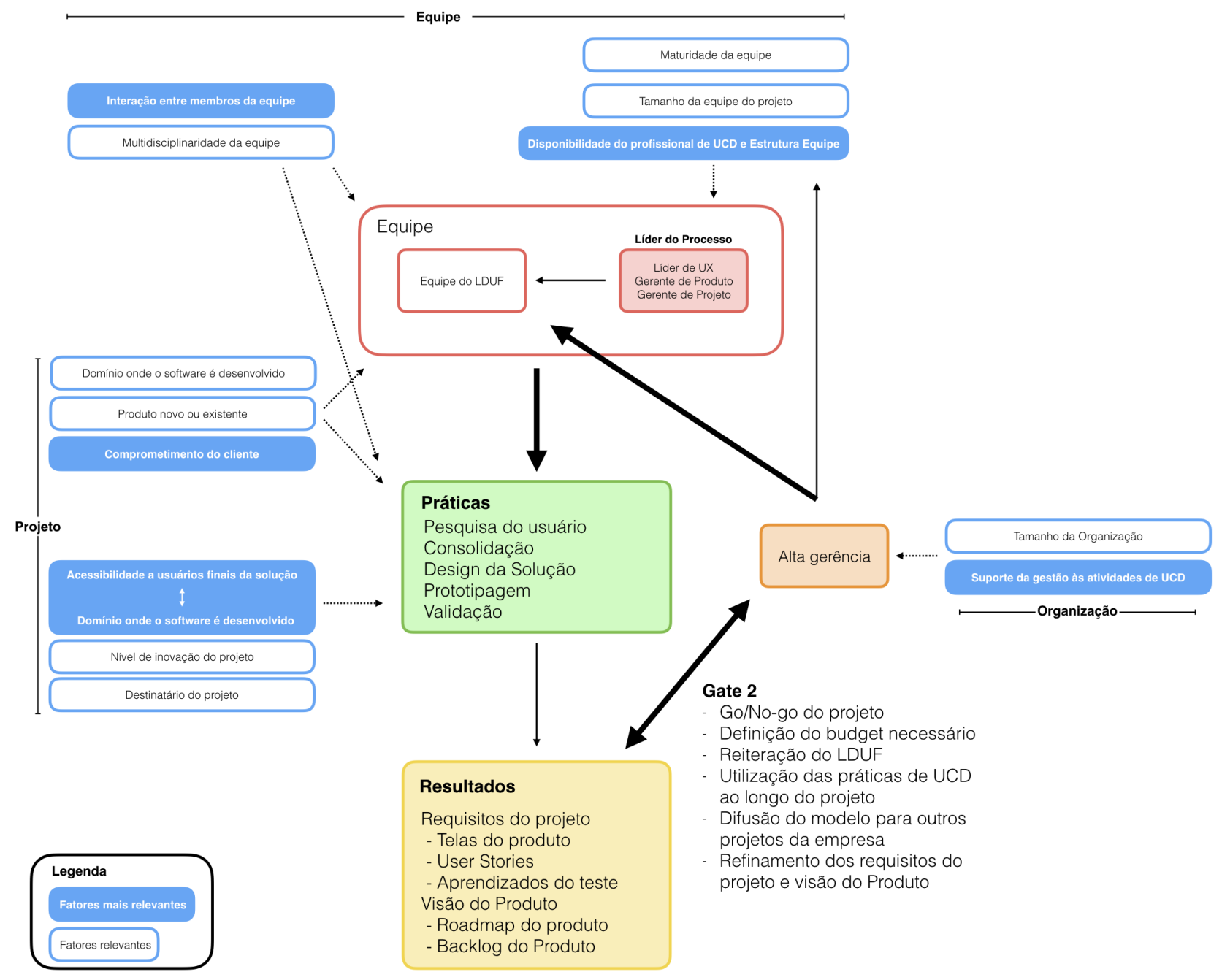

Figura 33: Framework conceitual atualizado do mapa de influências dos fatores contingenciais no LDUF. Fonte: O autor 


\section{CONCLUSÃO}

Este estudo teve como objetivo principal definir uma estruturação compreensível e replicável das diferentes etapas do ciclo de vida do UCASD, com foco nas etapas prévias ao desenvolvimento investigando as alternativas para gerenciar e executar técnicas, equipe, tempo de execução ideais para o processo de UFD. Além disso, sabendo que desenvolvedores e designers desviam de práticas prescritas, é discutido como os fatores contingenciais podem influenciar o processo. Para tanto, foi realizada uma revisão sistemática da literatura e um estudo de caso avaliando 27 processos de LDUF distintos.

Para a revisão sistemática da literatura, os estudos mais relevantes da área foram sistematicamente analisados usando uma abordagem híbrida que combinou várias metodologias de revisão de literatura (incluindo análise bibliométrica, de rede e de conteúdo) para trazer uma visão geral do processo e responder as primeiras perguntas de pesquisa, relacionadas aos participantes (especialistas versus generalistas), extensão do processo (LDUF versus BDUF), quais são as fases e técnicas disponíveis e quais são os fatores contingenciais que podem influenciar a maneira como o trabalho é feito.

Com base nos resultados obtidos na RSL, foi possível concretizar diversas definições em um tema ainda mal definido na literatura e estruturar um modelo de pesquisa que abrangesse de um lado o ciclo de vida do UCASD e os diferentes momentos de integração entre UCD e ASD, e levantar os fatores contingenciais envolvidos. Além disso, o modelo criado e definições propostas a partir da RSL serviram de alicerce para o desenvolvimento do estudo de caso e da construção do instrumento de pesquisa utilizados neste estudo e podem contribuir com o desenvolvimento futuro de pesquisas relacionadas com os temas abordados.

A realização do estudo de caso múltiplo permitiu a análise das principais características do UFD no âmbito prático, resultando em discussões que destrincharam como a prática contrasta com alguns achados na literatura, sobretudo em como as contingências dos projetos influenciam no planejamento e execução do mesmo, concluindo assim um dos principais objetivos da pesquisa, isto é, identificar como planejar e executar o up-front 
design no desenvolvimento ágil de software centrado no usuário, considerando seus fatores contingenciais tanto no âmbito teórico como prático.

Considerando os achados na RSL e no estudo de caso, a primeira contribuição significativa desta pesquisa consistiu em definir claramente a separação do UFD em duas etapas, BDUF (perspectiva exploratória) e LDUF (perspectiva confirmatória), e também posicionar como ambos se encaixam dentro do ciclo de vida do UCASD. Este estudo diferencia-se de outros trabalhos no tema, pois reconhece o UFD, o BDUF e o LDUF como processos formais com objetivos claros, em vez de visualizá-los como uma coleção de atividades dispersas. Agrega-se também à literatura o conceito de gates (pontos de decisão do $G O / N O-G O$, se o projeto deve continuar para as próximas etapas do ciclo de vida). O estudo também aporta conhecimento ao tema de UCASD ao sugerir uma visão holística deste processo com um atributo cíclico em três alternativas diferentes, dependendo do objetivo de inovação e melhorias desejadas e bidirecional na etapa de UFD, sugerindo que a etapa de BDUF pode levantar insumos para o LDUF e vice-versa.

Este trabalho também contribuiu para os profissionais, propondo um limite de tempo para o processo de LDUF de até duas semanas e uma análise das vantagens e desvantagens de usar diferentes configurações de equipe. Esta análise favorece o modelo híbrido sobre as abordagens especialista e generalista, pois traz o melhor dos dois mundos: uma equipe que entenda como aplicar as atividades de UCD, criando soluções viáveis e não perdendo qualquer informação na passagem de conhecimento para a equipe que irá desenvolver o projeto. Ainda são feitas sugestões de como proceder quando este modelo híbrido não for uma alternativa. A partir do estudo de caso, aparece um novo personagem não identificado na literatura que é o líder do processo. Uma proposição deste estudo é ter uma equipe composta por um líder com uma maior maturidade no tema exigido pelo processo, seja negócio, técnico ou UX, acompanhado de um designer para concepção de protótipos de alta-fidelidade.

Por fim, como proposto em Brhel et al. (2015), Ferreira, Sharp e Robinson (2012), Wale-Kolade, Nielsen e Paivarinta (2014) para abordar o fato de que a prática raramente corresponde ao que é prescrito na teoria, este artigo resumiu os principais fatores contingenciais que afetam como o trabalho é feito. Primeiramente são levantados na literatura os principais fatores contingenciais envolvidos, e por último são contrastadas as influências interpretadas da literatura com o visto nos casos estudados, dando espaço a criação de um framework conceitual para auxiliar praticantes da área no planejamento e execução do processo. Os dois principais aprendizados no estudo de campo sobre os achados na literatura é de que existem basicamente dois principais perfis envolvidos neste processo, a 
alta gerência que é responsável por lidar com os fatores contingenciais da organização no início e final do projeto, e o líder do processo que é responsável por lidar com os fatores contingenciais do projeto e da equipe, e o fato de que as principais contingências podem ser acompanhados e eventuais problemas mitigados ainda no planejamento do processo.

Os resultados apresentados por este estudo possuem limitações. Num primeiro momento existem limitações típicas de revisões sistemáticas da literatura, pois este estudo se limitou a alguns indexadores científicos e à combinação de palavras-chave pesquisadas, em que é possível que estudos prévios na área tenham sido deixados fora da amostra final. Como o objetivo desta pesquisa foi focar na qualidade e não na quantidade, como discutido anteriormente, acredita-se que os estudos selecionados sejam suficientes para identificar o estado atual da integração entre ASD e UCD, principalmente no tópico de UFD. Além disso, conforme detalhado na seção de método, a análise de conteúdo foi realizada e revisada por diferentes sujeitos para reduzir possíveis vieses e inconsistências, mas ainda assim a análise de conteúdo é passiva de erros humanos na interpretação, categorização e agrupamento de informações intra e inter artigos. Num segundo momento também existiu limitações no estudo de caso, citados na seção de mesmo nome, principalmente no que tange o estudo de apenas uma organização, que apesar de dispor de diversos casos com grande variabilidade de características para serem analisadas, ainda está confinado a uma visão de profissionais de uma mesma organização.

Desta forma, se faz relevante a replicação deste estudo em outras empresas que façam o UCASD de forma integrada para verificar se os resultados apresentados são, de fato, generalizáveis a outros contextos organizacionais. Ademais, a partir dos insumos gerados por esta pesquisa, se faz possível a condução de estudos com abordagens quantitativas, como surveys, para analisar e confirmar as características da integração entre ASD e UCD bem como os fatores contingenciais envolvidos. Visto o benefício alcançado em avaliar os temas de UCASD sob a ótica da linha de pesquisa de desenvolvimento de novos produtos, fica evidente a relevância investigar também possíveis correlações de UCASD com outras linhas de pesquisa adjascentes, como gestão de projetos, Lean Startup, Fuzzy Front End, Technology Roadmapping, gestão de portfolio, Design Thinking, entre outros. Finalmente, como visto ao longo da pesquisa, mostra-se relevante a condução de estudos futuros que explorem com maior profundidade as outras etapas de integração de ASD e UCD, como o BDUF, Interação de Design Implícita e Trabalho Paralelo. permitindo que empresas consigam melhor gerenciar e executar estes processos de forma a estimular a criação de softwares úteis, utilizáveis, desejáveis e atraentes. 


\section{REFERÊNCIAS}

ABBAS, N.; GRAVELL, A. M.; WILLS, G. B. Historical roots of agile methods: Where did "agile thinking" come from? In: SPRINGER. International Conference on Agile Processes and Extreme Programming in Software Engineering. [S.l.], 2008. p. 94-103.

ABRAHAMSSON, P. et al. New directions on agile methods: a comparative analysis. In: IEEE. Software Engineering, 2003. Proceedings. 25th International Conference on. [S.1.], 2003. p. 244-254.

ADIKARI, S.; MCDONALD, C.; CAMPBELL, J. Little design up-front: a design science approach to integrating usability into agile requirements engineering. In: SPRINGER. International Conference on Human-Computer Interaction. [S.l.], 2009. p. 549-558.

AHIMBISIBWE, A.; CAVANA, R.; DAELLENBACH, U. A contingency fit model of critical success factors for software development projects: A comparison of agile and traditional plan-based methodologies. v. 28, p. 7-33, 022015.

AJSMART. Design Sprint. 2018. Acessado em: 2019-05-03. Disponível em: 〈\texttt\{https://ajsmart.com/design-sprints\}.〉

AJSMART. Design Sprint 2.0 Process Explained 2018. 2018. Acessado em: 2019-05-03. Disponível em: 〈\texttt\{https://ajsmart.com/design-sprints\}.〉

ALBISETTI, M. Launchpad's quest for a better and agile user interface. In: SPRINGER. International Conference on Agile Software Development. [S.1.], 2010. p. 244-250.

ALMUGHRAM, O.; ALYAHYA, S. Coordination support for integrating user centered design in distributed agile projects. In: IEEE. Software Engineering Research, Management and Applications (SERA), 2017 IEEE 15th International Conference on. [S.l.], 2017. p. 229-238.

ANWAR, S. et al. User-centered design practices in scrum development process: A distinctive advantage? In: IEEE. 17th IEEE International Multi Topic Conference 2014. [S.l.], 2014. p. 161-166.

ARDITO, C. et al. Integrating a scrum-based process with human centred design: an experience from an action research study. In: IEEE. 2017 IEEE/ACM 5th International Workshop on Conducting Empirical Studies in Industry (CESI). [S.1.], 2017. p. 2-8.

ARDITO, C. et al. Investigating and promoting ux practice in industry: An experimental study. International Journal of Human-Computer Studies, Elsevier, v. 72, n. 6, p. 542-551, 2014.

ARITUA, B.; SMITH, N. J.; BOWER, D. Construction client multi-projects-a complex adaptive systems perspective. International Journal of Project Management, Elsevier, v. 27 , n. 1 , p. $72-79,2009$. 
ARROQUI, M. et al. Combination of agile development and user centered design to improve the usability of a beef cattle farm simulator. IEEE Latin America Transactions, v. 14, p. 3385-3392, 072016.

ASUNCION, H. et al. Serious game development as an iterative user-centered agile software project. In: ACM. Proceedings of the 1st International workshop on games and software engineering. [S.1.], 2011. p. 44-47.

AVISON, D. E.; FITZGERALD, G. Where now for development methodologies? Communications of the ACM, ACM, v. 46, n. 1, p. 78-82, 2003.

AZENHA, F. C. O papel do gerenciamento híbrido de projetos no desenvolvimento de produtos e serviços de base tecnológica. Tese (Doutorado) — Universidade de São Paulo, 2018.

BACON, E. Defining interaction design. interactions, v. 12, n. 3, p. 34-35, 2005.

BARKSDALE, J. T.; MCCRICKARD, D. S. Software product innovation in agile usability teams: An analytical framework of social capital, network governance, and usability knowledge management. Int. J. Agil. Extrem. Softw. Dev., Inderscience Publishers, Inderscience Publishers, Geneva, SWITZERLAND, v. 1, n. 1, p. 52-77, jul. 2012. ISSN 1743-5137. Disponível em:〈http://dx.doi.org/10.1504/IJAESD.2012.048302〉.

BECK, K. Embracing change with extreme programming. Computer, IEEE, v. 32, n. 10, p. 70-77, 1999.

BECK, K. et al. Manifesto for agile software development. 2001.

BEGNUM, M. E. N.; FURUHEIM, L. Exploration of user-centered agile development practices. DS 85-1: Proceedings of NordDesign 2016, Volume 1, Trondheim, Norway, 10th-12th August 2016, p. 391-400, 2016.

BELCHEV, B.; BAKER, P. Improving obama campaign software: Learning from users. In: IEEE. 2009 Agile Conference. [S.l.], 2009. p. 395-399.

BERTHOLDO, A. P. O. et al. Agile usability patterns for ucd early stages. In: SPRINGER. International Conference of Design, User Experience, and Usability. [S.1.], 2014. p. 33-44.

BEYER, H.; HOLTZBLATT, K.; BAKER, L. An agile customer-centered method: rapid contextual design. In: SPRINGER. Conference on Extreme Programming and Agile Methods. [S.l.], 2004. p. 50-59.

BLOMKVIST, J. K.; PERSSON, J.; ÅBERG, J. Communication through boundary objects in distributed agile teams. In: ACM. Proceedings of the 33rd Annual ACM Conference on Human Factors in Computing Systems. [S.l.], 2015. p. 1875-1884.

BLOMKVIST, S. Towards a Model for Bridging Agile Development and User-Centered Design. 2005. 219-244 p.

BOEHM, B. Get ready for agile methods, with care. Computer, IEEE, v. 35, n. 1, p. 64-69, 2002. 
BOEHM, B. W. A spiral model of software development and enhancement. Computer, IEEE, v. 21, n. 5, p. 61-72, 1988.

BRHEL, M. et al. Exploring principles of user-centered agile software development: A literature review. Information and Software Technology, Elsevier, v. 61, p. 163-181, 2015.

BROWN, J. M.; LINDGAARD, G.; BIDDLE, R. Collaborative events and shared artefacts: Agile interaction designers and developers working toward common aims. In: Proceedings of the 2011 Agile Conference. Washington, DC, USA: IEEE Computer Society, 2011. (AGILE 11), p. 87-96. ISBN 978-0-7695-4370-3. Disponível em: 〈http://dx.doi.org/10.1109/AGILE.2011.45〉.

BUDWIG, M.; JEONG, S.; KELKAR, K. When user experience met agile: a case study. In: ACM. CHI'09 Extended Abstracts on Human Factors in Computing Systems. [S.1.], 2009. p. 3075-3084.

BURNS, T. E.; STALKER, G. M. The management of innovation. 1961.

CABAllERO, L.; MORENO, A.; SEFFAH, A. Persona as a tool to involving human in agile methods: Contributions from hci and marketing. In: . [S.l.: s.n.], 2014. p. 283-290.

CABALlERO, L.; MORENO, A. M.; SEFFAH, A. How agile developers integrate user-centered design into their processes: A literature review. International Journal of Software Engineering and Knowledge Engineering, World Scientific, v. 26, n. 08, p. 1175-1201, 2016.

CARLETON, T.; COCKAYNE, W. R.; TAHVANAINEN, A.-J. Playbook for Strategic Foresight and Innovation: A Hands-on Guide for Modeling, Designing, and Leading Your Company's Next Radical Innovation. [S.l.: s.n.], 2013.

CARVAlHO, J. M. I. de; SILVA, T. S. da; SILVEIRA, M. S. Agile and ucd integration based on pre-development usability evaluations: An experience report. In: SPRINGER. International Conference on Human-Computer Interaction. [S.l.], 2016. p. 586-597.

CARVAlHO, M.; FLEURY, A.; LOPES, A. P. An overview of the literature on technology roadmapping (trm): Contributions and trends. Technological Forecasting and Social Change, Elsevier, v. 80, n. 7, p. 1418-1437, 2013.

CARVAlHO, M. A. de; GRILlO, J. G. B.; TESSARI, R. K. Methodology and software for new product ideation. Procedia engineering, Elsevier, v. 131, p. 352-358, 2015.

CHAMBERLAIN, S.; SHARP, H.; MAIDEN, N. Towards a framework for integrating agile development and user-centred design. In: SPRINGER. International Conference on Extreme Programming and Agile Processes in Software Engineering. [S.l.], 2006. p. $143-153$.

CHAMMAS, A.; QUARESMA, M.; MONTALVAO, C. A closer look on the user centred design. Procedia Manufacturing, Elsevier, v. 3, p. 5397-5404, 2015.

CHOMA, J.; ZAINA, L. A.; SILVA, T. S. D. Towards an approach matching cmd and dsr to improve the academia-industry software development partnership: A case of agile and ux integration. In: IEEE. 2015 29th Brazilian Symposium on Software Engineering. [S.l.], 2015. p. 51-60. 
CHRISSIS, M. B.; KONRAD, M.; SHRUM, S. CMMI guidlines for process integration and product improvement. [S.l.]: Addison-Wesley Longman Publishing Co., Inc., 2003.

CIVJAN J., F. J. L. T. . R. K. Client research that counts: involve your staff, engage your clients, and improve your services. In: . [S.l.]: ACM, 2010. p. 15-20.

COOPER, A.; REIMANN, R.; CRONIN, D. About face 3: the essentials of interaction design. [S.1.]: John Wiley \& Sons, 2007.

COOPER, R. Un-timely mediations: Questing thought. In: . [S.l.: s.n.], 2001. p. 321-47.

COOPER, R.; CORDOVA, T. The stage-gate system: A road map from idea to launch - an intro and summary. Technology Management, v. 157, n. 1, p. 20-31, 2014.

COOPER, R. G. What's next?: After stage-gate. Research-Technology Management, Taylor \& Francis, v. 57, n. 1, p. 20-31, 2014.

COURTNEY, J. Design Sprint 2.0 process explained 2018. 2018. Disponível em: $\langle$ https://www.youtube.com/watch?v=Z8MOwcqZuuU $\rangle$.

CROOM, S. Introduction to research methodology in operations management. In: Researching operations management. [S.1.]: Routledge, 2010. p. 56-97.

DAVIS, F. D.; VENKATESH, V. Toward preprototype user acceptance testing of new information systems: implications for software project management. IEEE Transactions on Engineering management, IEEE, v. 51, n. 1, p. 31-46, 2004.

DAYTON, D.; BARNUM, C. The impact of agile on user-centered design. Technical Communication, Society for Technical Communication, v. 56, n. 3, p. 219-234, 2009.

DESMET, P.; HEKKERT, P. Framework of product experience. International journal of design, Chinese Institute of Design, v. 1, n. 1, 2007.

DETWEILER, M.; MANAGING, U. Managing ucd within agile projects, interactions, v. 14 n. 3. May+ June, 2007.

DEUFF, D.; COSQUER, M.; FOUCAULT, B. Méthode centrée utilisateurs et développement agile: une perspective « gagnant-gagnant $\gg$ au service des projets de r\&d. 092010.

DIKICI, A.; TURETKEN, O.; DEMIRORS, O. Factors influencing the understandability of process models: A systematic literature review. Information and Software Technology, 092017.

DIS, I. 9241-210: 2010. ergonomics of human system interaction-part 210: Humancentred design for interactive systems. International Standardization Organization (ISO). Switzerland, 2009.

DOBRIGKEIT, F.; PAULA, D. de et al. The best of three worlds-the creation of innodev a software development approach that integrates design thinking, scrum and lean startup. In: Proceedings of the 21st International Conference on Engineering Design (ICED17). [S.1.: s.n.], 2017. v. 8, p. 319-328. 
DONK, D. P. van; MOLLOY, E. From organising as projects to projects as organisations. International Journal of Project Management, Elsevier, v. 26, n. 2, p. 129-137, 2008.

DOROW, P. et al. Ferramentas do design thinking para a inovação em modelo de negócio. Ciências \&J Cognição, v. 21, n. 1, 2016.

DÜCHTING, M.; ZIMMERMANN, D.; NEBE, K. Incorporating user centered requirement engineering into agile software development. In: SPRINGER. International Conference on Human-Computer Interaction. [S.1.], 2007. p. 58-67.

DYBÅ, T.; DINGSØYR, T. Empirical studies of agile software development: A systematic review. Inf. Softw. Technol., Butterworth-Heinemann, Newton, MA, USA, v. 50, n. 9-10, p. 833-859, ago. 2008. ISSN 0950-5849. Disponível em: $\langle$ http://dx.doi.org/10.1016/j.infsof.2008.01.006〉.

EISENHARDT, K. M. Building theories from case study research. Academy of management review, Academy of Management, v. 14, n. 4, p. 532-550, 1989.

FARINANGO, C. D.; BENAVIDES, J. S.; LOPEZ, D. M. Openup/mmu-iso 9241-210. process for the human centered development of software solutions. IEEE Latin America Transactions, IEEE, v. 13, n. 11, p. 3668-3675, 2015.

FEDEROFF, M.; COURAGE, C. Successful user experience in an agile enterprise environment. In: SPRINGER. Symposium on Human Interface. [S.l.], 2009. p. 233-242.

FELKER, C.; SLAMOVA, R.; DAVIS, J. Integrating ux with scrum in an undergraduate software development project. In: ACM. Proceedings of the 43rd ACM technical symposium on Computer Science Education. [S.1.], 2012. p. 301-306.

FERREIRA, J. Interaction design and agile development: a real world perspective. Victoria University of Wellington, 2008.

FERREIRA, J. Agile development and ux design: towards understanding work cultures to support integration. In: SPRINGER. International Conference on Advanced Information Systems Engineering. [S.1.], 2012. p. 608-615.

FERREIRA, J.; NOBLE, J.; BIDDLE, R. Agile development iterations and ui design. In: IEEE. Agile Conference (AGILE), 200\%. [S.1.], 2007. p. 50-58.

FERREIRA, J.; NOBLE, J.; BIDDLE, R. Up-front interaction design in agile development. In: SPRINGER. International Conference on Extreme Programming and Agile Processes in Software Engineering. [S.l.], 2007. p. 9-16.

FERREIRA, J.; SHARP, H.; ROBINSON, H. User experience design and agile development: managing cooperation through articulation work. Software: Practice and Experience, Wiley Online Library, v. 41, n. 9, p. 963-974, 2011.

FERREIRA, J.; SHARP, H.; ROBINSON, H. Agile development and user experience design integration as an ongoing achievement in practice. In: IEEE. Agile Conference (AGILE), 2012. [S.1.], 2012. p. 11-20.

FIGUEIREDO, L. et al. Strategy to market innovations: Systematic literature review on the different approaches. European Operations Managment Association (EurOMA), 2019. 
FISHER, K. G.; BANKSTON, A. From cradle to sprint: creating a full-lifecycle request pipeline at nationwide insurance. In: IEEE. 2009 Agile Conference. [S.1.], 2009. p. $223-228$.

FITZGERALD, B. The use of systems development methodologies in practice: a field study. Information Systems Journal, Wiley Online Library, v. 7, n. 3, p. 201-212, 1997.

FORZA, C. Survey research in operations management: a process-based perspective. International Journal of Operations \& Production Management, v. 22, n. 2, p. 152-194, 2002. Disponível em:〈https://doi.org/10.1108/01443570210414310〉.

FOX, B. D. Agile Methods and User-Centered Design: How These Two Methodologies are Being Integrated in Industry. Tese (Doutorado) — Citeseer, 2010.

FOX, D.; SILLITO, J.; MAURER, F. Agile methods and user-centered design: How these two methodologies are being successfully integrated in industry. In: IEEE. Agile, 2008. AGILE'08. Conference. [S.1.], 2008. p. 63-72.

GARBULHO, G. S. Avaliando o impacto da estratégia de design em negócios digitais. Tese (Doutorado) — Universidade de São Paulo, 2017.

GARRETT, J. J. The elements of user experience: user-centered design for the web and beyond. [S.1.]: Pearson Education, 2010.

GASSON, S. The reality of user-centered design. Journal of Organizational and End User Computing (JOEUC), IGI Global, v. 11, n. 4, p. 5-15, 1999.

GEISSDOERFER, M.; BOCKEN, N. M.; HULTINK, E. J. Design thinking to enhance the sustainable business modelling process-a workshop based on a value mapping process. Journal of Cleaner Production, Elsevier, v. 135, p. 1218-1232, 2016.

GLOMANN, L. Introducing 'human-centered agile workflow' (hcaw) - an agile conception and development process model. In: . [S.l.: s.n.], 2018. p. 646-655. ISBN 978-3-319-60491-6.

GONZALEZ, C.; TOLEDO, P.; MUOZ, V. Agile human centered methodologies to develop educational software. Dyna, 2006, Revista DYNA, v. 82, n. 193, p. 187-194, 2015 .

GONZÁLEZ, C. S. et al. Inclusive educational software design with agile approach. In: ACM. Proceedings of the First International Conference on Technological Ecosystem for Enhancing Multiculturality. [S.1.], 2013. p. 149-155.

GOOGLE. Design Sprint kit. 2016. Acessado em: 2016-10-10. Disponível em: 〈ไtexttt\{https://designsprintkit.withgoogle.co\}.〉

GRAY, D. UX Framework. 2014. Acessado em: 2018-06-06. Disponível em: 〈\texttt\{https://www.slideshare.net/dgray \char'\_xplane/ux-framework-3049358\}.〉

GUEDES, V. L.; BORSCHIVER, S. Bibliometria: uma ferramenta estatistica para a gestao da informacao e do conhecimento, em sistemas de informacao, de comunicacao e de avaliacao cientifica e tecnologica. Encontro Nacional de Ciencia da Informacao, v. 6, n. 1, p. 18, 2005. 
HALL, E. Just enough research. [S.l.]: A Book Apart New York, 2013.

HASSENZAHL, M.; TRACTINSKY, N. User experience-a research agenda. Behaviour \& information technology, Taylor \& Francis, v. 25, n. 2, p. 91-97, 2006.

HAZEN, B.; OVERSTREET, R.; BOONE, C. Suggested reporting guidelines for structural equation modeling in supply chain management research. The International Journal of Logistics Management, v. 26, 102015.

HIGHSMITH, J.; COCKBURN, A. Agile software development: The business of innovation. Computer, IEEE, v. 34, n. 9, p. 120-127, 2001.

HODA, R.; NOBLE, J.; MARSHALL, S. Self-organizing roles on agile software development teams. IEEE Transactions on Software Engineering, IEEE, v. 39, n. 3, p. 422-444, 2013.

HODGETTS, P. Experiences integrating sophisticated user experience design practices into agile processes. In: . [S.l.: s.n.], 2005. p. 235 - 242. ISBN 0-7695-2487-7.

HOKKANEN, L.; VÄÄNÄNEN-VAINIO-MATTILA, K. Ux work in startups: current practices and future needs. In: SPRINGER. International Conference on Agile Software Development. [S.l.], 2015. p. 81-92.

HONIOUS, J.; CLARK, J. Something to believe in [reed elsevier]. In: . [S.l.: s.n.], 2006. p. 8 pp. -212 .

HOWELL, D.; WINDAHL, C.; SEIDEL, R. A project contingency framework based on uncertainty and its consequences. International Journal of Project Management, Elsevier, v. 28, n. 3, p. 256-264, 2010.

HUMAYOUN, S. R.; DUBINSKY, Y.; CATARCI, T. A three-fold integration framework to incorporate user-centered design into agile software development. In: SPRINGER. International Conference on Human Centered Design. [S.1.], 2011. p. 55-64.

HUSSAIN, Z.; SLANY, W.; HOLZINGER, A. Current state of agile user-centered design: A survey. Springer-Verlag, Berlin, Heidelberg, p. 416-427, 2009.

HUSSAIN, Z.; SLANY, W.; HOLZINGER, A. Investigating agile user-centered design in practice: A grounded theory perspective. In: Proceedings of the 5th Symposium of the Workgroup Human-Computer Interaction and Usability Engineering of the Austrian Computer Society on HCI and Usability for e-Inclusion. Berlin, Heidelberg: Springer-Verlag, 2009. (USAB '09), p. 279-289. ISBN 978-3-642-10307-0. Disponível em: $\langle$ http://dx.doi.org/10.1007/978-3-642-10308-7\_19〉.

HUSSAIN, Z.; SLANY, W.; HOLZINGER, A. Agile software developement methods and usability/user centred design: Prespectives from an online survey. Journal of Systems and Software, v. 54, p. 86-88, 2012.

IRSHAD, M.; PETERSEN, K.; POULDING, S. A systematic literature review of software requirements reuse approaches. Information and Software Technology, Elsevier, v. 93, p. 223-245, 2018. 
ISA, W. A. R. W. M. et al. Engineering rural informatics using agile user centered design. In: IEEE. Information and Communication Technology (ICoICT), 2014 2nd International Conference on. [S.1.], 2014. p. 367-372.

ISOMURSU, M. et al. User experience design goes agile in lean transformation - a case study. In: . [S.l.: s.n.], 2012. p. 1-10. ISBN 978-1-4673-2622-3.

JIA, Y.; LARUSDOTTIR, M. K.; CAJANDER, A. The usage of usability techniques in scrum projects. In: SPRINGER. International Conference on Human-Centred Software Engineering. [S.1.], 2012. p. 331-341.

JOKELA, T. Characterizations, requirements, and activities of user-centered design - the kessu 2.2 model. In: Maturing Usability. [S.l.]: Springer, 2008. p. 168-196.

JOKELA, T.; ABRAHAMSSON, P. Modelling usability capability-introducing the dimensions. In: SPRINGER. International Conference on Product Focused Software Process Improvement. [S.1.], 2000. p. 73-87.

JOKELA, T.; ABRAHAMSSON, P. Usability assessment of an extreme programming project: Close co-operation with the customer does not equal to good usability. In: SPRINGER. International Conference on Product Focused Software Process Improvement. [S.l.], 2004. p. 393-407.

JUNIOR, R. R.; CARVALHO, M. Monteiro de. Gestão de projetos inovadores em uma perspectiva contingencial: análise teórico-conceitual e proposição de um modelo. RAI-Revista de Administração e Inovação, Universidade de São Paulo, v. 6, n. 3, 2009.

JURCA, G.; HELLMANN, T. D.; MAURER, F. Integrating agile and user-centered design: a systematic mapping and review of evaluation and validation studies of agile-ux. In: IEEE. 2014 Agile Conference. [S.1.], 2014. p. 24-32.

KAUTZ, K. Investigating the design process: participatory design in agile software development. Information Technology $\&$ People, Emerald Group Publishing Limited, v. 24 , n. 3 , p. 217-235, 2011.

KEENAN, F.; BUSTARD, D. Bpuf: Big picture up front. In: . [S.l.: s.n.], 2005. v. 3556, p. 251-254.

KNAPP, J.; ZERATSKY, J.; KOWITZ, B. Sprint: How to solve big problems and test new ideas in just five days. [S.l.]: Simon and Schuster, 2016.

KOLLMANN, J. Designing the user experience in an agile context. Faculty of Life Science, University College, London, London, Citeseer, 2008.

KUUSINEN, K. Improving ux work in scrum development: A three-year follow-up study in a company. In: SPRINGER. International Conference on Human-Centred Software Engineering. [S.1.], 2014. p. 259-266.

KUUSINEN, K. Task allocation between ux specialists and developers in agile software development projects. In: SPRINGER. IFIP Conference on Human-Computer Interaction. [S.1.], 2015. p. 27-44. 
KUUSINEN, K.; MIKKONEN, T. Designing user experience for mobile apps: long-term product owner perspective. In: IEEE. Software Engineering Conference (APSEC), 2013 20th Asia-Pacific. [S.1.], 2013. v. 1, p. 535-540.

KUUSINEN, K.; MIKKONEN, T.; PAKARINEN, S. Agile user experience development in a large software organization: good expertise but limited impact. In: SPRINGER. International Conference on Human-Centred Software Engineering. [S.l.], 2012. p. 94-111.

KUUSINEN, K.; VÄÄNÄNEN-VAINIO-MATTILA, K. How to make agile ux work more efficient: management and sales perspectives. In: ACM. Proceedings of the rth Nordic Conference on Human-Computer Interaction: Making Sense Through Design. [S.l.], 2012. p. 139-148.

LARMAN, C.; BASILI, V. R. Iterative and incremental developments. a brief history. Computer, IEEE, v. 36, n. 6, p. 47-56, 2003.

LÁRUSDÓTTIR, M. K.; CAJANDER, A.; GULLIKSEN, J. The big picture of ux is missing in scrum projects. In: Proceedings of the International Workshop on the Interplay between User Experience (UX) Evaluation and System Development (I-UxSED). [S.l.: s.n.], 2012. p. 49-54.

LAW, E. L.-C. et al. Understanding, scoping and defining user experience: a survey approach. In: ACM. Proceedings of the SIGCHI conference on human factors in computing systems. [S.1.], 2009. p. 719-728.

LAWRENCE, P. R.; LORSCH, J. W. Differentiation and integration in complex organizations. Administrative science quarterly, JSTOR, p. 1-47, 1967.

LEE, J. C.; MCCRICKARD, D. S. Towards extreme (ly) usable software: Exploring tensions between usability and agile software development. In: IEEE. Agile Conference (AGILE), 200\%. [S.1.], 2007. p. 59-71.

LEMÉTAYER, J. identifying the critical factors in software development methodology fit. Victoria University of Wellington, 2010.

LIEVESLEY, M. A.; YEE, J. S. The role of the interaction designer in an agile software development process. In: ACM. CHI'06 Extended Abstracts on Human Factors in Computing Systems. [S.l.], 2006. p. 1025-1030.

LIIKKANEN, L. A. et al. Lean ux: the next generation of user-centered agile development? In: ACM. Proceedings of the 8th Nordic Conference on Human-Computer Interaction: Fun, Fast, Foundational. [S.1.], 2014. p. 1095-1100.

LIMA, J. P. C. et al. Estudos de caso e sua aplicação: proposta de um esquema teórico para pesquisas no campo da contabilidade. Revista de Contabilidade e Organizações, v. 6, n. 14, p. 127-144, 2012.

LINDSTRÖM, H.; MALMSTEN, M. User-centred design and agile development: Rebuilding the swedish national union catalogue. Cataloging and Indexing: Challenges and Solutions, CRC Press, p. 252, 2011. 
LIZANO, F.; SANDOVAL, M. M.; STAGE, J. Integrating usability evaluations into scrum: a case study based on remote synchronous user testing. In: SPRINGER. International Conference on Human-Computer Interaction. [S.l.], 2014. p. 500-509.

LUCENA, P. et al. Ibm design thinking software development framework. In: SPRINGER. Brazilian Workshop on Agile Methods. [S.l.], 2016. p. 98-109.

MAGUIRE, M. Methods to support human-centred design. International journal of human-computer studies, Elsevier, v. 55, n. 4, p. 587-634, 2001.

MAGüES, D.; CASTRO, J.; ACUñA, S. Hci usability techniques in agile development. In: . [S.l.: s.n.], 2016. p. 1-7.

MAIER, F.; MEYER, M.; STEINBEREITHNER, M. Nonprofit organizations becoming business-like: A systematic review. Nonprofit and Voluntary Sector Quarterly, Sage Publications Sage CA: Los Angeles, CA, v. 45, n. 1, p. 64-86, 2016.

MANWARING, E.; CARTER, J. N.; MAYNARD, K. Redesigning educational dashboards for shifting user contexts. In: Proceedings of the 35th ACM International Conference on the Design of Communication. New York, NY, USA: ACM, 2017. (SIGDOC '17), p. 27:1-27:7. ISBN 978-1-4503-5160-7. Disponível em: $\langle$ http://doi.acm.org/10.1145/3121113.3121210〉.

MAO, J.-Y. et al. User-centered design methods in practice: a survey of the state of the art. In: IBM PRESS. Proceedings of the 2001 conference of the Centre for Advanced Studies on Collaborative research. [S.1.], 2001. p. 12.

MAY, B. Applying lean startup: An experience report-lean \& lean ux by a ux veteran: Lessons learned in creating \& launching a complex consumer app. In: IEEE. 2012 Agile Conference. [S.1.], 2012. p. 141-147.

MEMMEL, T.; GUNDELSWEILER, F.; REITERER, H. Agile human-centered software engineering. In: BRITISH COMPUTER SOCIETY. Proceedings of the 21st British HCI Group Annual Conference on People and Computers: HCI... but not as we know it-Volume 1. [S.1.], 2007. p. 167-175.

MESZAROS, G.; ASTON, J. Adding usability testing to an agile project. In: IEEE. Agile Conference, 2006. [S.1.], 2006. p. 6-pp.

MIGUEL, P. A. C. Adocao do estudo de caso na engenharia de producao. [S.l.]: Elsevier, 2010 .

MILES, M. B. et al. Qualitative data analysis: An expanded sourcebook. [S.l.]: sage, 1994.

MILLER, L. Case study of customer input for a successful product. In: IEEE. Agile Conference, 2005. Proceedings. [S.1.], 2005. p. 225-234.

MORABITO, R. et al. Metodologia de pesquisa em engenharia de produção e gestão de operações. [S.l.]: Elsevier Brasil, 2018.

MOSTAFA, D. Maturity models in the context of integrating agile development processes and user centred design. Tese (Doutorado) — University of York, 2013. 
NAJAFI, M.; TOYOSHIBA, L. Two case studies of user experience design and agile development. In: IEEE. Agile 2008 Conference. [S.1.], 2008. p. 531-536.

NAVARRO, P. M.; PEREZ, G. M.; SEVILLA, D. A script-based prototyping framework to boost agile-ux developments. Journal of Computer Science and Technology, v. 31, p. 1246-1261, 112016.

NEELY, A. The evolution of performance measurement research: developments in the last decade and a research agenda for the next. International Journal of Operations $\&$ Production Management, Emerald Group Publishing Limited, v. 25, n. 12, p. 1264-1277, 2005.

NICKERSON, R. Man-computer interaction: A challenge for human factors research. Ergonomics, Taylor \& Francis, v. 12, n. 4, p. 501-517, 1969.

NIELSEN, J. Agile User Experience Projects. 2009. Acessado em: 2019-05-05. Disponível em: 〈\texttt\{https://www.nngroup.com/articles/agile-user-experience-projects\}.〉

NIELSEN, J.; PHILLIPS, V. L. Estimating the relative usability of two interfaces: heuristic, formal, and empirical methods compared. In: ACM. Proceedings of the INTERACT'93 and CHI'93 conference on Human factors in computing systems. [S.1.], 1993. p. $214-221$.

NODDER, C.; NIELSEN, J. Agile usability: best practices for user experience on agile development projects. [S.l.: s.n.], 2010.

NORMAN, D. The design of everyday things: Revised and expanded edition. [S.l.]: Basic Books (AZ), 2013.

NORMAN, D. A.; DRAPER, S. W. User centered system design; new perspectives on human-computer interaction. [S.1.]: L. Erlbaum Associates Inc., 1986.

NOSSEIR, A. et al. Mobile development process spiral. In: IEEE. 2012 Seventh International Conference on Computer Engineering 65 Systems (ICCES). [S.l.], 2012. p. 281-286.

OBENDORF, H.; SCHMOLITZKY, A.; FINCK, M. Xpnue-defining and teaching a fusion of extreme programming and usability engineering. In: CITESEER. HCI Educators Workshop. [S.1.], 2006. p. 23-24.

PAAY, J. et al. Engineering the social: The role of shared artifacts. International Journal of Human-Computer Studies, Elsevier, v. 67, n. 5, p. 437-454, 2009.

PALMARINI, R. et al. A systematic review of augmented reality applications in maintenance. Robotics and Computer-Integrated Manufacturing, Elsevier, v. 49, p. $215-228,2018$.

PARSONS, D. et al. Software development methodologies, agile development and usability engineering. ACIS 2007 Proceedings, p. 32, 2007.

PATTON, J. Hitting the target: adding interaction design to agile software development. In: ACM. OOPSLA 2002 Practitioners Reports. [S.l.], 2002. p. 1-ff. 
PAULK, M. C. The capability maturity model: Guidelines for improving the software process. [S.1.]: Addison-Wesley Professional, 1995.

PLATTNER, H. Bootcamp bootleg. Design School Stanford, Palo Alto, 2010.

PLONKA, L. et al. Ux design in agile: a dsdm case study. In: SPRINGER. International Conference on Agile Software Development. [S.1.], 2014. p. 1-15.

PRIOR, S. et al. Use of an agile bridge in the development of assistive technology. In: ACM. Proceedings of the SIGCHI Conference on Human Factors in Computing Systems. [S.1.], 2013. p. 1579-1588.

RAGNARSDOTTIR, M. D. Untangling the mess-a redesign of a technical environment for a telecommunication company call centre: part ii: capturing a valid order for a telecommunication service. In: ACM. Proceedings of the 6th Nordic Conference on Human-Computer Interaction: Extending Boundaries. [S.1.], 2010. p. 857-862.

RANNIKKO, P. User-centered design in agile software development. 2011.

RATBE, D.; KING, W. R.; KIM, Y.-G. The fit between project characteristics and application development methodologies: A contingency approach. Journal of Computer Information Systems, Taylor \& Francis, v. 40, n. 2, p. 26-33, 1999.

RITTER, F. E.; BAXTER, G. D.; CHURCHILL, E. F. Foundations for designing user-centered systems. London: Springer. doi, Springer, v. 10, p. 978-1, 2014.

ROGERS, Y.; SHARP, H.; PREECE, J. Interaction design: beyond human-computer interaction. [S.l.]: John Wiley \& Sons, 2011.

ROJAS, L. A.; MACÍAS, J. A. An agile information-architecture-driven approach for the development of user-centered interactive software. In: Proceedings of the XVI International Conference on Human Computer Interaction. New York, NY, USA: ACM, 2015. (Interacci\&\#243;n '15), p. 50:1-50:8. ISBN 978-1-4503-3463-1. Disponível em: 〈http://doi.acm.org/10.1145/2829875.2829919〉.

ROYCE, W. W. Managing the development of large software systems: concepts and techniques. In: IEEE COMPUTER SOCIETY PRESS. Proceedings of the 9th international conference on Software Engineering. [S.1.], 1970. p. 328-338.

RUTHFORD, M. A. Mix and match usability methods: picking the pieces for our project. In: IEEE. Proceedings. IEEE International Professional Communication Conference. [S.l.], 2002. p. 343-351.

SAFFER, D. Designing for interaction. [S.1.]: New Riders Berkeley, 2010.

SALAH, D.; PAIGE, R.; CAIRNS, P. Integrating agile development processes and user centred design-a place for usability maturity models? In: SPRINGER. International Conference on Human-Centred Software Engineering. [S.1.], 2014. p. 108-125.

SALAH, D.; PAIGE, R.; CAIRNS, P. A practitioner perspective on integrating agile and user centred design. In: BCS. Proceedings of the 28th International BCS Human Computer Interaction Confernence on HCI 2014-Sand, Sea and Sky-Holiday HCI. [S.1.], 2014. p. 100-109. 
SALAH, D.; PAIGE, R. F.; CAIRNS, P. A systematic literature review for agile development processes and user centred design integration. In: ACM. Proceedings of the 18th international conference on evaluation and assessment in software engineering. [S.1.], 2014. p. 5.

SAUSER, B. J.; REILLY, R. R.; SHENHAR, A. J. Why projects fail? how contingency theory can provide new insights-a comparative analysis of nasa's mars climate orbiter loss. International Journal of Project Management, Elsevier, v. 27, n. 7, p. 665-679, 2009.

SAVAGE-KNEPSHIELD, P. et al. Designing the user experience for c4isr systems in the us army. In: SPRINGER. International Conference of Design, User Experience, and Usability. [S.l.], 2014. p. 338-346.

SCHÖN, E. M. A framework for modeling and improving agile requirements engineering. Tese (Doutorado) — Universidad de Sevilla, 2017.

SCHÖN, E.-M. et al. Enterprise experience into the integration of human-centered design and kanban. In: ICSOFT-EA. [S.l.: s.n.], 2016. p. 133-140.

SCHWABER, K. Agile project management with Scrum. [S.l.]: Microsoft press, 2004.

SEFFAH, A.; METZKER, E. The obstacles and myths of usability and software engineering. Communications of the ACM, ACM, v. 47, n. 12, p. 71-76, 2004.

SHENHAR, A. J.; DVIR, D. Reinventing project management: the diamond approach to successful growth and innovation. [S.l.]: Harvard Business Review Press, 2007.

SILVA, T. S. D. et al. User-centered design and agile methods: a systematic review. In: IEEE. Agile Conference (AGILE), 2011. [S.1.], 2011. p. 77-86.

SILVA, T. S. D. et al. The evolution of agile uxd. Information and Software Technology, Elsevier, v. 102, p. 1-5, 2018.

SILVA, T. S. D. et al. Understanding the ux designer's role within agile teams. In: SPRINGER. International Conference of Design, User Experience, and Usability. [S.1.], 2013. p. 599-609.

SILVA, T. S. da et al. A systematic mapping on agile ucd across the major agile and hci conferences. In: SPRINGER. International Conference on Computational Science and Its Applications. [S.1.], 2015. p. 86-100.

SILVA, T. S. da; SILVEIRA, M. S.; MAURER, F. Ten lessons learned from integrating interaction design and agile development. In: IEEE. 2013 Agile Conference. [S.l.], 2013. p. $42-49$.

SINGH, M. U-scrum: An agile methodology for promoting usability. In: IEEE. Agile, 2008. AGILE'08. Conference. [S.1.], 2008. p. 555-560.

SOHAIB, O.; KHAN, K. Integrating usability engineering and agile software development: A literature review. v. 2, p. V2-32, 072010.

SOMMERVILLE, I. Software engineering. international computer science series. ed: Addison Wesley, 2010. 
STARTUPS, G. for. Hangouts for Entrepreneurs: Lean Startup Meets Design Thinking in 10 Minutes. 2014. Acessado em: 2019-04-23. Disponível em: 〈 \texttt\{https: //www.youtube.com/watch?v=JzEg-Y0noR \}.

SWARD, D.; MACARTHUR, G. Making user experience a business strategy. In: E. Law et al.(eds.), Proceedings of the Workshop on Towards a UX Manifesto. [S.l.: s.n.], 2007. v. 3 , p. $35-40$.

SY, D. Adapting usability investigations for agile user-centered design. Journal of usability Studies, Usability Professionals' Association, v. 2, n. 3, p. 112-132, 2007.

TAKEY, S. M.; CARVALHO, M. M. Fuzzy front end of systemic innovations: A conceptual framework based on a systematic literature review. Technological Forecasting and Social Change, Elsevier, v. 111, p. 97-109, 2016.

TAWFIK, A. A.; BELDEN, J. L.; MOORE, J. L. Agile management of a mobile application development project for surgeon workflows. In: Cases on Educational Technology Planning, Design, and Implementation: A Project Management Perspective. [S.l.]: IGI Global, 2013. p. 252-273.

TEIXEIRA, F. Resultados da pesquisa: panorama do mercado de UX no Brasil. 2017. Disponível em: 〈https://brasil.uxdesign.cc/ panorama-do-mercado-de-ux-no-brasil-2fa1164a1f85〉.

TEIXEIRA, L. et al. Integrating human factors in information systems development: User centred and agile development approaches. In: . [S.l.: s.n.], 2016. v. 9745, p. 345-356. ISBN 978-3-319-40246-8.

TEKA, D.; DITTRICH, Y.; KIFLE, M. Contextualizing user centered design with agile methods in ethiopia. In: IEEE. 2017 IEEE AFRICON. [S.1.], 2017. p. 911-916.

UNGAR, J.; WHITE, J. Agile user centered design: enter the design studio-a case study. In: ACM. CHI'08 Extended Abstracts on Human Factors in Computing Systems. [S.1.], 2008. p. 2167-2178.

UXNET. User Experience Network. 2007.

VIJAYASARATHY, L. R.; BUTLER, C. W. Choice of software development methodologies: Do organizational, project, and team characteristics matter? IEEE software, IEEE, v. 33, n. 5, p. 86-94, 2016.

VREDENBURG, K. et al. A survey of user-centered design practice. In: ACM. Proceedings of the SIGCHI conference on Human factors in computing systems. [S.l.], 2002. p. 471-478.

WALE-KOLADE, A.; NIELSEN, P. A.; PAIVARINTA, T. Integrating usability practices into agile development: A case study. In: UNIVERSITY OF ZAGREB. International Conference on Information Systems Development: 02/09/2014-04/09/2014. [S.1.], 2014. p. 337-347.

WALE-KOLADE, A. Y. Integrating usability work into a large inter-organisational agile development project: Tactics developed by usability designers. Journal of Systems and Software, Elsevier, v. 100, p. 54-66, 2015. 
WASIKE, B. Africa rising: An analysis of emergent africa-focused mass communication scholarship from 2004-2014. International Journal of Communication, v. 11, n. 0, 2017. ISSN 1932-8036. Disponível em:〈https://ijoc.org/index.php/ijoc/article/view/5866〉.

WERDER, K.; ZOBEL, B.; MAEDCHE, A. Pdisc-towards a method for software product discovery. In: SPRINGER. International Conference of Software Business. [S.l.], 2016. p. 47-62.

WILLIAMS, H.; FERGUSON, A. The ucd perspective: Before and after agile. In: IEEE. Agile Conference (AGILE), 200\%. [S.1.], 2007. p. 285-290.

YIN, R. K. Estudo de Caso-: Planejamento e Métodos. [S.l.]: Bookman editora, 2015.

ZAPATA, C. Integration of usability and agile methodologies: a systematic review. In: SPRINGER. International Conference of Design, User Experience, and Usability. [S.l.], 2015. p. 368-378. 